\title{
EXPLORING ACADEMIC MAJOR CHOICE AND SELF-EFFICACY IN A SHIFTING LANDSCAPE: LOW-INCOME UNDERGRADUATE STUDENTS AND PURSUIT OF THE HUMANITIES DEGREE
}

\author{
A Dissertation \\ Presented to \\ The Faculty of the Curry School of Education \\ University of Virginia \\ In Partial Fulfillment \\ of the Requirements for the Degree \\ Doctor of Philosophy \\ by \\ Sarah E. Whitley, B.S., M.Ed.
}

May 2017 
CCopyright by

Sarah E. Whitley

All Rights Reserved

May 2017 


\section{ABSTRACT \\ Advisor: Dr. Karen Kurotsuchi Inkelas}

Relying upon explanatory mixed methods (Creswell, 2002, 2003, 2007;

Tashakkori \& Teddlie, 2003), this study investigated the academic decision-making of low-income undergraduate students with interest in humanities majors. The purpose of this study was to consider the influences, including those internal and external to the college environment as well as occurring prior to and during college, that shaped lowincome students' self-efficacy and academic decision-making at different points in the process. Moreover, this study sought to understand the barriers encountered by students in academic decision-making and to identify the supports recognized by students as improving their confidence in successfully choosing a major. Given the negative postRecession climate surrounding humanities study and a rise in focus on and funding for majors deemed vocational or pre-professional, this study examined why low-income students still express interest in humanities fields and whether majoring in these disciplines may be a benefit to this marginalized population.

Using Social Cognitive Career Theory (Lent, Brown \& Hackett, 1994, 2000, 2002) and Bronfenbrenner's $(1979,1993)$ Ecological Systems Theory as frameworks for considering goals, outcomes, efficacy, and environmental influences, this study considered the following research questions:

- What influences low-income undergraduate students to pursue academic majors in humanities disciplines?

- In what ways are low-income undergraduate students' senses of academic selfefficacy regarding their choice of major shaped through experiences and influences within the college and external environments? 
- What college and external environments or experiences, specifically, shape the major choice process for low-income undergraduate students interested in humanities disciplines?

Despite indicating humanities interest at the time of admission and identifying humanities-related interests in high school academic and extracurricular experiences, students were also encouraged to consider pre-professional majors by their immediate family and high school educators. The influence of parents and teachers, along with feeling connected to an academic discipline prior to entering college, improved confidence and self-efficacy in the pre-college major choice. However, upon entry, students identified multiple barriers (e.g., lack of information, poor faculty and advisor support, academic difficulties, shifting interests) that prompted a need to consider other majors and resulted in declines in decision-making efficacy. Students in the study sought mentoring relationships with older peers, returned to hobbies and interests as inspiration for major choice, and identified small, supportive academic communities as the supports necessary for regaining self-efficacy and choosing a major. Moreover, students reported finding these desired supports within humanities disciplines. Additionally, the presence of a comprehensive institutional aid model offered students unexpected freedom and flexibility in academic decision- making.

The study's findings offer support for the use of Social Cognitive Career Theory (SCCT) (Lent, Brown \& Hackett, 1996; Lent, 2005) and Bronfenbrenner's Ecological Systems Theory $(1979 ; 1993)$ as frameworks for exploring academic decision-making. Suggestions are offered for extending the use of SCCT to include college, major, and career choice as well as development of a consistent adaptation of Bronfenbrenner's model specific to higher education research. The study's findings offer support for 
considering how comprehensive financial aid models can be expanded to benefit students at varying types of institutions, continuing improvement in federal financial aid policies for low-income students, and reconsidering widespread funding cuts across humanities degree programs. For practitioners, the study findings suggest that students, and influential individuals, need better major choice information prior to college and for this information to be delivered with greater intention throughout matriculation. Moreover, findings support initiatives for greater awareness of faculty and staff regarding the barriers and supports identified in the major choice process for marginalized students alongside consideration of formalized mentoring programs for student support from consistent and knowledgeable resources. Recommendations are made not only for improvements in how humanities programs are marketing degree options and outcomes but, reciprocally, for non-humanities faculty to learn about ways in which the humanities foster learning environments favored by low-income students.

As this study considered a specific population at a selective institution, findings are not intended to be generalizable. However, the findings presented offer significant opportunity for future research including comparison samples across institutions of varying selectivities, financial aid models, academic disciplines and peer groups. Moreover, additional research exploring the informal development of academic mentoring relationships with peers, student perceptions of humanities faculty, and reported pervasive struggles with connecting majors with personal and career goals is recommended. 


\author{
Department of Leadership, Foundations, and Policy \\ Curry School of Education \\ University of Virginia \\ Charlottesville, VA
}

\begin{abstract}
APPROVAL OF THE DISSERTATION
This dissertation, "Explorating Academic Major Choice in a Shifting Landscape: LowIncome Undergraduate Students and Pursuit of the Humanities Degree," has been approved by the Graduate Faculty of the Curry School of Education in partial fulfillment of the requirements for the degree of Doctor of Philosophy.
\end{abstract}

Karen Kurotsuchi Inkelas, Advisor

John T. Casteen III

Nancy L. Deutsch

Josipa Roksa

March 31, 2017

Date 


\section{DEDICATION}

This dissertation is dedicated in loving memory of my father, Henry V. "Bubba" Whitley, Jr.,

who instilled in me a strong work ethic, fierce loyalty, and the strength to persist when difficult. Thank you for being my coach and champion, my consummate supporter, my unyielding cheerleader, and for sacrificing so much to allow me to pursue my dreams.

Nothing would make me happier than to have you here today.

Love and miss you, buddy. Okay, Okay. 


\section{ACKNOWLEDGEMENTS}

The completion of this task is not without tremendous appreciation to those who have encouraged me both personally and professionally and continue to be significant influences in my life. First, I must thank the students, particularly the eight interview participants, who excitedly shared their life experiences and allowed me to understand college through their eyes. Thank you to the Curry School of Education and the Higher Education program for funding my education, and the Curry School of Education IDEAs program and the American College Personnel Association Foundation for generously funding this research.

I am indebted to Dr. Teresa Gonzalez, Dr. Patricia Cormier, and Dr. Ken Perkins for their mentorship in the earliest parts of my career, encouraging doctoral education, and providing pathways to empower women in our field.

I chose to attend UVa for the opportunity to work with Dr. Karen Kurotsuchi Inkelas and it has been a highlight of my experience. Karen, the guidance you've provided is unparalleled. Not only do I walk away from this experience with an outstanding academic and professional mentor but a friend as well....and a greater appreciation for Egg McMuffins and the Cubs. Thank you. Dr. Josipa Roksa, you challenged me in ways I never knew existed. You forced me to think through a completely new lens while also being incredibly thoughtful, generous, and caring in the process. I'm so thankful our partnership and friendship will continue. It has been a privilege to learn from and with Dr. John T. Casteen III. The gracious opportunity you've provided in sharing your classroom and your interest in my education is eternally appreciated. Finally, to Dr. Nancy Deutsch, who sparked my interest in qualitative 
methods and, without fail, made time for every question and concern. Thank you for making me a better researcher and for always advocating for what is right in this world.

In addition to my committee, Dr. Amy K. Swan kindly "showed me the ropes" of doctoral education and gave me my earliest research experiences. Your patience, thoughtfulness, and friendship is so appreciated. Thank you to Dr. Christian L. Steinmetz for sharing your classroom, supporting my development, and helping me find a place in the program. However, without question, our friendship is one of my greatest gifts from this experience.

To my HERS sisters, Sue Frost, Donna Hight, Julie McDonald, and Ellen Schendel, your steadfast friendship, support and empowerment is a joy and privilege in my life. Thank you. Special thanks to Katie and Chad Harvell for a lifetime of friendship turned family and to Jessica Payne Stewart, who has lived away more than near, yet nothing changes.

To the children who have made me an "aunt" and have tremendous meaning in my life: Ethan, Brody, Annie, Olivia, and Jack. This "book" that I've been writing for so long is all about making decisions. I hope you have a lifetime of courage to make your own decisions, follow your dreams, and be absolutely anything you choose. No matter what you decide, I'll always be here to support you.

Stacey Underwood Wilkerson has been by my side through the most difficult moments of my life, listens when nobody else understands, and completely allows me to be myself. Her "arm punches" have been the perfect bookends to my UVa experience and no words describe the magnitude of our unlikely bond and eternal friendship. I am so very proud of you and can't wait to call you Dr. Stace very soon. 
To my maternal grandparents, Adren N. and Marian B. Ferrell, who left me so long ago but are with me every day. Thank you for supporting my education from the moment it began and teaching me so many life lessons that remain today.

Thanks to the best counselor around, our sweet pup, Jackson, for always making me feel better when times are tough, laying your head on the keyboard and making it impossible to type, and for being happy to see me no matter how far apart the visits.

The completion of this work and program is largely owed to the support, encouragement, and love of my mom, Janice Ferrell Whitley. Thank you for sacrificing so much to allow me to have the best opportunities possible in every part of my life. Without fail, you are by my side and have taught me to conquer the hardest parts of life. I am as proud of you every day as you are of me. Love you, bud.

Finally, to Sarah Sunde, thank you for being my partner in this often challenging life. You have supported my work, understood my struggles, and provided for me in countless ways. Thank you for choosing to take risks, always being ready for adventure, laughing with me, and having so much pride in even the smallest parts of this journey. I love you. Perhaps, now, our lives can finally begin and the greatest adventure awaits. 
TABLE OF CONTENTS

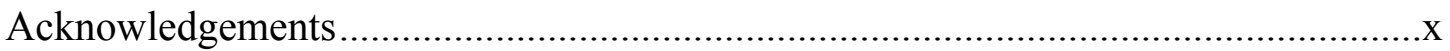

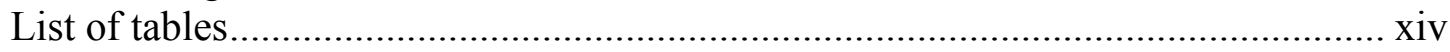

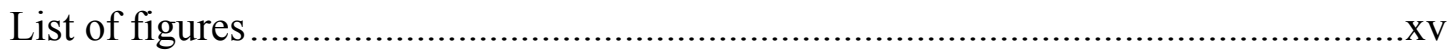

\section{CHAPTER I: INTRODUCTION AND STUDY PURPOSE}

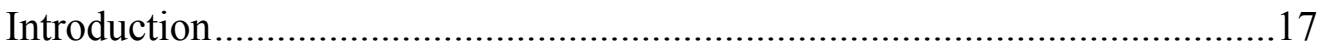

Primary Influences on Academic Major Choice...............................17

Low-Income Students: Navigating Barriers to Higher Education .......22

A Shifting National Landscape ....................................................23

The Humanities Under Scrutiny ................................................25

Humanities for All?..............................................................27

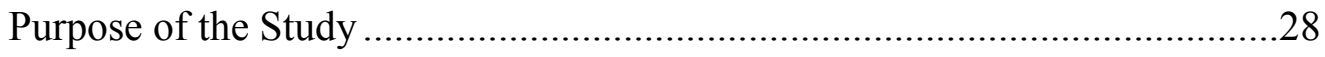

Significance of the Study .....................................................................29

\section{CHAPTER II: REVIEW OF LITERATURE}

The Humanities: A Historic Foundation for Higher Education ......................31

Challenging the Humanities in Modern Application ................................... 34

Stakeholders: A Closer Examination .........................................................39

Low-Income College Students............................................................43

Characteristics and Outcomes.....................................................44

Environmental Impact...........................................................4 47

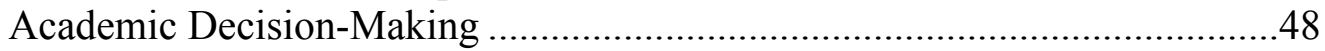

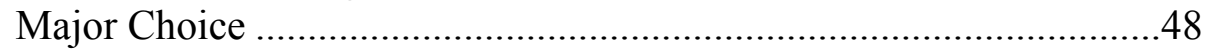

Class Impact...........................................................................50

Personal and Institutional Influences .............................................51

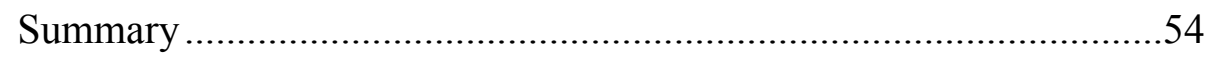

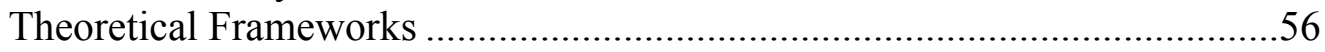

Social Cognitive Career Theory....................................................57

Bronfenbrenner's Ecological Systems Theory ................................60

\section{CHAPTER III: RESEARCH DESIGN AND METHODS}

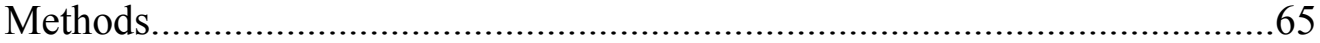

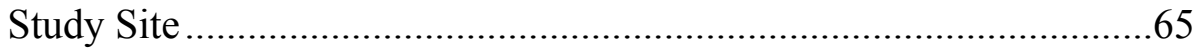

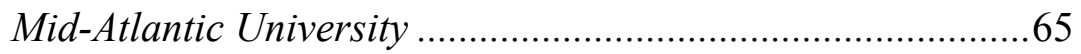

Academic Programs........................................................66

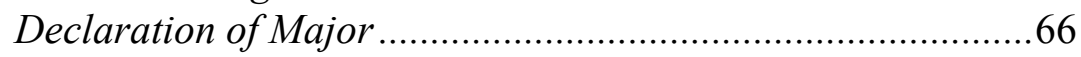

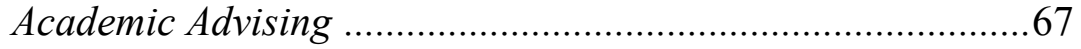

Study Design Overview .........................................................................68

Study Specific Mixed Methods Design ......................................................70

Phase One: Non-Dominant Quantitative Approach.....................................71

Sample ................................................................................ 71

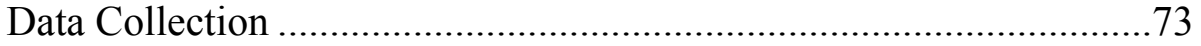

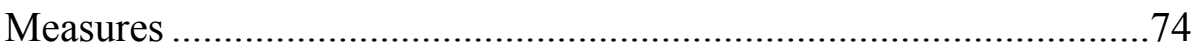




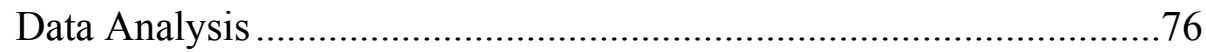

Phase Two: Dominant Qualitative Approach ..................................................77

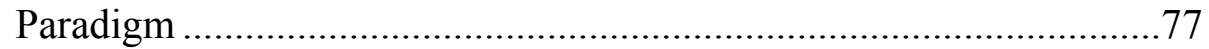

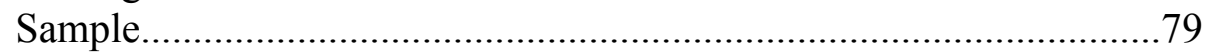

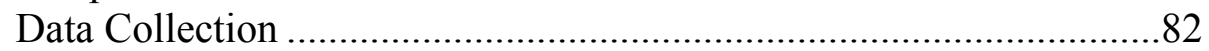

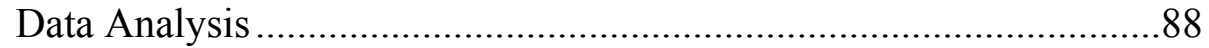

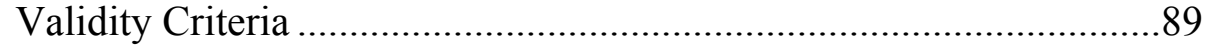

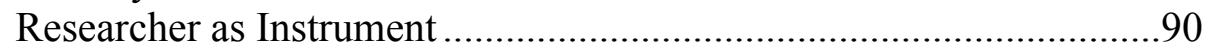

Ethical Considerations and Creating Trust ........................................92

Study Limitations ......................................................................................93

\section{CHAPTER IV: PARTICIPANT CONTEXT AND CASES}

Quantitative Participant Perspectives \& Experiences......................................95

Perceptions of Academic Majors ……………………………............95

Pre-College Information Gathering and Experiences ..........................97

Declaration Status, Timing, and Disciplinary Affiliation....................99

Major Change Over Time ................................................................101

Survey Participant Snapshot .............................................................102

Qualitative Participant Overview, Profiles, and Emerging Themes ...............103

Demographics …………………………………………….........103

Qualitative Participant Profiles .........................................................103

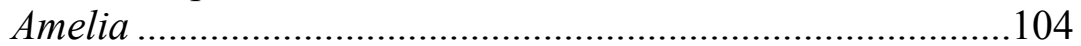

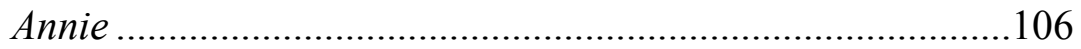

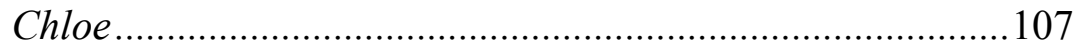

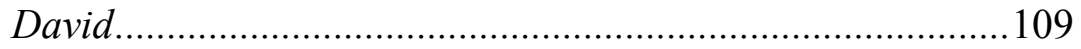

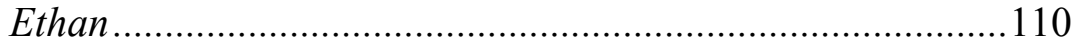

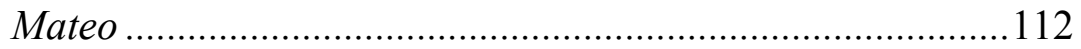

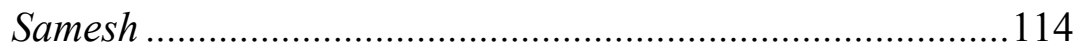

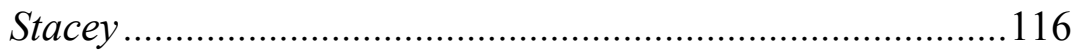

Pre-College Experiences Across Cases ...........................................118

College Experiences Across Case ....................................................119

Post-College Desired Outcomes Across Cases ...................................120

\section{CHAPTER V: FINDINGS AND ASSERTIONS}

Parallel Processes: College Choice and Major Choice ....................................125

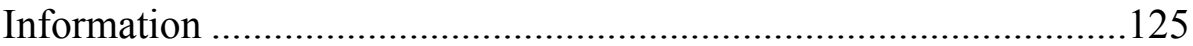

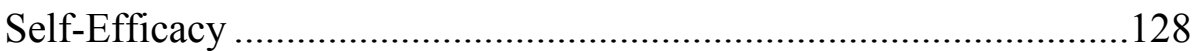

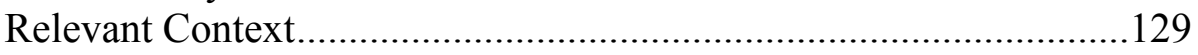

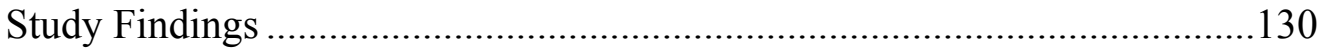

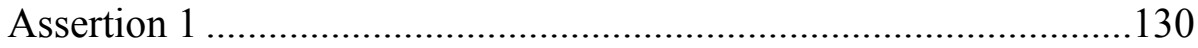

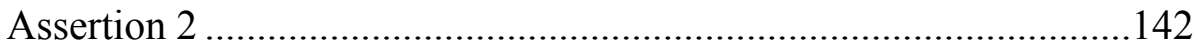

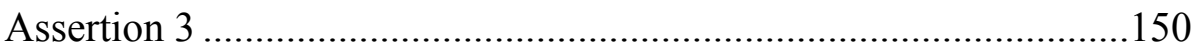

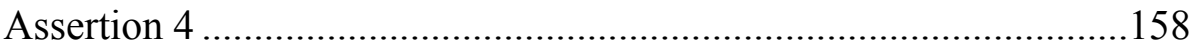

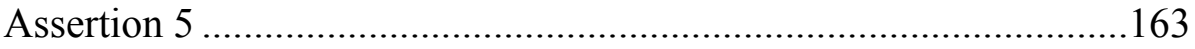

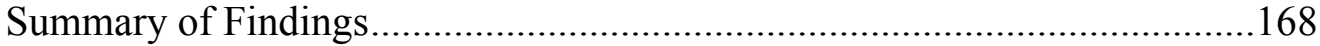




\section{CHAPTER VI: DISCUSSION AND IMPLICATIONS}

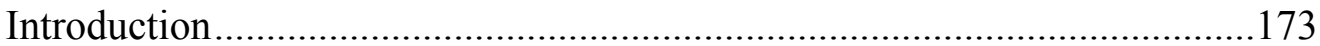

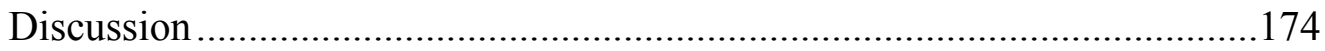

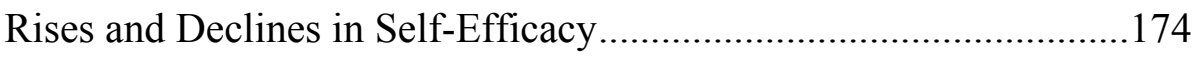

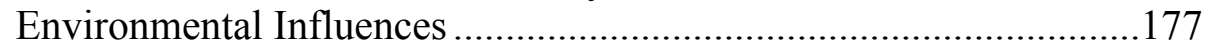

Pre-College Influences..................................................177

Critical Shifts from Pre-College to College Influences .........180

Upper-Class Peers....................................................................181

Hobbies and Personal Interests .................................................183

Small, Supportive Academic Communities .....................................184

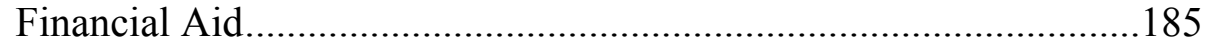

Relevance of Student Development Theory ..................................187

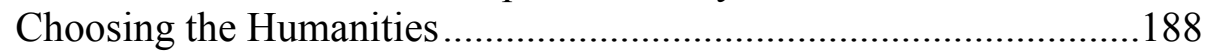

Humanities as a Benefit to All ........................................................189

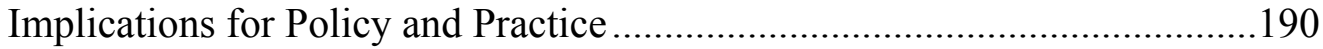

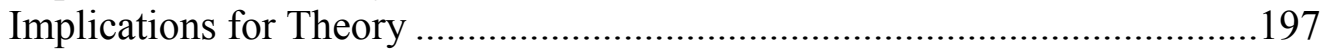

Implications for Future Research.......................................................198

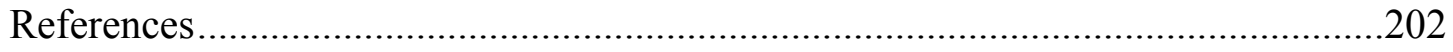

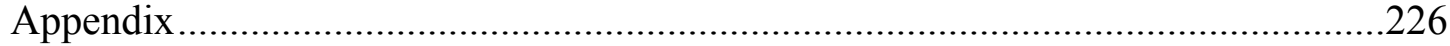

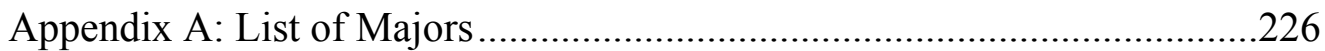

Appendix B: Survey Consent and Instrument ........................................22

Appendix C: Interview One Protocol ...................................................244

Appendix D: Interview Two Protocol.....................................................247

Appendix E: Interview Three Protocol .................................................250 


\section{LIST OF TABLES}

TABLE

Page

1. Enrollment of First-Time, Full-Time, First-Year (FTFY) Students Across

Four Cohorts and Delineated By Socioeconomic Status

2. Study Sample Demographics and Survey Respondent Demographics

3. Demographics and Academic Characteristics for Qualitative Phase Two Participants

4. Student Perceptions on Academic Majors .96

5. Level of Caregiver Education as Reported by Survey Respondents

6. Percentage of Students Reporting Engagement with Humanities Activities "Sometimes" or "Often" Alongside Students' Perceptions of Their Caregiver(s) Engagement

7. Qualitative Phase Two Participant Demographics and Characteristics as Delineated by Humanities Interest.

8. Importance of Desired Outcomes to Interview Participants as Reported in the Survey.....

9. Desired Outcomes as Reported by Survey Respondents

10. Summary of Assertions

11. Reported Frequency, By Percentage and Number, of Student Engagement with Faculty Across Various Situations and Settings 


\section{LIST OF FIGURES}

\section{FIGURE}

1. Social Cognitive Career Theory: Personal, Contextual, and Experiential Factors Affecting Academic Decision-Making Behavior.

2. Adapted Bronfenbrenner Model as Applied to Low-Income Undergraduate Students in the Context of Academic Decision-Making....

3. Explanatory Mixed Method Design: Participant Selection Model

4. Study Methods Flow Chart. A Study Specific Interpretation of Creswell's Explanatory Mixed Method Design: Participant Selection Model....

5. Number of Declared Students by Combined Primary and Secondary Major by Disciplinary Area

6. Non-Declared Student Current Interest in Academic Majors by Disciplinary Area as Reported in Survey.

7. Declared Student Instances of Departure from Majors of Interest at Admission to Official Declaration with MAU

8. David's Timeline Depicting His Lifelong Commitment to Math as an Academic Major

9. Amelia's Timeline Depicting the Influence of English and English-Related Hobbies and Experiences Shaping Academic Decision-Making.

10. Chloe's Timeline Depicting Her Vast Interests and Struggles in Narrowing Her Choice of Academic Major.

11. Samesh's Timeline Influences in Academic Decision-Making and His Shift from Pre-Medicine to Business, Despite Greater Interest in Humanities ......156

12. Comparison of SCCT model with estimated model of student findings related to efficacy....

13. Study specific estimated model depicting pre-college and college influences and efficacy findings 
"In a larger sense, the humanities help us all understand almost everything better -- and they liberate us from the myopia our media culture and politics impose upon us. Unlike our current culture wars, which have manufactured a false dialectic just to accentuate otherness, the humanities stand in complicated contrast, permitting a nuanced and sophisticated view of our history, as well as our present moment, replacing misplaced fear with admirable tolerance, providing important perspective and exalting in our often contradictory and confounding manifestations...Somehow, in recent times, the humanities have been needlessly scapegoated in our country by those who continually benefit from division and obfuscation. Let me make it perfectly clear: the United States of America is an enduring humanistic experiment."

-Ken Burns, documentary maker, in his Jefferson Lecture to the National Endowment for the Humanities, May 9, 2016 


\section{CHAPTER I}

\section{INTRODUCTION AND STUDY PURPOSE}

The transition to college is steeped in new challenges, adjustment to academic and social environments, and decisions perplexing for even the most prepared new student. While the choice of academic major may become swept into the myriad decisions involved in the college going process, it is arguably one of the most important in the academic career. Prior to college, the choice of major signals a clear decision on next steps a student may need or want to take in his or her education. It is an indicator of the type of career or vocation a student may want to pursue in the future. Moreover, the choice of major may also be reflective of the messages a student has received regarding how to be successful during and after college. In a postRecession climate, where a college degree now opens doors to employment once only requiring a high school diploma, the choice of academic major and subsequent beliefs about career outcomes can result in life-long implications for a student.

\section{Primary Influences on Academic Major Choice}

Beginning in grade school, children are often asked what they want to be when they grow up and, while an innocent inquiry, this may be the beginning of early influences on the academic major choice process. Over time, a student's stage of development, along with a multitude of influential experiences, individuals, and perspectives shape major choice (Evans, Forney, Guido, Patton \& Renn, 2010). For some students, the choice of major and related outcomes are the primary reason for considering college attendance (Selingo, 2016). For others, attending college may be an exercise in self-exploration and personal development with the choice of major as an 
outcome of multiple experiences (Selingo, 2016). Some students declare a major and persist in the chosen discipline while others may change majors multiple times across their academic career (Selingo, 2016). While higher education literature attributes the choice of college major to a multitude of experiences and characteristics (Eccles \& Harold, 1993; George-Jackson, 2010; Ma, 2009) which must be considered in context, there are three primary influences, detailed below, that must be considered: student background characteristics, college and external environments, and academic self-efficacy.

Student Background. The personal characteristics, influences, and experiences students bring with them to college are critically important to the academic-decision making process (Astin, 1993; Pascarella \& Terenzini, 2005). Central to the process may be the student's personal interests and talents, labor market roles held by family members, and the geographic location in which the family resides (Evans et al., 2010). In addition, the quality of high school education and the student's engagement with academic coursework, teachers, guidance counselors, and peers may direct academic interests (George-Jackson, 2010; Ma, 2009). Students, in varying stages of development, also hold ideas regarding what majors meet their own personal goals and the perceived expectations of others (Ma, 2009). Across decades, Astin (1991) tracked students' personal values and attitudes toward higher education, and indirectly college major choice, and found "being very well off financially" and "developing a meaningful purpose in life" to have varying degrees of impact (p. 137). By the end of the high school career, the values and beliefs developed across a student's lifetime regarding college attendance and particular occupations are also believed to influence academic major choices (Morgan, Gelbgiser \& Weeden, 2013).

A student's race, gender, and socioeconomic status are of paramount importance in the academic decision-making process. Lackland and De Lisi (2001) found women gravitated 
toward majors consistent with traditional gender roles while Porter and Umbach (2006) found variation across major choice for men and women. Malgwi, Howe, and Burnaby (2005) found women to be more positively influenced by aptitude where men were more likely to consider career advancement when selecting a major. The addition of race exacerbates these issues. Multiple studies (Goyette \& Mullen, 2006; Riegle-Crumb \& King, 2010; Simpson, 2001) have found differences across major choice for African-American, Hispanic, Asian, and White students. Moreover, a student's socioeconomic status, which often includes consideration of parental education, influences major choice. Student's from low-income families often enter college with less cultural capital to navigate the environment (Lareau, 2003), may face deficits in preparation (Pascarella \& Terenzini, 2005), and are less likely to seek critical resources (Engle \& Tinto, 2008), all which may influence the major choice process. Given a student's background characteristics influence their behaviors and perspectives prior to and during college, it is critically important to consider and acknowledge how these characteristics influence academic major decision-making as well.

College and External Environments. The college and external environmental influences a student encounters also informs the academic major choice. Specific to the college setting, a student's experiences with academic coursework, co-curricular involvement, and peers have been found to shape choice of major (Evans et al., 2010). In particular, the relationships a student builds with faculty and staff contributes not only to his or her sense of belonging on a campus but strengthens the ability to select a major (Kuh et al., 2007). Chambliss and Takacs (2014) identify faculty as central to the major choice process as gatekeepers who either welcome students to a discipline and inspire exploration or alienate students to a point where they choose to study in other fields. Similarly, high-impact practices, such as internships and living-learning 
communities, are thought to positively inform a student's choice of major (Kuh, 2008; O'Neill, 2010). A potential detriment, however, is the recent emphasis placed on institutional accountability and time to degree. Students now face increased pressure to declare a major earlier in the academic career, essentially removing the opportunity for exploration (Evans et al., 2010). Nonetheless, the college environment is an important factor in strengthening academic self-efficacy and decision-making, discussed further in the next section, while assisting students in navigating both personal and academic development (Pascarella \& Terenzini, 2005).

While the college experience may seem isolated, students are also influenced by a multitude of external environments. While still considered within a student's personal sphere, the influences and expectations of parents and important role models are believed to shape a student's interest, both positively and negatively, when considering academic decisions (Eccles \& Harold, 1993; Louie, 2004; Ma, 2009). Peripherally, a student's choice of major may be tied to economic occurrences, such as a depression or recession, or shifts in labor market demands (Blom, Cadena \& Keys, 2015). Similarly, historic events may play a role. For example, through the advent of space exploration in the 1960s, job opportunities in science and technology fields expanded and prompted a rise in academic majors in related disciplines (Pittaoulis, 2012). Similarly, the political and social unrest of the same decade is believed to have increased student interest in the social sciences (Pittaoulis, 2012). Students may also find influence through social, cultural, or religious beliefs developed prior to or during college (Bronfenbrenner, 1993). More recently, the 24-hour media cycle, through a web of television, radio, newspaper, blog, and social media outlets, bombards listeners with a convergence of ideas, opinions, facts, and figures which may shape the way a student understands academic opportunities, economic development, and labor market outcomes (Jones \& Fox, 2009; Matney \& Borland, 2009). The external influences 
faced by college students are so numerous that honing in on those which shape academic decision-making is difficult yet necessary for better understanding the major choice process, especially in particular contexts.

Academic Self-Efficacy. A student's choice of major is largely dependent upon his or her belief that he or she will be successful in that major (Eccles, 1987). When a student believes he or she possesses the abilities to complete academic tasks, successfully engage in an educational environment, and recognize progress toward degree completion, the student is said to be acting with academic self-efficacy (Bong \& Skaalvik, 2003; Schunk, 1991). It is a student's personal interests, talents, family influences, academic experiences, and external forces that inform personal beliefs regarding his or her ability to be successful in a particular endeavor (Bong \& Skaalvik, 2003; Schunk, 1991). For example, a student who enjoys math courses but did not achieve a high score on a math assignment may lose confidence in his or her ability to pursue disciplines requiring quantitative or computational skills. However, given self-efficacy is shaped not only by direct experiences but peripheral influences and contexts, it is possible a student's feelings of efficacy may not be consistent with his or her actual achievements, talents, abilities, and desires (Lent, Brown \& Hackett, 1996). It is at this intersection where college major choice may be impacted. If a student's self-efficacy is shaped by background characteristics and environmental influences, students may be choosing an academic major based on perceptions and misinformation, which could be detrimental in achieving goals and outcomes (Lent, Brown \& Hackett, 1994; 1996). Multiple studies have found students with a strong sense of academic self-efficacy possess greater motivation to set goals and achieve higher grades (Bandura \& Schunk, 1981) and adapt successfully to new learning environments (Chemers, Hu \& Garcia, 2001). Although higher education literature supports the notion that self-efficacy is 
important in college success (Chen \& Simpson, 2015; Pascarella \& Terenzini, 2005), deficits remain in understanding the specific influences prompting efficacious decision-making in the context of academic major choice.

\section{Low-Income Students: Navigating Barriers to Higher Education}

From concerns surrounding access and affordability to the value of particular disciplines and pathways to employment, higher education is under constant scrutiny in the United States. However, as debates take center stage across campuses, corporate boardrooms, and Capitol Hill, it calls into question who may be affected by this culture of divisive rhetoric. To be considered in this discourse are low-income students, who are already facing difficult challenges in entering and completing higher education. Students from low-income households enter higher education at an exponentially lower rate than well-resourced peers (Giancola \& Kahlenberg, 2016). In his first major address after his confirmation as U.S. Secretary of Education, John King focused on the significant barriers to higher education faced by low-income students and, in particular, to selective institutions. King shared a March 2016 publication citing that only 23 percent of highachieving, low-income students apply to selective institutions, and those students make up only three percent of enrollment at elite colleges, despite impressive completion rates (Chetty, Hendren, Kline \& Saez, 2014). Often, the decision to avoid applying to selective institutions results from a lack of information and misunderstanding that, despite high sticker prices, many elite universities can offer greater resources and financial assistance for low-income students (Giancola \& Kahlenberg, 2016). Without substantial assistance from family and often choosing institutions with fewer resources and Pell Grant dollars, low-income students are saddled with extensive loan debt upon completion (U.S. Department of Education, 2016).

Complicating college success is the lack of social capital possessed by most low-income 
students. Whether their families did not attend college or they attended a poorly resourced high school, many low-income students do not possess the knowledge to effectively navigate the services, experiences, and networks associated with success in higher education (Pascarella \& Terenzini, 2005). For low-income students who are the first in their families to attend college, they often feel pressure to live the vicarious dreams of parents and relatives or to secure lucrative employment after graduation to provide a better life for themselves and their families (Bures, 2011). The disparities across income level should not go unmentioned. Students with highincome parents are three times more likely to attend college than their low-income peers and are more likely to succeed after enrollment (Chetty, Hendren, Kline \& Saez, 2014). While only about half of Pell Grant recipients are completing the Bachelor's degree within six years, nearly 70 percent of those students from above the Pell threshold are obtaining the degree (Chetty, Hendren, Kline \& Saez, 2014; U.S. Department of Education, 2016). Along with these challenges, low-income students who do enter college must navigate significant academic choices and, often, do not seek resources for assistance (Engle \& Tinto, 2008; Lareau, 2003). However, we know little about how low-income students are making academic decisions regarding their majors, particularly post-Recession, and in a climate continuing to perpetuate college as the best investment Americans can make in their future (U.S. Department of Education, 2016).

\section{A Shifting National Landscape}

In addition to considering the background, environmental influences, and academic selfefficacy of students, and particularly those from low-income families, historic events and shifting national and global perspectives may also shape, perhaps surprisingly, the academic decisionmaking process. Following the Great Recession of 2008, increased focus on the linkages 
between academic disciplines, college completion, and labor market outcomes became prevalent (Carnevale, Cheah \& Strohl, 2012; Harpham, 2011; Obama, 2009). Driving much of this conversation was soaring tuition costs and rhetoric shifting from the merits of college attendance to the benefits of specific degree completion. The rising cost of college attendance prompted students to seek majors resulting in what they perceived to be quickly lucrative careers to pay loan debt (Musil, 2015). As business suffered and companies looked for efficient ways to produce and deliver products, science and technology disciplines gained appeal as avenues toward job attainment after graduation (Musil, 2015). This was also supported by policymaker desires for the United States to remain competitive in the global marketplace (National Research Council, 2012). Shifts in federal funding and grant opportunities resulted in institutional expansion of academic offerings in science, technology, engineering, and math (STEM); concerning as these funds were previously allocated largely to the humanities and social sciences (National Research Council, 2012). The Obama administration also brought the academic major decision into the national spotlight. As part of his American Recovery and Reinvestment Act, President Obama highlighted deficits in the number of Americans earning a college degree and identified higher education as a means for reshaping the nation's economy, with a push toward vocational training and focused career planning for timely completion (U.S. Department of Education, 2016). Subsequently, university leaders felt pressure from federal and state lawmakers to measure institutional success through time to completion, graduation rates, and employment outcomes (Musil, 2015). Moreover, families were taking a greater interest in these figures as the debate over return on investment heightened (Musil, 2015). While these discussions may seem larger than a student's choice of college major, and they are, the emphasis placed on the importance of a student choosing a major that can aid in the rebuilding of the 
nation's economy, timely degree completion, and lucrative employment outcomes increased the stakes. However, the impacts and influences on students, particularly on their decision-making, stemming from this highly public shift in thought remains largely unknown.

\section{The Humanities Under Scrutiny}

Caught in this changing climate and shifting educational landscape are the humanities. Once the cornerstone of a classic liberal arts college education, the humanities are now a source of controversy for policy makers, media pundits, and academics alike. From their inception at Harvard College in 1636 as a means for exploration of the human condition, fostering critical perspective, and formation of imagination and creative spirit, the humanities have held an important place in the personal and professional development of college students (Bailyn, 1986). The establishment of the National Endowment for the Humanities (NEH) in 1965 anchored the disciplines in a public spotlight and offered significant funding for research and development. Despite the expansion of academic offerings across a "college for all" environment, the humanities remained a staple in course catalogs as instrumental in the pursuit of life-long learning (Thelin, 2011).

The Great Recession of 2008 signaled a modern tipping point for the humanities and higher education (Harpham, 2011). Americans, seeking jobs and wages, identified obtainment of education credentials as a competitive advantage and returned to both undergraduate and graduate education (Musil, 2015). However, these students desired to learn specific skills, often within a particular vocational path, rather than the traditional disciplines of the humanities. Declines in humanities enrollment emerged (AAC\&U, 2015). As demands and costs soared, the indirect connection between humanities study and employment upon degree completion was widely questioned (Musil, 2015) and perpetuated by the mainstream media. The New York 
Times highlighted a 30 percent decline in humanities degree completion over the last decade at Harvard University (Schulten, 2013). The same article indicated that 45 percent of Stanford faculty are in humanities disciplines but only joined by 15 percent of enrolled students (Schulten, 2013). Student newspapers from New York (Van Dyke, 2013) to Seattle (Franzwa, 2013) featured the closure of four humanities programs to low enrollment at Edinboro University. Washington Monthly reported a decline from 14 percent to 7 percent in humanities degrees awarded between 1966 and 2010 (Luzer, 2013). In September 2015, Wellesley College, founded on liberal education ideals, revealed a 14 percent drop in humanities course enrollment in the last seven years while seeing a 29 percent rise in STEM discipline enrollment over the same period-and this data as consistent with national trends (Idrobo, 2015).

These statistics, and divide over the future of the humanities, is exacerbated by public calls to defund disciplines. Florida Governor Rick Scott proposed cuts to humanities and social sciences majors at Florida public institutions and encouraged the diversion of funds to STEM programs for increased job placement (Luzer, 2013). North Carolina Governor Pat McRory argued that public university funding should be based on job placement, with reward to high employment yield majors, and encouraged students with humanities interests to attend private colleges (Luzer, 2013). With the college going process already being a complicated endeavor and many students, particularly from marginalized populations, failing to get the necessary information to make informed decisions, negative media rhetoric surrounding the humanities may arguably be a contributing factor in these declines. Moreover, while prospective and current college students may not be closely following the public debate, it may be their families, teachers, mentors, and counselors who are using these snippets of knowledge to influence their student's decisions. 


\section{Humanities for All?}

What the negative rhetoric about the humanities is missing is that they can be meaningful majors for all students to choose. Rather than focusing on training in specific skills, which may become obsolete in an ever-changing job market, the humanities and social sciences place emphasis on the human condition, development of critical thinking and communication skills, and understanding life's universal questions (Kraus, 1961; Musil, 2015). Moreover, development of these skills is widely argued in popular press as being a better preparation for a competitive workforce (Sparks \& Waits, 2011). Those with humanities degrees have been cited as more adaptable in the workplace, possessing stronger oral and written communication skills, appreciative of diversity, and ethical decision-makers (Nussbaum, 2010). Proponents of humanities study stress the importance of these skills in a volatile labor market as an avenue for adaptability in changing climates (National Task Force, 2012). Similarly, these skills, unlike specific trades, provide benefits to the student across a lifetime and improve engagement in society (National Task Force, 2012). In a recent address to the European University Association, Ireland's president Michael D. Higgins warned against the narrowing of higher education to professional training and outcomes that are near-sighted and short-lived (Redden, 2016). Higgins identified the conflict between humanities and vocation-centered professions as "a moment of intellectual crisis" and cited declines in humanities offerings as "a betrayal of the purpose of education" (Redden, 2016, para. 1). While pervasive rhetoric may persuade the pursuit of vocational training and STEM education over humanities study, it may also be inadvertently leading students down a path lacking in life-long, transferable skills identified at the very core of a liberal education and shaping a student's self-efficacy regarding his or her ability to enter and succeed in college. 


\section{Purpose of the Study}

This study examined how environmental influences shape the self-efficacy and academic major choice process of low-income undergraduate students with interests in humanities disciplines. For this study, college environments include all aspects of the traditional college experience including academic, social, and co-curricular involvement. Similarly, external environments are defined as any instances, experiences, or relationships shaping academic decision-making outside the traditional college context. The findings of the study aimed to strengthen the knowledge base through the following research questions:

1. What influences low-income undergraduate students to pursue academic majors in humanities disciplines?

2. In what ways are low-income undergraduate students' senses of academic self-efficacy regarding their choice of major shaped through experiences and influences within the college and external environments?

3. What college and external environments or experiences, specifically, shape the major choice process for low-income undergraduate students interested in humanities disciplines?

The experiences of low-income students engaged in major choice provided a direct lens for understanding individuals, messages, resources, and experiences deemed critical to personal success. While low-income students are often studied in tandem with first-generation college students, and overlap exists, this study is limited specifically to low-income students in an attempt to understand needs specific to this population. Moreover, the negative rhetoric surrounding poor labor market outcomes for those choosing humanities study drives a desire to isolate how income status may shape decision-making. The research questions were developed in congruence with the Social Cognitive Career Theory model, indicating that self-efficacy is a product of a student's personal characteristics and learning environments and plays an important role in predicting the ability to inform interests, goals, and actions. Moreover, Bronfenbrenner's 
(1979) Ecological Systems Theory provided a research framework for considering, and going beyond, student development and decision-making through exploration of environmental, experiential, and contextual influences. The use of these frameworks for this study is further discussed in Chapter II.

\section{Significance of the Study}

The study's findings add to a fledgling knowledge base on the academic-decision making, and particularly major choice, of low-income students. Currently, there are a multitude of initiatives, both federally and institutionally, to both improve enrollment of low-income students and lessen the financial burden of college attendance (U.S. Department of Education, 2016). This includes establishment of the American Opportunity Tax Credit, increases in Pell Grant funds, student lending reform, and procedural shifts in the Free Application for Federal Student Aid (FAFSA) to provide low-income students a streamlined process (U.S. Department of Education, 2016). Moreover, the Obama administration issued the College Scorecard as an opportunity to bridge the knowledge gap for low-income families and to safeguard against poor investments in dishonest institutions (U.S. Department of Education, 2016). While federal efforts, and many other programs and initiatives, are beneficial in the enrollment of marginalized students in higher education, we must still work to retain low-income students once they enter college. As indicated, low-income students face tremendous challenges not seen by their wealthier peers and often avoid asking for assistance. By better understanding the foundation of what shapes a low-income student's sense of self-efficacy and, in turn, forms academic decisions such as major choice, we open a new door to student success. Moreover, this study’s specific focus on humanities study aims to provide insight into the influences of negative rhetoric regarding major choice for this population. More explicitly, the findings of this study examine 
students across varying levels of the academic decision-making process and in a highly volatile, post-Recession climate. This provides institutional leaders with an opportunity to examine the internal and external influences shaping the college major choice of low-income students and can result in renewed resource and service offerings for improved academic outcomes. Finally, contributions from this study provide a baseline for understanding specific influences on the academic decision process for low-income students resulting in opportunities for continued future research in specific areas and greater depth. 


\section{CHAPTER II}

\section{REVIEW OF THE LITERATURE}

This literature review summarizes four primary topics relevant to this study and begins with an overview of the historical background and purpose of the humanities in higher education. Next, the modern day challenges to the humanities with specific focus on the perceptions of employers, faculty, and students as stakeholders will be considered. Third, the experience of low-income college students and the role of self-efficacy will be examined. Finally, the relevant literature regarding academic major choice will be presented with specific attention devoted to the academic decision-making of low-income students.

\section{The Humanities: A Historic Foundation for Higher Education}

From the emergence of a 1636 curriculum based in Puritan beliefs, the classical trivium of language arts and the quadrivium of mathematics and sciences at Harvard College (Bailyn, 1986), to Jefferson's belief that our nation's success hinged upon a humanities-based education of its people, the quest for unitary knowledge has shaped post-secondary education (Jefferson, 1780). Across centuries, the humanities remained as a forum for exploration of the human condition, fostering critical perspective and formation of imagination and creative spirit (Kraus, 1961). The humanities provide a lens for understanding the moral, spiritual, and intellectual world around us, teach us to weigh subjective and contextual evidence logically, and foster a sense of social justice, equality, and empathy (Terras et al., 2013).

Not to be misconstrued with political rhetoric, a liberal education is an approach to higher learning where students are prepared and encouraged to explore "complexity, diversity and 
change" (AAC\&U, 2005; 2011). Within a liberal education lies the specific academic discipline of the natural and social sciences and, particular to this study, the humanities. The National Foundation on the Arts and the Humanities Act (1965) identified the humanities to formally include,

modern and classical languages, linguistics, literature, history, jurisprudence, philosophy, archaeology, comparative religions, ethics, the history, criticism and theory of the arts, any aspects of social sciences employing humanistic methods and the study and application of the humanities to the human environment with particular attention to reflecting our diverse heritage, traditions, and history and to the relevance of the humanities to the current conditions of national life (20 U.S.C. $\S \S 89-209)$.

Through the humanities, students are exposed to a wider breadth of knowledge regarding the world while closely examining topics within a specific area of human interest (Nussbaum, 2010). A cornerstone of the humanities remains the lasting impact of developing a student's intellectual curiosity, analytic reasoning, interpersonal communication, and social responsibility while also effectively applying these skills to the modern world (Nussbaum, 2010). Moreover, the humanities are credited with producing democratic citizens who seek to understand the driving humanistic questions of historic and contemporary significance (Nussbaum, 2010).

From their foundation, the humanities were developed to be more than occupational training but also personal and intellectual enlightenment to advance the self and society (Krause, 1961; Harpham, 2011). This belief garnered attention in the early $20^{\text {th }}$ century as Harvard grappled with varying iterations of a general education curriculum before returning to a strong humanities foundation as a necessity for shaping "democratic values, character and knowledge" (Harvard University, 1945, p. 7). Leading the way with general education reform in the 1930s, Harvard administrators and faculty took a new approach to curriculum development in which students selected from a breadth of courses of interest rather than foundational humanities courses (Harvard University, 1945) but this approach was deemed "inadequate" after only a few 
years (Harvard University, 1945). In 1945, Harvard president James Conant, along with a team of faculty and academic administrators, published Harvard's General Education in a Free Society, known in education circles as the Red Book. The report identified the humanities as imperative to a common general curriculum meant to cultivate "value judgments" necessary for active democratic citizenship (Harvard University, 1945). Regardless of academic major, each student would complete courses in humanities, along with social sciences, science and math, to enhance personal and scholarly development (Harvard University, 1945).

Harvard's return to the humanities as a foundation coincided with post-World War II realizations by political leaders that higher education should play a critical role in the recovery of nation-states (Thompson, 2014). President Truman's newly formed Commission on Higher Education issued Establishing The Goals (Zook, 1947), a multi-volume work identifying postsecondary education as a path toward "fuller realization of democracy in every phase of living" (p. 8) while calling for strengthened international understanding for advancing solutions to social and public affairs issues (Gilbert \& Heller, 2010). Scholars heeded this opportunity to advance humanities fields in considering historic and modern democratic ideals through a lens of race, religion and gender and to expand understanding of complex human actions, interactions and structures while increasing intercultural communication and competency (Gilbert \& Heller, 2010). The Truman Commission's work, and subsequent creation of the National Endowment for the Humanities (NEH) in 1965, arguably established a national rhetoric on higher education and presented postsecondary learning as a leading social, public policy, and economic contributor-an unknown foreshadow to the decades long debate about to unfurl. 


\section{Challenging the Humanities in Modern Application}

The late 1970s and early 1980s brought criticism from President Carter citing American disinterest in values, loss of national spirit, and an over indulgence in self-interest and personal wealth (Harpham, 2011). Simultaneously, the national institutes of the 1960s, including the $\mathrm{NEH}$, were turning a sharp focus from foundational texts and theories toward research and new knowledge (National Research Council, 2012). This shifting attention resulted in funding decreases and framed the humanities as being outdated, unnecessary, and a downfall to the future of higher education (National Research Council, 2012). The 1990s brought a partisan call, championed by conservative NEH chairs William Bennett and Lynne Cheney, for the abolishment of the NEH, accusing humanities scholars of promoting ideals misaligned with democratic interests (Harpham, 2011). While the NEH survived, uncertainty regarding the future of the humanities remained constant.

Emerging from the debate was the Liberal Education and America's Promise (LEAP) program, aiming to "turn a spotlight on the kinds of knowledge, skills, and values that are needed to prepare today's students for an era of greater expectations in every sphere of life" (AAC\&U, 1995, p. 1). Over the next decade and building upon the work of the American Association of Colleges and Universities (AAC\&U), LEAP identified necessary academic experiences regardless of major, partnered employer desires with college curricula, considered findings from national faculty and student surveys of student engagement, and included campus assessments of student gains over time (AAC\&U, 2015). From this report, LEAP emerged as a leading public advocacy campaign for encouraging democratic vitality and economic creativity across a liberal education curriculum for postsecondary students. 
Despite LEAP's progress, the Great Recession of 2008 reignited criticism of the humanities. As unemployment numbers rose, many Americans saw higher education as an opportunity to earn credentials for increasing job market competitiveness and earnings. Conversely, large cuts to higher education, particularly from state funding sources, increased cost of attendance while widening the stratification of who could afford to attend (Harpham, 2011). In a February 2009 speech to Congress, President Obama outlined the American Recovery and Reinvestment Act, identifying education as a primary means of workforce development and economic growth (Obama, 2009). This included defining a "complete and competitive education" as one obtained from birth until career establishment (Obama, 2009). Moreover, Obama indicated three-quarters of the fastest-growing occupations require a postsecondary education with only half of American citizens holding a college degree (Obama, 2009). By 2020, Obama slated America to have the highest proportion of college graduates globally (Obama, 2009). His words fueled debate surrounding labor market outcomes, the value of humanities in the college curriculum, and the philosophical divide regarding holistic knowledge and vocational training within postsecondary education.

In late 2009, U.S. Senators Lamar Alexander and Barbara Mikulski and U.S. Representatives Bart Gordon and Ralph Hall charged the American Academy of Arts and Sciences (Academy) with investigating improvements to doctoral and research education for global competition (Commission on the Humanities and Social Sciences [CHSS], 2012). In 2010, a Congressional subcommittee, led by Alexander and supported by Senator Mark Warner and Representatives Tom Petri and David Price, called for the Academy to answer the following question:

What are the top ten actions that Congress, state governments, universities, foundations, educators, individual benefactors, and others should take now to maintain national 
excellence in humanities and social scientific scholarship and education, and to achieve long-term national goals for our intellectual and economic well-being; for a stronger, more vibrant civil society; and for the success of cultural diplomacy in the $21^{\text {st }}$ century? (CHSS, 2012).

This prompted the Academy to create exploratory commissions while humanities proponents used popular press to regale the benefits of critical thought, creative expression, and life-long learning. Reciprocal claims emerged encouraging growth in vocational and STEM preparation focused on globalization, the $21^{\text {st }}$ century labor market, and economic impacts (Sparks \& Waits, 2011). As media debate ensued, a Civic Learning and Democratic Engagement National Task Force (NTF) delivered A Crucible Moment: College Learning and Democracy's Future, an attempt to map a $21^{\text {st }}$ century vision onto the foundational principles set forth by early leaders. Culling data from five national roundtable discussions, the report called for higher education to provide life-long learning, critical thought, appropriate employment preparation, knowledge for responsible citizenship and positioning for economic opportunity while identifying the humanities as critical to advancing a framework for civic ethos, literacy, inquiry and action (NTF, 2012). To much praise from humanities proponents, the report concluded "civic learning needs to be an integral component of every level of education, from grade school through graduate school, across all fields of study" and called for strengthened general education across the curriculum (NTF, 2012).

However, A Crucible Moment was soon challenged in Degrees for What Jobs? Raising Expectations for Universities and Colleges in a Global Economy, the National Governor's Association brief suggesting that public funding should be allocated based upon the promotion of “economic goals, workforce preparation and competitive advantage" and included cuts to humanities and social sciences programs (Sparks \& Waits, 2011). Praised by policy makers and shunned by academe, the report was characterized as "creating divisions where none needed to 
be" and promoting vocational preparation rhetoric (Musil, 2015). Adding to the debate, Divided We Fail: Why It's Time for a Broader, More Inclusive Conversation on the Future of Higher Education emerged as a non-partisan voice indicating 90 percent of those participating in 115 public forums agreed that college is a place for rich learning through humanities preparation (Johnson \& DeStasi, 2014). Moreover, 74 percent of forum attendees strongly endorsed institutional responsibility to encourage academic exploration regardless of occupational aspirations (Johnson \& DeStasi, 2014).

Attempting to reach new audiences and shift from policy to practice, AAC\&U, supported by NEH funds, established the Cultures to Form A Nation: Difference, Community and Democratic Thinking initiative (AAC\&U, 2015). From 2012 through 2014, invited community college faculty and leaders participated in curriculum and professional development workshops to improve civic learning, encourage two-year college completion and transfer rates, and strengthen curriculum in vocational degree programs (AAC\&U, 2015). The initiative reinforced humanities as a vehicle toward understanding diversity and the critical implications this has for success in a global society.

Responding to the 2010 Congressional request and, arguably, rebuking the STEM-centric Rising Above the Gathering Storm, the Academy issued The Heart of the Matter (2012), urging knowledge toward $21^{\text {st }}$ century democratic ideals, labor market competition, and strengthened cultural understanding. At its core, The Heart of the Matter argued why science cannot function independently from the humanities (CHSS, 2012). The report posited the importance of understanding history and context for success in innovation and how real-world application does not always occur in controlled, sterile environments (CHSS, 2012). The report cited the humanities as how we learn about ourselves and others, retain a national memory, and learn "not 
only what but why and how" (CHSS, 2012, p. 10). The report also accused policy makers of using tailored factors and figures to prevent a realistic picture of opportunities from being shared with students, particularly those from marginalized populations, as they grapple with college decisions (Musil, 2015).

Since the Congressional inquiries and subsequent publications, a shift toward data collection and assessment emerged as LEAP introduced a plan, set for incremental implementation from 2013 to 2017, aimed to establish stronger employer support for liberal education, increase student understanding of learning outcomes, and promote the use of proven high impact practices for humanities study (AAC\&U, 2011; Kuh, 2008). To track long-term outcomes, the Strategic National Arts Alumni Project (SNAAP) (2013) collected data from nearly 100,000 arts graduates to consider college experiences, preparation, and factors shaping post-graduate decision-making. Once shared with arts faculty, these findings are intended to aid in redefining academic curriculum toward workforce trends. The Academy's (2015) Humanities Indicators issued a comprehensive data source on humanities degree attainment, indicating that 8 percent of humanities departments at public institutions ceased to grant a degree at one or more levels between 2007 and 2012 while bachelor's degrees awarded in the humanities dropped from 12 percent in 2007 to 10 percent in 2013 .

As these publications fuel fervent discourse and divide across disciplines, findings are now used as economic and workforce development talking points on campaign trails while policy makers attempt to improve outcomes through blanket reform (White House, 2015). With the hands of those funding higher education deeply concerned with outcomes, university leaders are seemingly more focused in this direction as well. In addition, the post-Recession economic climate has prompted significant funding cuts for public universities. The Delta Cost Project at 
American Institutes for Research found local and state funding per student was 28 percent lower in 2013 than 2008 (Desrochers \& Hurlburg, 2016). However, seemingly missing from this discussion is whether policy driven shifts in curricular focus, significant funding cuts, and pervasive media rhetoric is shaping student academic decision-making and, if so, the subsequent impacts.

\section{Stakeholders: A Closer Examination}

Our world is a more demanding place and the need for college-educated workers who are adaptable, technologically current, and widely skilled is at an all-time high (AAC\&U, 2015). To understand these needs, we consider the debate surrounding the mission of higher education while exploring the interests of stakeholders who are, in a micro sense, navigating these debates in real time. While stakeholders have fundamentally varying interests, students play an important, and seemingly forgotten, role as they weigh employer demands, institutional messaging, and faculty interaction. The ways students navigate his or her own roles as stakeholders, experience influence from other stakeholders, and use information in personal decision-making is critically important yet lacking consideration.

\section{Employers}

In 2009, AAC\&U commissioned interviews of over 300 employers and issued Raising the Bar: Employers' Views On College Learning In The Wake Of The Economic Downturn, which indicated an increased desire for broad skill sets coupled with content knowledge in specific fields and greater interest in employing baccalaureate degree holders (Hart Research Associates [Hart], 2010). Employers placed a strong emphasis on the application of classroom knowledge in real-world settings, ethical decision-making, appreciating diversity, strong interpersonal communication skills, and critical and analytic thinking--often citing these as more 
important than the undergraduate major (Hart, 2009; 2013). When asked about the impact of college graduates on the economic recovery, former Chairman and CEO of Lockheed Martin, Norm Augustine, offered:

If the American economy is to recover from the Great Recession-and I believe that it can - it will be because of a ready supply of workers with the critical thinking, creative problem solving, technological, and communication skills needed to fuel productivity and growth. (AAC\&U, 2011; 2015)

Over 90 percent of employers identified increased reliance on employees to solve complex challenges, assume greater responsibility, and apply broad knowledge for success (Hart, 2013). Chief officers at major banking organizations describe top employees as having "empathy, understanding, listening skills, critical thinking, and an appreciation of context" from a study of broad-based knowledge rather than technical skills (National Task Force, 2012, p. 34).

Prominent technology companies, such as Google, are abandoning traditional hiring practices in favor of applicants demonstrating "adaptability, and social and emotional intelligence" (Hart, 2013, p. 4). By partnering field-specific work with foundational skills of a liberal education, the number of job opportunities open to liberal arts graduates can nearly double (Vedder, Denhart \& Robe, 2013). Collectively, these findings support post-recession desires by employers to hire those with mixed talents rather than those, subscribing to the debate, only focusing in a specific vocation within higher education (Hart, 2013).

\section{Faculty}

As enrollment declines are highlighted in support of applied disciplines and federal funding has declined from $\$ 855$ million in 2008 to $\$ 594$ million in 2014 (Holm, Jarrick \& Scott, 2015), humanities faculty are forced to examine their disciplinary purpose and personal pedagogy while advocating for their professional livelihoods. Increasingly, students enroll in humanities courses as general education requirements rather than by choice--an environment 
arguably difficult for enticing major enrollment (Gair \& Mullins, 2001). This concern is supported by a 57 percent exodus of students who arrive at college with the intention to pursue a humanities major, but instead declare a major in another discipline (Harvard University, 2013). The administrative push toward creative academic collaboration has exacerbated these outcomes. Faculty are asked to create dynamic, interdisciplinary learning environments but often fall into criticism over discipline-based differences with colleagues, which leaves students feeling baffled and disenchanted with further pursuit (Menand, 2010). Grafton (2012), critiquing Menand's work, offers the state of graduate education and the corporatization of higher education as detrimental to institutional and major commitment. For those pursuing the terminal degree in the humanities, the experience has turned into training rather than exploration. Upon degree attainment, new faculty are joining adjuncts and visiting faculty taking on large general education course loads while teaching between multiple institutions to earn a living wage and, sometimes, benefits (Grafton, 2012). As adjuncts are spread thinly across multiple institutions, sometimes not affiliated with a particular department or program, or are teaching overwhelming course loads, meaningful student interaction is lessened (Grafton, 2012). Shown to play an important role in student commitment to the institution and major, lessened interaction between faculty and students also weakens an argument to students that humanities courses are more than required hurdles in the early years of college (Grafton, 2012).

Compounding the external debate are divides among humanities faculty themselves over the future of their disciplines. Progressive faculty support the humanities as an important underpinning to the vocation and actively seek opportunities for innovation and crossdisciplinary collaboration toward enrollment growth (Hearn \& Belasco, 2015). This often comes in the form of digital humanities where traditional texts and topics are being discovered through 
new approaches. At Stanford University, students use technology developed to explore rap music as a means for annotating the work of Homer and Virgil (Holm, Jarrick \& Scott, 2015). At UCLA, an undergraduate minor and graduate certificate in digital humanities offers innovative approaches to classic disciplines (Holm, Jarrick \& Scott, 2015). These faculty argue that explicit connections between the humanities and vocational outcomes are necessary for major enrollment to grow (Hearn \& Belasco, 2015). However, stalwart faculty believe the humanities should only be taught as originally intended and new approaches are unneeded or the responsibility of junior faculty (Hearn \& Belasco, 2015). What results is an inconsistency across curricula, impediments to change, and continued difficulty in student recruitment and persistence (Grafton, 2012).

\section{Students}

As criticism about major choice and career aspirations paint an unpleasant picture for humanities students, the outcomes of humanities study may not be as bleak as commonly thought. The Strategic National Arts Alumni Project (SNAAP) (2013) report found that 70 percent of recent fine arts graduates feel well prepared by undergraduate institutions in oral communication, persuasion, and network building. Eighty percent of these students identified finding jobs out of college related to his or her field of study and 75 percent reported overall job satisfaction (SNAAP, 2013). Comparatively, a survey of recent graduates found only 53 percent of mechanical engineering and 56 percent of accounting majors entered initial jobs related to their undergraduate study (Carnevale, Strohl \& Melton, 2011). Similarly, students are also entering college for reasons greater than vocational training or employment outcomes. Astin et al. (2007), in a survey of over 112,000 students across 236 universities, found that three quarters of students identify college as a time for personal discovery and development and not simply a pathway to employment. Dey et al. (2009) identified that 62 percent of students, in a sample of 
24,000 , overwhelmingly believed an outcome of college attendance should be local and global civic engagement.

These experiences and beliefs are supported by long-term financial benefits. Humanities graduates earn a median salary just $\$ 5000$ below that of all bachelor's degree holders, and 45 percent more than median salaries for high school graduates (Academy, 2015). Because many humanities graduates move into other fields, such as medicine and law, tracking the impact of disciplinary learning becomes difficult (Academy, 2015). The Georgetown Center on Education and the Workforce suggests that mean salaries will remain highest in positions with needs for strong communication and problem solving skills, math proficiency, originality and social skills-all with ties to the humanities (Carnevale, Smith \& Strohl, 2013). Current undergraduates will enter a unique labor market with a predicted 63 percent of all jobs requiring some level of postsecondary education by 2018 and, with graduation rates remaining flat, a shortage of three million college educated workers to fill these roles (Carnevale, Smith \& Strohl, 2013). An important consideration, college graduates paying average annual tuition neighboring $\$ 20,000$ can recoup the costs of schooling by age 40 (AAC\&U, 2015), while average college graduates earn over $\$ 800,000$ more than average high school graduates by retirement age (Daly \& Bengali, 2014). While these findings are critically important for all students, those from low-income families face greater risks than peers that may impact their thinking regarding major choice.

\section{Low-Income College Students}

Caught in the multi-faceted debate regarding the role of the humanities in higher education are low-income students attending, or desiring, postsecondary education. Defined as having a family income 200 percent below the poverty line, low-income students are often heavily reliant upon federal and institutional financial aid and loans to attend college (Federal 
Student Aid, 2015). While these options may be useful, navigating debt risk while considering college attendance benefits can be overwhelming for high school students. However, benefits are found to be much larger than employment and earnings. Those completing undergraduate degrees live longer and healthier lives, work in improved conditions, and live in safer neighborhoods while society receives benefits of increased civic engagement and volunteerism, widening of the tax base, and lessened dependence on social welfare programs (Baum, Ma \& Payea, 2013). Literature exists regarding the low-income student experience (Kezar, Walpole \& Perna, 2014), particularly college choice (Cabrera \& LaNasa, 2000), but the interplay between institutional environmental factors, self-efficacy, major choice processes, and policy rhetoric and media debate are less well understood for low-income students.

\section{Characteristics and Outcomes}

As the number of low-income students desiring higher education grows, the enrollment of this population lags (White House, 2015). Within our borders, data from the 2013 Current Population Survey indicated individuals from the highest income quartile were over 8 times more likely to complete a bachelor's degree by age 24 as those in the lowest income quartile (Mortenson, 2014). Concerning low-income students, the average tuition and fees at U.S. postsecondary institutions more than doubled between 1970 and the 2012-13 academic year with the share of education costs paid by students and families moving from 33 percent in 1977 to 49 percent in 2012 (Mortenson, 2014).

Despite often receiving Federal Pell Grants, offering nearly $\$ 4$ million in need-based aid annually, low-income students still, on average, borrow more money toward college completion than peers not qualifying for the same assistance (Engle \& Tinto, 2008; Federal Student Aid, 2015). Income is also highly predictive of where a student attends college, with low-income 
students more likely to attend private, for-profit or public, two-year institutions (Engle \& Tinto, 2008). However, for-profit attendees carry massive loan debt and, often, depart prior to completion (NCES, 2015a). Conversely, students from high-income families are highly represented at doctoral degree granting institutions (Mortenson, 2014). The Pell Institute found that 22 percent of low-income students depart college after the first year compared to only 7 percent of those from stable family incomes (Engle \& Tinto, 2008). Moreover, half of all highincome students obtain a college degree by age 25 but only 1 in every 10 low-income students meet the same goal (Bailey \& Dynarski, 2011). However, propelling federal and institutional action is data concerning the long-term benefits of college attendance for students born into lowincome families. Obtainment of a college degree for these students doubles his or her chances of moving out of poverty and quadruples their potential to achieve the highest income quartile (Isaac, Sawhill \& Haskins, 2008). A 2014 White House statement on college affordability and access suggested substantial financial aid and loan policy reform to be a priority of the Obama administration. The March 2016 report issued by the U.S. Department of Education overviewed progress toward these goals including procedural changes to the Free Application for Federal Student Aid (FAFSA) aimed to benefit low-income families, elimination of student loan subsidies for private banks, and significant increases in Pell Grant funding, including a first time tie between aid and inflation to ensure that values do not fall (U.S. Department of Education, 2016). Moreover, programs such as the Accelerated Study in Associate Programs at the City University of New York have been highlighted by policy makers for providing intensive academic and career counseling, financial resources, and pathways toward degree completion (U.S. Department of Education, 2016). While these new approaches and initiatives are intended to benefit low-income students, the current political climate and the competing interests of 
stakeholders may impede long-term progress and spark controversy (For an evaluation of the 2016 presidential platforms on higher education and college affordability, see Baum \& Chingos, 2015). Moreover, these changes do not speak to the state control over higher education and the discussion in these settings to funnel funds and resources to non-humanities fields (see Luzer, 2013).

In addition to financial difficulties, low-income students often lack the necessary cultural capital and support important for college success (Kezar, Walpole \& Perna, 2014; Lareau, 2003). In this context, cultural capital refers to the non-financial assets, often knowledge, experiences, and social awareness (Lareau, 2003), which contribute to a student's ability to navigate the college environment. Low-income students may attend poorly resourced high schools where opportunities for accelerated courses and college preparation are limited (Pascarella \& Terenzini, 2005), resulting in diminished competitive advantage with more privileged peers (Engle \& O’Brien, 2007). Less likely to attend college preparation events and facing deficits in completing financial aid forms (Kezar, Walpole \& Perna, 2014), low-income students take cues regarding their abilities, both academically and monetarily, from their surroundings with only 8 percent of high-achieving, low-income students applying to institutions deemed rigorous matches for their academic abilities (Hoxby \& Avery, 2009). These students are also likely to avoid applying to elite or selective institutions because of the shocking sticker prices, as they are unaware of the tremendous financial incentives and resources often available (Giancola \& Kahlenberg, 2016). Given these factors and likelihood of attending institutions with sub-par completion rates, attention turns to how higher education can close gaps detrimental to low-income student success. 


\section{Environmental Impact}

Taking into account demographic information, enrollment characteristics, and academic preparation, low-income students still face greater challenges in persisting through completion when compared to financially stable peers. As identified by Engle and Tinto (2008), this signals consideration of what happens during college as being equally or more important than a student's experiences prior to enrollment. Shaped by the institutional environment, a student's academic self-confidence and sense of belonging are critical to long-term success (Ostrove \& Long, 2007). The White House (2014) recently praised selective universities for providing greater academic and financial resources during the college search process and increased oncampus support for students upon arrival. However, given that low-income students are not likely to attend selective institutions, they may fail to receive the services needed for success. Both Gair and Mullins (2001) and Bergerson (2007) found institutional culture and the messages of faculty and administrators to shape a student's sense of belonging with students characterizing negative experiences as leaving them feeling "insignificant, intimidated and embarrassed" (p. 106). Moreover, low-income students, when compared to middle-class peers, are less likely to question institutional policies or advocate for their own needs (Lareau, 2003) and may be unfairly labeled as academically disinterested (Walpole, 2003; 2011). Often, a need to find employment or care for family prevents low-income students from engaging with study groups or attending class events, which may be misconstrued as lacking commitment (Walpole, 2003; 2011). When criticized by faculty for lacking commitment, sense of belonging is damaged and, in some cases, leads to departure (DeRosa \& Dolby, 2014).

Despite the importance of making early academic, social, and resource connections for all students (Astin, 1993; Pascarella \& Terenzini, 2005), low-income students may miss important 
matriculation events (DeRosa \& Dolby, 2014) are less likely to seek academic resources or study groups, engage socially, or approach faculty (Engle \& Tinto, 2008; Lareau, 2003). In particular, missing orientation and transition events may stunt a student's sense of belonging and impact self-efficacy (DeRosa \& Dolby, 2014). Stemming from peer inability to understand college costs, low-income students may possess feelings of marginalization regarding personal belongings and social disengagement (Bergerson, 2007). While some high impact practices, such as living-learning communities, provide low-income students with purposeful opportunities to build networks and meet similar peers (Inkelas, Vogt, Longerbeam, Owen \& Johnson, 2006; Kuh, 2008), student integration remains a challenge. By failing to make connections, low-income students may struggle with efficacy in academic decision-making, meeting deadlines, and finding developmental opportunities on campus (Pascarella \& Terenzini, 2005). Reciprocally, institutions may lack appropriate resources and outreach to low-income students that may help inform their academic decisions and improve outcomes and efficacy (Kezar, Walpole \& Perna, 2014). However, low-income students are not alone in making difficult decisions regarding their college experiences. Indeed, the choice of major is a difficult decision for most young adults, regardless of socioeconomic status, but those from marginalized backgrounds tend to experience greater barriers to success.

\section{Academic Decision-Making}

There is, perhaps, no college decision that is more thought-provoking, gut wrenching and rest-of-your-life oriented - or disoriented - than the choice of major. (St. John, 2000, p. 22).

\section{Major Choice}

Across the literature, less attention is devoted to the major choice process when compared with college choice, despite being arguably as important. Within the limited research on major choice, the independent variable of interest is most often race or gender (Crisp, Nora \& Taggart, 
2009; Staniec, 2002; Gill \& Leigh, 2000) rather than socioeconomic status and is studied independently rather than as a collective process. However, students indicating personal satisfaction with a chosen major have a greater likelihood of persistence and completion (Bloom, 2008), providing impetus for further study. Given the economic downturn, policy and funding shifts toward STEM promotion, and subsequent changes in academic offerings, a rise in major choices based upon labor market outcomes is not surprising and poses unique dilemmas. With institutions reporting over 1500 major options to the U. S. Department of Education, and some institutions offering over 300 majors on a single campus, the choice process may be overwhelming and uninformed (National Center for Educational Statistics [NCES], 2015b). Developmentally, students entering college are often not equipped to navigate these choices and rely upon others (i.e., faculty, peers, family and advisors) for guidance (Evans et al, 2010). In this dualistic state, students may believe that only one "right" major exists, and meanwhile, institutions are encouraging faster academic decision-making to improve commitment and completion outcomes (Evans et al., 2010). With institutions hurrying declaration of majors and students making uninformed decisions, student discontent and repetitive major changes increase (Bloom, 2008). Converse to institutional desires, the National Academic Advising Association (NACADA) encourages greater exploratory opportunities within the first two college years and delaying major declaration until the completion of four semesters. Some institutions have shifted to "exploratory" rather than "undeclared" as a more supportive entering status for students (Bloom, 2008).

Today, students are choosing multiple majors to increase competitiveness in the job market. Between 2001 and 2011, the number of students with double majors rose 70 percent alongside increases in minors and concentrations (NCES, 2015b). Moreover, major choice is 
now synonymous with career choice and exacerbated by contradictory institutional messages. While encouraging exploration, students learn many major curricula (e.g., engineering, premedicine) require commitment within the first semester for timely graduation (Fogg, Harrington \& Harrington, 2004). Students no longer have the "luxury of stumbling into a major or making mistakes" in the first year of college (Fogg, Harrington \& Harrington, 2004). With today's workers changing careers an average of seven times throughout employment (Fogg, Harrington \& Harrington, 2004) and major choice experts advocating transferable skills across multiple disciplines, policy, institutional, and media rhetoric widens the disciplinary divide.

\section{Class Impact}

For many low-income students, there is increased pressure from family to make academic decisions that "follow the money" and promise strong post-completion job opportunities (Bures, 2011). In order to do so, low-income students need to begin college well-informed and choose a major based upon fit in order to save money and complete degrees more quickly (ACT, 2014). However, with 32 percent of ACT (2014) test-takers intending majors deemed a poor fit with interests, deficits in cultural capital (Lareau, 2003), and limited understanding of requirements and resources, the risks of major mis-match for low-income students are substantial. Weeden (in Pinsker, 2015) found parent income and occupation have a large impact on the major decisions of low-income students. Well-resourced families often seek opportunities for their students, typically in the form of pre-college experiences and educational preparation, to increase the likelihood of rewarding employment (Ma, 2009). Financially stable students more often choose humanities majors where low-income students gravitate toward math, sciences, and fields lucrative for future earnings, such as engineering, computer science, and architecture (Pinsker, 2015). Wealthier students are believed to be afforded greater risks in selecting a major, due to a 
potential buffer against future under-employment and increased childhood exposure to the arts and culture (Pinsker, 2015). Moreover, Weeden (in Pinsker, 2015) found that low-income students are inclined to attend schools and select majors with strict vocational parameters, such as law enforcement and medical technology, uncommon options at comprehensive universities. Low-income families are often characterized as being "relatively risk averse" and many see college attendance as both a hazard and an avenue for success (Breen \& Goldthorpe, 1997; Ma, 2009). When financial need and desires toward greater social mobility conflict with personal interests, goals, and abilities, a troublesome environment for low-income students may result (Ma, 2009). Complicating risk-aversion are misinformed choices, which may result in pursuing short-expectancy vocations or avoiding majors with lasting benefits (Saks \& Shore, 2005). A challenge for secondary and higher education is identifying the resources and experiences critical to low-income students leading to an improved choice process.

\section{Personal and Institutional Influences}

Environmental influences, both internal and external to college and before and after enrollment, are believed to shape the academic major choice process (Astin, 1993; Vogel \& Feldman, 2009). While high school counselors, peers, and educational experiences play a role (George-Jackson, 2010), the influence of family is believed to be important in student success (Eccles \& Harold, 1993, Ma, 2009). For advantaged students, parents have often been involved in the secondary education experience and continue on through college (Lareau, 2003). For lowincome students, the experience may be different. Many low-income families identify college as an opportunity to provide social mobility to the next generation while pushing their students toward majors they have deemed lucrative (Lucas, 2001). For parents who did not attend college, personal skills and interests are often used for encouragement toward specific majors 
(Hoover-Dempsey \& Sandler, 1997). For some students, this may shape their academic selfefficacy and inform their perceived success within a particular college major (Hackett \& Lent, 1992). Conversely, some low-income families choose to disengage during the academic decision-making process (Ma, 2009). For some students, this potentially results in feelings of neglect while other students claim this independence as an impetus to seek resources and make decisions unassisted (Ma, 2009). A 2010 study of 1800 undergraduate students regarding precollege decision-making identified guidance counselors, parents, siblings, peers, and religious figures as influencing major choice but, upon closer examination, found students indicated their experiences in courses and personal research on majors to be most influential (George-Jackson, 2010). Moreover, students reported choosing a major encouraged by their parents but changing based upon personal interests within the first year (George-Jackson, 2010). These findings highlight the possibility that influences during college affect the major decision-making process and support a need for further exploration.

Regardless of income-level, Astin (1993) found that some students have personality traits compelling them toward specific majors and argued that those scoring highly on social activism scales often seek majors in humanities and social sciences disciplines. Several studies support the notion that students regularly choose a major which parallels their personality and, often, because it increases self-efficacy (Chen \& Simpson, 2015; Hackett \& Lent, 1992; Smart, Feldman \& Ethington, 2000.) Similarly, multiple studies place importance on personenvironment fit in the college choice process as it signals likelihood of successful acclimation and confidence in decision-making (Porter \& Umbach, 2006; Smart et al., 2000; Vogel \& Feldman, 2009) while matching interests and values (Holland \& Nichols, 1964). 
Significant research on major choice has found race and gender to have strong influences on college major. Lackland and De Lisi (2001) found women are more likely to select majors traditionally dominated by their gender (i.e., education, nursing, English) while Crisp, Nora and Taggert (2009) indicated that females are less likely than men to earn degrees in STEM disciplines. Porter and Umbach (2006) also found females to be significantly more likely than males to choose interdisciplinary and social science degree programs. Xie and Shauman (2003) argued that women's academic and occupational choices are affected by family and social influences while Ridgeway and Fisk (2012) contended that self-assessed competence in a field, rather than prior grades or achievement, lead women to specific disciplines. In considering race, Goyette and Mullen (2006) found that African-American students were more likely than Whites to select occupational tracks associated with lucrative incomes and were less likely to select an education major. While Asian Americans leaned toward science and math fields and Hispanics were found to choose business, White students were most likely to choose humanities majors (Goyette \& Mullen, 2006). Contradicting this, Porter and Umbach (2006) found AfricanAmerican students to be more likely to select interdisciplinary or social science majors over science, while Hispanics tended to choose arts, humanities, social science, or interdisciplinary fields, rather than science or math, when compared to White peers. Ma (2009) added socioeconomic status to the discussion in finding that low-income women are as likely as their male counterparts in choosing a college major considered to be lucrative. However, more affluent male students gravitated toward business or health majors while affluent female students considered the social sciences and humanities (Ma, 2009). In considering pre-college occurrences and high school performance (Porter \& Umbach, 2006), engagement in discipline specific programs such as STEM or fine arts (Shernoff \& Hoogstra, 2001) and perceived 
academic ability (Wang, 2013) may also inform major choice. Findings across these studies highlight a multitude of personal influences on college major choice yet the influences specific to low-income students and selection of humanities disciplines remains largely unexplored.

Experiences within the college environment are also critical to academic success and degree completion (Astin, 1993; Pascarella \& Terenzini, 2005). Academic advising, both with faculty and professional advisors, is considered instrumental in assisting students with major choice (Kuh et al, 2007). Because low-income students often possess multiple risk factors, institutional early warning systems are successful in purposefully connecting students with resources (Kuh, 2008; Pascarella \& Terenzini, 2005). In the first year, transition-focused seminars and career development courses are considered high-impact practices providing information to disadvantaged students (Kuh, 2008; Pascarella \& Terenzini, 2005). Both formal and informal interactions with faculty provide low-income students with connections for major and academic exploration (Kuh, 2008; Pascarella \& Terenzini, 2005) while the influence of peers reportedly shapes the major choice process (Kuh et al., 2007). A compounding issue, yet largely unexamined, is the disconnect between low-income student apprehension to seek assistance when needed and institutions being the primary sources of information to this population. Moreover, pervasive research utilizes the contexts of race, gender and discipline (e.g., Zhang, 2007), rather than socioeconomic status, leaving deficits in the knowledge base.

\section{In Summary}

As the reviewed literature details, the humanities have remained the foundational core of higher education as a pathway toward understanding the human condition, honing critical thinking, writing, and communication skills, building analytic reasoning, and providing a creative lens with which to see the world (Kraus, 1961; Nussbaum, 2010; Terras et al., 2013). 
However, since the Great Recession, the higher education landscape has shifted with wide debate over the importance and value of humanities disciplines as academic degree programs (Harpham, 2011; Holm, Jarrick \& Scott, 2015). As families and prospective college students grappled with an already turbulent college going process, the choice of academic major was now in the national spotlight (Lewin, 2013). University faculty and leaders, politicians, lawmakers, employers, and media pundits were publicly considering academic disciplines, particularly in STEM fields and occupation-focused majors, as advantageous choices for greater job security and economic development (Carnevale, Cheah \& Hanson, 2015; Musil, 2015; White House, 2015). Caught in this debate are low-income students who already face a multitude of barriers to college success and often lack the necessary support and resources to assist in efficacious decision-making (Kezar, Walpole \& Perna, 2014; Pascarella \& Terenzini, 2005). From one perspective, the humanities remain as a core value of higher education for development of life-long learning for a marginalized population (Musil, 2015; Nussbaum, 2010, Sparks \& Waits, 2011; Redden, 2016). From another, the humanities are a chopping block item for state politician's budgets and a barrier to job and financial security (Geer \& Halisky, 2011; Luzer, 2013; Schulten, 2013). It is important to note that, concurrent with this study, the humanities have remained a priority target as a shift in power occurs. In following a blueprint designed by The Heritage Foundation, a conservative think tank, early estimates indicate a proposed $\$ 10.5$ trillion reduction in federal spending over the next 10 years. Included in this reduction is the privatization of the Corporation for Public Broadcasting (CPB) and complete elimination of the National Endowment for the Arts and National Endowment for the Humanities (Bolton, 2017). Early documents describe the agencies as a "waste," despite the annual allocations across all three comprises only .016 percent of the total U.S. budget (Emmert, 2017). Compounding this are the 
significant number of organizations, projects, and initiatives, many based in secondary and postsecondary education, which are funded through the NEA and NEH and will, subsequently, face cuts or closure (Bolton, 2017). These recent revelations support the notion that the humanities remain under scrutiny alongside little apparent information about the place of higher education under the Trump administration.

Through this literature, what becomes evident is that we know little about the academic decision-making of low-income students, what informs their self-efficacy in choosing a major, and the influences shaping decisions to pursue humanities disciplines. The next sections detail loose consideration of student development theories and how utilizing Social Cognitive Career Theory and Bronfenbrenner's Ecological Systems Theory as a framework for understanding efficacy and influences expanded understanding of the academic decision-making process for low-income students while filling critical gaps in the knowledge base.

\section{Theoretical Frameworks}

As low-income students face barriers--both real and perceived--to success, the academic decision-making process rises to critical importance in their college transition and development. While many characteristics and experiences influence how a student navigates the major choice process, the shifting post-recession landscape of higher education offers a new set of opportunities and challenges for low-income students that are minimally examined by the extant literature. To better understand the decision-making processes of low-income students while examining the multi-faceted influences on this process, Social Cognitive Career Theory (SCCT) and Bronfenbrenner's Ecological Systems Theory served as primary frameworks for this study.

As subsequently detailed, SCCT's career choice model provides a unique framework for considering academic major choice. The model, divided into three components, considers the 
identification of a primary choice or goal, taking steps toward the goal, and the performance experiences shaping how a person interprets their ability to be successful (Lent, Brown \& Hackett, 1996; Lent, 2005). While this study does not focus on career choice, the three components of the SCCT model are applicable to the process a student takes in choosing an academic major. Any emerging themes related to career interest are unintentional but may be used to better understand findings. As further described in the methods section, this study considered the identification of goals, progress toward goals, and performance experiences of students are varying stages of the major declaration process.

Because the context of a student's family, finances, and life experiences are important to this study and not represented in the SCCT framework, Bronfenbrenner's Ecological Systems Theory (1979) provided an additional lens to this inquiry. Moreover, Bronfenbrenner's theory also allowed for the consideration of time, including: events across a student's life, historic events such as the 2008 recession, and recent occurrences in the college environment, which shapes how a student sets and pursues goals and interprets performance. By combining the impact of the ecological systems in which a student lives, consciously and unconsciously, with the decision-making frames offered through SCCT, an elucidated understanding of the factors shaping low-income student academic choice and commitment could be achieved.

\section{Social Cognitive Career Theory}

A variation of Bandura's (1977) social cognitive theory, SCCT posits lasting academic and career interests are formed when a student has feelings of personal competence and subsequent positive outcomes when engaged in an experience or activity. Conversely, lacking feelings of competence or negative outcomes may influence a student's desire to pursue different academic or career paths. SCCT offers three areas, outlined below and depicted in2, critical to a 
student's exploration of interests, which are believed to be in constant flux throughout adolescence (Lent, Brown \& Hackett, 1994, 1996). In addition, consideration of supports and barriers through the lens of SCCT were considered in this study and outlined subsequently.

\section{Social Cognitive Career Theory}

(Lent, Brown \& Hackett, 1994, 2000, 2002)

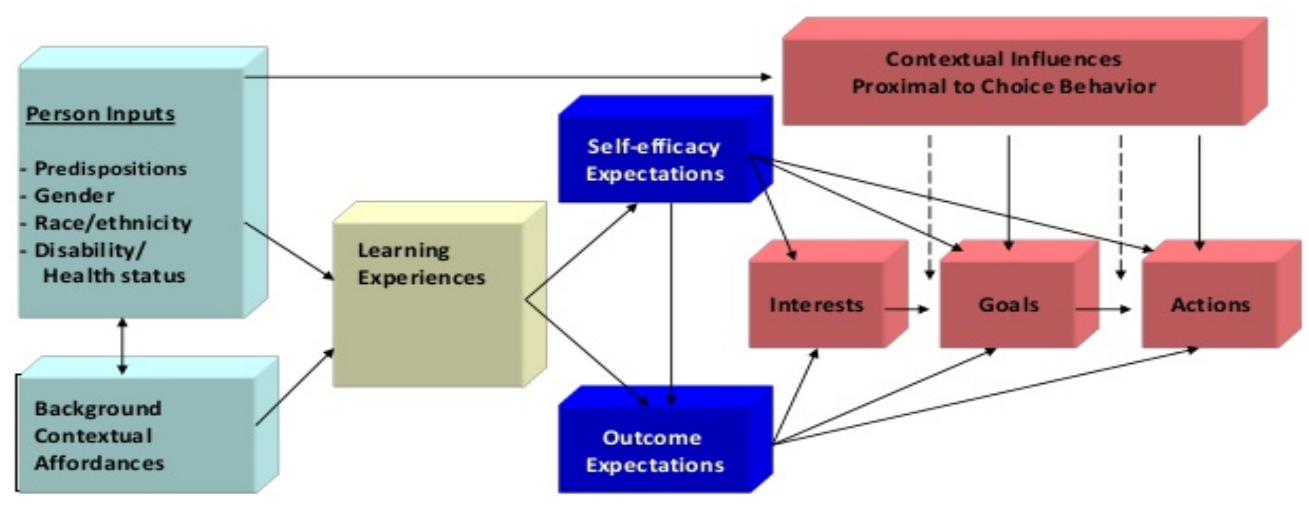

Figure 1. Personal, contextual, and experiential factors affecting academic decision-making behavior. Source: Lent, Brown \& Hackett (1994, 2000, 2002)

Self-efficacy. This term refers to the feelings and beliefs students have about their ability to successfully complete steps toward task fulfillment or desired outcomes. These feelings and beliefs are fluid and shaped through interactions, experiences and environments both personally and with others (Lent et al., 1994, 1996). Specific to this study is academic self-efficacy: the beliefs students possess regarding their abilities to complete necessary tasks, make progress and be successful within an academic setting (Bong \& Skaalvik, 2003; Schunk, 1991). Students with a strong sense of academic self-efficacy are found to earn higher grades, possess motivation to set and achieve goals (Bandura \& Schunk, 1981), and adapt better to new learning environments 
(Chemers, Hu \& Garcia, 2001).

Outcome expectations. Related to self-efficacy, outcome expectations refer to the consequences a student anticipates from performing certain behaviors or actions (Lent, Brown \& Hackett, 1996). Expectations are developed through previous experiences, extrinsic motivating factors, task understanding and, importantly, the perceived outcomes of these occurrences. Selfefficacy often shapes outcome expectations, especially when considering actual or perceived performance (Lent et al., 1994, 1996).

Goals. Defined as the decision to begin a particular plan, activity or interaction, goals shape behavior and decision-making. While environments and genetics play a role, individuals are believed to be primary in determining behaviors. Subsequently, behaviors shaped by goals are thought to be organized and sustained toward achievement but can also be informed by selfefficacy and outcome expectations (Lent et al., 1994, 1996).

Barriers and Supports. With the rise in use of SCCT in educational research came a desire to more closely understand the distal and proximal influences on a person's decision making. These influences, or barriers and supports, may include exposure to educational experiences, financial support, interactions with family and peers, and personal interpretation of environments and life events (Lent, Brown \& Hackett, 2000). Swanson and Woitke (1997) identified barriers as events or conditions within a person (i.e., self-efficacy, financial resources) or environment (i.e., university setting, workplace) that may impede or challenge progress or decision-making. Barriers are considered through both an interpersonal and contextual lens, as they are not believed to work independent of each other (Swanson \& Woitke, 1997). Although not as widely considered, supports became important for understanding influences in decisionmaking for this study. Supports refer to individuals, events, experiences or perceptions that allow 
for progress toward decisions and goals. Both supports and barriers are considered best studied in temporal dimensions, as they were for this study, to understand individual's perceptions over time (Lent, Brown \& Hackett, 2000).

While traditional students are believed to stabilize academic and career interests as they move through college, marginalized students often continue to perceive barriers, potentially shaping self-efficacy, outcome expectations and goals, creating instability (Gibbons \& Shoffner, 2004). Moreover, little is known about how these students perceive shifts in supports as they matriculate through college. As a framework for this study, SCCT allowed for greater understanding of how low-income students identify and navigate these supports and barriers while engaged in the decision-making process.

\section{Bronfenbrenner's Ecological Systems Theory}

Bronfenbrenner's (1979) Ecological Systems Theory provides a lens for considering, and going beyond, student development and decision-making through the exploration of environmental, experiential and contextual influences. Bronfenbrenner (1979) posited that individuals interact with their environment in a Person-Process-Context-Time (PPCT) model with influences by individuals, external forces, settings and behaviors. To understand these relationships, Bronfenbrenner (1979) introduced the ecological environment as "a nested arrangement of concentric structures" (p. 22) (see Figure 2) demonstrating patterns and influences both direct and external to the student. These structures are critically important to this study and higher education research, as they provide a lens for examining occurrences and interactions within the college environment shaping academic decision-making as well as distal factors, often unnoticed by the student (Renn \& Arnold, 2003). Moreover, Ecological Systems Theory and the PPCT model can be applied universally since, regardless of background or 
setting, all students utilize multiple systems to influence and navigate decision-making (Bronfenbrenner, 1979, 1993; Renn \& Arnold, 2003). As depicted in Figure 2, this study considered adaptations of Bronfenbrenner's model as it has been applied across higher education literature (see Renn, 2012; Renn \& Arnold, 2003; Stebleton, 2011; Swan, 2011) to best reflect the participants and constructs being studied. As subsequently described, higher education research identifies the mesosystem as an environment where multiple microsystems interact, the exosystem as containing persons, experiences, and conditions not containing a student but still influential in decision-making, and the chronosystem as being a global environment where students may be influenced by forces and occurrences but lacking any control.

Person. The person component of the PPCT model is comprised of personal experiences, characteristics, identities, and ideologies students bring to college (Renn \& Arnold, 2003), and are believed to "induce or exhibit dynamic dispositions toward the immediate environment" (Bronfenbrenner, 1993, p. 11). These dispositions are posited as critical to student development and engagement with environments, and they can shape a sense of interactional agency (Renn \& Arnold, 2003).

Process. Individual dispositions or, as termed by Bronfenbrenner (1993), developmentally instigative characteristics, shape environmental interactions leading to, but not determining, identity development (Renn \& Arnold, 2003). Often compared with Sanford's (1960) concept of challenge and support, the process component refers to a student's willingness to take risks in the college environment and the level of support and resources available to the student. In this study, the process component may be shaped by low-income status, academic and social self-efficacy, and motivation.

Context. Bronfenbrenner's (1979) nested structure provides the context component of the 
PPCT. Most personal to the student and representing "particular physical, social, and symbolic features that invite, permit, or inhibit engagement in sustained, progressively more complex interaction with, and activity in, the immediate environment" (Bronfenbrenner, 1993, p. 15), the microsystem often includes family, peers, employers, academic faculty, and university settings.

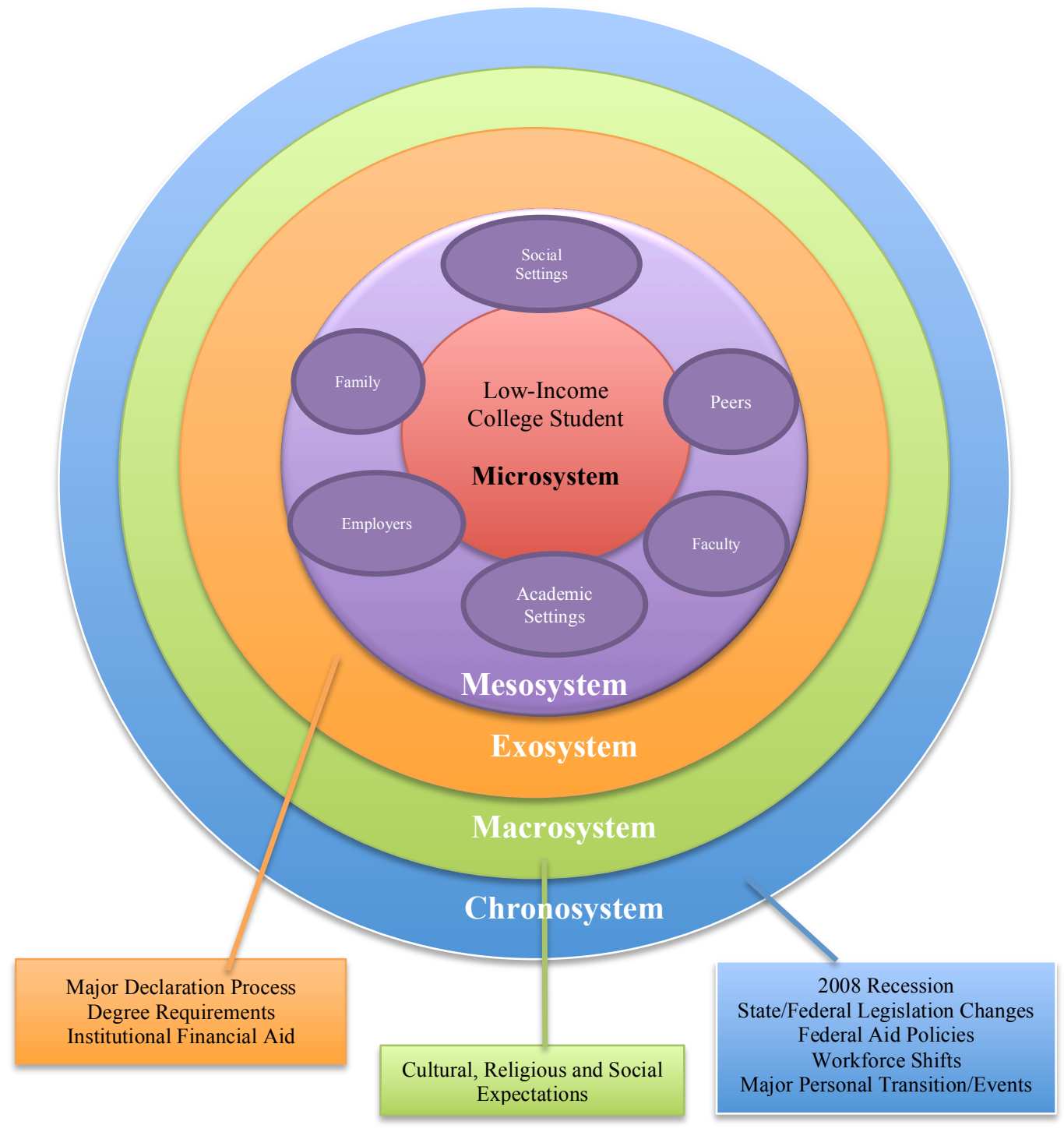

Figure 2. Adapted Bronfenbrenner model as applied to low-income undergraduate students in the context of academic decision-making. Source: Adapted from Renn \& Arnold (2003) and Bronfenbrenner (1979, 1993) 
Because a student spends significant time interacting within microsystems, it is important to understand how those environments are perceived and shape behavior and outcome expectations. When two or more microsystems interact, they are said to be in a mesosystem (Bronfenbrenner, 1993) where "special attention is focused on the synergistic effects created by the interaction of developmentally instigative or inhibitory features and processes present in each setting” (Bronfenbrenner, 1993, p. 22). Particular to this study, academic, social, and work environments combine and inform the identity development of those from marginalized backgrounds.

The outer systems include the exosystem, referring to influences from a setting not directly containing the student but having an impact on the student. In higher education research, consideration of the exosystem highlights how external influences shape student development and decision-making providing unique contexts outside the traditional college environment. Beyond the exosystem is the macrosystem, which considers the developmental possibilities student's face within and across systems (Bronfenbrenner, 1993). The macrosystem comprises historic, cultural, religious, and social expectations that shape the environment in which a student exists (Bronfenbrenner, 1993). Across these systems, and examples important to this study, are institutional decisions about degree requirements, changes to federal financial aid policy, transition in family employment, and media rhetoric regarding economic or education policy.

Time. Despite wavering on its importance, Bronfenbrenner $(1979,1993,1995)$ ultimately identified time as a critical aspect of the PPCT model on student interaction with the environment. The most distal within the nested structure, the chronosystem represents the time component of the PPCT model and the represents the "timing of biological and social transitions as they relate to the culturally defined age, role expectations, and opportunities occurring 
throughout the life course" (Bronfenbrenner, 1995, p. 641). These events, which may be personal, contextual and global in nature and occurring before and during college, are considered critical to the identity development, interactions, and decision-making of students (Bronfenbrenner, 1995). Examples within this study include personal experiences and relationships established before and during college as well as global events such as the 2008 economic downturn and shifts in financial aid policy.

Specific to this study, SCCT provided a framework for determining experiences, environments, and behaviors, which influenced the self-efficacy a student feels in selecting an academic major. Additionally, SCCT allowed for an examination of the real and perceived barriers and supports students identify in decision-making. To better understand the distal, proximal, and temporal influences shaping efficacy and academic decisions, in the form of supports and barriers, Bronfenbrenner's Ecological Systems Theory provided a useful lens. 


\section{CHAPTER III}

\section{RESEARCH DESIGN AND METHODS}

\section{Methods}

\section{Study Site}

Mid-Atlantic University ${ }^{l}$. Located in a small Mid-Atlantic town, the university is a selective, mid-sized, public research institution. Mid-Atlantic University (MAU) boasts a competitive acceptance rate with incoming students coming from the top percentiles of secondary education. Enrollment during the 2016-17 academic year indicated a nearly half split between male and female attendees with 70 percent of the total hailing from the home state of the university. MAU offers a wide variety of undergraduate programs of study as well as comprehensive graduate and pre-professional education. MAU is consistently a leader in persistence and graduation rates.

MAU holds a strong commitment to admitting students regardless of economic circumstances and limiting undergraduate student debt. To do so, the university offers a needbased financial aid program meeting 100 percent of demonstrated need for admitted students who are U.S. residents and have family incomes falling below $200 \%$ of the federal poverty threshold.

Access to this site was obtained through colleague connections from my career as a higher education administrator. This allowed for navigation of the university institutional review

1 Pseudonyms have been given to the institution and financial aid program to avoid identification. 
process, provided access to necessary records and student populations for data collection, and allowed for greater depth of investigation, critical in case study research.

Academic Programs ${ }^{2}$. Upon entry, undergraduate students affiliate with one of the colleges and schools at MAU. Particular to this study, all humanities degrees are awarded through the College of Arts and Sciences (CAS), enrolling the largest portion of undergraduates at the institution. CAS offers over 50 undergraduate degree programs with 34 (see Appendix A) meeting the definition of interdisciplinary or humanities study offered by the National Foundation on the Arts and the Humanities Act (1965). For majors of recent occurrence that may not have been directly included in the Act (e.g., American studies, gender studies, race and culture studies), the American Academy of Arts \& Sciences Humanities Indicators (2015) were consulted. For interdisciplinary majors, an audit was conducted of major requirements. If a major required at least 50 percent of the major courses to be in humanities field, it was designated a humanities major for the purposes of this study. During the 2012-2013 academic year, 961 baccalaureate degrees were awarded across humanities programs but decreased to 756 the following academic year. Students in CAS must complete two, three-credit hour courses in the humanities toward completion of a general education requirement. However, students matriculating to schools outside CAS may have no humanities requirement or find it placed toward the end of their academic curriculum; essentially removing them from consideration as a major.

Declaration of Major. During the university admission process, students apply to a college or school of interest. Of the colleges and schools, five accept first-year students. Those interested in a school that does not accept first-year students will enter CAS as an undeclared

\footnotetext{
${ }^{2}$ Names of some academic programs have been adjusted to protect the identity of the institution and qualitative participants.
} 
student upon matriculation. Students are asked to submit two academic majors of interest with the school application but this does not guarantee a place in the major, nor does it require matriculated students to declare those majors. Once affiliated with a school, students remain undeclared or a "pre-major" while completing initial general education or competency requirements. Some academic programs allow students to declare upon completion of prerequisites while others require formal application to a major during the first two years. All students must officially declare a major at MAU by the end of the second year of full-time enrollment or completion of 60 credit hours.

Academic advising. The majority of first year students enter MAU as affiliates of CAS and are assigned two academic advisors. The first, an advising dean, is assigned by student housing assignment and assists students with academic matters and understanding university resources and services. Students are also assigned a faculty advisor, assigned in two ways, with whom they meet upon arrival and until declaring a major. Students enrolling in an optional first year seminar course during the first semester are assigned the course instructor as an academic advisor. Students not enrolling in this course are assigned a faculty member "roughly" by academic interest. Students considering majors outside of CAS, such a business, are encouraged to seek academic resources within those programs while completing general education and prerequisite courses in CAS. Also, student-athletes, veterans, and those in specialized honors programs receive tailored advising from a trained faculty member or administrator. All students are assigned a major advisor after declaring. For the small number of students who enter an academic program directly (e.g., pre-professional health, pre-engineering, architecture), a faculty advisor within the respective school and program is assigned to aid with course registration and academic concerns. This faculty member may later become the major advisor should a student 
stay within the program or a new major advisor will be assigned. Most faculty advisors receive some training from the university, the extent to which is unknown, and are provided a faculty advising manual from their respective school or college.

\section{Study Design Overview}

This study employed a mixed methods (Tashakkori \& Teddlie, 2003) design, a methodology for collecting, analyzing, and "mixing" both quantitative and qualitative data within a single study to better understand a research problem (Creswell, 2007). The underlying principle for mixing is that neither quantitative nor qualitative methods are individually adequate to capture the details and complexity of the condition being studied. When used in combination, quantitative and qualitative methods complement each other and allow for more comprehensive analysis (Greene, Caracelli, \& Graham, 1989; Tashakkori \& Teddlie, 1998).

This study utilized a sequential explanatory mixed methods design, consisting of two distinct phases (Creswell, 2002, 2003; Creswell et al., 2003), and the participation selection model variant (Creswell, 2007), as depicted in Figure 3. This model is used when a researcher needs quantitative information to identify criteria and purposefully select participants for a follow-up, in-depth, qualitative study (Creswell, 2007). The two-phase structure of the explanatory method is considered a strength of the design as it is easily implemented and allows findings to be reported using a format dividing the quantitative and qualitative phases for the reader (Creswell, 2007). 


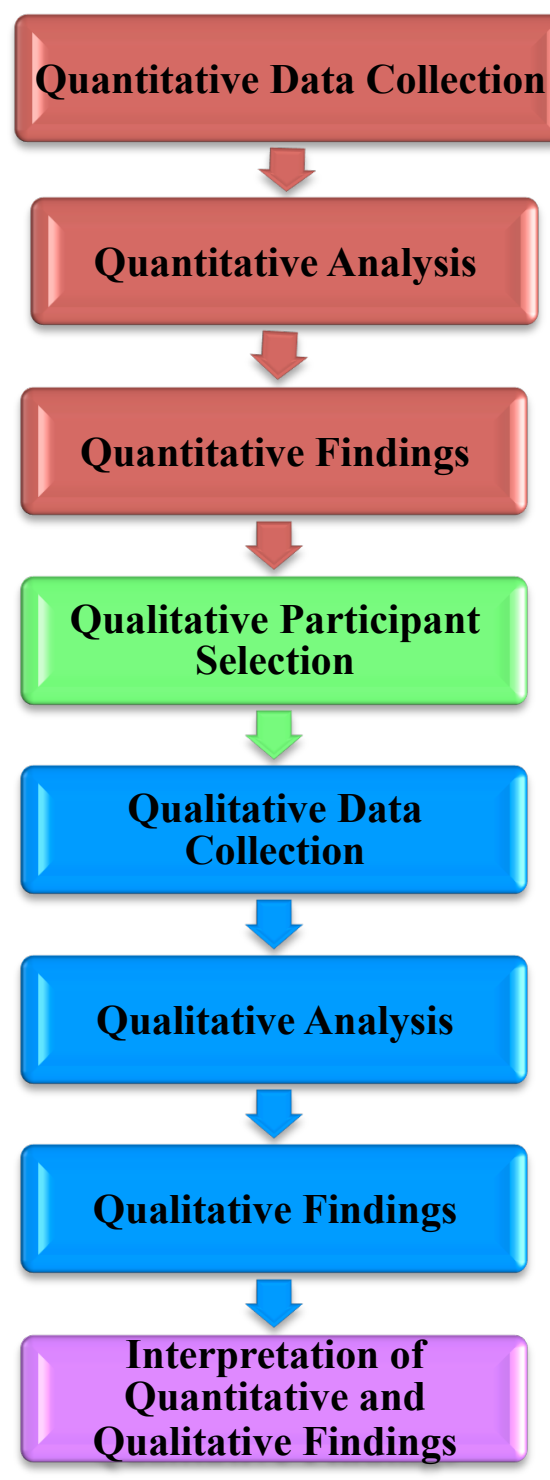

Figure 3. Explanatory Mixed Method Design: Participant Selection Model. Adapted from Qualitative Inquiry \& Research Design: Choosing Among Five Approaches, by J. W. Creswell, 2007, p. 73. Reprinted with permission.

Qualitative methods served as the dominant approach for this study, representing the emphasis of data collection and analysis. In this study's sequential approach, the non-dominant quantitative component occurred first and was used for descriptive statistics, information 
gathering, protocol development, and participant selection for the subsequent qualitative phase. The results of the two phases were combined in data analysis and reporting.

\section{Study Specific Mixed Methods Design}

The quantitative first phase of this study aimed to collect a breadth of data regarding the major exploration and declaration process for low-income undergraduate students indicating an interest in humanities majors during the university admission process or selecting a humanities major when declaring. Using survey methods, questions sought to explore a student's level of interest in majors at admission, timing and milestones influencing declaration, pre-college experiences impacting major choice, financial aid supporting attendance, supports and barriers in decision-making, as well as goal and career planning. Survey data was used to select participants for qualitative phase participation and interview protocol development. The full survey is available in Appendix B.

In the second phase, multiple qualitative methods were used to develop comparative case studies meant to deeply understand the influences, experiences, and environments shaping selfefficacy and academic decision-making of low-income undergraduate students. Because students could not be followed individually and longitudinally over four years due to limited resources, this approach allowed for the study of eight low-income students each at differing points in the major declaration process. This temporal dimension allowed for consideration of changes in perceived barriers and supports, college and external influences, and self-efficacy across the decision process.

In alignment with the mixed methods approach and Erickson's (1986) model of analytic induction, data from these phases were reviewed in an iterative process, used to inform decisions, and ultimately, combined to develop findings and assertions. 


\section{Phase One: Non-Dominant Quantitative Approach}

\section{Sample}

Using the web-based Qualtrics platform, the study survey was distributed to a sample of low-income undergraduate students indicating interest in a humanities major on the official application for university admission or having declared a humanities major by the end of the second year of college. After obtaining study approval through the MAU Institutional Review Board (IRB) and administration in the College of Education and Division of Student Affairs, sample information was provided by the MAU Office of Institutional Research. The information is stored as "Interested Major 1," "Interested Major 2" or "Declared Major" within the university enrollment management system. Students are not required to list a major of interest at admission. In fact, admissions officers posit some students purposefully skip this question as they fear it will be negatively factored in to admissions decisions despite this being untrue. The survey was administered during the Fall 2016 academic semester and included students matriculating during Fall 2013, 2014, 2015 and 2016 to provide a breadth of experiences and finalize criteria for case study selection. Including students from multiple cohorts allowed for greater insight into the decision-making process over time when resources for a longitudinal study were not feasible. This study adopted the university definition for low-income students as being those whose family income falls below 200 percent of the federal poverty threshold as determined by household size.

Table 1, below, presents data regarding MAU enrollment across the academic years considered for this study and delineated by low-income status. The numbers presented represent full-time, first year students entering the university. Collectively, low-income students represent only 6.9 percent of the total population currently enrolled at MAU and are reflective of the 
literature indicating the unlikely attendance of low-income students at highly selective institutions. While this number may fluctuate slightly as student and family financial situations change, the low-income population at MAU has remained relatively consistent in recent years.

Table 1

Enrollment of first-time, full-time, first-year (FTFY) students across the four cohorts considered in this study and delineated by socioeconomic status.

Note: Enrollment data provided by the MAU Office of Institutional Research.

\begin{tabular}{llllll}
\hline & Fall 2013 & Fall 2014 & Fall 2015 & Fall 2016 & Total \\
& FTFY & FTFY & FTFY & FTFY & Across \\
& Enrolled & Enrolled & Enrolled & Enrolled & All Years \\
\hline Low Income Students & 238 & 260 & 248 & 263 & 1009 \\
Not Low Income Students & 3279 & 3449 & 3426 & 3415 & 13569 \\
Total Matriculated Students & 3517 & 3709 & 3674 & 3678 & 14578 \\
$\begin{array}{l}\text { Low-Income Population as } \\
\text { Percentage of Total }\end{array}$ & 6.7 & 7.0 & 6.8 & 7.2 & 6.9 \\
\hline
\end{tabular}

To be considered for study participation, students must have met one of the following criteria:

1. Indicated interest in a study designated humanities major (see Appendix A) at the time of admission;

2. Indicated interest in a non-humanities field at the time of admission but declared a humanities major by the end of the second year;

3. Failed to indicate any interest in an intended major at the time of admission but declared a humanities major by the end of the second year.

Of the 1009 low-income students enrolled at MAU, as presented in Table 1, 864 indicated academic majors of interest at the time of admission. 245 students did not list any major of interest at admission as it is not required. Of the 864 students, 210 students indicated interest in a humanities major at the time of admission, meeting the first criteria. To expand sample size, criteria two and three were added. Criteria two added 42 students who indicated interest in non- 
humanities fields but went on to declare a humanities major to the sample. Criteria three added an additional 11 students who failed to list any interest at admission but declared a humanities major. Collectively, this added an additional 53 students to the initial 210 selected students, resulting in a total sample size of 263 low-income students. The survey yielded a 68.4 percent response rate with 180 of the 263 students completing the instrument. Table 2 , below, provides a comparison of sample demographics with survey respondent demographics, which are representative of the sample.

Table 2

Study Sample Demographics and Survey Respondent Demographics

\begin{tabular}{|c|c|c|c|c|}
\hline Variable & $\begin{array}{l}\text { Sample } \\
(\mathrm{n}=263)\end{array}$ & $\begin{array}{l}\text { Sample \% } \\
\text { of total }\end{array}$ & $\begin{array}{l}\text { Survey } \\
(n=180)\end{array}$ & $\begin{array}{l}\text { Survey \% } \\
\text { of total }\end{array}$ \\
\hline \multicolumn{5}{|l|}{ Gender } \\
\hline Female & 188 & 71.5 & 140 & 77.8 \\
\hline Male & 75 & 28.5 & 40 & 22.2 \\
\hline \multicolumn{5}{|l|}{ Race* } \\
\hline African American & 65 & 24.7 & 43 & 24.0 \\
\hline Asian & 48 & 18.3 & 33 & 18.3 \\
\hline Hispanic & 34 & 12.9 & 22 & 12.2 \\
\hline Multi-Race & 13 & 4.9 & 11 & 6.1 \\
\hline Unknown/Alien & 12 & 4.6 & 6 & 3.3 \\
\hline White & 91 & 34.6 & 65 & 36.1 \\
\hline \multicolumn{5}{|l|}{ Matriculation Year } \\
\hline Fall 2013 & 71 & 27.0 & 49 & 27.2 \\
\hline Fall 2014 & 76 & 28.9 & 53 & 29.4 \\
\hline Fall 2015 & 60 & 22.8 & 41 & 22.8 \\
\hline Fall 2016 & 56 & 21.3 & 37 & 20.6 \\
\hline
\end{tabular}

*Race categories are in alignment with IPEDs categories as reported by MAU.

\section{Data Collection}

This study was conducted during the Fall 2016 academic semester. Students were contacted regarding survey participation during the second week of the academic year. A survey administration plan was developed, relying upon the work of Salant and Dillman (1994), to maximize response rate. This included use of six contact letters strategically scheduled across varying dates and times--a best practice in survey research. The use of Qualtrics allowed for 
confidential, electronic distribution of surveys to university-provided student email addresses. Upon opening the survey, students were directed to a consent form and were instructed that, by selecting the option to continue into the survey, they were providing consent to participate in the study. To incentivize participation, each student completing the survey received a $\$ 10$ Amazon gift card delivered via email. The survey remained open for approximately four weeks and was closed when respondents were no longer actively engaging after reminder emails. Upon survey closure, responses were downloaded from Qualtrics and held in a password-protected file only accessible by the researcher.

\section{Measures}

The survey included a breadth of constructs intended to understand multiple aspects of the decision-making process, in alignment with the theoretical frameworks, and are presented in the order of most importance to answering the research questions. Survey questions, both closed and open-ended and of varying types, were established using Salant and Dillman's (1994) guide for survey development. After development, experts in areas of importance to this study (e.g., higher education, career advising, survey instrument construction) were consulted to improve content validity. Cognitive interviews, using think-aloud protocol, were employed with a team of undergraduate and graduate students unaffiliated with the study to evaluate the clarity of question wording and the respondent's ability to interpret and answer questions in the intended way. Prior to administration, the student team, as well as a group of student affairs professionals, reviewed the survey through the online interface to test for usability, clarity, and technical concerns.

An important component of the survey was the determination of student level of interest in humanities majors at the time of admission. Using the "pick, group, and rank" feature in 
Qualtrics, students were presented with a list of humanities academic majors selected for consideration in this study (see Appendix A). Because this study considers interest in humanities fields, the list was narrowed to only include those disciplines. Students were asked to sort the majors of interest at the time of admission into two categories: "high to very high interest" at admission or "low to moderate interest" at admission. For majors within the list that students identified as having "no interest" in pursuing, the major simply remained in the list. This information was of critical importance in selecting case study participants during phase two.

Additional survey questions were related to the current status of the student's major choice process, personal opinions of college attendance and college major, pre-college and current influences, goals, outcomes, and family background. Any information that could be garnered from university data was omitted from the survey for brevity. While a portion of the survey questions were newly developed, previously validated scales were also used. The Academic Major Satisfaction Scale (AMSS) was selected to better understand the satisfaction of students who have declared an academic major. Nauta (2007) reported that the AMSS had a good internal reliability with a Cronbach's alpha of .90 and .94 in two large samples of undergraduate students across various majors. Survey items related to student's opinions of college attendance and college major were borrowed from a survey in Pittaoulis' (2012) dissertation on academic major choice through the context of post-completion planfulness. Pittaoulis (2012) created these items using emerging themes from qualitative interviews. To generate relevant pre-college involvement categories, an expansive list developed by Barge (2015) was consulted. To generate campus and community involvement categories reflective of experiences during college, the MAU student activities and athletics websites were utilized. 
To measure student orientations toward life and career goals, four subscales were combined to create a 21-item survey scale. The 21-item scale was originally developed by the Higher Education Research Institute (HERI) at the University of California at Los Angeles (UCLA) for use in the Cooperative Institutional Research Program (CIRP) Survey. Researchers with the Wabash National Study of Liberal Arts Education (WNSLAE), with permission from HERI, used factor analysis of the 21-item scale to yield four subscales detailed below.

Contributions to the Arts \& Humanities Scale. This three-item scale identifies the importance respondents place on contributing to arts and humanities fields. The internal consistency reliability for the scale is .69 .

Contribution to Science Scale. This two-item scale asks respondents to indicate the importance they place on making contributions to scientific fields. The internal consistency reliability for the scale ranges from .70 to .76

Professional Success Scale. This five-item scale asks respondents to indicate how important it is to them to be successful in a profession. The internal consistency reliability for the scale ranges from .75 to .76 .

Political and Social Involvement Scale. This eleven-item scale identifies the importance respondents place on being politically and socially active in communities. The internal consistency reliability for the scale ranges from .80 to .83

\section{Data Analysis}

The Statistical Package for Social Sciences (SPSS) Version 24 was used for descriptive analysis of survey data. Since the dominant mode of this study is the qualitative portion, primarily descriptive statistics (e.g., distributions, mean differences, correlations) were used to examine the survey data. Moreover, the researcher studied each set of survey responses, 
individually and comparing across questions, to develop analytic memos meant to inform the next phase and to assist in creation of assertions. Dedoose, qualitative coding software, as well as continual rereading and comparison of data, was used to develop codes and identify themes within the open-ended questions. Findings and themes of significance to the research questions also shaped the participant selection process for the qualitative phase of this study.

\section{Phase Two: Dominant Qualitative Approach}

As this study considered the experiences and decisions of low-income undergraduate students involved in the academic major selection process, the use of qualitative methods is well suited as the dominant design. As it comes from no single perspective, qualitative methods allow for naturalistic inquiry in settings that have not been controlled, manipulated or predetermined, ideal for educational environments. Naturalistic inquiry allows for an inherent emergence of data that better examines the ways in which individuals make and ascribe unique meaning to experiences. Most importantly, qualitative methods allow for examination of the processes an individual undergoes within a specific context; a critical component of this study (Maxwell, 2005). While research on major selection is primarily quantitative and often limited to specific experiences within college, the use of qualitative methods for this study allowed for greater insight into the student's meaning making processes.

\section{Paradigm}

The interpretivist paradigm was chosen for this study and comes with unique ontological, epistemological, and methodological assumptions to guide action. This paradigm was chosen out of a desire to understand the defining and meaning-making experiences of particular actors within the context of particular events (Erickson, 1986). Ontologically, it must be considered that multiple realities exist, which are unique and local to the individual. Because of this, it must be 
acknowledged that $\mathrm{I}$, the researcher, also hold a personal reality in the research setting that could not be imposed onto the individuals or environments with which I study (Erickson, 1986). To determine the relationship between the knower and the known, I was responsible for investigating the immediate and local meaning of the occurrence. This is important as what is seen or visible is not the only thing that matters. To truly be interpretive, I considered the meanings ascribed by the individuals with the knowledge these meanings vary for each person no matter the similarity of the experience or event. Moreover, these individuals and their realities exist concurrently in a complex, contextual state. Because this research employed multiple strategies, described below, to better understand meaning, I must also acknowledge that my own meanings and realities are combined with the experiences of the individuals being studied and influenced the data interpretation and resulting assertions.

A methodological assumption, posed by Erickson (1986), important to this research is the consideration of intentionality of acts. Because this study examined the process of meaning making in regards to self-efficacy, academic decisions, and major selection for low-income students, the intentional and unintentional acts of the individuals in shaping their experiences is quite important. Broadly, I considered the sequences in which acts occur and looked for patterns to emerge from the data to shape assertions. It is important that interpretive researchers avoid imposing meaning on participants or phenomena too quickly through the creation of predetermined categories or being closed to the natural emergence of patterns. Researchers must create conditions to identify sequences of events that will lead to larger interpretations of actions. Erickson (1986) reinforced the fallibility of only using a single research method and encouraged the use of multiple approaches to create greater opportunities for triangulation. In 
heeding Erickson's advice, multiple approaches were utilized for this phase, in combination with the quantitative phase, and detailed in the data collection section.

\section{Sample}

As all survey participants met the definition of low-income and were currently enrolled as full-time undergraduate students at MAU, survey responses regarding level of interest in humanities, current or intended major, and responses to questions regarding academic and social experiences were considered in choosing the interview sample. Figure 4, on the next page, offers a detailed overview of the full participant selection process for the study. Specifically, the majors of interest at the time of admission were compared to those listed in the "pick, group, and rank" option offered in the survey. A total of eight students who completed the survey were selected for qualitative phase participation. Three students were selected because of "high interest" in the humanities at admission. Three students were selected because of "low interest" in the humanities at admission. Two students were selected because of having "no interest" in the humanities at admission but went on to declare a humanities major. The following process was used to identify these categories:

- High Interest: A student must have listed humanities majors on the admissions application and sorted these majors into the "high interest" field in the "pick, group, and rank" question on the study survey. Moreover, these students must have sorted additional humanities majors into the "high interest" field on the survey.

- Low Interest: A student must have listed at least one humanities major at the time of admission and sorted this major into the "low interest" field in the "pick, group, and rank" question on the study survey. Moreover, a student failed to have a significant 


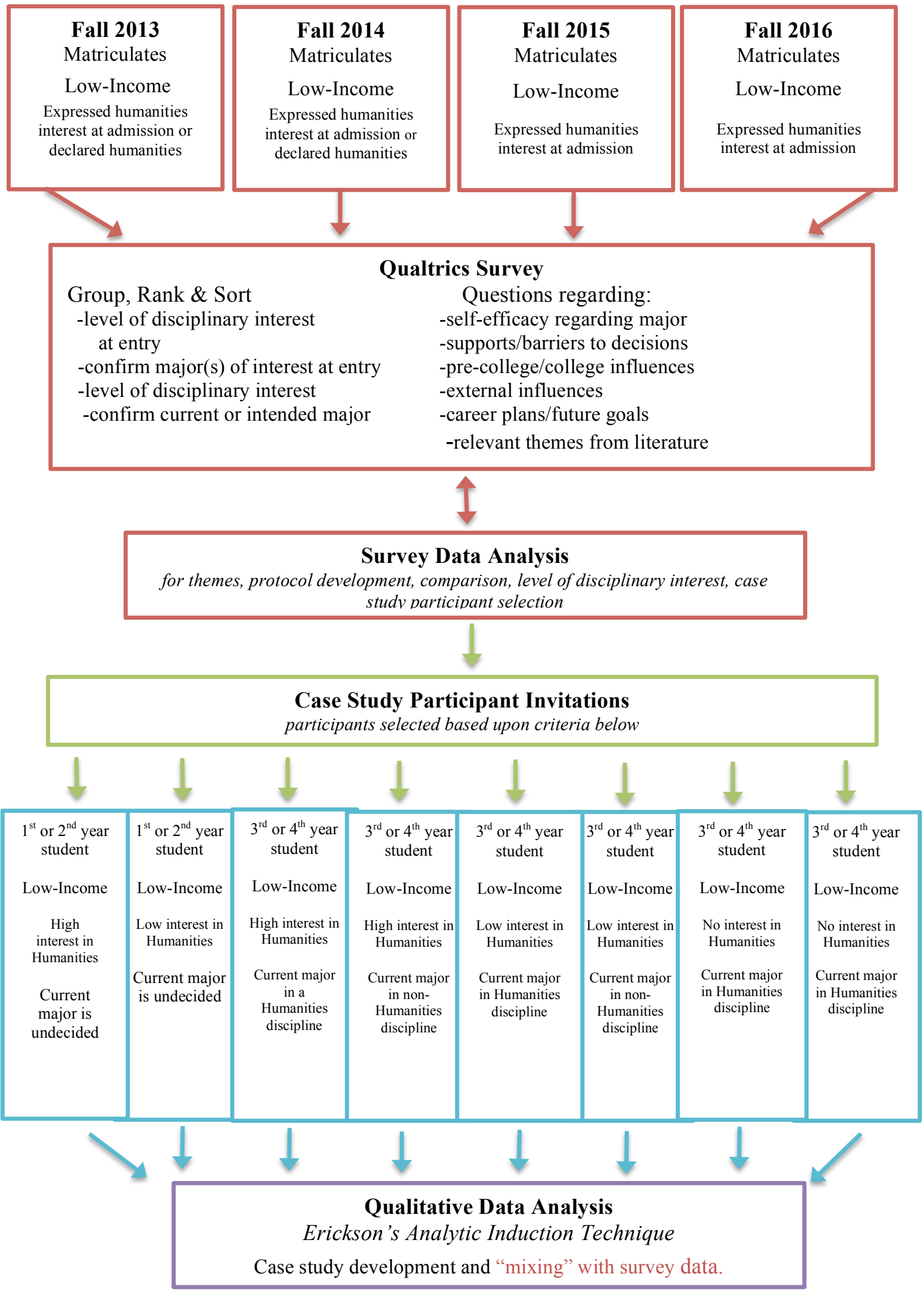

Figure 4. Study Methods Flow Chart. A study specific interpretation of Creswell's Explanatory Mixed Method Design: Participant Selection Model shown in Figure 3. 
- number of humanities majors sorted into the "high interest" category with the major remaining in "low interest" or "no interest."

- No Interest: A student must have listed non-humanities majors at the time of admission but went on to declare a humanities major by the end of the second year. On the survey, the student must have only listed humanities majors in the "low interest" or "no interest" fields in the "pick, group, and rank" question.

After determining interest, participants were considered based upon academic year, gender, race, and academic major in an attempt to be representative. Table 3, below, offers additional insight into the demographics and academic characteristics of interview participants.

Table 3

Demographics and Academic Characteristics for Qualitative Phase Two Participants

\begin{tabular}{|c|c|c|c|c|c|c|}
\hline Name & Gender & Race & Residency & $\begin{array}{l}\text { Academic } \\
\text { Year }\end{array}$ & $\begin{array}{l}\text { Humanities } \\
\text { Interest at } \\
\text { Admission }\end{array}$ & $\begin{array}{l}\text { Current } \\
\text { Academic } \\
\text { Major }\end{array}$ \\
\hline Amelia & Female & $\begin{array}{l}\text { African } \\
\text { American }\end{array}$ & In State & Junior & $\begin{array}{l}\text { High } \\
\text { Interest }\end{array}$ & English \\
\hline Annie & Female & White & In State & Junior & $\begin{array}{l}\text { Low } \\
\text { Interest }\end{array}$ & Music \\
\hline Chloe & Female & $\begin{array}{l}\text { Multi- } \\
\text { Race }\end{array}$ & In State & Sophomore & $\begin{array}{l}\text { High } \\
\text { Interest }\end{array}$ & Undeclared* \\
\hline David & Male & $\begin{array}{l}\text { African } \\
\text { American }\end{array}$ & In State & Senior & $\begin{array}{l}\text { No } \\
\text { Interest }\end{array}$ & $\begin{array}{l}\text { Race \& Culture } \\
\text { Studies }\end{array}$ \\
\hline Ethan & Male & White & In State & Junior & $\begin{array}{l}\text { High } \\
\text { Interest }\end{array}$ & $\begin{array}{l}\text { Interdisciplinary } \\
\text { Social Sciences } \\
\text { \& Economics }\end{array}$ \\
\hline Mateo & Male & Hispanic & $\begin{array}{l}\text { Out of } \\
\text { State }\end{array}$ & Senior & $\begin{array}{l}\text { Low } \\
\text { Interest }\end{array}$ & Business \\
\hline Samesh & Male & Asian & $\begin{array}{l}\text { Out of } \\
\text { State }\end{array}$ & Freshman & $\begin{array}{l}\text { Low } \\
\text { Interest }\end{array}$ & Undeclared* \\
\hline Stacey & Female & White & In State & Junior & $\begin{array}{l}\text { No } \\
\text { Interest }\end{array}$ & Gender Studies \\
\hline
\end{tabular}

* As a sophomore, Chloe is leaning toward declaring majors in foreign affairs and Spanish. As a freshman, Samesh is now taking pre-business courses and planning to apply to the business major during his sophomore year.

As displayed in Table 3, each level of interest grouping was not only stratified across gender, race, and academic year but also academic major. The three students identified as "high 
interest" represented a humanities major (English), a non-humanities major (interdisciplinary social sciences and economics), and undeclared. The three "low interest" students represented a humanities major (music), a non-humanities major (business), and undeclared. Finally, the two "no interest" students both represented humanities majors (race and culture studies and gender studies). After survey participants were sorted into categories by interest and additional demographics were considered, an initial set of eight students were selected with 16 students chosen as alternates.

The initially chosen eight students each received an email describing the study, compensation, and an invitation to participate. Each agreed to participate so consideration of alternates was not needed. In addition to Table, 3 , a detailed profile of each participant is provided in Chapter IV. Each participant agreed to attend three interviews, each lasting 75 minutes, and to complete one "take home" assignment between interviews one and two. To maintain engagement, each participant was compensated \$25 cash at the completion of interview one, $\$ 40$ cash at the completion of interview two, and $\$ 60$ cash after completing the third interview. All eight participants persisted through the study and completed all requirements.

\section{Data Collection}

In alignment with Erickson's (1986) urging to use multiple data collection methods to provide a variety of evidence, multiple, individual participant interviews, qualitative elicitation techniques, participant document analysis, and researcher document analysis were used in this study. In developing cases for comparison, a depth of information is important for validity. By asking participants to complete three interviews, ample opportunity was provided to build trust and understanding, ask clarifying questions, and use each meeting as an opportunity to build upon previous discussion and explore new topics. The three-interview series approach was 
loosely developed on the work of Seidman (2013) who encouraged a multi-staged approach in phenomenological interviewing for better understanding life history and details of an experience, both important facets of this interpretive study. Given the bulk of survey responses were collected within the first two weeks of administration, initial consideration of interview participants began. Participants were contacted via email regarding interview participation in late-September 2016 with interviews beginning in early October and occurring every 2.5 to 3 weeks during the Fall semester. All interviews were completed by mid-November 2016. All participants followed this schedule except Stacey who, due to a death in her immediate family, had a 4.5-week gap between interviews one and two and a 2 week gap between interviews two and three.

Interviews. Participants completed three 75-minute individual interviews held in a private location on the MAU campus. This resulted in 24 interviews across the eight participants. Interviews were scheduled at the convenience of each participant and confirmed via email. At the initial meeting, students were presented with a consent form for review and signature and were also asked for consent to be audio recorded. Each participant received a copy of the consent form for his or her records. Each interview was audio recorded using the researcher's personal computer and cell phone and files were immediately uploaded to a password-protected file and removed from the mobile devices. Interview protocols were developed using relevant literature, guidance from the theoretical frameworks, and through initial analysis of the survey data. Protocols for subsequent interviews were updated as analytic memos were written, data analyzed, and themes emerged. As a supplement to the traditional interview protocol, qualitative elicitation techniques were utilized in each meeting to garner 
additional data using a variety of methods and to provide linkages to the presented theoretical frameworks.

Interview One: The initial interview collected information on the student's personal and educational history relevant to the study, confirmed individual survey responses and comparisons with aggregate responses, and established trust with the researcher. An interview protocol was used (see Appendix C) as a means for creating consistency across interviews and for probing into the meaning-making experiences of students. In alignment with the approach of Erickson (1986), analytic vignettes (see Appendix C) were employed during this interview as a means to create a comfortable environment for the participant while also understanding connections between students' own choices and those they would make for others. These vignettes provided a platform for inquiry regarding a student's level of efficacy in academic decision-making, knowledge and use of resources, and environmental influences in the process. The vignettes also made subtle connections to the low-income status of the student and aimed to provide a temporal dimension, as the scenarios are set across the perceived decisionmaking timeline. Each vignette was provided to the participant in hard copy during the interview for silent reading. Debrief questions (also available in Appendix C) immediately followed each prompt. Subsequent vignettes and debrief questions were offered and discussed until complete. Upon conclusion of the interview, students were provided a packet of art materials (i.e., construction paper, markers, index cards, stickers, pens, and pencils) and an activity prompt (see Appendix D). Students were asked to spend time prior to the next interview using the materials to construct a visual timeline of perceived influences on their major choice since their earliest memory. Students were instructed to remember back as far as possible to milestones, obstacles, events, experiences, and individuals who may have influenced personal decisions regarding their 
major, the resources utilized, and steps taken. Students were encouraged to talk with friends and family and creatively engage with the activity as these techniques are meant to trigger memories and garner information often not elicited in a traditional interview setting. Moreover, the use of hand drawn work is believed to elicit different memories than simple verbal discussion (Berends, 2011).

Interview Two: The second interview focused on components of the major selection process as well as college and external influences shaping academic decisionmaking. To begin, the student was asked to present the decision-making timeline created between the first and second meeting and respond to follow up questions. Based upon the work on Bagnoli (2009) and Sheridan, Chamberlain, and Dupuis (2011), timelines are a visual, artsbased data collection method, derived from a broader framework of graphic elicitation methods, and include the placement of a participant's life events in a meaningful, chronological arrangement (Berends, 2011). While this technique has been primarily used outside of higher education, it has been successfully applied when navigating sensitive topics or working with marginalized populations (Berends, 2011; Sheridan et al., 2011). The interview protocol, graphic elicitation utilizing timelines technique, and debrief questions are presented in Appendix D. Because participants were very creative in their timeline development (see examples presented throughout Chapter V), these became the focal point of discussion in the second interview. In addition to allowing the student an opportunity to openly process meaningful experiences, this provided the researcher an opportunity to confirm information presented in the survey and interview one and to ask questions specific to the theoretical frameworks for clarity and deeper understanding. The timelines also provided a temporal dimension to the study. At 
the conclusion of the interview, students agreed to allow the researcher to keep timelines for document analysis and to include in findings.

Interview Three: After reflecting upon the emerging themes from the survey and interviews one and two, the final interview was designed to probe at particular meaning-making experiences specific to each participant, assist in confirming developing assertions, and consider the influences of media and public policy rhetoric. To expand upon the standard interview protocol and to engage with the public rhetoric surrounding the place of the humanities in higher education, a qualitative elicitation technique, card sorting, was used.

Drawing from Kelly's (1955) original use of sorting techniques in the development of Personal Construct Theory, and from Rugg and McGeorge's (2005) expansion of these techniques to include the card sort, participants were asked to engage with media and public policy headlines related to the pervasive humanities debate. Rather than asking participants to read lengthy, and potentially biased, articles from pro-humanities and pro-vocation pundits, the card sort allowed students to hone in on specific pieces of information which may have influenced their personal major choice and the individuals or outlets from which they received this information. Using a traditional card sort method (Rugg \& McGeorge, 2005), 20 cards were developed, all of the same size, color, and style, each containing a relevant news headline occurring during the time of the participant's college matriculation process. Because college students often receive information in small snippets and using mobile devices, each headline was presented in the form of a Twitter social media feed. The interview protocol and card sorting materials are presented in Appendix E. A headline supporting and opposing humanities study was included from each chosen media outlet to avoid participant bias through preexisting opinions on specific media outlets.

Participants were asked to sort the cards based upon a set of categories and questions related to 
their knowledge of headlines, influence on personal choices and efficacy, and inclination toward certain statements. The card sort activity and debrief questions lasted, on average, 45 minutes and remaining time was spent using traditional interview protocol. When combined with qualitative interviewing, card sorting has a number of distinct advantages including ease of understanding for the participant, speed of the process, and simplicity of implementation from an administrative perspective (Fincher \& Tenenberg, 2005).

Participant document analysis. The timelines created during the graphic elicitation process were used for participant document analysis. In addition to creating the visual timeline, participants were asked to analyze the timelines during the second interview. This approach garnered information not captured through traditional interview methods and combines visualization with oral discussion. As participants processed through their timeline and responded to follow up questions, significant detail was added to previously shared experiences and specific milestones in the meaning-making experience were revealed that proved beneficial in data analysis.

Analytic Memos. Analytic memos have played a significant role in data collection, analysis, and development of emerging assertions. The initial survey data was downloaded from the Qualtrics system, read repeatedly, detailed notes were taken to capture a sense of initial findings. Analytic memos, chronicling emerging trends and themes that were pertinent to interview protocol develop, were created. At the completion of each interview or document analysis, the researcher spent, on average, 90 to 120 minutes detailing experiences through analytic memos to provide rich, detailed description. These documents have proven critical in the analysis of data and have served as the foundation for assertion development. All analytic 
memos were de-identified and stored in a password-protected folder only accessible to the researcher.

\section{Data Analysis}

Qualitative data analysis is not a linear process and does not begin synchronously with the close of data collection (Marshall \& Rossman, 1999). Rather, data analysis occurs throughout data collection. Moreover, there are multiple approaches to qualitative data analysis and the selected approach should be carefully chosen with the research paradigm in mind (Marshall \& Rossman, 1999; Miles \& Huberman, 1994). In alignment with the interpretivist paradigm, Erickson's (1986) model of analytic induction was selected as the primary method of data analysis. Moreover, as described by Yin (1994), case studies are suitable for use in exploratory, explanatory, and descriptive research and this work, along with Stake's (2005) work on framing intrinsic multiple case studies, were loosely considered in analysis. While using Erickson's (1986) guidelines for analysis, Yin's (2009) work on pattern coding also provided a useful framework for analysis. Through repeated review of quantitative survey findings, field notes, analytic summaries, interview transcripts, audio recordings, and document analysis, I searched for patterns of data to emerge at each step in the process. As themes emerged, the next step of the data collection process was tailored to better understand these assumptions and to determine if themes did indeed exist. I considered specifically how emerging themes were connecting to the intended research questions and also looked for themes related to the theoretical frameworks, specifically goals, outcomes, self-efficacy, and environmental factors, chosen for the study. At the conclusion of data collection, patterns were reviewed holistically with memos written to assist in identifying empirical assertions across all qualitative data and then compared with quantitative survey results. As patterns became clear and assertions formed 
through quantitative and qualitative data, information was placed in a two-column chart to evaluate confirming and disconfirming evidence. Through this iterative process, the assertions were continually reshaped until disconfirming data could be explained and the level of scope and inference identified. Disconfirming evidence is further discussed throughout assertions in Chapter V. In alignment with Erickson's (1986) model, multiple forms of data, such as quotes, vignettes, and tables, are presented in Chapter $\mathrm{V}$ to support assertions.

\section{Validity Criteria}

There are multiple threats to validity in interpretive qualitative research as identified by Erickson (1986), including lack of and insufficient variety of evidence and providing a poor account of disconfirming evidence. Specific steps were taken to reduce threats to validity and increase plausibility including deep exploration of the literature, use of multiple mixed methods approaches for data collection, employing member checking as a component of the multiple interview format, and utilizing the iterative, two-column chart method for data analysis. Moreover, the use of multiple qualitative techniques during interviews offered additional evidence and allowed for verification of responses across multiple settings. These steps resulted in extensive field notes, analytic memos, audio recordings, transcripts, documents, and summary analysis to provide a breadth and variety of evidence and several perspectives with detail for rich description. The use of these multiple methods was important for triangulation (multiple data collection methods, member checking, memos and field notes), dependability (providing an abundance of data to support assertions), and confirmability (returning to test themes and assumptions). However, it is important to note that this type of qualitative inquiry is not meant to be generalizable but, rather, a descriptive accurate account of the cases being studied. While some general themes have emerged and cases were compared and contrasted, the validity rests 
within the clear, rich, thick description of the cases and the ability for the reader to believe the accounts are credible and believable.

\section{Researcher as Instrument}

For the qualitative phase, the researcher also serves as the instrument in conducting interviews, document analysis, developing field and analytic notes, and data analysis. As a qualitative researcher, I do not view myself as removed from the topic, or from the processes associated with data collection and analysis. My experience as a higher education administrator with a particular focus on new student transition and academic student success initiatives shaped this study. In this role, I also served as an academic advisor for undergraduate students while assisting them through the major declaration process. Moreover, I employed an average of 75 students each academic year, a portion of whom were low-income, and learned about specific struggles navigating payment, financial aid, and external pressures that jeopardized their abilities to persist and complete. My extensive experience working with college students, knowledge of postsecondary literature and theoretical frameworks, and interest in supporting at-risk populations admittedly served as a lens for this research. Similarly, my interest and experiences with these topics have made me keenly aware of the pervasive media and public policy rhetoric surrounding the topics of this study.

Currently, I am a doctoral candidate and graduate research assistant studying higher education. My research interests focus on academic advising and decision-making, the experiences of low-income students, academic motivation, and the outcomes of high-impact practices during student matriculation. This explanatory study is an outgrowth of previous research and a desire to bring a different perspective to the narrative. In particular, two recent experiences have profoundly shaped my interest in this topic and contributed to my personal 
worldview. First, as a project in my Advanced Qualitative Methods course, I studied the academic motivation of low-income, white male undergraduate students and, for the first time independently, used Erickson's (1986) work as a guide for analysis. This study allowed me to engage directly with low-income students in a research setting for the first time and findings contributed to my understanding of the student experience. This experience expanded my interest in this student population and, in many ways, shaped my decisions for dissertation work. Similarly, and concurrent with this study, was my involvement as a research assistant with a team exploring parental engagement and support for low-income and first-generation (LIFG) undergraduate students. I was responsible for the administration of a large survey to over 400 LIFG students and also facilitated 35 individual interviews with student respondents. This experience not only strengthened my confidence as a mixed methods researcher but also provided significant insight into shaping this study and my understanding of the LIFG population.

While I did not grow up in a low-income family, my father did work two jobs for a large portion of my childhood and we were not wealthy by any means. Despite graduating at the top of my class in secondary education, I am also a first generation college student and a junior college transfer student. These experiences have similarities with many low-income students and also make me something of an outlier when it comes to academic achievements. The choices I made in pursuing and completing my undergraduate education have shaped my perspectives on both academic decision-making and low-income students. It should also be noted that I personally hold an affinity for the humanities. I spent my formative years immersed in traditional humanities-related activities and, still today, am an active supporter of arts 
engagement. I hold minors in history and women's studies, support the humanities in general education curriculum, and volunteer with arts education initiatives in my local community.

Because fieldwork is a series of strategic decisions guided by prior knowledge and experience, I remained aware of potentially biased decision-making on my part with regard to sampling, interviews, and analysis. In order to avoid imposing generalizations from my previous experiences and current perspectives onto the participants and the analyses, I remained conscious of my own assumptions and worked diligently to make documented choices regarding these impositions and their role within the project.

\section{Ethical Considerations and Creating Trust}

As participants were asked to share personal information about finances, family life, and academic experiences and decisions, clear communication, confidentiality, a hospitable environment and trust were imperative in both phases. The survey offered an electronic consent form (as seen in Appendix B) with a direct email address to the researcher to ask any questions. Participation was voluntary and had no bearing on the student's personal or academic status. Students selected for qualitative interviews were offered multiple options for private meeting locations and times that met scheduling needs. Upon meeting, I reviewed study procedures multiple times, provided copies of consent forms, and reinforced the option to withdraw without penalty at any time. This process was reiterated at the beginning of each interview. Prior to recording conversations, I gained permission and confirmed the use of a pseudonym to protect participant identity. To gain trust and develop a personal relationship, I spoke with each participant during the first interview about my role as a doctoral student, my interest in this research, and offered an opportunity to ask questions. Because I was spending significant time on the MAU campus, it became a concern that I could encounter study participants on sidewalks 
and in academic buildings. I notified the participants that I would not make the first point of contact in those situation; however, should they choose to acknowledge my presence, I would reciprocate but not discuss the study or reveal our relationship to those nearby. This happened twice with two of the interview participants; we shared brief greetings and moved on.

\section{Study Limitations}

Despite the strengths of the explanatory mixed method design and steps taken to provide validity and plausibility, several limitations are worth nothing. This study is based at only one institution, limiting findings to experiences in this particular environment. Because this is a selective institution, the students face unique academic struggles and are often navigating the selection of multiple majors rather than just one. For most students, MAU may present the first instance of academic struggle or failure. Moreover, and important to the study findings, this institution covers 100 percent of need-based aid for qualified low-income students. This became an important consideration in the academic decision-making process for study participants that may not have existed at other institutions or under different aid models.

While, ideally, this study would follow students longitudinally, beginning in high school and through college, to understand influences and decisions in real time, resources were not available to execute a longitudinal research design. Students were thus strategically chosen to represent varying temporal dimensions of the academic decision-making process. In addition, it must be acknowledged that students were asked to reflect upon past experiences, while also examining decisions as they are happening, and this may shape their responses. Qualitative elicitation techniques (e.g., visual timelines, analytic vignettes, card sorting) were employed as a means of better understanding past experiences and to assist in recall. Due to the single researcher nature of this study, the number of cases was limited to provide appropriate depth of 
data collection. Finally, it is critical to acknowledge that case study experiences are not intended to be generalizable or replicable but to provide insight into specific experiences within a defined context. 


\section{CHAPTER IV}

\section{PARTICIPANT CONTEXT AND CASES}

\section{Quantitative Participant Perspectives \& Experiences}

The choice of academic major is one that happens over time and through processes of information gathering and influential experiences that shape students perspectives. This study sought to explore the process of academic decision-making, from pre-college experiences to declaration of major and beyond, to better understand how low-income students navigate major choice. In order to do this, it is important to understand, broadly, the perspectives and experiences of survey respondents as it provided useful context for both the major choice process and subsequent assertions. Moreover, these broad findings generated introductory themes and shaped decisions in developing a depth of understanding through qualitative case studies. This chapter provides initial survey findings as a means for introducing survey participants through the foundational data collected in this study and is followed by detailed qualitative cases for each of the eight interview participants and emerging themes found through early comparisons.

\section{Perceptions of Academic Majors}

While this study primarily considered the specific experiences of students involved in their own decision-making process, survey respondents were also asked to reflect upon the purpose and value of academic majors in general. By understanding how participants value the importance of academic majors, as well as the requirement at most universities to declare a major, it provided context for how students approach major choice and the outcomes expected 
Table 4

Student Perceptions on Academic Majors

\begin{tabular}{|c|c|c|c|c|c|c|}
\hline & $\begin{array}{l}\text { Strongly } \\
\text { Agree/ } \\
\text { Agree }\end{array}$ & Neutral & $\begin{array}{l}\text { Strongly } \\
\text { Disagree } \\
\text { /Disagree }\end{array}$ & Mean* & SD & $\mathrm{N}$ \\
\hline $\begin{array}{l}\text { Studying a major helps students } \\
\text { focus on what they want to do in } \\
\text { the future. }\end{array}$ & $80.65 \%$ & $15.08 \%$ & $4.47 \%$ & 2.12 & 0.69 & 179 \\
\hline $\begin{array}{l}\text { It is more important to pick a } \\
\text { major that you are interested in } \\
\text { than one that is directly related to } \\
\text { a career. }\end{array}$ & $64.45 \%$ & $21.67 \%$ & $14.09 \%$ & 2.31 & 0.98 & 180 \\
\hline $\begin{array}{l}\text { Students should pick college } \\
\text { majors that are related to their } \\
\text { career goals. }\end{array}$ & $61.00 \%$ & $30.00 \%$ & $8.89 \%$ & 2.34 & 0.82 & 180 \\
\hline $\begin{array}{l}\text { Majors provide students with } \\
\text { skills that they will use in their } \\
\text { jobs. }\end{array}$ & $63.34 \%$ & $25.56 \%$ & $11.11 \%$ & 2.37 & 0.73 & 180 \\
\hline $\begin{array}{l}\text { A college major should prepare } \\
\text { students for entry into a specific } \\
\text { occupation. }\end{array}$ & $55.00 \%$ & $41.67 \%$ & $10 \%$ & 2.43 & 0.88 & 180 \\
\hline $\begin{array}{l}\text { When picking a major, students } \\
\text { should consider the field's } \\
\text { income potential. }\end{array}$ & $55.55 \%$ & $31.11 \%$ & $13.33 \%$ & 2.50 & 0.93 & 180 \\
\hline $\begin{array}{l}\text { Students benefit from having to } \\
\text { pick a major. }\end{array}$ & $50.55 \%$ & $38.89 \%$ & $10.55 \%$ & 2.54 & 0.85 & 180 \\
\hline $\begin{array}{l}\text { When getting a job after } \\
\text { graduation, a student's college } \\
\text { major is relatively unimportant. }\end{array}$ & $34.46 \%$ & $35.56 \%$ & $30 \%$ & 2.97 & 0.92 & 180 \\
\hline $\begin{array}{l}\text { You should be able to get a } \\
\text { college degree without studying } \\
\text { a major. }\end{array}$ & $31.67 \%$ & $28.33 \%$ & $40.00 \%$ & 3.07 & 1.03 & 180 \\
\hline $\begin{array}{l}\text { A major that is interesting but } \\
\text { offers few career options is a } \\
\text { waste of time and money. }\end{array}$ & $25.56 \%$ & $24.44 \%$ & $50 \%$ & 3.32 & 1.19 & 180 \\
\hline
\end{tabular}

$*$ denotes minimum $=1.00 ;$ maximum $=5.00$

after making those decisions. As presented in Table 4, above, the opinions of survey participants mirror the national debate on major choice and college outcomes. While students indicated academic majors provide direction and skills necessary for jobs, 65 percent also identified picking a major in alignment with interests as being more important than alignment with career goals. Yet, responses are broadly split when students are asked opinions on majors deemed primarily for personal interest but are perceived to result in few career options. Only half of 
respondents felt comfortable agreeing that a major should be preparatory for a specific occupation and only 55 percent supported financial outcomes being a consideration in decisionmaking. As academic major choice is being publicly debated and greater focus is placed on labor market outcomes and the preparatory abilities of college majors, students appear to be having a similar debate with wide-ranging opinions on the purpose of college majors and post-completion outcomes. Although students did not overwhelmingly indicate negative rhetoric from media and policymakers played a role in decision-making, Table 4 offers survey findings identifying students not being in complete agreement on the purpose or outcomes of academic majors in a general context.

\section{Pre-College Information Gathering and Experiences}

Survey respondents quickly identified family and educational experiences as important pre-college resources for information gathering when initially considering college majors. While marital status was not asked, students overwhelmingly identified their biological mothers (88.3 percent) as primary caregivers and biological fathers (62.5 percent) as secondary caregivers. Extant literature supports the influence of parental level of education in college-related decisionmaking (Engle \& Tinto, 2008; Lareau, 2003; Pascarella \& Terenzini, 2005). As presented in Table 5, 45 percent of biological mothers have attained the bachelor's degree or higher with the same holding true for 45 percent of biological fathers. This data may be an indicator that, despite low-income status, these families place value on higher education and may be involved in major choice. This offered a baseline for consideration and understanding but further research is needed into the specific ways parents may influence decision-making for this population. As a primary focus of this study concerns pursuit of academic majors in humanities disciplines, family support of these humanities majors became a consideration. 
Table 5

Level of Caregiver Education as Reported by Survey Respondents.

\begin{tabular}{lllll}
\hline Level of Education & $\begin{array}{l}\text { Caregiver } \\
1^{*}\end{array}$ & $\begin{array}{l}\text { Caregiver 1 } \\
\text { percent of } \\
\text { total } \\
(\mathrm{n}=172)\end{array}$ & $\begin{array}{l}\text { Caregiver } \\
2^{* *}\end{array}$ & $\begin{array}{l}\text { Caregiver 2 } \\
\text { percent of } \\
\text { total } \\
(\mathrm{n}=163)\end{array}$ \\
\hline No Schooling or & 4 & $2.3 \%$ & 15 & $9.2 \%$ \\
Unknown & 14 & $8.1 \%$ & 10 & $6.1 \%$ \\
K-12; no diploma & 38 & $22.1 \%$ & 36 & $22.1 \%$ \\
High School Diploma & 5 & $2.9 \%$ & 2 & $1.2 \%$ \\
Some College, no degree & 18 & $10.5 \%$ & 15 & $9.2 \%$ \\
Trade/Vocational School & 16 & $9.3 \%$ & 12 & $7.4 \%$ \\
Associate's Degree & 16 & $29.7 \%$ & 43 & $26.4 \%$ \\
Bachelor's Degree & 51 & $2.9 \%$ & 3 & $1.8 \%$ \\
Some Graduate School & 5 & $12.2 \%$ & 27 & $16.6 \%$ \\
Graduate Degree & 21 & $100 \%$ & 163 & $100 \%$ \\
\hline Total & 173 & $16 \%$ & \\
\hline
\end{tabular}

* 88.3 percent of survey respondents identified "caregiver 1 " to be the biological mother. ** 62.5 percent of survey respondents identified "caregiver 2 " to be the biological father.

Table 6 presents a comparison of the percentages of students who responded as participating in humanities-related activities "sometimes" or "often" alongside the perceptions of how often caregivers engage in these activities. It is not unusual for student participation to be relatively high, given pre-determined interest in the humanities, recency of high school attendance where arts are often part of the curriculum, and current enrollment at a highly selective, liberal arts supportive institution. However, the seemingly strong participation by close family members may be an indicator of interest in the humanities and, possibly, influence or support in student pursuit of related disciplines.

In addition to family, educators and secondary education experiences reportedly shaped decision-making for students. Only five of the 180 survey respondents indicated not being enrolled in an advanced placement, college-preparation, or International Baccalaureate (IB) program in high school, yet, while influential, 75 percent of surveyed students indicated outside of class involvement, through school clubs, organizations, and athletics, to have a greater 
Table 6

Percentage of Students Reporting Engagement with Humanities Activities "Sometimes" or “Often” Alongside Students' Perceptions of Their Caregiver(s) Engagement.

\begin{tabular}{lll}
\hline Humanities-Related Activities & $\begin{array}{l}\text { Students } \\
(\mathbf{n}=180)\end{array}$ & $\begin{array}{l}\text { Caregiver(s) } \\
(\mathbf{n = 1 7 3})\end{array}$ \\
\hline Reading for pleasure & 87.2 & 66.5 \\
Discussing politics & 85.0 & 72.9 \\
Visiting museums/galleries & 86.7 & 54.3 \\
Speaking a language other than English & 77.8 & 52.7 \\
Attending plays or dramatic performances & 75.6 & 44.5 \\
Attending concerts or music performances & 69.3 & 44.6 \\
Taking classes to better oneself & 65.6 & 44.5 \\
Playing a musical instrument & 57.0 & 25.2 \\
\hline
\end{tabular}

influence on major choice than high school coursework. When researching college majors, 60.5 percent turned to high school guidance counselors for advice, despite nearly 70 percent indicating general internet searches as most influential, a likely sign of generational shifts. While some students go on to face academic challenge and most report not returning to high school teachers or counselors for support after graduating, club and organizational involvement in high school appears to contribute to student decision-making over time and is the basis of subsequent assertions.

\section{Declaration Status, Timing, and Disciplinary Affiliation}

As this study considers decision-making as a process over time, survey respondents comprised all four academic years; with some still exploring majors while others finalizing choices. Of the 180 participants, 99 students (55 percent) reported declaring a major while 81 (45 percent) were in the first or second year and still active in the major exploration process. Of the 99 students with declared majors, 40 had officially added a second major, common at MAU and a reminder that student's may be navigating multiple decisions, while an additional 16 remained in consideration. Timing of and confidence in student's decisions was also an important consideration in understanding efficacy and barriers as 53.9 percent of declared students waited 
until the latest deadline to declare a major. Similarly, 52 percent of undeclared students indicated lacking or possessing no confidence in their ability to select a major.

Despite displaying humanities interest, not all students declare in these fields. Figure 5, below, identifies the humanities still being a primary destination for declared students, with 79 declaring humanities options, but students are still departing for STEM and social science options. A similar trend presented when undeclared students were asked to identify all majors currently under serious consideration for declaration.

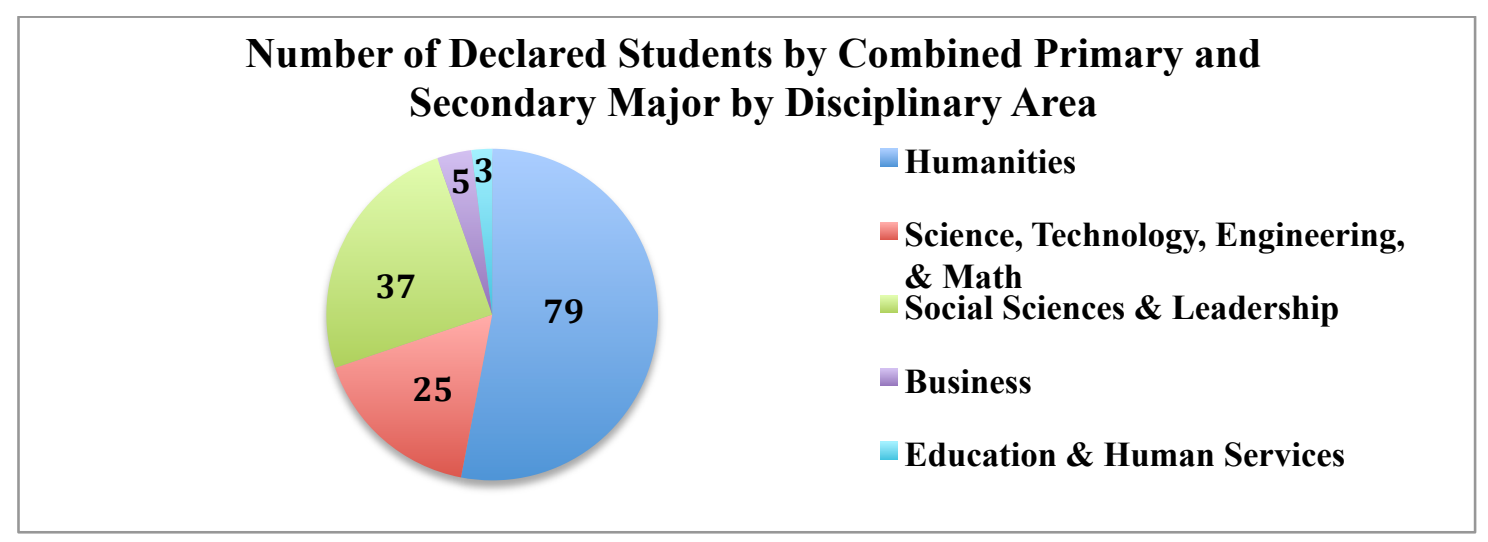

Figure 5. Number of Declared Students by Combined Primary and Secondary Major by Disciplinary Area

As depicted in Figure 6, students were still largely considering the humanities but strong interest remained in STEM and social sciences, once again supporting major choice as a fluid process.

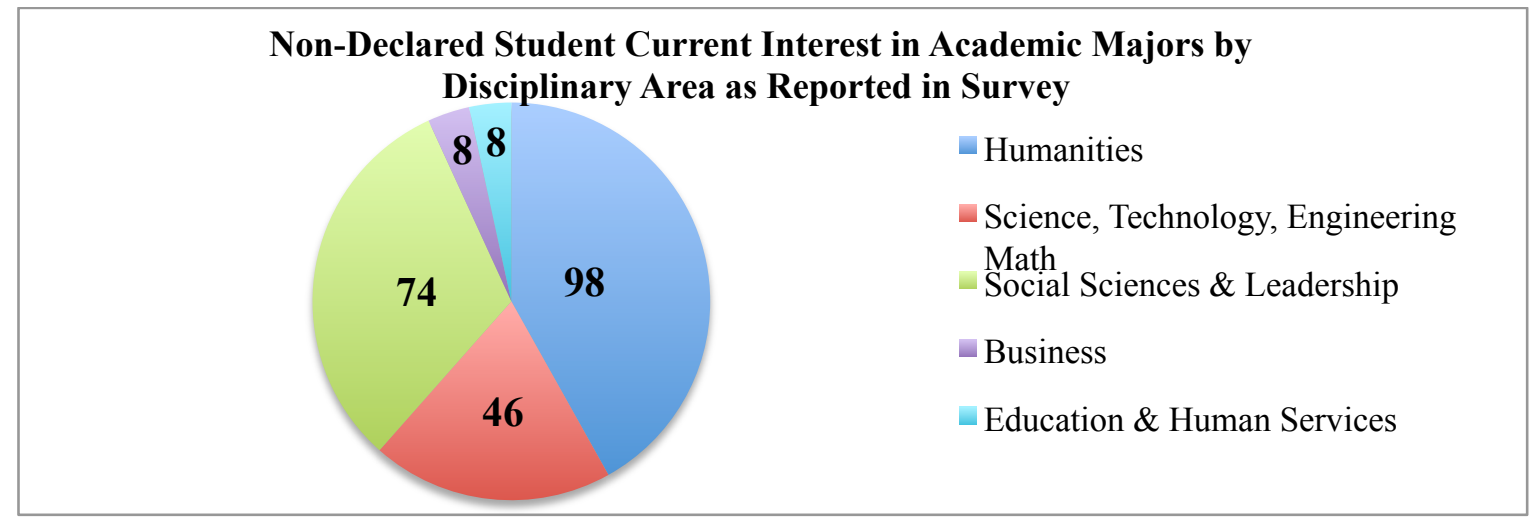

Figure 6. Non-Declared Student Current Interest in Academic Majors by Disciplinary Area as Reported in Survey 


\section{Major Change Over Time}

From pre-college considerations until survey completion, students were exposed to new environments, systems, and experiences that shifted their interest in a particular major.

Moreover, extant literature indicates that students are struggling to identify academic majors and changing majors at an increasing rate (Gordon \& Steele, 2015). Comparisons can be considered in multiple ways. For declared students, comparison was made between interested major as reported on the admissions application and the official major(s) declared with the institution. This comparison became insightful as, presented in Figure 7, a significant number of students were departing from intended majors of interest.

\section{Instances of departure from interested major at admission to declared major across declared students $(n=99)$}

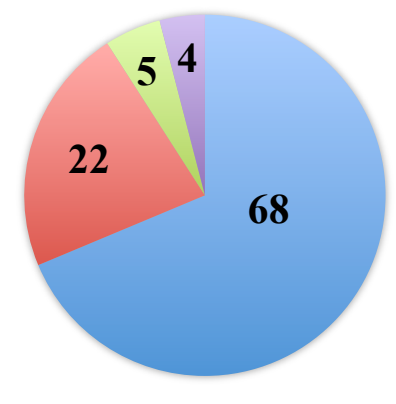

Full Departure from Interests

- Half Departure from Interests

No Departure from Interests

Unable to Determine

Figure 7. Declared Student Instances of Departure from Majors of Interest at Admission to Official Declaration with MAU.

To determine departure, the following criteria were used with supporting examples presented.

- "Fully departed": a student must have declared a primary or secondary major different than either "academic major interest \#1" or "academic major interest \#2" reported with the university at the time of admission.

- Example: a survey respondent who applied with interest in mathematics and music is now declared as a double major in Japanese and anthropology.

- "Half departed" a student declared one of the two academic majors of interest at admissions but did not declare a major in the second interest or added a second major in a different field.

- Example: a survey respondent who applied with intention to declare pre-medicine and biology went on to declare psychology and biology. 
- "No departure": a student has declared double majors in the two disciplines listed at admission or only listed one interest at admission and declared that one major.

- Example: a survey respondent who applied with interest in English and music went on to declare majors in English and music.

With 68 of 99 declared students "fully departing" from both intended academic majors and an additional 22 "half departing," this provided an important indicator and confirmation that what happens within the college environment may prompt students to consider alternative academic paths.

\section{Survey Participant Snapshot}

From this data, along with supporting evidence provided throughout Chapter V, a snapshot of survey respondents takes shape and is also reflected in the qualitative participants. These students are gifted, achieving highly in advanced courses in high school, and were involved both academically and co-curricularly before arriving at MAU. Many of these students indicated having at least one parent with some education beyond high school, over half speaking languages other than English, and possessing some interest in humanities-related disciplines.

Moreover, parents, as well as high school educators and involvement experiences, were primary influences on initial decision-making efficacy. Because these students represent four academic years, the split between declared and undeclared majors is understandable, yet, findings supported major choice as being an ever-changing process. For many students, initial interest in the humanities stalled for a short time, while students considered other pursuits in their new college environment but, often, students returned to the humanities when declaring. This will become an important theme in the presented assertions. The transition to college posed challenges for these students, especially in information gathering and seeking assistance, with students often waiting until the last minute to declare. However, despite challenges and feeling 
unable to connect majors with desired outcomes, students reported happiness with the ultimate choice of major once declared and planned to persist through completion.

\section{Qualitative Participant Overview, Profiles, and Emerging Themes}

\section{Demographics}

As qualitative methods are the dominant approach used in this study, this section presents overview insight into the eight participants selected as cases for this study. As noted by Yin (1994), case studies are quite useful in exploratory, explanatory, and descriptive research and interviewing people with different perspectives can be a valuable approach for understanding. Using presented data to inform choices, these eight participants were selected and their experiences analyzed individually and comparatively to identify confirming and disconfirming evidence and to develop assertions. As presented in Chapter III, student demographics and level of interest in the humanities was a critical consideration in choosing participants. Table 7 , on the next page, provides a snapshot of qualitative participants delineated by level of humanities interest.

\section{Qualitative Participant Profiles}

Because each interview participant serves as a critically important case in this study, a detailed synopsis of each is provided for context, clarity, and rich description. The intent is to allow for greater understanding of individual experiences as well as comparisons across cases and to provide initial support to the assertions presented in Chapter V. Moreover, as this study relies on Bronfenbrenner's $(1979 ; 1993)$ framework, having a detailed understanding of the multiple systems shaping the decision-making experience is important. 
Table 7

Qualitative Phase Two Participant Demographics and Characteristics as Delineated by Humanities Interest and Indicating Disciplinary Affiliation.

\begin{tabular}{|c|c|c|c|c|c|c|c|}
\hline Name & Gender & Race & Residency & $\begin{array}{l}\text { Academic } \\
\text { Year }\end{array}$ & $\begin{array}{l}\text { Humanities } \\
\text { Interest }\end{array}$ & $\begin{array}{l}\text { Current } \\
\text { Academic } \\
\text { Major } \\
\end{array}$ & $\begin{array}{l}\text { Disciplinary } \\
\text { Affiliation }\end{array}$ \\
\hline Amelia & Female & $\begin{array}{l}\text { African- } \\
\text { American }\end{array}$ & In State & Junior & $\begin{array}{l}\text { High } \\
\text { Interest }\end{array}$ & English & $\begin{array}{l}\text { Declared } \\
\text { Humanities }\end{array}$ \\
\hline Chloe & Female & Bi-Racial & In State & Sophomore & $\begin{array}{l}\text { High } \\
\text { Interest }\end{array}$ & $\begin{array}{l}\text { Undeclared } \\
\text { (likely Foreign } \\
\text { Affairs \& } \\
\text { Spanish) }\end{array}$ & $\begin{array}{l}\text { Considering } \\
\text { Social } \\
\text { Sciences \& } \\
\text { Humanities }\end{array}$ \\
\hline Ethan & Male & White & In State & Junior & $\begin{array}{l}\text { High } \\
\text { Interest }\end{array}$ & $\begin{array}{l}\text { Interdisciplinary } \\
\text { Social Sciences } \\
\text { \& Economics }\end{array}$ & $\begin{array}{l}\text { Non- } \\
\text { Humanities* }\end{array}$ \\
\hline Annie & Female & White & In State & Junior & $\begin{array}{l}\text { Low } \\
\text { Interest }\end{array}$ & Music & Humanities \\
\hline Mateo & Male & Hispanic & $\begin{array}{l}\text { Out of } \\
\text { State }\end{array}$ & Senior & $\begin{array}{l}\text { Low } \\
\text { Interest }\end{array}$ & Business & $\begin{array}{l}\text { Non- } \\
\text { Humanities }\end{array}$ \\
\hline Samesh & Male & Asian & $\begin{array}{l}\text { Out of } \\
\text { State }\end{array}$ & Freshman & $\begin{array}{l}\text { Low } \\
\text { Interest }\end{array}$ & $\begin{array}{l}\text { Undeclared } \\
\text { (applying to } \\
\text { Business) }\end{array}$ & $\begin{array}{l}\text { Considering } \\
\text { Non- } \\
\text { Humanities** }\end{array}$ \\
\hline Stacey & Female & White & In State & Junior & No Interest & Gender Studies & Humanities \\
\hline David & Male & $\begin{array}{l}\text { African- } \\
\text { American }\end{array}$ & In State & Senior & No Interest & $\begin{array}{l}\text { Race \& Culture } \\
\text { Studies }\end{array}$ & Humanities \\
\hline
\end{tabular}

* A common theme throughout interviews included Ethan's beliefs that his academic major choice was heavily influenced by humanities courses. He was surprised to learn that his interdisciplinary social sciences major was not considered a humanities discipline and this shaped many of his observations and contributions.

** Samesh is applying to the business program after not being able to find a humanities interest that meets his interest in photography and cinematography. This is a significant theme throughout his interviews.

Amelia (High Humanities Interest, Declared Humanities Major). Amelia is a junior majoring in English and will soon declare a minor in gender studies. She grew up in a suburb of a major metropolitan city in the same state as the university. Amelia is the youngest child in her family and identifies as bi-racial; her father is White while her mother is African-American. Her mother finished college online and her father spent 12 years earning an undergraduate degree in music. He was recently laid off from a job in IT but still performs music as a hobby and her mother works inconsistently as a bookkeeper. She has two sisters who are significantly older; one graduated from college but works outside her degree area and the other is now taking classes while working fulltime. Amelia describes having a close relationship with her family and her parents have always been overwhelmingly supportive of anything she chooses to do. She noted 
that her family does not like to plan ahead and are very "relaxed," which is evident in her personality. Amelia identified a pivotal moment in $7^{\text {th }}$ grade when she "fell in love with reading" that has contributed to her major choice.

Amelia considers her high school to be "competitive" and she was actively involved in humanities-related activities - marching band, literary magazine, drama club, and choir. She had a close relationship with an English teacher, who also attended MAU, and prompted her interest in the major. While supportive of her attendance, Amelia's parents were distant in her college search process and her oldest sister drove her to campus visits. For affordability, she applied to all in-state, public universities that have strong English programs. However, after failing to read a number of emails from universities regarding missing SAT scores, MAU was the only school where she was offered admission. Fortunately, she was excited to attend MAU and was also accepted to a living-learning program lasting the duration of her college experience.

Since arriving at MAU, Amelia has enjoyed her English courses and feels she has a professional relationship with her advisor. He has encouraged her to explore courses in multiple disciplines but she feels confident in her decision to major in English. She briefly considered majors in music - performance and media studies -- but was not persuaded to switch. Amelia enjoys the ability to explore different types of English courses and to be in small settings with other bright students who challenge her. Her post-college plans are uncertain, mentioning graduate school, and that she "will figure it out eventually." Amelia is a member of two music performance groups and has a strong social circle. Repeatedly, she mentioned that she has to be truly invested in a topic and feel confident in her abilities to be successful in order to persist. During our interviews, Amelia was struggling with a broken computer and finding the finances for a repair so she was often spending significant time in the library to use public computers. 
Annie (Low Humanities Interest, Declared Humanities Major). Annie is a very spirited third year student majoring in music. After a brief time living out of state, she returned to the same coastal city where her mother grew up. She moved 14 times prior to college - often between the homes of her mother and grandmother - but never left the city. Her mother did not complete college and her grandmother, a major source of support, works as a school nurse. She does not discuss her father, other than that he has a military background, and she has a close relationship with a much younger half-sister. Annie is admittedly swayed by those around her and, as a child, chose activities because her friends were involved. Her grandmother worked tirelessly to provide her music, dance, and athletics lessons. This included a summer music program in high school that Annie describes as "pivotal in her choice of major."

Annie chose to attend a different public high school than her feeder school because it offered an IB curriculum. However, the rigor of high school and the distance to be involved in a community orchestra forced Annie to give up practice of her instrument in $10^{\text {th }}$ grade. In high school, Annie's mom believed she was depressed and took her to see a therapist where she completed a battery of tests and inventories. From this, it was suggested that she consider architecture as a college major and this became her sole focus in the college search process. Her grandmother arranged visits to colleges with architecture programs and she applied as a "prearchitecture" student. She decided to attend MAU because of the prestige of the institution and the generous financial aid package.

During high school, Annie became invested in a local swim team and made money as a lifeguard and swim instructor. Upon arriving at MAU, she quickly acquired a job at the university swim facility where she is now serving as a swim lessons supervisor. This is an important source of income. Academically, she enjoyed the cohort structure of the architecture 
school but quickly realized it was not an academic home. She began exploring multiple majors but consistently felt "at home and in a community" in music courses. She brought her instrument to campus and, after being asked to join a music-related organization, it seemed like a sign to pursue music. She has declared the major and is very happy with her choice.

Annie acknowledges that music performance is not an option for her as the financial instability of that lifestyle is too difficult. However, when she attended the summer music program in high school, she learned about music therapy and is considering a graduate degree in this field. Prior to graduate school, Annie will complete an internship at Disney World where she credits her water safety proficiency as a benefit equal to her music skills. Annie is also in a long distance relationship with an MAU graduate who is currently in medical school and is very supportive of her music major. Her mother and grandmother are also supportive but often suggest adding a psychology major for "more stability."

Chloe (High Humanities Interest, Undeclared Major). Born on the West Coast, Chloe's family moved East when she was small and she is now the oldest of seven siblings. She is an African-American student in her second year at MAU. In fourth grade, Chloe's mom decided she lacked academic challenge and began homeschooling. Her mom served as the primary instructor but she, along with her siblings, were also engaged with homeschool consortiums, online learning, and local teachers in particular content areas. Chloe enjoyed being homeschooled because it allowed her to explore her many interests, particularly history and languages, and she benefitted from the experiential learning opportunities. She developed a close relationship with her online Spanish instructor and believes this drives her love of languages. She describes herself as "desperate to travel the world" but her experiences currently are quite limited. She is actively seeking funds to pursue study abroad opportunities. 
In $10^{\text {th }}$ grade, Chloe's chemistry teacher "appointed herself as de facto guidance counselor." She prepared Chloe for her SATs, coordinated campus visits, and reviewed college applications with a constant focus on Ivy League options. While Chloe had interest in a small, private, liberal arts college, she chose MAU for the prestige and financial assistance. Chloe is responsible for the cost of her education outside of the aid she is receiving from the institution. She makes extra money by working in campus recreation and is involved with a campus religious organization, club swimming, and taking piano lessons when home.

Since arriving at MAU, Chloe has focused on general education courses. She accidentally took an upper level biology course and struggled in that course and in math. Chloe indicated that her mother is "obsessed with the human body" and wants her to go to medical school but, because Chloe is paying for her education, she feels she can make her own choices. Through her interest in travel and her passion of courtroom and crime dramas, she is considering a major in foreign affairs and Spanish with a plan to go to law school in the future. Admittedly, she has not explored her options and still feels nervous about committing to a major. She is hoping an internship might help her decide and believes law school will provide enough to pay any debt she has after college. She is primarily taking humanities general education courses.

Because Chloe was homeschooled, she is accustomed to having close relationships with adults and teachers. She did not take any of the recommended freshman seminar courses so she often feels lost in how to navigate the university. She often comments that she "feels too young" to be making major life decisions She feels supported by her family to be in college and choose a major of her liking but her father often reminds her to "choose a major that will lead to a steady job and a secure income." She believes finances are important but should be equal to happiness. 
Chloe's parents met while attending college in California and both have held jobs in law enforcement, which Chloe also credits as driving her interest in law school.

David (No Humanities Interest, Declared Humanities). David is a fourth year, AfricanAmerican male student from an in-state city. He enrolled in MAU with a life-long plan to major in mathematics but, after significant academic difficulty, declared his major in race and culture studies (RCS). He became interested in RCS after taking a number of general education courses in this discipline and having a positive relationship with faculty. David credits an older fraternity brother at MAU as being an advisor and confidant as he navigated academic difficulty and ultimately declared his major.

While David physically lived with his mother and grandmother as a child, his grandmother's two sisters (his great aunts) have, and continue to, play a significant role in his life. Both aunt's graduated from MAU in the 1970s and are the only people in David's immediate family to attend college. One aunt works as a physician and the other is a highranking judge in his home community. These women have been responsible for every major educational decision in David's life and, by sending him to summer camps on MAU's campus every year, planted a seed of college attendance at an early age. David looks to his aunts for guidance in all areas of his life and they are now actively involved in his post-graduation employment plans. David acknowledges that this has caused animosity with his mother and grandmother at times in his life but his family is very proud that he is attending MAU.

David, and his younger sister, attended a private Christian high school until he was in $10^{\text {th }}$ grade. His sister was struggling and the family decided to send her to boarding school in the Deep South. She would not go without David so he enrolled as well. While he enjoyed boarding school, the curriculum did not offer honors and AP courses and he was forced to stop taking 
language courses. He feels this has been a detriment in his preparation at MAU. While MAU was always a priority institution, David took interest in a prominent historically black college. His mother failed to complete the necessary financial aid paperwork and he was not offered any tuition assistance, making it impossible to attend. David receives significant funding from the institution with any additional costs covered by his aunts. He also holds a part-time position at a campus library to make spending money.

Throughout his life, David has struggled with reading and writing and excelled in math and science. However, once arriving at MAU, he began performing poorly in advanced math courses and lacked adequate high school preparation. David attended a summer bridge program during the month before his first semester at MAU and descried the program as giving very little information on declaring a major. After withdrawing from multiple math courses, he became concerned about his ability to declare a major by the deadline or even to remain at MAU. As the deadline approached, David worked with a fraternity brother to create an academic plan. While the rigorous reading and writing requirements of RCS presented a significant challenge, David believes his interest in the topics, engaging course discussion, and internship opportunities have made the choice of RCS worthwhile. He currently holds a major campus leadership position for underrepresented students and identified his desire to "help out other students who are struggling like my frat brother did for me" as his motivation. Currently, David is seeking positions where he hopes to "feel financially secure, enjoy life, and buy a house at some point." He does not foresee attending graduate school but believes his RCS degree provides him with transferable skills that are marketable in many fields.

Ethan (High Humanities Interest, Declared Non-Humanities Major). Ethan is a White, male student in his junior year at MAU. He grew up in a suburb of the state capitol where his 
parents divorced when he was in first grade. Both remarried quickly and Ethan is quick to identify his mother's family as being "more focused on education." He has faced difficult relationships with both of his stepparents but is amicable now and has myriad stepsiblings. His only biological sister is a first year student at another state university. Ethan performed well in high school, was actively involved in church youth group, and considers his youth minister to be the male role model missing in his life. Ethan applied to less selective state institutions and was offered a scholarship at a large, private religious college - which his mother encouraged. He chose MAU for the prestige and large financial package offered by the institution.

Ethan is unique in that he found a plan for what he hoped to do beyond college but struggled to find a major to fit those interests. His plan began in $9^{\text {th }}$ grade when his same-aged stepsister was removed from high school to raise her younger siblings. Ethan was outraged and this has driven his desire to study instances of dropout in secondary education. It was also in high school when Ethan became interested in religious hip-hop music and began questioning social inequality. However, when arriving at MAU, he chose to explore Classics as his major because of success in high school and also considered business for a short time. During his first weekend at MAU, Ethan became involved with a Christian student organization, now very meaningful in his decision-making. After attending alternative break trips to work with homeless youth and inner-city schools through this organization, Ethan began searching for a major that explained urban education, social stratification, and the economics of poverty. As he was preparing to enroll in courses, he talked with peers in the accounting courses he was considering and had a "gut instinct" that he was doing the wrong thing. He searched the "MAU Majors" website for hours and found interdisciplinary social sciences. He decided to drop accounting, take the introductory course for interdisciplinary social sciences and, after a positive experience, applied 
to the major. In addition, to better understand poverty, he has added economics as a second major.

Ethan remains actively involved with a religiously affiliated inner-city youth schooling project near his hometown. After visiting on an alternative break trip, he volunteers regularly and interns with the children's summer programs. Ethan describes his involvement as a "lifechanging experience" and he is considering a long-term fellowship after graduation. While his parents are supportive, they are concerned that non-profit work will not be lucrative and his mother chooses to ignore the plight of these individuals living so near to her. Ethan often struggles in having conversations with his mother and stepfather because of their use of religion as a defense. In an effort to self-explore, Ethan has taken a number of religion courses at MAU and identifies those as the most rewarding of his academic tenure. He also appreciates the small, cohort style of interdisciplinary social sciences juxtaposed with the large, lecture courses in economics.

Mateo (Low Humanities Interest, Declared Non-Humanities). Born in South America, Mateo's family immigrated to the United States when he was five years old in order to escape political and social unrest and to provide a better future for him and his older sister. The family settled in a southern state where his dad performed custodial work and his mom skilled labor. Both attended college in their home country but hold degrees in vocational areas that did not translate well to the United States. Spanish remains the primary language spoken at home and Mateo noted that higher education was an expectation in his household. Mateo is in his final year at MAU.

Mateo's family lived near "communities full of doctors and lawyers" and his family sacrificed to send him to a private preparatory school. In $9^{\text {th }}$ grade, he moved to a public high 
school offering a prestigious IB curriculum. He acknowledges being ashamed of his parents' inability to speak English, while admiring the lifestyles of classmates, and this drives his desire to make a significant salary. He navigated the college search process on his own and focused on Ivy League institutions. He hoped to attend Harvard or Stanford and makes his displeasure with attended a "lesser institution like MAU" known. After committing, he found a letter at his home requesting his participation in a prestigious college matching program and he remains frustrated about this oversight. He does not visit home often but is in communication with his family.

Mateo's college transition was very difficult and he arrived believing he was already accepted into the business major, not understanding that he would be required to formally apply during his second year. He considered pre-medicine, because it is lucrative, but quickly decided that he did not want to "study that hard or be responsible for the lives of others." Despite being openly gay since $10^{\text {th }}$ grade, Mateo did not feel safe at MAU and "went back in the closet" during his first year. After involvement with alternative spring break programs, a campus dialogue organization, and social justice groups, he felt more settled at MAU but still wishes he transferred. He refers to his social life as "networks [he] can tap into as needed" and often describes his life as "bearing a cross and bearing it alone."

While business as a major does not excite Mateo, he sees it as a path to success, wealth, and prestige. He wants to live in a large, urban environment, afford nice belongings, travel, and provide lavishly for his parents. He believes his family would have more pride if he attended an Ivy League university. He has done well academically but faced some hiccups in particular business courses, does not find the faculty to be helpful, and describes the resources as "lacking." Failure to secure an internship caused significant mental distress for Mateo and a major 
disagreement with his family. However, by the final interview, Mateo was negotiating two job offers, yet he did not appear completely pleased with either.

Interestingly, when asked what he would have preferred to study in college, he noted that the humanities courses at MAU seemed "fascinating" and described the faculty as "warm and welcoming." He regrets using his general education requirements to only take Mandarin Chinese - a ploy to gain admission to business - and not exploring. He hoped to take courses related to gender studies, political thought, and societal issues. Mateo's disdain for MAU is in stark contrast to other participants who see admission as a major achievement and completion as a valuable piece of capital.

Samesh (Low Humanities Interest, Undeclared Major). Samesh's family moved from India to the United States just before he was born and settled in New England. His father had a job with a fast food chain and his mother in baking. After being displeased with living conditions, the family moved South so his father could work for a gas station and his grandparents could immigrate to live with them. Samesh grew up in a suburb of a major metropolitan city in the Southeast and has two younger siblings. After performing well academically, he chose to attend an IB magnet high school over an hour away. While his parents wanted him to have the opportunity, they were very frustrated with the travel obligations and this persisted until Samesh was able to drive himself.

Samesh lost his grandfather to a heart attack and his grandmother has significant cardiac issues. He decided at a young age to be a cardiologist where he could make a lucrative salary while also helping people - two things of great importance to him. In high school, Samesh established a popular student medical organization and became a passionate volunteer with a local children's medical charity. He enjoyed being in the clinical setting and spoke often with his 
guidance counselor about his plans to attend medical school. Samesh was offered the opportunity to participate in a prestigious college placement program but did not move beyond the finalist round. It was through this process he learned about MAU and ultimately applied.

During high school, Samesh also became interested in photography and digital media. $\mathrm{He}$ began watching YouTube videos to learn more about his cameras and creative approaches to his craft, which later expanded to painting. While his parents were supportive, they never understood his interests. During the college application process, Samesh began to consider his life goals and the idea of "being in medical school until [he] was 30 just seemed crazy." He wanted to graduate, travel, and start a family while still in his 20 s. However, in Indian culture, only medicine, hard sciences, business, and law are seen as noble professions. He felt business might be a viable option but it also seemed "dirty and not helpful to anyone." He identified a joint business and cinematography degree program on the West Coast but, after being admitted, his family did not support his attendance. He settled on MAU with the plan to create something similar for himself but still identified his intended major as neuroscience.

Samesh has made a strong network of friends, unintentionally mostly Indian, and many are pursuing business. After learning more about media studies and not being pleased with course offerings, he has decided to focus on business as a major. He has joined a number of student organizations related to digital arts and was recruited for a part-time job in the university's digital media lab. Samesh has also been accepted to a program that assists local community members who are struggling financially with grant funds - he sees this as his way of making "business seem more like it can help people." Samesh is struggling academically, especially in comparison to his friends, and has concerns about his ability to gain admission to the business program. He is also concerned about his parents' reaction to his performance as 
they are only comfortable with his interest in film should it be partnered with business. He has not sought assistance and only likes to study alone but, by our final interview, acknowledged "it might be time to get some help." While he only desires to have enough money to travel, he does feel obligated to provide for parents, an Indian custom. Samesh plans to continue pursuing admission to the business major but does not have an alternative plan should that not occur.

Stacey (No Humanities Interest, Declared Humanities). Raised in an in-state town, Stacey has a large, close-knit family. Her father, after being injured at work, is now a selfemployed carpenter and her mom works as an elementary school nurse. Her parents also have custody of Stacey's nephew - a child her older sister had while in high school. Stacey was active in her public high school and performed well academically. She is a White female in her third year at MAU.

Stacey became interested in medicine at a young age. She was present when her mom gave birth to her youngest sibling and faced complications. In $6^{\text {th }}$ grade, Stacey's grandfather was diagnosed with cancer and spent significant time in the MAU medical center. This was when she both decided to pursue medicine and identified MAU as her “dream school." Stacey's college search process was held in conjunction with a same-aged cousin and her aunt, who is a college graduate, took her on visits. She also found support in a thoughtful high school teacher who encouraged her to attend MAU. Stacey applied to a number of public, state universities, as she believed them more affordable than private options, but jumped at the opportunity to attend MAU. She receives a full scholarship from the institution.

Stacey enrolled in courses designated for pre-medicine students during her first semester and immediately found academic difficulty. She struggled in math and science courses and was placed on academic probation after her first semester. She had a very brief, required meeting 
with an academic advisor who did little more than scold her while suggesting she consider other options for an academic major. She continued on in pre-medicine courses for another semester but, facing concern about suspension, shifted to general education requirements. Stacey enjoyed a number of courses in the humanities but still struggled with the disappointment leaving premedicine. She found interest in media studies and gender studies courses but remained in biology classes in an attempt to redeem herself. She did poorly. However, a course on "women and sport" caught her attention as she was simultaneously trying out for club field hockey and softball - both sports she played in high school - and serving as a volunteer manager for an athletics team.

Because Stacey did not declare until entering her third year, she has not taken many gender studies courses at this point but is very happy with her major. She struggles to explain to family the purpose of the major and she is still very unsure of a career path. However, she believes working with Title IX and women in university athletics could be an option. Her semester has been difficult because her grandfather passed away during the interview process. Stacey struggles to keep up academically while also remaining involved in club sports, volunteer positions, and a campus religious organization. Stacey's boyfriend has moved to be near campus and his mother holds a women's studies degree. Her support gives Stacey confidence. Her parents are understanding of her choice but are concerned about future employment. Stacey relies upon the idea that an MAU degree is valuable, no matter the academic discipline. She also feels strongly that she wants to be self-sufficient and independent with no need to rely upon others for financial support. 


\section{Pre-College Experiences Across Cases}

Students' secondary education experiences vary notably across cases. Mateo, Samesh, and Annie all attended IB programs outside their assigned school district, David landed at boarding school many states away, and Chloe was homeschooled while Amelia, Stacey, and Ethan remained in public high schools taking Advanced Placement courses. The students can all be considered academically high achieving but did not receive significant guidance in the college search process, especially from parents.

Collectively, the students find support from their parents and immediate family and communicate regularly despite some students reporting differing opinions related to college decisions and personal values. While some immediate family members have started college or completed an associate's degree, Annie, Ethan, Samesh, and Stacey are the first in their family to attend a four-year institution. David's experience is heavily influenced by his aunt's attendance at MAU but, technically, he would also be considered a first generation student. While Chloe's parents attended college, she is the oldest sibling and the first to attend. Both Amelia and Mateo have older siblings who are college graduates and Mateo's parents attended a vocational college in South America. Parental employment also varies across cases. Both Annie and Chloe's mothers have recently returned to full-time employment, Amelia's father recently lost his job and her mother only works periodically. Stacey's father was injured while working and is now selfemployed. After many years of struggle, Mateo's father now owns his business and Samesh's parents are both employed. David relies upon his aunts for support as his mother and grandmother do not work and Ethan's family relies upon his stepfather's military pension. 


\section{College Experiences Across Cases}

After all experiencing struggles in the college selection process, the eight participants have adequately navigated the MAU academic and social climate and chosen to remain. As discussed in Chapter V, all eight students have struggled with academic decision-making and fail to seek resources. With the exception of Chloe, the students also do not report having meaningful relationships with faculty or university staff. In considering the student's survey responses, general education courses have been positive influences on major choice. David and Stacey both selected majors, race and culture studies and gender studies, respectively, after academic difficulty and stumbling upon topics of interest in general education courses. The students are quite divided on graduate school attendance. Annie, Samesh, Stacey, and Chloe are all planning to pursue graduate education, Mateo and Ethan may return in the future, David has no interest and, as true to her personality, Amelia contradicted herself throughout interviews about future plans. Only Chloe has engaged with any research experiences since arriving at MAU.

With the exception of Mateo, who has struggled to find a niche, the students are all socially engaged and very active in the campus community. Interestingly, all eight students are engaged in activities with a humanities focus. Annie, Chloe, Amelia, and Samesh are in the visual and performing arts, David, Ethan, and Stacey are active with cultural and religious organizations, and Mateo found a home with gender and dialogue groups. As discussed later in Assertion 1, the students have a collective interest in helping others and this is prevalent in their involvement. David, Annie, Chloe, and Samesh also hold part-time jobs on the MAU campus. 


\section{Post-College Desired Outcomes Across Cases}

While pre-college and college influences are important in academic decision-making, so are the desired outcomes students hope to achieve upon and obtain after graduation. As will be discussed further, students reported struggles in making connections between desired outcomes and academic majors. However, a student's desired outcomes speak to personal and professional values and goals that may be important in shaping academic decisions throughout the undergraduate experience while also shedding light upon interests in humanities disciplines. Using a set of 21 prompts, survey participants were asked to identify how important a particular outcome may be. While not generalizable, the desired outcomes of interview participants are representative of trends also found in survey responses. Across the 21 desired outcomes, the responses of interview participants were compared and sorted into three groups: strong importance, split importance, and minimal importance. For strong importance, 7 to 8 of the interview participants must have indicated the outcome to be "very important" or "essential." For split importance, the cohort of participants must have been an array of responses with, often, half selecting "very important" or "essential" and half selecting "somewhat important" or "not important." Finally, for minimal importance, 7 to 8 of the participants must have selected "somewhat important" or "not important." Table 8, on the next page, identifies the importance of desired outcomes to interview participants.

In comparing the importance placed on specific outcomes across survey responses and interview responses, striking similarities emerged. Students placed strong importance on opportunities to help and serve while exploring philosophy, social and cultural values, and political thought; all connected with humanities study. The responses of split importance appeared to be along specific demographic lines. For example, the four men in the interview 
Table 8

Importance of Desired Outcomes to Interview Participants as Reported in the Survey

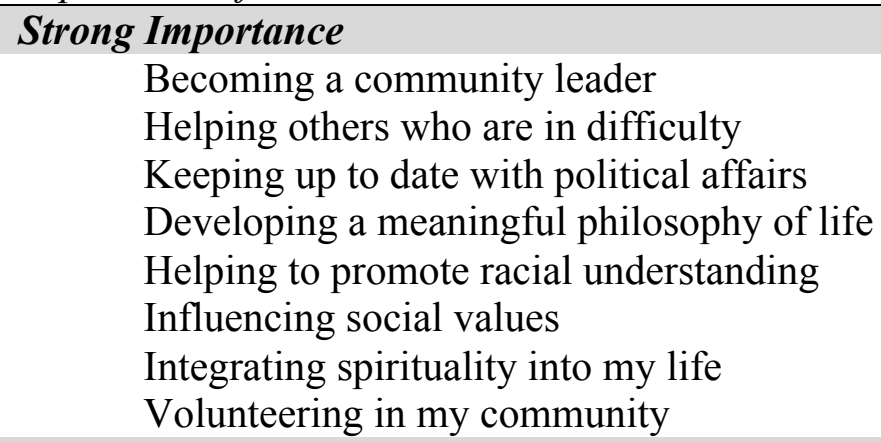

\section{Split Importance}

Writing original works (e.g., poems, novels, short stories)

Becoming involved in activities that preserve and enrich the environment

Improving my understanding of other countries and cultures

Influencing the political structure

Obtaining recognition from my colleagues for contributions to my field of expertise

Having administrative responsibility for the work of others

Working in a prestigious occupation

Making a lot of money

Becoming successful in a business of my own

\section{Minimal Importance}

Becoming accomplished in one of the performing arts (e.g., acting, dancing, singing)

Creating artistic work (e.g., painting, sculpture, film)

Making a theoretical contribution to science

Working to find a cure for a disease or illness

cohort placed importance on receiving recognition from colleagues, having administrative

oversight, making a lucrative salary, and achieving a prestigious occupation when compared to

women. Similarly, it is the White students who desired to improve understanding of countries

and cultures when compared to minority students in the cohort. In terms of minimal importance,

the lack of interest in science and technology is understandable for this population. Similarly, it

was only Annie, a music major, who desires accomplishment in the performing arts while

Samesh, a self-proclaimed artist, was the only student to place importance in creating artistic

work. When comparing the interview findings with collective survey responses, the strength of

the alignment became worthy of note. As depicted in Table 9, survey respondents collectively

aligned with the desired outcomes of interview participants in all but two instances. Survey 
Table 9

Desired Outcomes as Reported by Survey Respondents.

\begin{tabular}{|c|c|c|c|c|c|c|}
\hline Outcome & Mean* & $\mathrm{SD}$ & Variance & $\mathrm{N}$ & $\begin{array}{l}\text { Bottom } \\
2 \text { Box } \%\end{array}$ & $\begin{array}{l}\text { Top } 2 \\
\text { Box } \%\end{array}$ \\
\hline $\begin{array}{l}\text { Becoming accomplished in one of } \\
\text { the performing arts (e.g., acting, } \\
\text { dancing, singing) }\end{array}$ & 1.50 & 0.87 & 0.76 & 179 & 87.7 & 12.2 \\
\hline $\begin{array}{l}\text { Creating artistic work (e.g., } \\
\text { painting, sculpture, film) }\end{array}$ & 1.66 & 0.99 & 0.98 & 179 & 82.1 & 17.8 \\
\hline $\begin{array}{l}\text { Writing original works (e.g., } \\
\text { poems, novels, short stories) }\end{array}$ & 1.74 & 1.00 & 0.99 & 178 & 79.2 & 20.7 \\
\hline $\begin{array}{l}\text { Making a theoretical contribution } \\
\text { to science }\end{array}$ & 1.54 & 0.85 & 0.72 & 178 & 84.2 & 15.7 \\
\hline $\begin{array}{l}\text { Working to find a cure for a disease } \\
\text { or illness }\end{array}$ & 1.55 & 0.87 & 0.76 & 179 & 85.4 & 14.5 \\
\hline Becoming a community leader & 2.53 & 0.93 & 0.86 & 179 & 51.9 & 48.0 \\
\hline $\begin{array}{l}\text { Becoming involved in activities } \\
\text { that preserve and enrich the } \\
\text { environment }\end{array}$ & 2.38 & 1.02 & 1.05 & 180 & 60.0 & 40.0 \\
\hline Helping others who are in difficulty & 3.14 & 0.85 & 0.73 & 180 & 21.6 & 78.3 \\
\hline $\begin{array}{l}\text { Improving my understanding of } \\
\text { other countries and cultures }\end{array}$ & 3.02 & 0.87 & 0.76 & 180 & 27.2 & $72.7 * *$ \\
\hline $\begin{array}{l}\text { Keeping up to date with political } \\
\text { affairs }\end{array}$ & 2.78 & 0.93 & 0.86 & 178 & 41.0 & 58.9 \\
\hline $\begin{array}{l}\text { Developing a meaningful } \\
\text { philosophy of life }\end{array}$ & 2.94 & 0.96 & 0.92 & 179 & 33.5 & 66.4 \\
\hline $\begin{array}{l}\text { Helping to promote racial } \\
\text { understanding }\end{array}$ & 2.93 & 1.00 & 1.00 & 178 & 34.2 & 65.7 \\
\hline Influencing social values & 2.80 & 0.95 & 0.89 & 179 & 37.4 & 62.5 \\
\hline Influencing the political structure & 2.42 & 1.03 & 1.06 & 179 & 56.9 & 43.0 \\
\hline Integrating spirituality into my life & 2.25 & 1.11 & 1.24 & 180 & 64.4 & $35.5^{* *}$ \\
\hline Volunteering in my community & 2.85 & 0.95 & 0.90 & 177 & 36.7 & 63.2 \\
\hline $\begin{array}{l}\text { Obtaining recognition from my } \\
\text { colleagues for contributions to my } \\
\text { field of expertise }\end{array}$ & 2.32 & 0.98 & 0.96 & 179 & 57.5 & 42.4 \\
\hline $\begin{array}{l}\text { Having administrative } \\
\text { responsibility for the work of } \\
\text { others }\end{array}$ & 2.24 & 0.97 & 0.93 & 178 & 62.3 & 37.6 \\
\hline $\begin{array}{l}\text { Working in a prestigious } \\
\text { occupation }\end{array}$ & 2.47 & 1.06 & 1.13 & 179 & 52.5 & 47.4 \\
\hline Making a lot of money & 2.48 & 0.99 & 0.97 & 180 & 54.4 & 45.5 \\
\hline
\end{tabular}


Becoming successful in a business of my own 2.25 $1.15 \quad 1.33$ 179 60.34 39.66

$*$ denotes minimum $=1.00$, maximum $=4.00$

** denotes differences in importance between survey respondents and interview participants. respondents placed greater emphasis on understanding other countries and cultures and less importance on integrating spirituality into their lives (denoted with an asterisk in Table 9).

While having many similarities, the eight students each shared a unique set of circumstances and experiences that provided useful insight into the academic decision-making of low-income students and their perceptions of humanities study. Moreover, these individual experiences were reflective of the myriad journeys also expressed through survey responses. Collectively, this data is combined to develop the detailed information, findings, and assertions presented in Chapter V. 


\section{CHAPTER V}

\section{FINDINGS AND ASSERTIONS}

Using Erickson's (1986) analytic induction model as a guide, this chapter presents study findings through the use of assertions with supporting data in multiple formats. These findings intend to contribute to the higher education literature by addressing the presented research questions and offering insight into the academic decision-making process as it pertains to lowincome undergraduate students attending a highly selective institution. To review, this study's research questions are:

1. What influences low-income undergraduate students to pursue academic majors in humanities disciplines?

2. In what ways are low-income undergraduate students' senses of academic self-efficacy regarding their choice of major shaped through experiences and influences within the college and external environments?

3. What college and external environments or experiences, specifically, shape the major choice process for low-income undergraduate students interested in humanities disciplines?

This chapter presents findings in two sections. The first section concerns parallels between the college choice and major choice processes for low-income students. While an unexpected theme and further research is recommended before moving this finding to assertion status, the parallels in processes provide useful context for considering academic decisionmaking and, in particular, the important roles information and efficacy play in major choice. Subsequently, study findings will be presented through five assertions to highlight direct influences, as well as supports and barriers, shaping academic decision-making. 


\section{Parallel Processes: College Choice and Major Choice}

Extant literature, presented in Chapter II and widely discussed across higher education, details the barriers low-income students often face in the college choice process. Low-income students attending highly selective institutions, like MAU, are found to have the same struggles as low-income students attending less selective institutions. In fact, students attending highly selective institutions often face greater struggles in college choice and transition as these universities typically offer fewer resources for disadvantaged students while wealthier students possess the necessary cultural capital to be successful (see Hoxby \& Avery, 2009; Hoxby \& Tuner, 2013; Lareau, 2003). Although students were not directly asked about the college choice process in the study survey, barriers in this process widely emerged in qualitative interviews. Students discussed at length the trials and tribulations faced in determining college options, navigating visits and applications, and untangling financial aid details. Arising from this theme were stark similarities to the same issues low-income students faced in navigating academic decision-making. Moreover, given the choice of major is the next most important academic decision a student makes after the choice of institution, seeing a continuation of barriers across this process and for this population of students caused concern.

\section{Information}

Across both college choice and major choice processes, deficits in important information surfaced as a primary concern in decision-making. Extant literature widely supports deficits in information as being a primary concern for low-income students (see Giancola \& Kahlenberg, 2016; Kuh, 2008; Kuh et al. 2007; Pascarella \& Terenzini, 2005). Commonly, these students do not understand the college-going process, struggle to identify institutions of appropriate selectivity for academic abilities, experience difficulty in processing financial aid applications, 
and, for some, are unable to visit the campus prior to selection. These issues rang true for interview participants in this study. Mateo disclosed not knowing he was eligible for a prestigious college-matching program and, when letters arrived in the mail, his family discarded the applications as trash. He blames this oversight for his inability to attend an Ivy League university. Annie took the advice of a therapist and attended MAU because it's a "good school" and chose a major she knew little about because she was unable to attend admissions events. Although MAU was her top choice, Stacey remained concerned that being away from home would not allow her to support family needs. Ethan's family pressured him to attend a highly religious institution because of the substantial aid package offered despite misalignment with his personal beliefs. Amelia, unaware that college correspondence would come via email rather than postal mail, missed communication from several colleges concerning missing SAT scores. She was removed from the applicant pool at every institution she applied, other than MAU, despite being a highly competitive candidate. Finances also presented concern. Failure by David's mother to complete required paperwork precluded him from attending a prominent historically black institution. Without visiting, Samesh chose a West Coast institution because he "heard they had a good film and business program" but his parents quickly decided, without research, that travel costs would be too high. Chloe hoped to attend a small, private school but was discouraged by her dad because "it's probably too expensive" despite likely being eligible for substantial aid.

These deficits in information and subsequent struggles continued in a similar way during the major choice process. One quarter of survey respondents identified a general lack of understanding regarding the major declaration process and requirements as being the primary barrier in academic decision-making. Because of this, students identified lacking confidence in 
decision-making and academic abilities. Interview participants reported never receiving information regarding how to formally declare majors and indicated initial meetings with an academic advisor to be unhelpful. David, who attended a summer bridge preparation program, does not remember major declaration ever being discussed, and he feared being suspended for not choosing a major quickly enough. Both Samesh and Mateo recalled similar stories of surprise in learning that they still had to apply to the business program during the second year and frustration in not attending another university where admission was guaranteed. After securing an application to his interdisciplinary major, Ethan found himself wandering around an academic building and ultimately sliding the form under a locked door and hoping it would be received. While the male students did seem to face more difficulty, Amelia discussed having to wait until a faculty member returned from sabbatical to declare a minor, Annie went without an advisor for quite some time when switching majors, and Stacey waited until the start of her third year before officially declaring. Even Chloe, who is the only interview participant to develop strong relationships with administrators, remained feeling ill equipped with the information or confidence necessary to declare her major.

Some may misconstrue these experiences and identify the students as being delinquent or disorganized. Rather, these students simply lack the necessary information to overcome barriers. While some students, especially ones as academically gifted as those in this study, nevertheless persist and succeed, the process is often complicated and difficult. Across both experiences, students were struggling to understand processes, obtain pertinent information, and seek university resources. Given the college choice and major choice processes happen relatively close together, these students are spending substantial time navigating important decisions and overcoming barriers without all the tools to promote success. 


\section{Self-Efficacy}

For students in the major choice process, reflecting upon the most recent academic decision, choice of college, may conjure memories of a rocky start. The deficits in information found during the college choice process, previously presented, continued into the major choice process and negatively shaped self-efficacy. Students appeared to lack information regarding the purpose of specific majors, particularly in the humanities, and why these fields of study would be a feasible option. This issue began during college choice, when students were considering academic interest to select institutions, and persisted through major choice. Despite having humanities interests, many low-income students reported entering college with plans to pursue a vocational or pre-professional degree with a defined outcome (e.g., pre-medicine to become a doctor). Yet, when those plans went awry, understanding other options (a "Plan B") became a challenge. As students faced rises and declines in self-efficacy in the college choice process, the same pattern then occurred during major choice. When facing barriers in decision-making, efficacy may plummet and lead to feelings of self-doubt, academic inability, and loss of motivation. For low-income students who already struggle to obtain assistance, feelings of low self-efficacy can be damaging to not only decision-making but also persistence and completion.

Compounding issues of self-efficacy is a reported inability for low-income students to make connections between academic majors and post-completion goals and outcomes. Of the 180 survey respondents, 64 percent reported difficulties in understanding how different majors contribute to future paths in life as their primary struggle in choosing an academic major with a nearly half split between currently declared and undeclared students. All eight interview participants identified this struggle as "believable" and resonating with their own experiences. For the majority, there was a concern about finding a graduate program or career path that 
aligned with the chosen academic major. This left students in a position of uncertainty as to the importance of a specific major and how that major contributed to achievement of goals and outcomes. Deficits in information compounded this challenge by lowering self-efficacy and leaving students struggling to determine how to right an academic path that feels off course. In considering this concept through the Social Cognitive Career Theory framework (Lent, Brown \& Hackett, 1994, 2000, 2002), decision-making is hindered when goals and outcomes are unable to be considered. The left side of the SCCT model (see Figure 1) posits the need for learning experiences to assist in shaping a person's ability to make connections between specific experiences and goals and outcomes. However, for low-income students, often lacking the social and cultural capital necessary to engage in pivotal learning experiences, the ability to make connections between academic majors and long-term plans is stunted, efficacy suffers, outcome expectations fail to develop and, in the SCCT context, progress on the right side of the model (interest, goals, and actions) is limited.

\section{Relevant Context}

The parallels in the college choice and major choice processes provide useful context and understanding for the specific influences on academic decision-making presented in the forthcoming assertions. Deficits in information and a wavering sense of self-efficacy emerged as a common theme throughout both processes. Understanding these themes provided foundational explanation as to why low-income students were searching for ways, often within the college environment, to close gaps and gain necessary insight in decision-making. While this parallel in processes was not an intended finding, it offers useful insight into the supports, barriers, and influences experienced by low-income students. However, because this study did not 
specifically focus on the college choice process, further research is recommended before

evolving into a study assertion.

\section{Study Findings}

To address the stated research questions and in alignment with Erickson's (1986)

methods of analytic induction and presentation of findings, five assertions are offered with supporting data.

Table 10

Summary of assertions.

\section{Assertions}

Assertion 1: External to the college context, low-income students identified specific individuals and significant events as influences on their initial choice of major. However, once entering college, students faced unexpected barriers and challenges that prompted a difficult change and impacted self-efficacy in decision-making.

Assertion 2: Within the college environment, low-income students with humanities interest (declared as a major or otherwise), relied minimally on faculty/advisor relationships and received significant guidance from upper class peers when selecting an academic major.

Assertion 3: When a student established a connection between a humanities major and a personal interest or hobby, he or she felt greater self-efficacy in declaring the major and persisting through completion.

Assertion 4: Presence of institutional financial support allowed low-income students to feel they can take greater risks in choosing a major. This often resulted in following passion rather than assumed financial outcomes when making academic decisions.

Assertion 5: Low-income students, with interest in or declaring humanities disciplines as majors, felt most satisfied and confident in major choice when part of a small, personal academic community. The ability to find and maintain this community was a driving factor in major choice and often present in humanities disciplines.

Assertion 1: External to the college context, low-income students identified specific individuals and significant events as influences on their initial choice of major. However, once entering college, students faced unexpected barriers and challenges that prompted a difficult change and impacted self-efficacy in decision-making. 


\section{Pre-College Influences from Family \& Significant Events}

Overwhelmingly, survey participants identified immediate family and pre-college educators as highly influential in academic decision-making and choice of initial major. Of 180 respondents, 164 (91 percent) selected parents, grandparents, siblings, and close family as influential, while 146 (81 percent) selected high school teachers and counselors as making a primary impact. The influences of these individuals, often in the context of a meaningful or traumatic life event, were also evident with the interview cohort. While students were quick to identify individuals and experiences specific to their initial decision-making, the consistent inclusion of these individuals and experiences in the academic timeline activity and as support resources when responding to analytic vignettes provided additional support. Moreover, Bronfenbrenner's (1979; 1993) ecological systems theory identifies a nested framework of five environments, which directly and indirectly influences how an individual perceives and interacts within the world and across various contexts. The two systems in closest proximity to the student, the microsystem and mesosystem, hold the greatest influence and are where immediate family and important educators typically reside. This placement within the proximal environments reinforces the importance these individuals and related experiences have on the decision-making of students.

Consistent with survey findings, initial choice of major was influenced by a mix of family and educational experiences for students across the interview cohort. Samesh and Stacey, who both experienced traumatic medical emergencies with grandparents, chose neuroscience and a double major in biology and chemistry, respectively, as paths toward medical careers. Despite coming to college as a classics major after doing well in high school Latin, Ethan found initial 
interest in education after his same-aged stepsister was forced to drop out of high school and care for younger siblings. He described his struggles with the situation,

It was crazy. We are like three months apart and everyone, like my dad and step-mom, just decided that she needed to leave high school. Like dropout. We were in $9^{\text {th }}$ grade. I mean, we went to different schools because we live with different parents but, you know, same grade. I knew they were talking about it and I said it was stupid. I just couldn't believe, like, you know, it really happened. I got to stay and finish school and now I'm here. She works at [grocery store]. It's just crazy....it's made me want to study dropout or like how to help students like her but I wasn't sure how to do that in college, ya know. I didn't want to be an actual teacher. I wanted to study it like research, I guess.

After concerns from family and teachers that she was depressed, Annie's mom took her to see a therapist. After a battery of tests, it was recommended that Annie pursue architecture as a major and despite "not having any idea what architecture even was, it sounded like a good idea...a way to be creative." This recommendation also propelled Annie's mother and grandmother into a campaign of support for architecture, despite having no additional information, which included preventing Annie from considering colleges without an architecture major. For Chloe, the influence of her parent's background in law enforcement, coupled with influential experiences with her Spanish teachers while homeschooled, peaked her interest in foreign affairs, Spanish, and law. For some students, it was also family support and reinforcement of talents that lead to initial decision-making. From a young age, Amelia's parents encouraged her to "do anything [she] wanted with her life and to follow [her] passions" and she reported never feeling pressure to do otherwise. While his immediate family did not attend college, David's aunts, both highly successful MAU alumnae, prompted not only his desire to attend college but to major in mathematics. He noted,

My aunts have said that they had to buy me advanced counting toys when I was a baby because I just always loved numbers. Like I would just master them so quick. I did well in math in school. They sent me to math camps in the summer growing up. Like, I actually came to MAU a couple times for it. I spent a lot of time in my aunt's courtroom as a kid, she is a judge - I wasn't in trouble or anything - just learning and stuff. I 
thought about law school from just being around there but math is what I've always been real good at.

For these students, having experiences that provided some initial academic direction and the support and encouragement of family offered a sense of confidence and strengthened selfefficacy in attending college and choosing a major. This confidence often allowed them to feel "ready for college" and "successful" when thinking about an academic major. Interviewed students shared that they felt they had something to focus on when looking for colleges and family members regularly reinforced their pride in future plans. As Samesh shared,

My grandma has been so excited that I wanted to be a doctor. Not just a doctor but a heart doctor, a cardiologist. My grandpa had a heart attack and she has heart problems. Like real bad. She always told her friends that I was gonna be a doctor.

While most students' personal experiences have seemingly encouraged an initial interest in a particular major, Mateo's childhood prompted his focus on developing a specific outcome; personal wealth. After writing a separate note in his survey responses indicating his childhood commitment to business, the following interview conversation depicts his decision-making.

Mateo: So, I've known since I was 10 years old that I wanted to be a businessman. Interviewer: Really? What happened at 10 years old? Tell me more.

Mateo: You know how I told you that my parents came here from [South America] and things were really hard at first? Like, my dad was a janitor at [chain restaurant] and my mom did, umm, I don't know what to call it. Maybe like skilled labor. You know like flip flops? She worked putting little decorations on them. Like this. (Mateo grabs a pen and quickly draws a flip flop with a flower on the strap.)

Interviewer: Okay, right. I remember. You said you all moved here when you were five years old. What happened when you were 10 ?

Mateo: Well, we moved into a neighborhood that was kinda in the middle. (Mateo puts his hands up in a parallel shape to represent two sides of his community.) Like, there was a beach on one side and a beach on the other but we weren't really near the beach at all, if that makes sense. All the rich people lived at the beach. The doctors and lawyers. I went to school with those kids because it was the best private school around. My parents thought private school meant you were being successful. I don't know if that's true. Anyway. (Mateo rolls his eyes.) The rich kids started being my friends. You know, you kinda start getting friends around that age. They invited me to the beach and stuff. 
Interviewer: Oh wow. So, those might have been some of your first experiences with other families. Families who may look or live differently than yours?

Mateo: Exactly. Of course, they wanted to come to my house, too. It was the first time I felt, I guess ashamed, of my family. My parents didn't, well still don't, speak much English and I would get so mad at them for speaking Spanish. Oh my God. So mad. I was so embarrassed by them. They would want me to speak Spanish to them at home, like we always do, and I just remember being so angry.

Interviewer: That must have been really hard for you. A lot to navigate at that age.

Mateo: Yeah. I feel bad about it now. I was being a brat. But, I also knew I wanted to be like those people. To have it all. I thought maybe a doctor but I decided on business. For some reason, I thought I could do that.

Interviewer: What does it mean to be a "businessman" at 10 years old?

Mateo: I'm not sure. I'm not even sure now, I guess. But, I knew that business people made money and I wanted to make money. My dad has a business now, like commercial painting, and has worked really hard but I still want to make a lot of money and help them too. I remember seeing commercials on TV for businesses and thinking those people must be doing something right. It sounds kinda crazy now.

Interviewer: And you haven't changed your mind? On business?

Mateo: No. Well, there are a lot of other things I'd probably rather be. I considered medicine right when I got here. That's too much pressure. Ugh. I've hated business classes - I'm sure we will talk more about that - but I had to stick with it. Ya know, goals.

It is through these experiences that the influence of individuals and pivotal moments prior to college are evident and offer necessary direction and confidence. However, it is important to note that these influences are often on the initial academic decision-making or choice of major a student is considering when arriving at college. As described in the next section, students reported challenges with their proposed major path once entering college and were often looking for support and influence from others within the college context. Additionally, the pre-college influences on initial major choice are prompting selection of disciplines with an apparent connection to a specific vocational or pre-professional outcome. For instance, Samesh and Stacey naturally chose pre-medicine fields on a path to becoming doctors. Chloe looked for prelaw concentrations as a starting place for future law school attendance. Amelia selected English in a desire to be a book editor. However, when challenges arose and self-efficacy declined, 
students were not returning to their pre-college influences for support or advice but seeking alternative solutions. Moreover, when navigating these new obstacles in academic decisionmaking, findings indicate students struggled to identify the humanities as viable options, even when enjoying courses, due to inability to align content with vocational or pre-professional interests. Not only does this represent a concern seen across both survey respondents and interview participants, but reflects the divide across humanities faculty regarding whether course offerings should still be advertised as opportunities for exploration, a path toward employment, or both.

\section{Barriers to Declaration of Major}

As most students described entering college "excited" and "confident" in their choice of intended major and encouraged by the support of family members, experiences often took a negative turn once they matriculated. Students entered college with a strong sense of selfefficacy stemming from the support of family members and positive educational experiences. However, once students entered college, they became disconnected from these pre-college influences, faced struggles in the college environment, and experienced declines in self-efficacy. Students overwhelmingly reported running into challenges during the academic decision-making process once at MAU that, for all but one student, led to an ultimate change of plans. Even Amelia, who remained an English major, took classes in other disciplines to "test the waters" and had unpleasant experiences. Moreover, Amelia admitted being hesitant to invest in things that she "doesn't feel she is good at" and English-related courses and activities have persisted as positive experiences throughout her life.

Across the interview cohort, the challenges manifested in different ways. Because, collectively, these students have a history of academic success and attend a highly selective 
institution, most have not considered whether they possess the academic ability to be successful in a desired major. Despite being "pretty good in math and science" in high school, Stacey found herself on academic probation after performing poorly in pre-medicine courses. After being deemed a "child math prodigy" by his aunts and "committing to a math major by middle school," David quickly found himself lost in advanced college math courses and "absolutely shocked" that he would need to find a new major. In developing his academic timeline ${ }^{3}$, David chose to create themes ("always thought math") and, depicted below, he demonstrated his lifelong commitment to math.

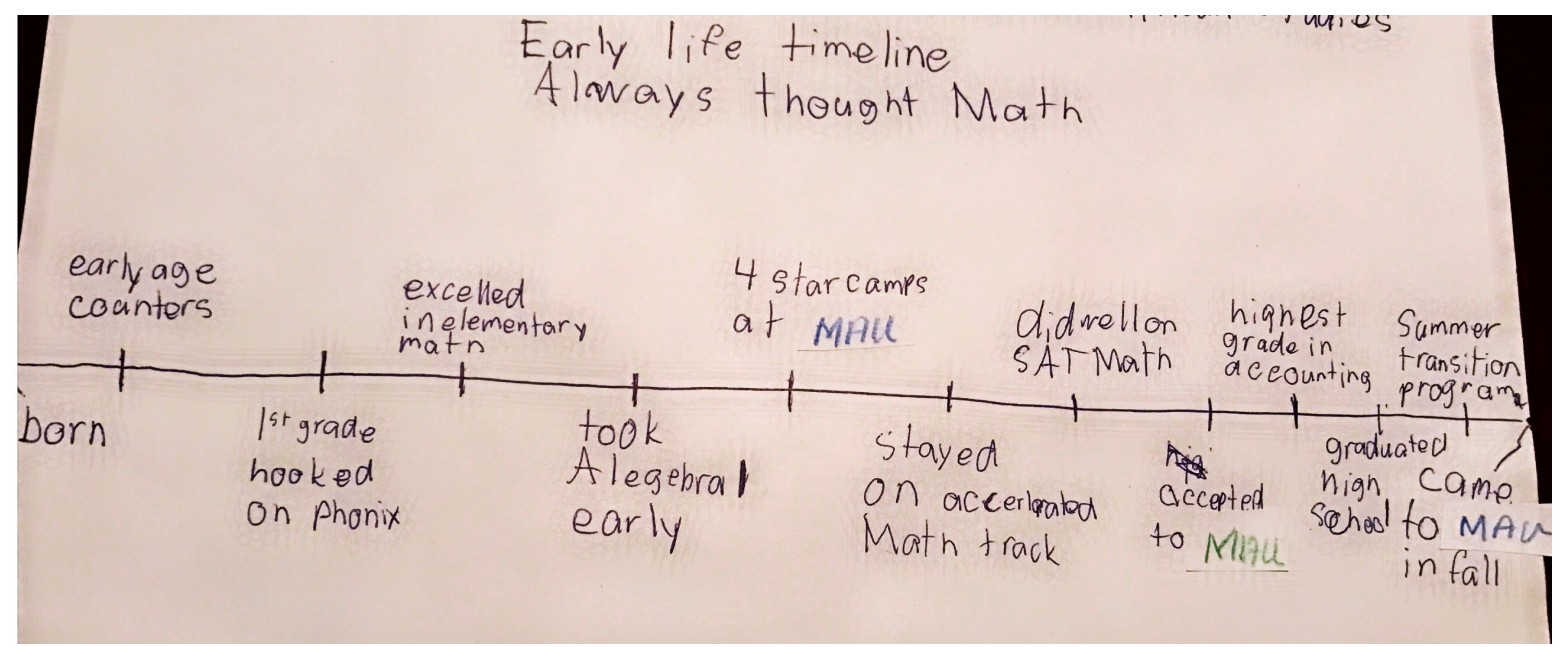

Figure 8. David's timeline depicting his lifelong commitment to math as an academic major.

For other students, like Chloe, a general lack of confidence precluded her ability to declare. As she explained, 'I'm just too nervous. Like, I'm too young to make big decisions like that" and noted that homeschooling did not force her, or prepare her, to make any major academic decisions.

Students also faced information challenges after not researching the academic courses necessary for degree completion and whether proposed academic paths aligned with future goals.

3 With permission of the student, timelines have been slightly edited to disguise the identity of the institution and students. 
Samesh, who struggled in introductory business courses, switched from pre-medicine after discovering,

It was going to take until I'm in my 30s to finish medical school and that's not at all what I want. I wanna get married and have kids and travel and stuff. I can't wait until I'm 30 to start life. I just, I guess I didn't realize it would take that long.

Annie also struggled with goal alignment. After entering MAU as an architecture student, Annie quickly realized she did not have the passion or competitive nature needed to persist. She detailed a phone call to her grandfather, who was not involved or influential in her pre-college decision-making but "knows about real estate," to ask what "architecture is all about" after not feeling connected in the classroom. Mateo's struggles offer an alternative perspective. While he remained committed to his business major and faced some academic difficulties, he often struggled with feelings of unhappiness. He coveted the experiences students were having in other majors, particularly in the humanities, but felt compelled to remain in business to meet his financial goals. This reasoning in decision-making offers compelling insight into the thought processes of low-income students. Through interviews, students described feeling compelled to struggle or suffer through a major of lesser interest in hopes that a benefit or reward, likely financial, would present in the future and appeared to be inherent in their decision-making. However, an argument can be made that this notion of delayed gratification is specific to lowincome students who may be accustomed to a worldview of difficult work coming prior to reward. Moreover, this mindset may be a barrier in decision-making but future research, particularly in comparison to well-resources peers, is needed to further develop this claim.

After beginning college full of confidence regarding their majors, students reported quickly feeling "lost," "defeated," and "stressed" when trouble arose and prompted the need for a new academic path. As presented in subsequent assertions, students were now faced with 
finding the support, direction, and efficacy once provided from family and pre-college experiences in their new college environment. An initial response across students included a refocusing on personal "happiness" and removing emphasis on finances, wealth, or career goals; an act of stepping away from delayed gratification approach just presented. However, students remained lost in how to connect academic majors to goals and outcomes and often relied on "figuring it out later" as a plan. Even for those who were enjoying specific courses through general education requirements, particularly in the humanities, students needed additional support in understanding how these disciplines could be potential major choices.

\section{Figuring Out What It Means to "Help"}

An example of the struggles students faced in connecting academic majors with goals and outcomes, particularly in the humanities, involved the desire to help. When asked about influences on choice of academic majors, 77.6 percent of survey respondents indicated the "ability to help others facing difficulty" as a priority. In comparison, only 60.9 percent indicated having a "lucrative income" and 68 percent identified the ability to "find a job after college" as influential. Moreover, 78.3 percent of respondents indicated "helping others" as an important college outcome; the most important out of 21 options. However, the desire to help is also an example of how low-income students reported struggling with goals, outcomes, and major choice. Many of the pre-college experiences of students in the interview cohort encouraged consideration of helping professions. However, students interpreted that in literal, tangible ways. According to the interview respondents, to help means either needing to find a helping profession, such as medicine, law, or teaching, or pursuing a career "where you can make a lot of money," such as business. Through financial security, students saw an opportunity to help by providing for struggling family members or through charitable contributions. Indeed, 72.7 
percent of students in the survey listed both helping others and having a lucrative income as a priority, so they did not see the two as mutually exclusive. When difficulties began in those prerequisite courses, students struggled to find alternative majors, which may not have obvious linkages to outcomes, for consideration. Moreover, because students could not identify a new major and efficacy suffered, the focus shifted to joining student organizations to fill this gap. Stacey became involved in a leadership program for underprivileged youth, David volunteered as an elementary school tutor, Mateo and Ethan became heavily involved in volunteer break trips, and Annie began meeting regularly with her assigned "little sister" for mentoring. For Ethan and Annie, these experiences as shaped major choice and career plans. Through a volunteer trip, Ethan learned about the social services center at which he now volunteers and plans to work after graduation and this experience solidified his decision to pursue economics and interdisciplinary social sciences majors. Similarly, Annie's mentoring relationship, alongside working with children in her part-time job, fostered her desire to pursue a graduate degree toward offering music therapy for struggling youth.

For most students, particularly those in humanities fields, the desire to help is through acts of service. Moreover, there is not a pervasive sense of needing to help family, specifically, but the community in general. The only disconfirming evidence of desiring to help came from Amelia, who described her position as the youngest child as precluding her from the obligation of helping her family or others. According to Amelia,

I have two sisters who are much older than I am. One is married. They have jobs and are established. If my parents need something, they are going to ask my older sisters before they ask me. Don't get me wrong, I'd help them if they need it but I don't feel any pressure. Maybe my sisters do, I don't know.

Additionally, Mateo and Samesh both indicated a desire to financially support family in addition to acts of community service. However, both attributed this to cultural obligations and an 
immigrant upbringing. These emerging findings regarding helping through finances versus service and impacts of variables such as birth order, cultural obligations, and immigration need further evaluation.

\section{Intersecting Decisions with Development}

While each student in the interview cohort chose a different path and experienced unique challenges, his or her difficulties in being resilient and inabilities to make connections between interest, majors, goals, and outcomes were evident as a consistent issue. As these low-income students entered college seemingly confident and prepared to make efficacious decisions, challenges reportedly altered progress, lessened efficacy, and prompted new approaches. Interviewed students identified this as a "low point" in the college experience and beginning not long after arriving on campus. The current experiences of younger students, Samesh and Chloe, closely aligned with the experiences of older students when asked to reflect upon challenges in decision-making. Resulting was a decline in the confidence established prior to college as students encountered barriers in their new college environment. Students are then forced to quickly devise a new life path while also navigating a new environment, often without the capital needed to succeed. These barriers in decision-making are examples of significant developmental shifts similar to those found in self determination theories in the higher education literature.

Baxter-Magolda's Theory of Self-Authorship $(2001,2008)$ offers a useful framework for considering student declines in efficacy as "crossroads" in the college experience followed by a need to reinvent, or self-author, a life plan that is different from originally intended. BaxterMagolda (2001) defines self-authorship as "the internal capacity to define one's beliefs, identity, and social relations" (p. 269). In order to seek self-authorship, a student must explore values, make sense and meaning of information gained about the world, determine a path for one's life, 
and then set out to take steps along this path. In doing so, Baxter-Magolda $(2001,2008)$ offers three driving questions to shape early thinking and decision-making:

- How do I know?

- Who am I?

- How do I want to construct relationships with others?

Also within this process, students are believed to shift from being externally identified and defined by others to being internally motivated by personal values, beliefs and desires. BaxterMagolda (2001) posits four phases through which students progress toward achieving self authorship:

- Phase 1: Following Formulas

- Allowing others to define who you are;

- Phase 2: Crossroads

- Feelings that a current life plan is no longer feasible and new plans need to be established;

- Phase 3: Becoming the Author of One's Life:

- Creating the ability to choose own beliefs and stand up for them;

- Phase 4: Internal Foundation:

- Finding grounding in a personal belief system, establishing a sense of self, and being a mutual partner in relationships (Evans et al., 2010).

As academic decision-making is a process over time, it is assumed to be shaped by both occurrences external to and within the college environment. Baxter-Magolda's (2001) theory provides a developmental context for considering changes within a temporal dimension, identifying influences both prior to and during college on values and beliefs, and how students navigate obstacles prompting shifts in life plans and building a foundation for success. The choices students made in overcoming issues and working toward self-authorship are presented in subsequent assertions.

In addition to self-authorship, findings from Assertion 1 are evocative of psychosocial student development. Through use of seven tasks, known as vectors, Chickering's (1969) Theory of Psychosocial Development presents a series of developmental milestones students are 
expected to progress through while in the college environment (Chickering \& Reisser, 1993).

Arranged as a sequence, but not as a hierarchical model, Chickering's theory posits fluidity across developmental tasks, with no two individuals working through the vectors in the same ways or at the same pace. While a student may work through more than one vector concurrently, each vector is the central focus at any given time. Moreover, the vectors are heavily influenced by institutional context, an important consideration when applying to both students and research. Chickering (1969) offered the following developmental tasks as vectors:

- developing competence,

- managing emotions,

- moving through autonomy toward interdependence,

- developing mature interpersonal relationships,

- establishing identity,

- developing purpose, and

- developing integrity.

Through considering Chickering's developmental vectors, the barriers presented in Assertion 1 force students to question their competence and struggle to manage emotions while facing declines in self-efficacy. However, as presented in subsequent assertions, low-income students seek support through interpersonal relationships with older students who offer capital and information that allow for the establishment of a personal identity through decision-making. These successful decisions allow students to foster a sense of purpose in helping others and identifying future goals and outcomes. By remaining cognizant of the parallel experiences students are having in decision-making and identity and psychosocial development, useful context is offered in understanding the findings of this study as well as the low-income student experience.

Assertion 2: Within the college environment, low-income students with humanities interest (declared as a major or otherwise), relied minimally on faculty/advisor relationships and received significant guidance from upper class peers when selecting an academic major. 
While the college environment offers myriad opportunities and experiences for students to develop academically, two strong themes emerged in both survey responses and the interview setting regarding academic decision-making. First, students did not have strong relationships with faculty or advisors and did not look to them as a primary resource in academic decisionmaking. This was particularly true for students in non-humanities fields. Second, upper class peers (i.e., college juniors and seniors), particularly those met through student organizations, provided influential advice and support in the academic decision-making process. These upper class students became a primary resource for removing barriers and considering long-term goals and outcomes while bolstering self-efficacy for their younger peers. As described below, students considering or having declared a business major specifically desired relationships with upper class peers in their major but, when compared to humanities students, struggled in developing those connections.

\section{Relationships with Faculty}

Throughout higher education literature, relationships with faculty are commonly reported as having positive impacts on belonging, completion, and overall student success (Kuh et al., 2007). Moreover, extant research identifies low-income students as commonly struggling with establishing and sustaining relationships with faculty and university officials despite the benefits (Chambliss \&Takacs, 2014; Kuh et al., 2007). This foundational knowledge was supported by survey data, as seen in Table 11, indicating student interaction with faculty was minimal or nonexistent in many circumstances. Moreover, those indicating more frequent faculty engagement were upper class students with declared majors, reinforcing the notion that faculty were missing during the academic decision-making process which occurs in the first two years for low-income students. Additionally, a majority of new students indicated discussing career 
plans "sometimes" and this may be reflective of required meetings with advisors early in the first semester.

Table 11

Reported frequency, by percentage and number, of student engagement with faculty across various situations and settings.

\begin{tabular}{lllll}
\hline & Never & Sometimes & Often & $\begin{array}{l}\text { Very } \\
\text { Often }\end{array}$ \\
\hline $\begin{array}{l}\text { Discussed your academic } \\
\text { performance with a faculty } \\
\text { member (n=180) }\end{array}$ & $26.1(47)$ & $48.3(87)$ & $16.1(29)$ & $9.5(17)$ \\
$\begin{array}{l}\text { Talked about career plans } \\
\text { with a faculty member (n=180) }\end{array}$ & $16.7(30)$ & $52.8(95)$ & $19.4(35)$ & $11.1(20)$ \\
$\begin{array}{l}\text { Worked with a faculty member on } \\
\text { activities other than coursework } \\
\text { (committees, student groups, etc.) } \\
\text { (n=180) }\end{array}$ & $49.5(89)$ & $29.4(53)$ & $12.8(23)$ & $8.3(15)$ \\
$\begin{array}{l}\text { Worked with a faculty member } \\
\text { on a research project (n=177) }\end{array}$ & $68.9(122)$ & $16.9(30)$ & $5.1(9)$ & $9.1(16)$ \\
$\begin{array}{l}\text { Discussed course topics, ideas, or } \\
\text { concepts with a faculty member } \\
\text { outside of class (n=180) }\end{array}$ & $28.3(51)$ & $39.5(71)$ & $22.2(40)$ & $10.0(18)$ \\
\hline
\end{tabular}

These emerging themes prompted closer examination of important university relationships throughout the interview process. As students were presented challenging situations through analytic vignettes during interview one, a common theme emerged indicating that faculty "could be" or "should be" a helpful resource but that they were not a primary resource often recommended or utilized. During interview two, when students created timelines of their academic decision-making, the faculty was boldly absent. This theme of absent faculty persisted while asking students about important influences and experiences in their own educational journey. For most, the initial advising experience was obligatory and with a randomly assigned faculty member with whom the students felt no connection. According to Samesh, who had recently experienced this as a first-year student, ...there is no connection with the advisor. It's like a 15-minute thing you have to go to. They don't know anything about what you want to do and you really aren't important to them because you aren't in their program. Like, the lady I talked to was in astronomy or 
something. So, you just exchange smiles and talk a little and then they send you somewhere else. They told me to talk to the business program but I've never gone.

Upon finding herself on academic probation, Stacey was required to meet with an advisor. Describing the meeting as a "punishment" and being told by the faculty advisor that she "needed to figure out a new plan for her life because [she] wasn't going to be a doctor," she left the meeting with little information. After not knowing how to navigate these barriers to her goals, she decided to enroll randomly in general education courses that seemed interesting and felt her overall experiences were positive. David described his experiences with race and culture studies faculty as being "more engaging" than other courses and that his advisor was "helpful" when he decided to declare his major. However, despite these experiences, he indicated being more likely to seek other resources, such as his older fraternity brothers or peers in his RCS courses, when making decisions or needing assistance. David also noted that his summer bridge experience, meant to offer meaningful connections with faculty, provided him with little long-term support. Ethan offered an interesting juxtaposition when considering his faculty through the lens of his double major. While he considered his economics professors to be "wickedly smart," the large class sizes made meaningful relationships "impossible." However, in his interdisciplinary social sciences major, the small class sizes allowed him to be on a first name basis with faculty who he described as "kind and attentive." Yet, he still identified upper class peers as a primary influence on decision-making. Classroom experiences such as Ethan's become an important consideration in Assertion 5. Amelia acknowledged having pleasant conversations with an advisor in English who encouraged her exploration of multiple disciplines but the relationship remained "all business."

While students were not recognizing faculty as important resources in academic-decision making, there was a common notion that humanities faculty are more supportive of students than 
those in other disciplines. Stacey noted that her experiences in general education courses gave her an impression that humanities faculty are "more genuinely caring about students" than faculty from other disciplines but she still has not established lasting relationships. Mateo shared multiple experiences where he hoped to establish relationships with business faculty and was met with negativity. However, he reflected fondly upon his general education experiences in humanities courses, particularly Mandarin Chinese, where the faculty seemed "warm, approachable, and caring." Samesh echoed this experience in his short time at MAU. He considered his business faculty to be "self-centered" while humanities faculty attempted to learn his name and acknowledged him in the classroom. Similarly, Annie described the music faculty as "creating a community or family" that she is excited to be a part of as her career progressed. While humanities faculty indirectly assisted students in feeling welcome, competent, and as though they matter in the classroom, they remained a distant choice for seeking decision-making guidance. Students reported feelings of apathy toward faculty engagement after poor early experiences with advisors, fruitless attempts to attend office hours, and facing negativity when seeking assistance with academic struggles that left them seeking support elsewhere. While the perceptions of and relationships with humanities faculty, in particular, need further investigation, the positive classroom experiences they fostered did appear to encourage a new outlook on faculty by students but did not go as far as claiming these individuals to be primary resources in decision-making.

Chloe's unique experiences with faculty provided a noteworthy exception. As she was homeschooled from $4^{\text {th }}-12^{\text {th }}$ grade, her education included individual relationships with adults as her instructors. She spoke warmly about "walking down the street for chemistry lessons with a family friend" and how excited she would be to meet her online instructors at annual 
homeschool conventions. Because Chloe long relied on these relationships, she quickly sought out faculty and administrators at the university to fill this void. She scheduled regular meetings with administrators in the MAU multicultural affairs office, where she discussed her academic and social experiences, and enjoyed visiting office hours to meet with faculty. However, because Chloe is the only known homeschooled student in the interview cohort or survey sample, further research is needed to determine if this is a pervasive trend across students with similar educational backgrounds or unique to Chloe's circumstances.

\section{Relationships with Upper Class Peers}

For both survey respondents and interview participants, upper class peers (i.e., college juniors and seniors) often provided the information and support likely expected from university faculty. Upon entering the university, these upper class peers emerged as influential components of the younger student's new college community. Moreover, upper class peers bridged a gap between the initial major interests, subsequent struggles, and future planning of new students, which, evident through interviews, provided the confidence and efficacy needed to make decisions. Not only did upper class peers provide the practical advice, or capital, needed to navigate university life but encouraged students to consider their strengths, weaknesses, longterm goals, and outcomes. Moreover, upper class peers were credited with providing the emotional support needed to take next steps in academic decision-making.

For most students, upper class peer relationships were established early in the academic career and, often, through student organization involvement. During his first weekend on campus, Ethan stopped a group of men to ask for directions and, instead, was steered to a meeting of a campus Christian organization rather than his destination. Given his involvement with a church youth group in high school, he quickly established meaningful relationships with 
upper class group leaders who became his confidants. When Ethan could not find a major to meet his interest in education and felt conflicted about classics or business, it was his small group leader who helped research options online and prompted an overhaul of his planned course load to better align with his goals. Similarly, Stacey identified her closest friends on campus as those from her Christian small group where she regularly processed academic decisions with her group leader. When challenged by a peer for picking a "pointless humanities degree," it was Stacey's group leader who defended her choice. This reaffirmed her decision and "established pride" in her new path. For Annie and Amelia, living in a four-year residential learning community provided opportunities to connect with upper class students and establish mentoring relationships. After dissatisfaction in architecture, it was her acceptance into a campus music organization that connected Annie with like-minded upper class students and propelled her decision to return to music as her major. Even Chloe, who valued faculty relationships, noted the upper class students she met through student organizations and her swim team to be people she "trusts and looks to for guidance." David's experience in particular depicted the significant power in the peer experience. The following vignette, as described by David when sharing his timeline activity, detailed the support he found in a fraternity brother:

It had been a long and difficult second year. David was struggling in his advanced math courses and final exams had not gone well. Recently, he received another email reminder about declaring his major. There was no way he could declare mathematics and his attempts at computer science were not going well either. He wondered if MAU could kick him out for not declaring his major? He didn't know what to do and, now, he had the responsibility of a campus leadership position to weigh as well. Sitting on the couch of his fraternity house, an older brother stopped in and asked how things were going. James, a well-respected brother and student-athlete, was preparing for graduation and starting graduate school at MAU in a few weeks. After reluctantly explaining his struggles, James quickly sat down and offered to help. He asked David, "What was it that you really loved about math? Why did you want that major?" David replied, "Well, it's what I've always been good at. Everyone told me I was good at math." "Okay," James offered, "it seems like you are having some struggles with math but it's not a reason to give up. Let's think about what else you might be good at. You seem to like 
your race and culture studies classes, right? You've taken a bunch of those for Gen Ed, and the information seems to help you in your frat leadership role. Have you thought about that?" David, who was surprised by the notion of race and culture studies, offered, "I do like those classes. They are a lot of writing and reading but I can get better at writing and the reading is pretty easy because it's so interesting. Plus, the teachers are all nice and supportive. Do you think I could maybe do computer science and race and culture studies together?" After sitting for a moment to collect his thoughts, James replied, "how about this. You sit down tonight and look at the online course plans for RCS and CS and make a list of the classes you've taken. Then, tomorrow, let's get some food on Order Up and we will sit down and map out a plan for you. Not just getting you declared but what you need to do to graduate. Right now, you are struggling too much and your grades are bad. We've gotta get you turned around. You can't miss the GPA requirement for the frat either." David replied, "yeah, bro, I can do that. All the other brothers are doing engineering and stuff and I'm just so lost." He thanked James and agreed to his offer. He immediately felt better about navigating this situation. The next day, James followed up on his promise and helped David develop a plan for declaring his major, meeting with his faculty advisor, and plotting out his courses for the remainder of college. They agreed that CS would add too much strain to his struggling GPA and likely cause him to need an extra semester at MAU. James remains a confidant and source of support for David and is currently assisting him with his impending job search.

Supporting the importance of upper class peers were the contrasting experiences of Mateo and Samesh who, despite having humanities interest, pursued business. During his first year, Mateo overcame struggles by forging a relationship with an upper class student leader who helped him get established in a campus organization. However, he lamented his inability to connect with upper class students in his major and identified this as a downfall in his college career. Similar for Samesh, early in his academic career, his friend group comprised same-aged peers and he longed for connections to older students who could answer questions, calm his fears about major declaration and, most importantly, assist in developing a new path should he not be admitted into the business program.

Despite upper class peers being new influences in the daily lives of these students, their collective credibility as individuals who have successfully navigated college and could understand the struggles of academic decision-making allowed them to quickly become tremendous resources. Moreover, upper class peers may often be more readily available and less 
intimidating than faculty, which, for low-income students, made these relationships more appealing. While upper class peers were not professionally trained as academic advisors and there was no way of ensuring consistency or accuracy of information, students reported these relationships as providing them not only with guidance but the reassurance to confidently follow a particular path toward emerging goals and make academic decisions with efficacy.

Assertion 3: When a student established a connection between a humanities major and a personal interest or hobby, he or she felt greater self-efficacy in declaring the major and persisting in it.

Of the eight students in the interview cohort, only Amelia did not changed majors, despite some initial exploration. Amelia entered MAU as a highly interested humanities student, based upon academic and extracurricular experiences from middle and high school, only explored courses within the humanities, and remained an English major. Amelia's academic timeline ${ }^{4}$, presented on the proceeding pages, creatively depicts her classroom commitment to English alongside her participation in English-related hobbies.

${ }^{4}$ Given the formatting needs of these figures, the title for Figure 9. Amelia's timeline depicting the influence of English and English-related hobbies and experiences shaping academic decisionmaking, is presented here rather than at the bottom of subsequent pages. 


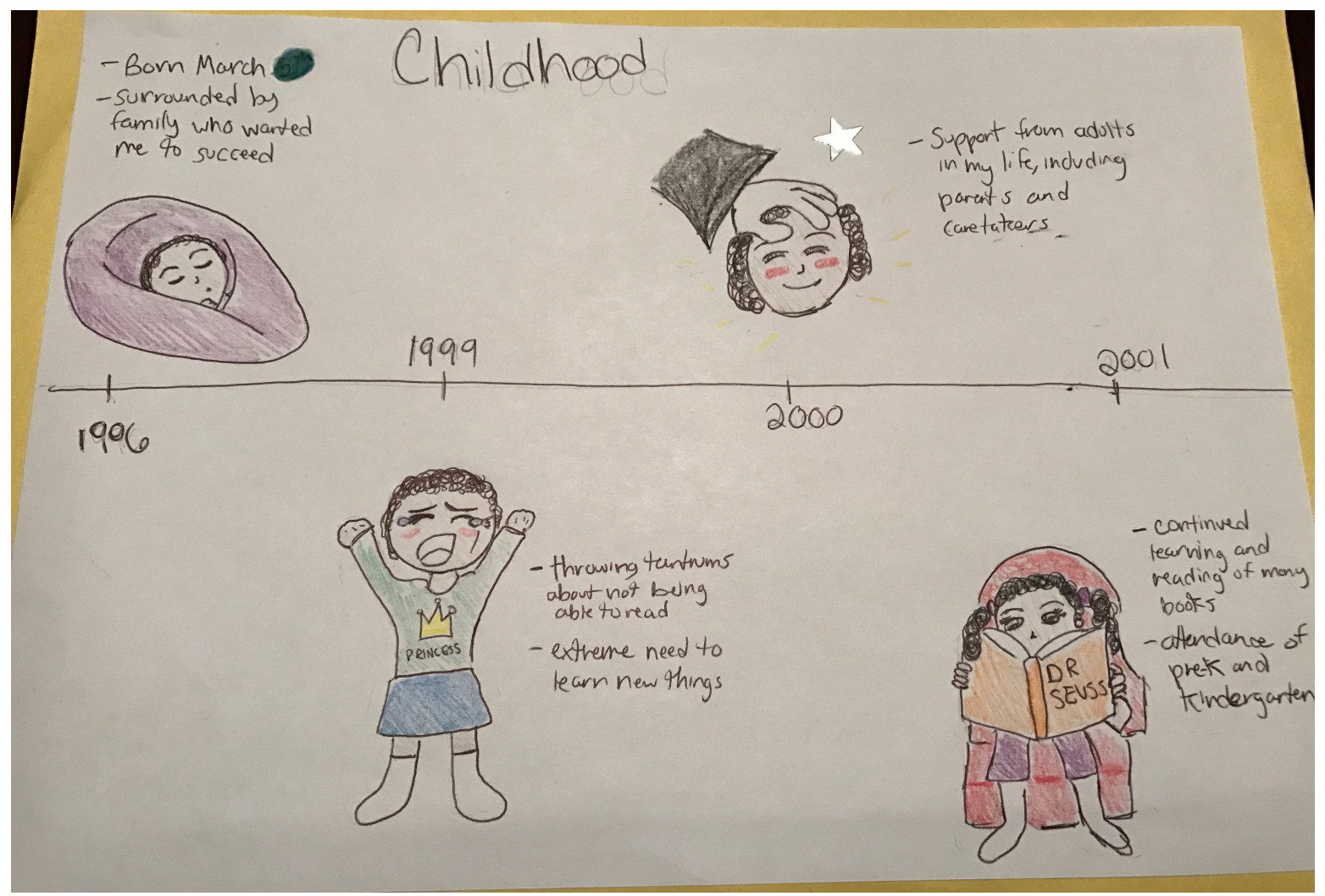

1. Desire to read at early age, support from family, Pre-K focus on developing reading skills

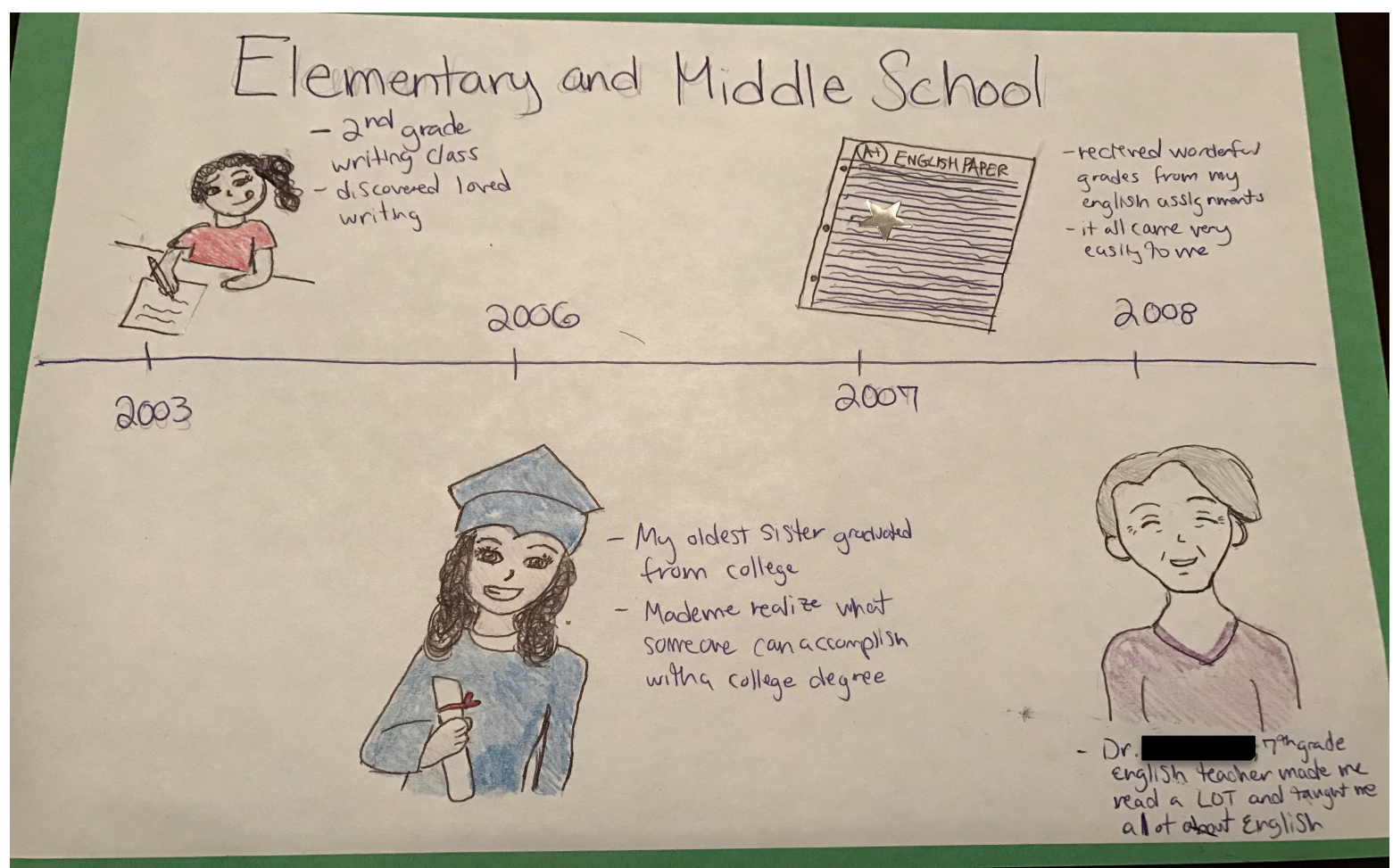

2. $2^{\text {nd }}$ grade writing class fostered interest in English, received awards and high grades in English, positive encouragement from teachers, sister graduated college 


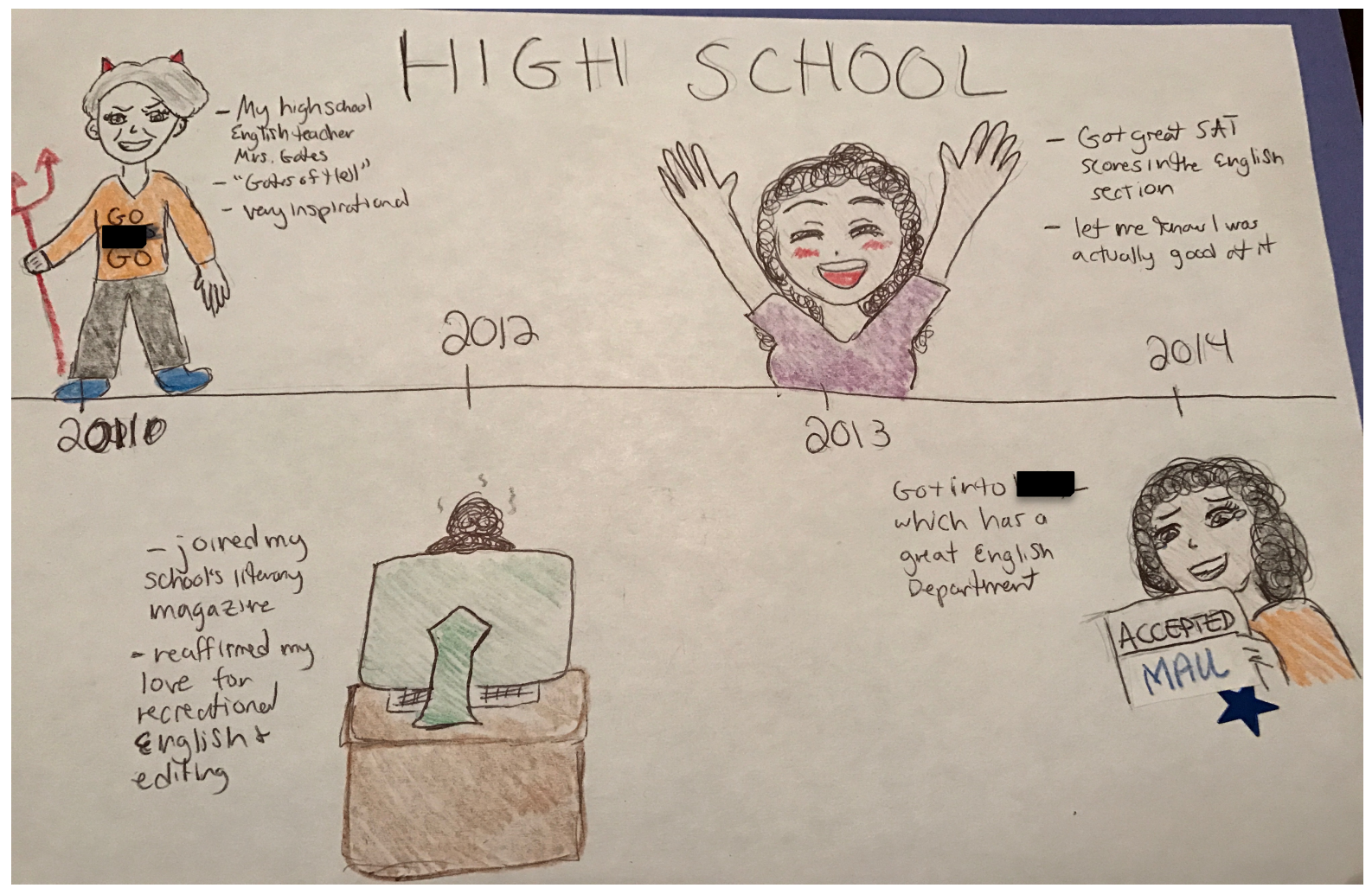

3. Inspirational high school teacher, great verbal SAT scores, joined literary magazine, yearbook, English-related clubs, accepted to MAU

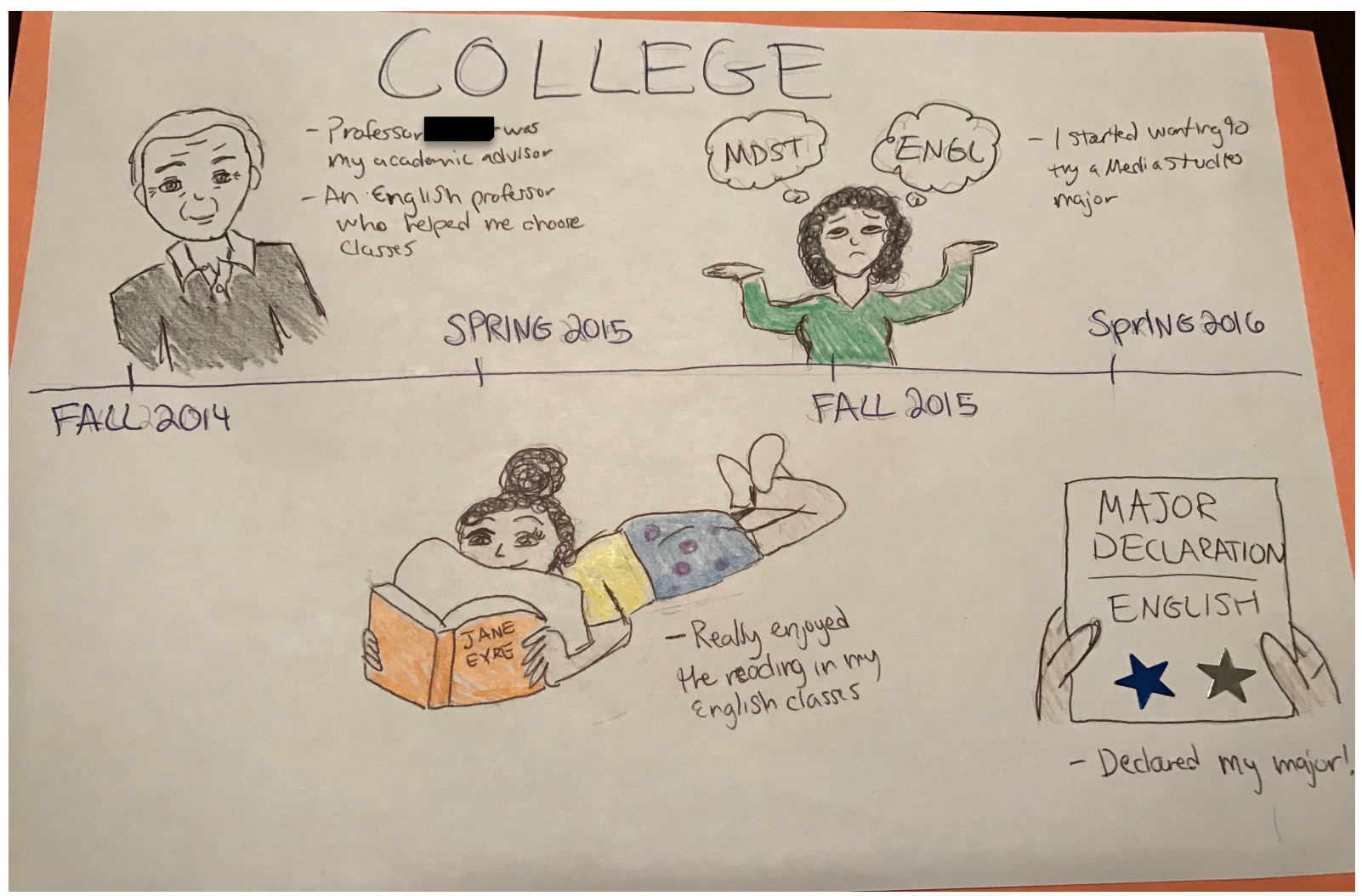

4. Found MAU English faculty engaging, poor experiences exploring other majors, enjoys English coursework, feels "at home" 
Additionally, when considering the academic decision-making of the entire cohort upon entering college and the resulting major declarations, the importance of personal interests or hobbies in supporting the major was evident. Often, these interests and hobbies were fostered by pre-college involvement, which according to survey responses, carried over to MAU. All but five students in the survey (97.2 percent) identified being actively involved at MAU, with strong interests in volunteer and service opportunities, leadership and mentoring organizations, academic societies, religious and race-centered clubs, and visual and performing arts. Of the 180 survey respondents, 91.0 percent strongly agreed or agreed with "personal interests or hobbies" being influential on academic major-choice once entering college. This selection surpassed prominent influences such as classroom experiences, family, and belief in personal academic aptitude. For students interested in or having declared humanities majors, connecting a major with an established interest or hobby provided a sense of comfort in the decision and, in turn, reinforced a student's feelings of efficacy and an ability to be successful. This was particularly true once a student faced struggles in navigating an initially intended major and, often with little guidance, returned to a field that felt academically and emotionally satisfying.

After growing up in a family of musicians, continuing in the marching band and joining a women's chorus was a natural fit in college for Amelia. Similarly, her experiences as editor of a high school literary journal and contributions to the student newspaper and yearbook reaffirmed her decision to pursue English. When describing her major choice through her academic timeline, Amelia indicated,

When I was three, I begged my parents to learn how to read. Threw tantrums about it. They always tell stories about it. I didn't want to be read to but I wanted to read on my own. That's where it started...I was always reading and then I had some good teachers who encouraged me, like, in middle school. Then, it was kinda like everything I did was related to English. School newspaper. The [literary journal]. Yearbook. Drama club. My English teacher, and she was kinda my advisor for some stuff too, she went to MAU, 
too...now that I'm in college, I know I can do English. I just get it and it's familiar to me. My engineering friends have trouble writing papers but that's not what they are trained for. I can read books and crank out papers and it feels good and right to me.

Annie found the humanities to provide the creative spark she desired as a child. After beginning music lessons at a young age, she worked multiple summer jobs in high school to buy her own instrument. After "lugging" it to college on a whim and figuring it would "sit in the corner," Annie returned to music as a major after dissatisfaction in architecture. She described her first day in a music classroom as "being at home" and, while understanding the stereotypes concerning employment outcomes for her major, the opportunity to create and be comfortable was more important.

When Stacey's academic struggles left her lost, an accidental enrollment in a gender studies course focused on athletics changed her life plan. A multi-sport athlete in high school, Stacey was in the midst of trying out for two club teams at MAU and working as a student assistant to a varsity team when she "fell in love" with her major. Athletics were what sustained her in high school and considering sports through the lens of gender opened a new world of possibilities. As a minority student at MAU, David enrolled in race and culture studies courses as a first year student to better understand his own race and culture. However, after academic struggles, RCS also offered important context for David's place in a historically black fraternity and as a campus leader for a minority student organization. When her mother began transforming a bedroom in their home into a full-time classroom, Chloe was allowed to select a series of maps to use as teaching tools for the walls. According to Chloe,

I think that's where it all began. I would sit and stare at the maps and think about all the places I wanted to go and what I could learn and the languages other people speak. I just think other cultures and people are so cool. I've never been much of anywhere but I think about it all the time. Just daydreaming. Then, when I actually got to learn languages, it was so great. I loved it. I guess all that, plus my love of watching crime dramas like Law \& Order on TV, just all that together made me want to do these majors. 
Foreign affairs will let me travel and help me get to law school and languages are just really helpful in learning about other people and also when you travel. It's all my favorite stuff. I guess I'm just nervous about making the decision to declare even though I know I love all this.

A small collection of photos from Chloe's academic timeline are presented in Figure 10 to depict the multiple influences on her decision-making and to demonstrate her struggles in narrowing her focus and confidently declaring her major.

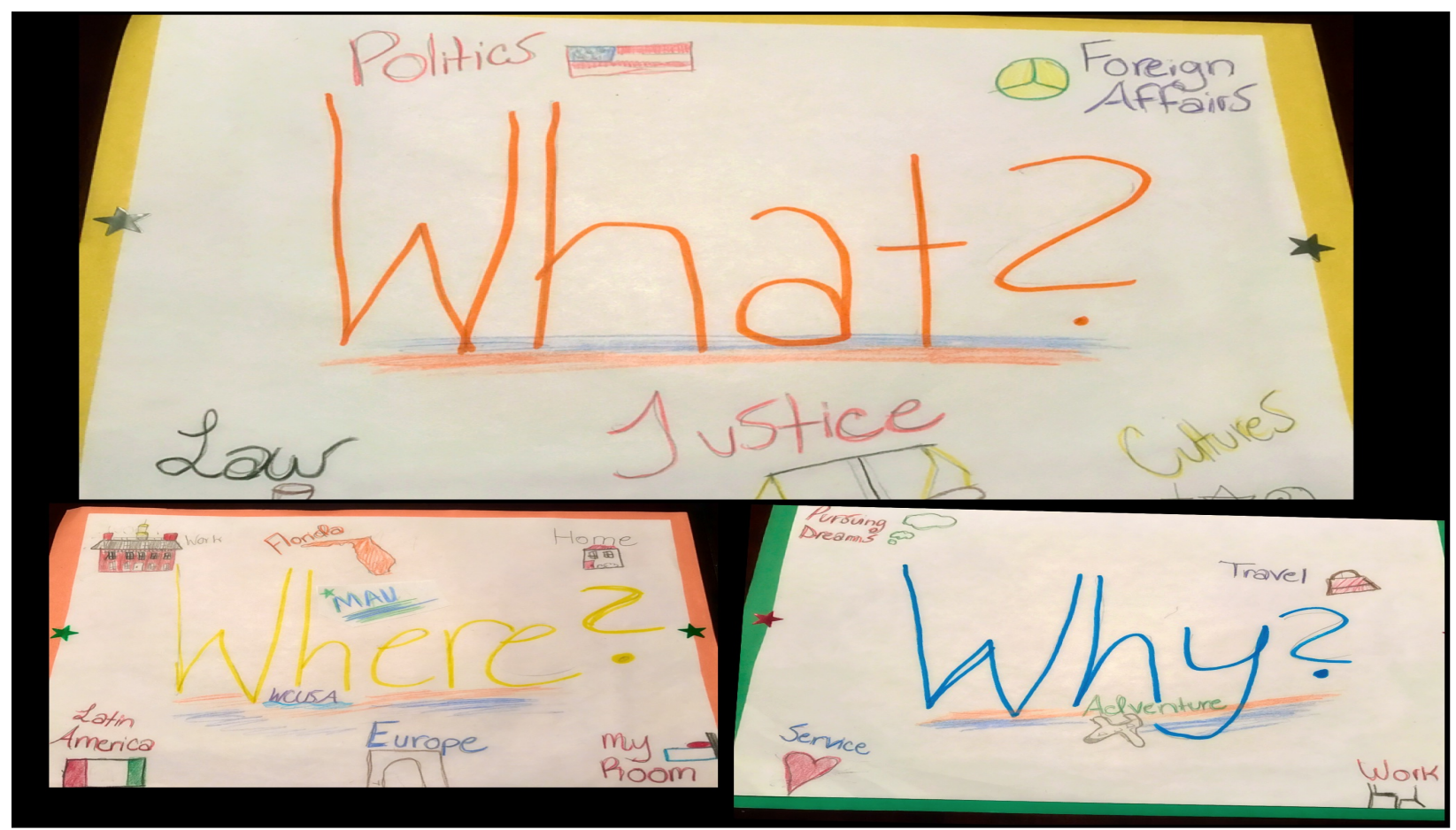

Figure 10. Chloe's timeline depicting her vast interests and struggles in narrowing her choice of academic major.

This assertion is also supported by the contrasting experiences of students who were not pursuing a degree in the humanities. Throughout his interviews, Mateo discussed his academic interests in gender studies and politics and his organizational involvement in activism, dialogues, and serving the low-income student population. While he openly wished he had pursued other majors, particularly gender studies or political thought, he unhappily remained in business for the assumed lucrative outcomes. For Mateo, having financial wealth allows him to pursue his personal interests later rather than using them as a means for future goal obtainment. Similarly, 
Samesh worked diligently to incorporate his creative spirit into the business major encouraged by his parents. Because he could not find a humanities degree that would fit with his art and media interests, he joined multiple arts-based student organizations and obtained employment as a photography and creative arts specialist in a campus library. He remained hopeful that a business degree would provide him with a solid footing for working on the corporate side of a film company in the future. Below, Samesh's academic timeline artistically depicted the influences and struggles he faced both prior to attending and in his short time at MAU, through shifting from medicine to arts to business, and how hobbies and personal interests played a significant role.

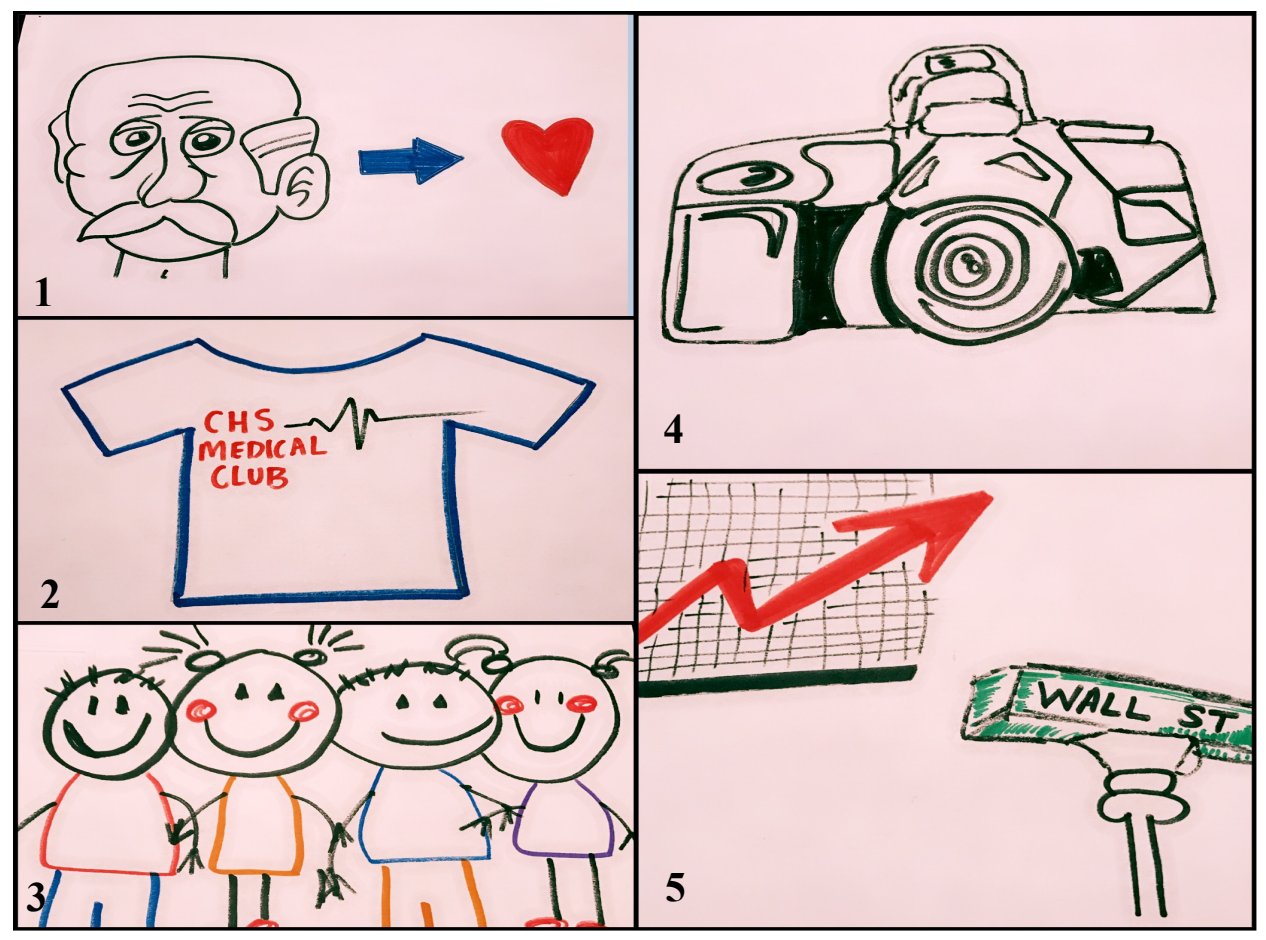

1. Grandfather's heart attack encouraged interest in cardiology

2. Samesh established a medical club at his high school to get hands on experience in preparation for medical school.

3. Samesh volunteered at a local children's hospital, shifting his interest into other areas of medicine.

4. Samesh purchased a camera on a whim and this fostered his passion for photography and art, yet, he still felt obligated to pursue medicine.

5. After realizing medicine was not a fit with academic abilities and life goals, and his parents did not fully support art, business became a reluctant choice.

Figure 11. Samesh's timeline influences in academic decision-making and his shift from premedicine to business, despite greater interest in humanities. 
Ethan's experiences presented a delicate balance in that his declared majors fell into social sciences designations but both, along with his selected general education courses, were heavily influenced by the humanities. In addition to pre-college family experiences, Ethan's service trips through his Christian campus organization and volunteer work with underrepresented children have guided not only his major choice but also long term goals in nonprofit education.

By pursuing majors that connect with preexisting interests or hobbies, humanities students appeared to have a strengthened sense of confidence in the classroom. This confidence was often a welcome change for these students who, at the time of admission, were considering majors related to a vocation or pre-professional track with little information. Moreover, it was in these initial majors where academic struggles began for some students. When pursuing an interest or hobby, students reported feeling the ability to be efficacious decision-makers and, because of greater familiarity with topics, were more inclined to explore future career options. Moreover, when explaining to family the desire to change from a traditionally vocation-focused major to the humanities, having pre-existing success in an interest or hobby appeared to ease concerns. As described by Stacey,

Yeah, my mom was kinda like, 'um, what?' when I told her about gender studies. It's hard to explain and my dad didn't think I could get a job. But, when I told them about how it connected to sports and about the Title IX stuff and the people I'm meeting at my internship, it helped. They know how much I love sports. My cousin is on a field hockey scholarship. I guess it made it seem more realistic and they like that I'm happy.

For these low-income students, who already faced additional challenges in the college environment, finding a major that aligned with interests and hobbies allowed academics to become a more enjoyable part of the college experience. It should not be misconstrued that these students did not think about long-term financial outcomes but, collectively, humanities students 
believed that, while economic stability was important, overall happiness should be central in decision-making. Moreover, alignment with pre-existing interests and hobbies was helpful. By choosing, or in many instances returning to, a familiar hobby or interest, students overcame the notion that an enjoyable personal interest could not be a career path or worthy of study, and appeared to gain self-efficacy needed for success.

Assertion 4: Presence of institutional financial support allowed low-income students to feel they can take greater risks in choosing a major. This often resulted in following passion rather than assumed financial outcomes when making academic decisions.

To be considered for this study, students were required to meet the university definition of low-income, which falls in alignment with the federal definition of having a family income of at least 200 percent below the poverty line. In 2016 , this was defined as $\$ 48,600$ for a family of four (U.S. Department of Health \& Human Services, 2016). This meant that most students would be receiving some level of federal and institutional aid as well as relying upon scholarships and loans for college attendance. It was also assumed that a student's low-income status and aid would play a role within his or her life and college experiences. However, themes emerged in both survey responses and interview data that lead to greater consideration of distal influences shaping students experiences; where policy, economic, and societal influences often reside. The rising cost of college attendance alongside soaring student loan debt and lessening federal aid is commonly debated in higher education. These variables play a significant role in a low-income student's ability to attend college and, if able, which institution. However, little research examines how financial aid availability and policies may impact the choice of academic major and, in particular, for low-income students. Findings in this study indicate that a particular aid model used by MAU plays a significantly important role in the academic decision-making process. However, due to the unexpected nature of this finding, further comparison research is 
needed across multiple sites and aid models to better understand a breadth of low-income students experiences and improve generalizability.

Unlike most universities, MAU's financial aid program guarantees low-income students provision of 100 percent of need toward attendance through a number of revenue sources. For students with significant need, like those in this study, this provides a nearly free education at a highly selective, top-ranked public university. As described by Ethan, who had accepted admission to a private university when receiving his financial aid package from MAU, "it's really an opportunity you can't pass up.” During interviews, all students disclosed receipt of significant funding and noted that any additional costs of attendance incurred, such as offcampus housing, transportation, or personal expenses, would be the responsibility of the student to repay after graduation. David is the only participant who reported steady family financial support, primarily for books and personal needs, which comes from his aunts. Annie and Chloe hold part-time positions with campus recreation while David and Samesh both work in campus libraries. Amelia, Chloe, and Annie all sought opportunities to remain in more affordable campus housing for the entirety of college. However, these students also noted that having the pressure of loan repayment removed from college allowed for opportunities to have a more traditional college experience. Amelia could devote nights and weekends to the marching band, Samesh remained involved in a competitive dance team, and Stacey accepted an unpaid internship with campus athletics. David saved money to join his fraternity while Ethan and Mateo served on alternative break trips nearly every semester. As out of state students, Mateo and Samesh afforded to travel home more often as well.

The impact of the financial aid program on the academic decision-making of the interview cohort is noteworthy. Students described having the "freedom" to consider their own 
goals and interests when thinking about major choice and not being "obligated to do what [my]

parents think I should do." Moreover, students felt "less stressed" about having significant loan debt to repay immediately after college and this allowed for consideration of graduate school or internship opportunities after completing the undergraduate degree. As Chloe explained,

My mom loves medicine. She is so interested in the how the human body works and she watches all those weird TV shows about medicine and surgeries and stuff. She has always wanted me to be a doctor. To kinda live through me. She always says, 'but you are so good at science' but I don't really like science... Because I have this special financial aid, I'm not relying on my parents to pay for college and they've made it very clear that I have to pay back any other loans I take out. Okay, so, it makes it easier to tell her I am doing what I want to do. I mean, they think law school and learning Spanish is great and my dad just wants me to be self-sufficient and happy. 'Get a good job, Chloe!' But, and not that I think I'd ever do this but, if things got bad, I can just say, 'well, you aren't paying for my college and I can do what I want.'

Through her music background and experiences as a water safety instructor, Annie landed an exciting post-graduation internship with Disney. However, this internship offered minimal pay and no health insurance. Because she is not saddled with loan debt, Annie felt she could not only pursue music but also afford to take this internship and then consider graduate school. She plans to pursue a psychology graduate degree and offer music therapy for children in the future in an attempt to combine her passion for helping others with music performance. Annie indicated, Long-term financial stability is really important but these post-graduation opportunities are also important and not having to begin crazy high [loan] payments as soon as I walk across the stage makes a difference. It makes me less nervous and it makes my mom and grandma less nervous, too.

Ethan echoed these sentiments. Given his sister was forced to drop out of high school, Ethan expressed a sense of guilt in the opportunity he was given to attend MAU. His dad remained vocal about Ethan's need to pursue a lucrative career but the idea of pursuing business just "left a pit in [his] stomach." After talking with upper class peers who have completed accounting 
courses, he knew that he needed to follow his passion to serve underrepresented communities.

According to Ethan,

I'm not clueless. I know non-profit work is never going to make me rich. I see the people who work at [volunteer agency]. My mom doesn't really like to acknowledge that kids living so close to her at [volunteer agency] have nothing - like not even a grocery store. My dad just wants me to make a lot of money. But, they aren't paying for my education. I want to take this fellowship at [volunteer agency] after college. I want to explore my religion. I don't want to be poor, who does? But not having debt is like really allowing me to do the things I want after college and I hadn't really realized that until lately. Like, the after college impact.

After the difficult realization that becoming a doctor was likely not in her undergraduate plans,

Stacey spent a year exploring options through general education courses. Not only has the

financial aid provided efficacy in academic decision-making but also in the relationship with her

family. She explained,

I'm probably going to want to go to graduate school. Maybe for something with gender studies or something to expand my options with athletics. I don't know, I'm not good about thinking in the future. But, MAU financial aid has been a blessing. Oh my gosh. It's not put any extra pressure on my parents. My sister is at [state university] and she has loans and my parents are paying tons of money every month. She is going to have so much to pay back and I'm not. Sometimes I feel a little guilty but it's gonna let me be able to go to graduate school sooner. If I need to take some loans then, I can do it and not feel as overwhelmed.

As previously indicated, Mateo believed business to be his best option for accumulating quick wealth while expanding his ability to live in a large, metropolitan city. Moreover, he believes his parents do have some pride in him for securing such a large financial aid package, despite not attending an Ivy League institution, and this will allow him to achieve his goals more quickly. Complicating Samesh's decision-making were the cultural beliefs of his family. He explained, My parents are Indian and very traditional. They believe that the only real things you should study are medicine, engineering, business. Maybe law. Things that get you jobs. I think they would be okay if I did the creative stuff I love but also have a business degree. Especially my dad. Like a back up plan. They can't tell their friends I'm just doing art.... They don't like that I'm so far away and they didn't know anything about MAU but they like all the money I'm getting. They have to think about my brother and 
my sister and my grandma. She still lives with us....So, I'm kinda trying to make up a major and make it work here since I'm getting so much money. I have a friend here who is out of state and I can't even believe how much debt he is in already. We just got here. It's crazy.

While students were never directly asked about financial aid until the end of the final interview, the regularity at which the influence of the financial aid program arose throughout the interviews became an important finding. By removing the seeming obligation to please parents as bill payers and the guilt of adding financial burden to the family, students reported a greater ability to explore majors and follow areas of interest. Through the card sort activity, students acknowledged understanding the economic climate and the stereotypes often associated with humanities job placement but also believed this information to be skewed and unreliable. When provided with a list of possible barriers in the major choice process, only 22 of 180 survey respondents, or 12 percent, selected "financial resources" as a barrier and none of the students listed this as the only barrier. This was a surprising finding given the study population and lends support to the notion that MAU's comprehensive financial aid model may be removing traditional barriers. MAU leveled the playing field by removing the barriers of post-graduation loan debt, inability to consider graduate education, and pressures to pursue majors deemed "lucrative," even when data may prove otherwise. Unexpectedly, the pressures of being a lowincome student shifted further from the student's daily experiences, the economic climate is lessened as a threat in decision-making, and student's gained the efficacy needed to move forward from early college barriers impacting choice of major.

In revisiting Bronfenbrenner's $(1979,1993)$ ecological systems model, this finding highlights a number of important interactions that were supported through survey data, interview findings, and the card sort activity. First, status as a low-income student, which heavily influences the microsystem, is shifted to a more distal system within the student's college 
awareness as MAU's comprehensive aid package alleviates burdens unexpectedly. Second, influences in the chronosystem surrounding the post-recession economic climate and federal financial aid are countered by MAU's aid program in the exosystem which, again, alleviates burdens and allows students to make efficacious decisions alongside well-resourced peers. The presence of MAU's aid program in the center ring of Bronfenbrenner's model provides a unique barrier for external influences outside the control of the student (e.g., economic and political climate) to influence the identity and interactions of the student in the mesosystem and microsystem. Third, negative rhetoric from media sources and policy makers, found distally in the chronosystem, have minimal direct impact on student opinions of humanities majors but do play a significant role in the opinions of parents, who traditionally influence the microsystem and mesosystem. Students identified, particularly through the card sort activity, their parents' opinions as potentially influencing their major decisions prior to college. However, MAU's comprehensive aid program offers more autonomy for students in decision-making, which, as reported by study participants, resulted in a shift during college from parents residing in the most proximal systems of influence to those most distal in the context of major choice.

Assertion 5: Low-income students, with interest in or declaring humanities disciplines as majors, felt most satisfied and confident in major choice when part of a small, personal academic community. The ability to find and maintain this community was a driving factor in major choice and often present in humanities disciplines.

When asked to reflect upon his experiences as a business student as he approached graduation, Mateo commented on his disappointment in the lack of community and elitist attitude of faculty. In his opinion, friends in other majors, particularly humanities, appeared to have more enjoyable classroom experiences and were academically challenged in different ways. As presented in Assertion 1, Mateo reflected fondly on his humanities general education courses, particularly the feeling of inclusion he found in the classroom, and was disappointed to not find 
this experience in business courses. Similarly, Samesh expressed concern about his ability to get to know faculty and peers in the business classroom. While his small circle of friends all planned to apply to the business major, Samesh described his introductory class as "pretty miserable" and simply being an avenue for "the professor to force you to buy an expensive book he wrote." This is contrasted with his enjoyment of being employed with the library creative media team where he learned from staff in a small group setting. He noted,

The director guy has already taught me so much. Like I already know how to work the high-powered cameras already. It's almost like he's my friend. It's awesome...I just started and I am already getting some projects of my own.

The academic experiences of Samesh and Mateo are in stark contrast to those considering or majoring in humanities disciplines. Across interviews, students consistently reported either having positive experiences in small classroom environments or being in situations where negative experiences in large classrooms prompted a desire for a more personal academic experience. Students described the opportunity to engage both with challenging materials and invested peers as being pivotal in choice of academic major. Moreover, the small, supportive classroom environment, often found in the humanities, encouraged students to be less concerned about future outcomes and to be more present in daily academic experiences. It is the ability to find academic classrooms that foster peer connections and intellectual discussion while removing feelings of being "lost in a sea of faces" that provided students with the efficacy to declare a humanities major with confidence. As reported earlier, opportunities to engage intellectually while developing communication skills was an important outcome for survey respondents and appeared to be fostered for low-income students in small academic communities. Amelia shared,

I tried a couple other classes in other majors just to make sure English was right and it just wasn't as good of an experience. I love that I can walk into an [English] classroom and see both new and familiar faces. Everyone comes prepared and we have real, intellectual conversation. Like we sit in a circle and just feed off each other. I also like 
that it's not monotonous. I can take writing classes. Lit classes. These random classes about certain periods of history or authors. I took some classes about medieval literature that were awesome because of the people in the room.

In reflecting on her academic journey, Annie shared similar experiences,

The people in architecture were really cool. Creative people, ya know. Over there, they start all the new students kinda like in a group and you do projects together. You kinda live in the study rooms because there is so much work. I liked that atmosphere but it was also really competitive and I didn't like that. It seemed supportive but it wasn't, I guess... Once I got into [music organization] and remembered what it was like to have people who also loved music around me, I knew I needed to take a class. It was a perfect fit. We sit and listen to the original pieces other students have created. It's really supportive. The people are so cool. I love working with other students on projects and it feels like everyone wants you to do well... Of course, people ask me what I'm gonna do with a music degree and I'm still figuring that out. But, I like knowing I have people to help me. I'm not the best musician but I like trying.

Additionally, students reported finding greater challenges overcoming academic difficulty when

in larger classes and without a supportive community. Stacey reflected upon her experience,

I really couldn't believe how poorly I was doing. I had done well in math and science in high school but it was terrible. My bio and calc classes had so many students and they all seemed to be getting it. I don't know. I tried to talk to the TA and get help but I just kept doing worse. Like, even when I tried another teacher....It's been different in gender studies. I don't think I'm a great writer but I get feedback. I couldn't figure out how to do an assignment once and my teacher helped me. It's just different... I've seen it in other humanities classes, too, like my German class.

For David, the close-knit humanities classroom also provided greater opportunities to see growth and connect with curriculum and to gain some of the cultural capital necessary for navigating college,

I was going to be a math major and I'm terrible at writing. Like, so bad. My aunts told me that I came home in first grade and said I couldn't learn how to read. They ordered me that 'hooked on phonics' tape, you remember that? I was worried about keeping up in RCS. Because it's small, you get to know your classmates and kinda even the teachers. They give you notes on your papers - like feedback - and you can improve. The reading was easier because I really thought it was interesting - like I could connect it to my own life - and I had people in my classes to talk to. In math, I couldn't ever figure out how to get help. I tried office hours and stuff but nothing ever worked. Not too long ago, my advisor even told me my writing had improved. Never expected that. 
Ethan's experiences having majors in large and small academic communities offered support to this assertion. While he found his economics courses to be an ideal way to study poverty, he also noted that there is only so much you can do "with 400 other people in class with you."

Conversely, Ethan spoke warmly about the support he received from his interdisciplinary social sciences cohort and how he felt more connected with the course content. He noted, "I really like all the group work and just getting to brainstorm with my classmates and knowing those people are there for me every time I walk in the door." While Ethan's small major was not considered a humanities discipline for this study, his experiences were reflective of the size and composition of many humanities courses at MAU and, as mentioned, Ethan believed his coursework to be heavily influenced by the humanities. The small, supportive communities found in the humanities have allowed Chloe to overcome some of her nervousness and to get to know her peers rather than being intimidated by them. She described her peers as "so smart" and "so prepared." Because political science and foreign affairs are popular and exciting majors for new students at MAU, Chloe's prerequisite courses were much larger than she expected. Chloe attributed some of her initial worries to the transition from homeschool to mainstream style education and acknowledged that small classes allowed her to create study groups and individual relationships to bridge that gap.

Overwhelmingly, the positive, supportive classroom environments students reported, often experienced through general education requirements, led to their return to the humanities during the major declaration process. For those who entered with a humanities interest, the experiences reaffirmed initial decisions. For those who struggled in other majors, the switch to humanities provided a sense of comfort and confidence needed for major declaration and persistence. These small supportive environments foster development of the capital many low- 
income students lack when entering college and remove barriers of missing information, academic difficulty, and low confidence in classroom performance. In many ways, students appeared to need conditions that allowed them to take control over their surroundings and create a close network of support and relationships to make progress in academic decision-making. By having this control over their academic experience, students reportedly gained the self-efficacy needed to not only declare but feel confident in a major through completion. In considering these experiences through the SCCT model, small, supportive academic communities provide necessary learning experiences for low-income students that foster the development of outcome expectations and clear a path of understanding in how choice of major relates to goals, interests, and actions. Moreover, it is within these positive learning environments where students gain a sense of confidence, and efficacy, through positive faculty and peer relationships and rewarding intellectual engagement. These experiences, often in humanities classrooms in the context of this study's findings, send a message to students that they matter, belong, and are welcome in the classroom and in the academic discipline. This finding is evocative of Schlossberg's (1989) Theory on Mattering and Marginality which considers how feelings of acceptance shape actions. When a person experiences a significant transition, such as entering college, he or she may develop feelings of being marginal that can lead to deficits in efficacy and competence. In order to overcome these feelings, Schlossberg (1989) posits that individuals must identify ways to feel as though they matter to someone else (e.g., institutional leaders, faculty, peers) within the college environment. This is often accomplished through dimensions of mattering that include:

- establishing feelings of being noticed (attention),

- believing that one is noticed (importance),

- believing someone else is proud of you (ego-extension),

- feeling needed (dependence), and

- feeling appreciated by others (appreciation) (Schlossberg, 1989). 
In the context of this study, when students feel recognized, supported, appreciated, and needed in the college environment, as they indicate finding in small academic communities through the humanities, they are able to establish feelings of mattering, or belonging, that lead to improved academic and social outcomes. By having these positive experiences in humanitiesbased academic communities, not only are students becoming efficacious decision-makers, they are fostering a greater sense of belonging with the institution and, as the college impact literature supports, are more likely to persist through college (Astin, 1993; Pascarella \& Terenzini, 2005). Extant research, particularly regarding college impact models, identifies the establishment of a sense of belonging to be among the most important milestones a student must have to be successful in college (Astin, 1993; Pascarella \& Terenzini, 2005).

\section{Summary of Findings}

Regardless of pre-conceived interest or declaration of major, study participants overwhelmingly identified the humanities as playing a crucial role in the undergraduate student experience. Moreover, participants believe the humanities provide useful, transferable skills that contributed to critical thinking, communication skills, and development of well-rounded citizens. These sentiments were especially true with interview participants as they considered major choice from a multitude of perspectives. Participants identified being familiar with targeted attacks on the humanities by the media and lawmakers, particularly regarding long-term job and financial outcomes, but collectively agreed that supporting cuts or elimination of humanities degree programs would do more harm than good. A common theme throughout interviews was the notion of happiness. For the majority of students, majoring in a field that created personal happiness and satisfaction was more important than significant wealth. Students discussed being "independent" and "self-sufficient" but not needing to be "extravagant" and made connections 
with beliefs that humanities careers may pay "a bit" lower than vocational or pre-professional career paths. For Mateo, this manifested in a way different than his peers. He chose a path he believes will result in significant wealth but acknowledged that he is sacrificing his happiness to do so.

Prior to college, experiences with family and education play a highly influential role in the choice of initial academic major. These experiences and individuals gave students direction when considering college options and provided necessary self-efficacy in decision-making. However, after arrival at MAU, students experienced challenges that tested their initial academic plans and confidence. These challenges ranged from academic difficulty to misalignment with personal goals to general feelings of ill preparedness. However, interviewed students did not return to the primary pre-college influence of family members and educators for advice or direction but, rather, sought out resources to build a new community of support at the university. In addition, when considering new options for majors, students struggled with identifying choices that were not blatantly connected to a vocational or pre-professional outcome (i.e., premedicine to doctor) despite having positive classroom experiences. However, this bridge may be gapped, especially when considering humanities disciplines, if students are able to connect a preexisting interest or hobby with a major. Having initial knowledge or prior success with a topic built confidence and decision-making efficacy and seemingly allowed students to visualize a future in this major that, in turn, supported alignment with goals.

Study participants reported reluctance in considering faculty as primary resources in academic decision-making, yet, upper class peers emerged as highly influential. These students, who have a perceived proven record of success and persistence at the university, served as role models who could remove barriers of missing information and provide the necessary capital and 
support allowing a student to feel comfortable in decision-making. It is important to note that these upper class peer relationships were not formally established through the university but, rather, happenstance connections through student organizations or classroom experiences. Similar to the influence of upper class peers, students desired to be in a small, supportive academic community when choosing a major. Students reported gravitating toward experiences where they felt intellectually challenged by peers, received feedback on assignments, and were recognized as an individual rather than one of many. By finding these environments, often through general education experiences, students reported feeling more confident in not only their classroom performance but in efficacious academic decision-making.

Findings from this study indicate that the most important influences are proximal but often because students have made specific choices to surround themselves with conditions they need to feel successful. It is this strong system of support that allowed students to overcome the hurdle of low self-efficacy and progress toward efficacious decision-making and consideration of outcomes. Students do appear to struggle in considering long-term goals and career opportunities but further consideration is needed to determine if that is specific to this population or whether it is a trend of the modern college student. One distal influence, however, that holds dramatic impact is the presence of a significant financial aid package. By removing the barrier of post-college loan debt and the obligation to meet family demands due to financial support, students reported feeling they can choose an academic major that is a best fit for their needs and interests and removes many of the barriers held in their identity as low-income students.

While these findings are not generalizable, when considered collectively they present an opportunity to better understand and positively influence the academic decision-making of lowincome undergraduate students. When low-income students, with interest in or having declared a 
humanities major, are presented with a significant financial aid package, can identify a small, supportive classroom environment in connection with an interest or hobby, and can establish a means of information gathering through upper class peers, they may achieve the self-efficacy needed to choose a major. Though assembling these personal experiences to make meaning and by seeking support to overcome barriers within the college environment, students are also, in the context of Baxter-Magolda (2001, 2008), making developmental strides toward self-authorship in addition to decision-making. Prior to college, students are solidly in phase one of BaxterMagolda's model by allowing others to dictate plans and decisions. However, soon after entering, students find themselves at a "crossroads", or phase two, and needing to reconsider plans, actions, and outcomes - representative of the major choice process in this study. Yet, it is when students can assemble these meaning-making experiences and turn them into the support necessary for efficacious decision-making, they are believed to be moving into phase three and becoming the authors of their own lives. Long term, by identifying the supports to achieve efficacious decision-making, students are more likely to gain academic confidence, desired outcomes, and happiness regardless of public criticism of the field. Additionally, the student gains control of his or her surroundings and can build a continued system of support and capital within the university community. To be clear, it is not essential that all of these variables be present in the case of every student to successfully choose an academic major with confidence or to choose a major in the humanities. Moreover, given the limited size and scope of this study, findings and assertions need to be tested on more diverse low-income populations and against comparison samples. However, findings suggest that when a majority of these conditions are met, students face fewer deficits in self-efficacy, arrive at desired decisions more quickly, and have positive academic experiences. When a student removes one or more of these components, 
as in the case of both Mateo and Samesh, he or she may feel less satisfied or efficacious in academic decisions. 


\section{CHAPTER VI}

\section{DISCUSSION AND IMPLICATIONS}

\section{Introduction}

This mixed methods research study aimed to identify the influences and environments shaping low-income student academic decision-making and, in particular, the experiences of those students with interest in humanities disciplines in an unsettled economic and political climate. Moreover, this study sought to understand the supports and barriers contributing to the academic self-efficacy of low-income students throughout the college major choice process. Employing Social Cognitive Career Theory (Lent, Brown \& Hackett, 1996) and Bronfenbrenner's (1979) ecological systems theory as frameworks, this study was guided by three research questions:

1. What influences low-income undergraduate students to pursue academic majors in humanities disciplines?

2. In what ways are low-income undergraduate students' senses of academic selfefficacy regarding their choice of major shaped through experiences and influences within the college and external environments?

3. What college and external environments or experiences, specifically, shape the major choice process for low-income undergraduate students interested in humanities disciplines?

Findings were based upon a mixed data analysis approach utilizing responses from the phase one quantitative survey and multiple collection methods during the phase two qualitative processes. This included closed and open-ended survey responses, interviews, analytic vignettes, 
and qualitative elicitation techniques including visual timelines and card sorting. Findings were presented, in alignment with Erickson's (1986) model of analytic induction, through charts, tables, figures, quotes, examples, vignettes, and photos in Chapter V. This chapter summarizes study findings while situating specific outcomes within the current literature. Finally, implications for policy, practice, and future research will be offered.

\section{Discussion}

In order to address why students are interested in and choosing majors in the humanities (research question \#1), it is imperative to first consider rises and declines in self-efficacy (research question \#2) and the environments influencing choice (research question \#3). The concepts of environments, efficacy, and major choice became intertwined through findings in such a way that considering each autonomously is nearly impossible.

\section{Rises and Declines in Self-Efficacy}

Social Cognitive Career Theory (SCCT) was chosen as a framework for this study as it has been long applied with success in understanding career decision-making. Given the parallels in career and major choice, use of this model seemed an applicable choice. Moreover, as lowincome students are known to face significant barriers in differing aspects of the college experience, SCCT provided an opportunity to consider self-efficacy in decision-making and, particularly, the supports low-income students may desire in reaching goals and outcomes. Selfefficacy quickly became an important consideration in this study as apparent rises and declines in efficacy emerged across the pre-college and college experiences. As presented in Figure 12 on the next page, the pre-college and early college experiences of low-income students closely reflect the early phases of SCCT. In addition to income status, students have significant pre- 


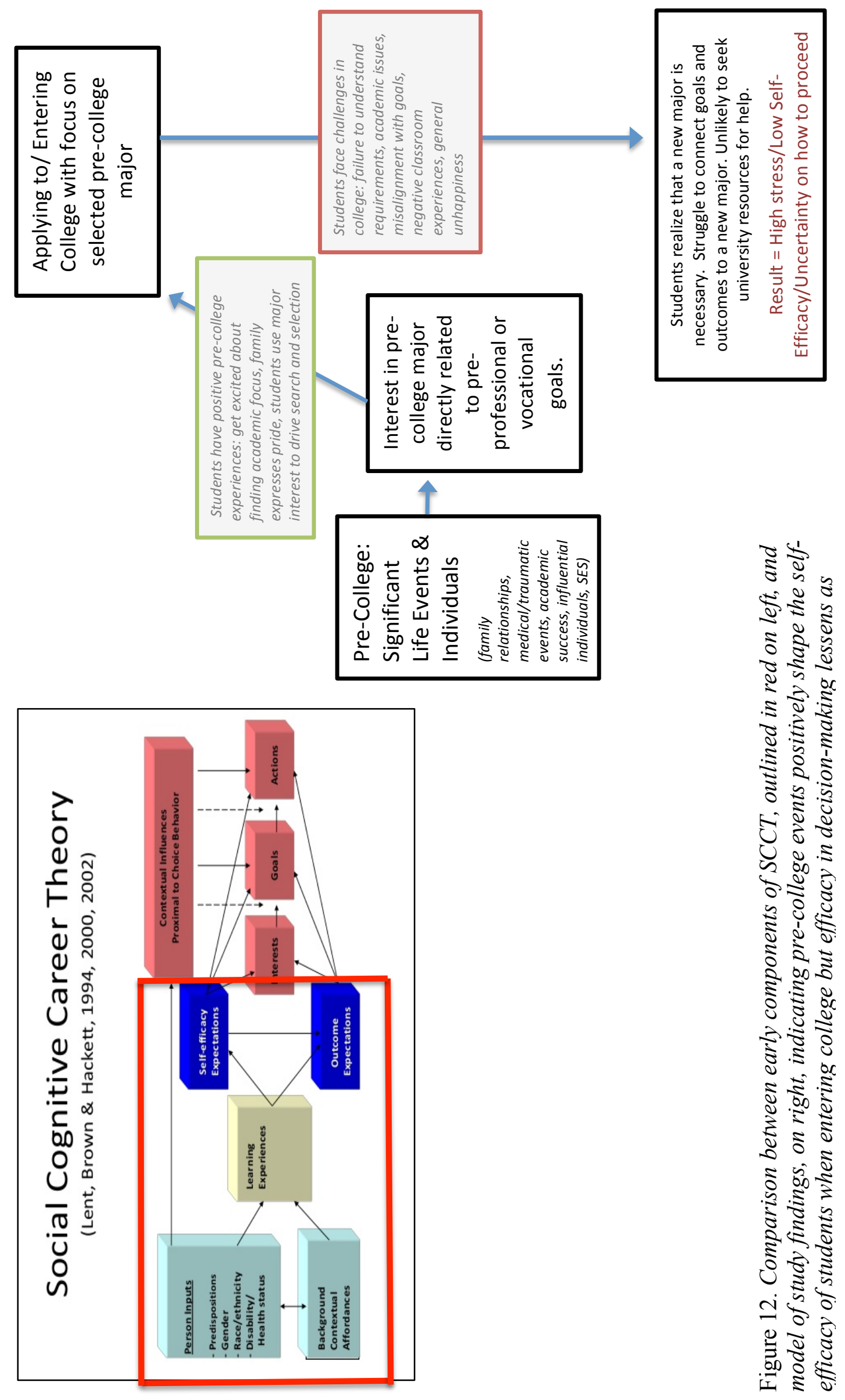


college life events or relationships that shape interest in a particular major. For most students in this study, these experiences encouraged consideration of pre-professional majors, such as medicine, or pursuit of majors where they previously found academic success. Moreover, students did not appear to concern themselves with whether these majors would be enjoyable or, because of a strong high school academic record, whether they possessed the ability to be successful in college-level academics. What appeared to matter, especially after a rocky college choice process, was the support and encouragement from close family and influential educators. This is not an unusual finding given the primary scope of a student's life prior to college, regardless of socioeconomic status, fixates upon immediately family and school. Moreover, extant literature identifies parents as playing an important role in student decision-making in many facets of college. Therefore, as depicted, having an identified major, with support and encouragement from family and educators, boosted the self-efficacy of students and allowed them to enter college eager to begin college coursework in the selected discipline.

Regardless of academic year at the time of interviews, students identified the end of the first semester of college through the end of the second year of college as being turbulent in the context of academic decision-making. Despite entering college with confidence and excitement, barriers quickly presented in the form of academic difficulty, inability to seek assistance, misalignment with personal interests, and, important in the context of SCCT, difficulties in connecting majors with intended goals and outcomes. Surrounded by peers who were not perceived to be having the same struggles, the low-income students in this study floundered and self-efficacy declined. In some instances, students with less academic abilities may choose to depart the institution at this time, however, students in this study remained confident in their desire to persist through completion. Concurrent with this decline in self-efficacy was university 
pressure to declare an academic major and, according to students, with little information or understanding of the process. With efficacy at its lowest point in the college experience for most study participants, each began a somewhat haphazard journey through considering new college majors, often through trial and error, but seemingly found consistent influences within the college environment for support and, in turn, improved efficacy.

\section{Environmental Influences}

Overcoming the declines in self-efficacy faced by study participants was no easy feat and, for most, it was their first experiences in navigating difficulty within an educational setting. In addition to their own concerns, students feared disapproval from the family members who prompted initial feelings of efficacy in decision-making. Through these students' experiences, study findings identified two pre-college and four college environmental influences, presented in Figure 13 on the next page, that improved self-efficacy and, in turn, shaped decision making. For students still considering academic majors or having declared in non-humanities disciplines, typically unhappily, these influences resonated. In examining the second and third research questions, these environmental influences are important considerations not only in guiding major choice but also in redirecting points of low self-efficacy for low-income students.

Pre-College Influences. As presented, an important pre-college influence on initial academic decision-making is the immediate family of students. This influence is not surprising given the traditionally proximal relationship between students and families during high school. Additionally, students reported being influenced by major events involving families, such as an illness or traumatic event, or circumstances related to race, culture, or socioeconomic status. It is through these relationships that students indicate forming an initial major choice, typically in a vocational or pre-professional discipline where outcomes are more apparent, and feeling 


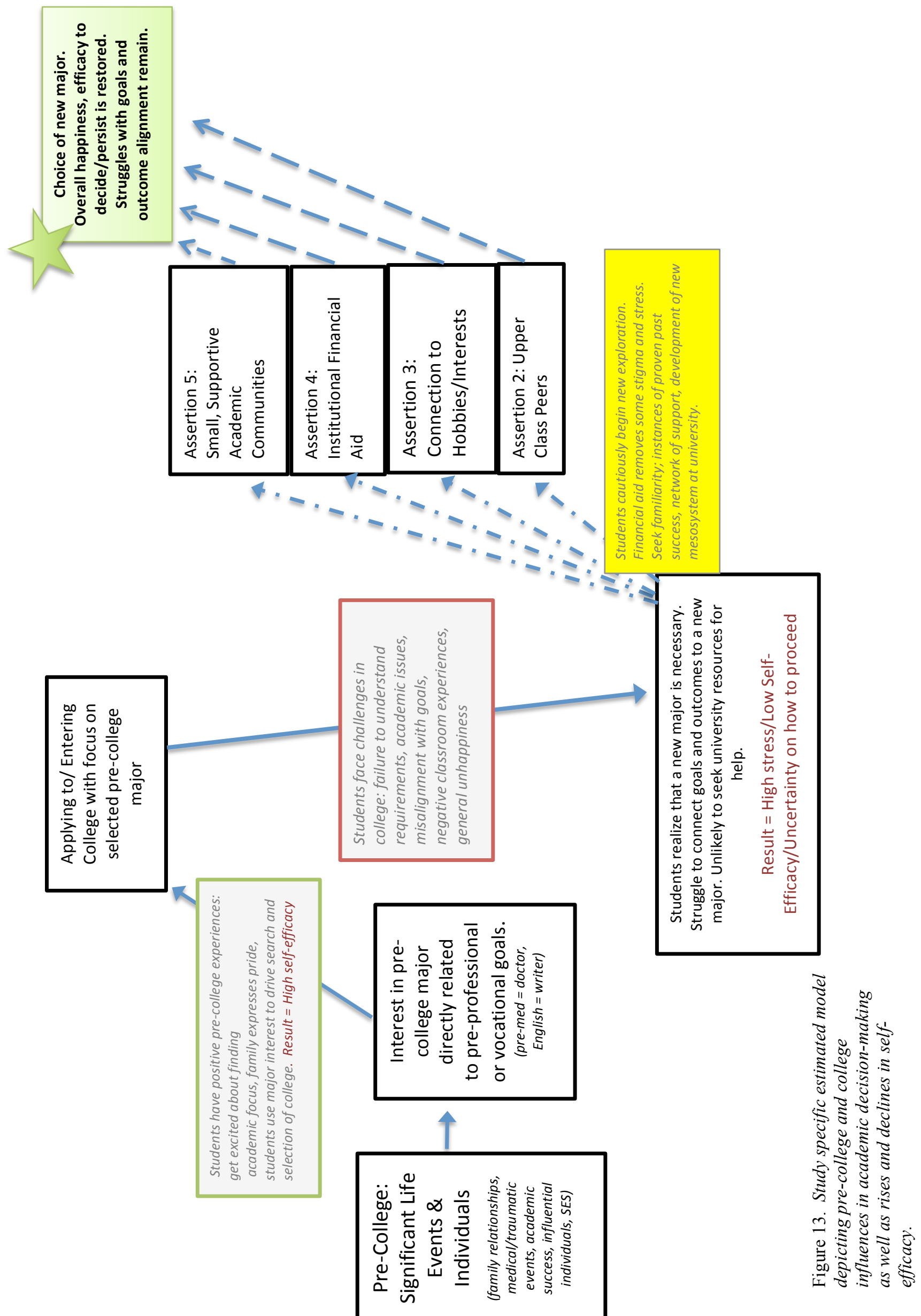


supported and encouraged. These findings are supported by prior research demonstrating the importance of family involvement in a student's education and development of academic aspirations (Hill et al., 2004; Trusty, 1998). Moreover, parental level of education has been correlated with low-income student aspirations (Davis-Kean, 2005, Choy, 2001). Lovelace (2012) found that students as early as the third grade were knowledgeable about college, yet the extent and accuracy of the information was often attributed to parental income and education. While most of the higher education literature tends to measure students' educational aspirations while in high school, Lovelace's (2012) work supports early experiences as being relevant in the formation of experiences that shape college understanding. Given a relatively large portion of student survey respondents identified having at least one parent with a college degree, this may explain a student's aspirations or feelings of pressure to attend a highly selective institution and to consider rigorous majors which are important to his or her family (e.g., medicine, business, law).

Given the academic success demonstrated by study participants, the influence of precollege educational experiences is fathomable. Not only have these experiences pointed students in a particular academic direction, they have fostered a sense of confidence and meaning making. For some students, this has been success in a particular academic subject and continual reinforcement of academic ability and achievement. For others, it has been caring relationships with high school teachers and counselors. Despite still facing deficits when compared to wellresourced peers, it is reportedly these educational experiences and individuals that provided students with an early level of confidence to navigate the college search process and make initial academic decisions. Moreover, similar to family, influential educators provided the necessary support to foster strengthened academic self-efficacy prior to attending college. As noted by 
George-Jackson (2010), students often identified high school teachers and counselors, parents, siblings, and religious leaders as influential in pre-college decision-making. Despite students feeling disconnected from these individuals once entering college and choosing to not seek continued support, the influence of these individuals prior to matriculation should not be diminished. As further discussed in the implications for practice section, improvement is still needed in the pre-college preparation of low-income students, particularly those with the academic prowess displayed by these students, to bridge gaps in decision-making efficacy and provide greater cultural capital for navigating institutional norms and impending barriers after matriculation.

Critical Shifts from Pre-College to College Influences. While the pre-college influences of family and educational experiences serve a vital role in initial academic decision-making, it is what happens with these influences concurrently with declines in efficacy that is important. In considering the study's second framework, Bronfenbrenner's $(1979 ; 1993)$ ecological systems model, family and educational experiences play a primary role in a student's microsystem and mesosystem. Given the proximal nature of these systems, existing nearest to the student, each shapes the ways in which a student views the world and makes decisions. However, it is what happens to these influences once a student enters college that gives pause. Study participants, when at their lowest points of self-efficacy, chose to find new supports within the college environment rather than returning to pre-college influences for support. This shift is in alignment with the concept of informational support often considered in psychology literature on the social support needs of adolescents and young adults. Building upon the four social support identifiers developed by House (1981), Dubow and Ullman (1989), Furman and Buhrmester (1985), and Malecki and Demaray (2003) all identified parents and high school educators as 
being primary providers of information or advice needed to make decisions and understand experiences. While students in this study identified having this informational support from parents and teachers prior to college, this relationship changed once a student entered college. As students faced difficulty in the early semesters of college and struggled to identify a new academic major, parents and high school educators were no longer seen to possess the information or advice needed to successfully overcome barriers. Instead, after having negative experiences with faculty and advisors, students looked to upper-class peers as a reliable source of informational support needed in decision-making. In applying these findings to Bronfenbrenner's model, as students faced declines in self-efficacy and sought academic support, they begin shifting steadfast components of their own microsystem and mesosystem into more distal positions and replacing those with influences, presented subsequently, in the college environment. While high school educators do not appear to play a significant role in the lives of students upon entering college, it is important to note that instances of students seeking information from peers is not evocative of a disconnect from family relationships. In fact, students reported still looking to immediate family members as sources of emotional and moral support despite not being primary choices for college information.

Upper Class Peers. As pre-college influences such as parents and high school teachers are moved into distal systems when considering academic decisions, findings suggest upper class peers quickly move into proximal systems as primary influences. While friendships with upper class students were important, the role these students reportedly played in guiding academic decisions and providing the cultural capital necessary to navigate the university was critical. These findings align with current literature positing the deficits low-income students often face in utilizing resources, such as not seeking assistance when struggling academically, failing to 
engage with faculty or advisors, and not taking advantage of institutional offerings such as career services, which widen gaps in knowledge and capital in detrimental ways (Hoxby \& Avery, 2009; Kezar, Walpole \& Perna, 2014). Upper class peers stepped in to fill gaps in information low-income students could not obtain through faculty or advisor relationships which, in previous literature, was believed to be imperative to success (Clawson \& Leiblum, 2008; Granfield, 1991; Stanton-Salazar, 1997). In addition to decision-making, older peers have been found to influence student development (Chickering \& Reisser, 1993), institutional satisfaction (Astin, 1993), and need fulfillment (Carbery \& Buhrmester, 1998) and, in this study, self-efficacy. Extant literature in adolescent psychology supports the formation of natural mentoring relationships (Zimmerman Bingenheimer, \& Behrendt, 2005), particularly those from non-family who share similar demographics and interests (Hurd, Sanchez, Zimmerman \& Caldwell, 2012; Hurd \& Sellers, 2013; Hurd, Varner \& Rowley, 2013), as beneficial in navigating psychological distress, difficult situations, and academic and social integration, particularly for students from marginalized backgrounds (Erickson, McDonald \& Elder, 2009). Yet, the study of natural mentor establishment within the college context is still in early stages (see Hurd, Tan \& Loeb, 2016). The seemingly haphazard, natural pairing of low-income students in this study with upper class peers in academic counseling roles illuminates a lack of understanding in how these relationships are developed. In the context of this study, friendships were formed through student organization involvement and assistance with academic decision-making appeared to happen without formal intent. This offers a converse perspective to the existing mentoring literature, which prioritizes faculty mentoring (Engle \& Tinto, 2008) or advocates for peer relationships to be developed formally through university supported peer mentoring programs (Allen, 2003; Sanchez, Bauer \& Paronto, 2006). This is not to suggest that structured programs are not 
beneficial for this population, and targeted programmatic development is suggested in the implications for practice section, but further understanding of how low-income students are exposed to and making use of these academic mentoring relationships could offer useful insight. Regardless, the replacement of pre-college influences by upper class peers in the most proximal systems of support is an important consideration for improving deficits in efficacy throughout the major choice process.

Hobbies and Personal Interests. Reframing the notion that a casual interest, hobby, or skill could also be a suitable choice of major may be difficult for college students. Bandura (1977) utilized the term performance accomplishments to describe the knowledge and skills a person gains through active participation in personal interests, hobbies, activities, and internships. Previous studies (Hackett, Betz, O’Halloran \& Romac, 1990; Lent, Lopez \& Bieschke, 1991) have supported the notion that performance accomplishments lead to increased self-efficacy in completing specific tasks related to a goal or outcome in college. Findings from this study posit that, once a student faces barriers in the college environment and subsequently experiences deficits in self-efficacy, finding an academic major related to a previously held hobby or interest is useful in gaining confidence. Survey participants, particularly those who went on to declare a humanities major, identified personal hobbies as being highly influential in choice of major. Moreover, interview participants overwhelmingly made connections between ultimate choice of major and hobbies or interests. For the students who declared in the humanities, this often meant turning to a major related to previous hobbies, clubs, or the visual and performing arts. For those pursuing non-humanities degrees, a sense of disappointment or longing was reported. These students felt, by not following a passion, the academic experience was diminished and they sought other avenues to continue engagement with humanities activities 
of interest. While performance accomplishments have not been widely studied when considering academic decision-making, Hackett, Betz, O’Halloran \& Romac (1990) and Lent, Lopez \& Bieschke (1991), in their discussions of the Social Cognitive Career Theory, identified the critical importance of these experiences in career decision-making, a worthwhile comparison. Moreover, consistent with literature on low-income populations, finding meaningful opportunities for these students to feel academically competitive and appreciated in the classroom is imperative in student success (Tierney, 2000) and partnering hobbies and interests with academic pursuits appears to be well-suited (Bandura, 1977; Holland \& Nichols, 1964).

Small, Supportive Academic Communities. Although students reported failing to make important connections with faculty and advisors, what happens within the classroom environment was reportedly influential in academic decision-making. Extant literature touts the importance of small, supportive academic communities in improving belonging, connectedness to peers, and self-efficacy (Gardner, 2009; Kuh et al., 2007; Zumbrunn, McKimm, Buhs, \& Hawley, 2014). After experiences in large classrooms, often in introductory courses, students reported frustration in making connections with faculty, receiving minimal feedback, and struggling to obtain assistance when facing academic difficulty. However, when seeking a new major after encountering barriers, students, regardless of major, identified experiences in small classrooms, often in humanities general education courses, as being welcoming, supportive, and engaging. For those students who ultimately declared a humanities major, these experiences are reportedly a primary influence in decision-making. Moreover, in considering Schlossberg's (1989) work and, specific to marginalized populations, the supportive academic communities found in the humanities create the ideal aspects of mattering for students. Through recognizing students as individuals, providing guidance and feedback, and challenging and supporting 
students appropriately, faculty are offering the attention, importance, dependence, ego-extension, and appreciation Schlossberg posits as being critical in belonging. Moreover, for low-income students who are often at risk of leaving the institution, finding environments where mattering and belonging can be fostered not only improves decision-making and general happiness but a greater likelihood of remaining at the institution through completion. Indeed, the opportunity to feel connected and successful in the classroom takes precedence for low-income student participants over perceived future earnings or employment outcomes. Repeatedly, students indicated believing the transferable skills from an engaging major where they are academically successful is more important than persisting in a major where minimal support is present, interests are misaligned, and academic difficulties abound.

Financial Aid. Finally, an unexpected yet important finding specific to this study concerns the influence of a comprehensive financial aid package offered to low-income students at MAU. Extant literature supports the importance of aid in the college choice process, particularly for low-income students, as most students will still need to contribute personally or acquire loans to cover remaining need (Giancola \& Kahlenberg, 2016; Kezar, Walpole \& Perna, 2014; U.S. Department of Education, 2016). Moreover, with a national spotlight on the heavy burdens of student loan debt and many non-college goers using this as a reason for not attending, financial aid is an ever-present discussion in higher education. Findings from this study offer a unique perspective on the support provided by financial aid in a particular context. While uncommon across institutions in the United States, the aid package at MAU offered study participants not only a nearly debt-free college education but important advantages in the academic decision-making process. Students reported feeling able to explore courses of interest, rather than speeding to the finish line as many low-income students must do, and choosing 
academic majors regardless of perceived outcomes. Moreover, findings indicate that the presence of this aid package allowed students to remove the burden of family obligation in decision-making and to consider, often for the first time, graduate education. Current literature identified family obligation as a significant concern to low-income students (Bures, 2011; Walpole, 2003; 2011) with very few low-income students persisting on to graduate education (Engle \& Tinto, 2008). Through offering this aid package, MAU not only provided financially but also leveled a competitive academic landscape and removed burdens in decision-making for low-income students.

It is also important to consider how MAU's comprehensive aid program shifts the environmental systems, through the framework of Bronfenbrenner $(1979,1993)$ influencing student's development, decision-making, and meaning making. By having the burdens of college attendance alleviated or removed, some of the stigma and concerns associated with being labeled as a low-income student are removed from the student's microsystem. While low-income status is inherent in a student's lived experiences, a shift from a proximal environment to one that is more distal seemingly allowed students to have greater comfort in the college environment and to make decisions out of personal desire rather than financial obligation. Similarly, by removing parents, who influence through the mesosystem, as financial contributors and shifting their role in academic decision-making to a distal system, students could make decisions autonomously and progress developmentally. Finally, the presence of MAU's aid program in the exosystem functions as a barrier between the influence of negative policy and media rhetoric and a difficult federal aid system in the chronosystem and the daily experiences of students in the microsystem and mesosystem. By removing seemingly negative influences from external forces, the MAU comprehensive aid system is providing not only financial support but strengthened ease in 
decision-making and the opportunity for low-income students to be recognized for merit rather than hindered by need. These findings have significant implications as discussed in the subsequent policy, practice, and research sections.

\section{Relevance of Student Development Theory}

As data emerged across quantitative and qualitative phases of this study, concurrent experiences in academic decision-making and student development offered useful context. In particular, several findings were evocative of some of the major tenets of student development theory, in particular, psychosocial development, feelings of mattering and belonging, and selfauthorship. First, the barriers students faced in the college environment not only caused deficits in self-efficacy but, in applying Chickering's (1969; 1993) Theory of Psychosocial Development, students questioned their competence and struggled to manage emotions. However, in seeking relationships through upper class peers and within supportive academic communities, students were able to overcome these hurdles by developing mature interpersonal relationships and progressing toward foster a sense of purpose.

The work of Baxter-Magolda $(2001,2008)$ highlights the reported "low point" in the college experience when students realize their choice of academic major may no longer be feasible. As posited through her theory of self-authorship, Baxter-Magolda (2004, 2010), identified students as beginning college heavily influenced by authority figures (i.e., parents) but soon facing a "crossroads" that prompts reconsideration of a determined life path. In the context of this study, the barriers students face upon entering college create unanticipated distress in the choice of academic major and force students to consider alternative options and, often, with little support. It is how students choose to navigate this crossroads that determines success in moving toward self-authorship. For study participants, by developing a close environment of supports 
that fostered efficacious decision-making, they appeared to be progressing from the crossroads phase toward advanced levels of self-authorship despite early struggles.

Throughout study findings, a consistent theme emerged regarding the ways experiences within the college environment made a student feel. Whether it was difficulty connecting with faculty or university resources or comparing academic abilities to peers, the ways in which students perceived their acceptance within the MAU community played a role in efficacy and decision-making. As outlined in Schlossberg's (1989) Theory of Marginality and Mattering, finding avenues for feeling wanted, needed, and appreciated is critical in developing a foundational sense of belonging that provides a pathway to persistence and completion. Through creating meaningful relationships with older peers, developing intellectual communities with classmates, and establishing positive partnerships with humanities faculty as supports in decision-making and improving efficacy, many study participants gained a sense of mattering that not only contributed to choice of major but also their overall happiness at MAU. For those students, particularly Samesh and Mateo, who identified these supports as missing from their business programs, finding a sense of mattering in the classroom was reportedly a constant struggle and both looked for opportunities to matter in social environments instead.

\section{Choosing the Humanities}

In response to the second and third research questions, several of this study's findings detail the environmental influences and experiences leading to initial increases in self-efficacy, subsequent decreases when facing barriers, and the college influences that assisted students in gaining efficacy and choosing a major. By understanding this often rocky journey, it is possible to considering the first research question and why low-income students continue to choose humanities majors in the first place. The process of declaring a humanities major is not direct by 
any means. While students in this study indicated humanities interest at the time of admission, this is seemingly a product of extracurricular involvement and positive academic experiences in the humanities during high school. However, between high school and college enrollment, many students began considering pre-professional or non-humanities majors, as suggested by parents and teachers, and sought those courses during the first semester. For most, the humanities remained important through hobbies and student organizations but students reportedly struggled to make connections between these majors and career outcomes. However, after facing barriers and failing to find much support through university resources, students sought the advice of upper class peers and found efficacy in returning to previous hobbies or interests as academic majors in supportive humanities classrooms and with the burdens of financial outcomes removed. With the understanding that these findings are not widely generalizable, the reasons low-income students are choosing the humanities are primarily about community and confidence. The ability to feel seen and supported in the classroom, to receive feedback, and to move forward with the knowledge that success is likely. Institutions, and humanities departments in particular, have an opportunity to better understand how these academic disciplines are serving a marginalized population and, in turn, may be able to reach these students in a more timely and positive manner rather than being a refuge after difficulty.

\section{Humanities as a Benefit to All}

While this study intended to understand why low-income students would choose humanities majors in their own academic journeys, an important detail emerged regarding the value participants place on the humanities in general. Through the survey, students were asked to reflect upon the influence of negative media and policy rhetoric regarding the humanities as well as desired outcomes from academic study. Through interviews, students discussed humanities 
study at length and were also presented facts regarding the current state of humanities programs and funding through the card sorting activity. Initially, it was evident that all students in the interview cohort strongly supported humanities study. Annie, who began in architecture, is now a music major. Samesh, who is disappointed in his family obligation to consider business, wants to pursue film and fine arts. However, what became telling was the support interview participants held for the humanities as a fundamental component of a college education. Without prompting, students described humanities course experiences as "enriching" and wishing their academic programs allowed for greater exploration. Students indicated supporting, and even expanding, the academic requirements in the humanities for all students. Amelia spoke at length about the difficulties her friends in STEM fields have in reading and writing and she believes a wider course of study would benefit all students. Students expressed outrage at proposed state funding cuts to public universities who encourage humanities enrollment and expressed surprise at the number of program closures occurring at institutions. Across survey responses, students' desired outcomes were in alignment and reported the negative media and policy rhetoric as having minimal bearing on decision-making. Through the card sorting activity, interview participants expressed surprise when positive labor market outcomes for humanities majors were presented and noted that, even when believing earning would be less, the humanities were still a worthwhile choice of academic major-perhaps a surprising response from low-income students. While not central to this study, widespread humanities support as a benefit to all students is an important theme during a controversial time and offers unique insight to future research, policy decisions, and practice.

\section{Implications for Policy and Practice}

The opportunity to inform policy and practice as a means for understanding and 
improving the low-income student experience was the primary motivation in developing this study. Given the current United States economic climate and labor market, government agencies and institutions are widely developing initiatives to increase low-income student enrollment across higher education (Engle \& Tinto, 2008; U.S. Department of Education, 2016). As this study shows, low-income students face a number of barriers in the college-going and academic decision-making processes and findings from this study offer initial insight into and recommendations for policy and practical improvements.

Considerations for policy improvements regarding financial aid are threefold: federal financial aid, the future of comprehensive aid models such as the one offered at MAU, and expansion of need-blind, full coverage aid models across public institutions. Despite recent reforms, the Free Application for Federal Student Aid (FAFSA) remains a burdensome and confusing process for many low-income and marginalized students (Bettinger et al., 2012; Dynarski \& Scott-Clayton, 2006). Often, students struggle to understand the FAFSA submission process and cannot obtain the financial documentation necessary from parents (Bettinger et al., 2012). By failing to meet FAFSA requirements, students who have the greatest need are often precluded from receiving the most lucrative aid packages, which, in turn, may limit options for attendance. While recent changes in the submission requirements for FAFSA greatly benefit the low-income student population (Gunn, 2016), it is not an ultimate solution. Students in the interview cohort discussed at length the difficulties faced in obtaining federal aid and shared instances where he or she lost opportunities to attend first choice institutions simply because of missing documentation from parents. This study offers additional support for a continued discussion regarding the necessary overhaul of the federal aid system and, in particular, demonstrates how highly competent students may be disadvantaged in the aid process. 
An important finding from this study surrounds the expanse of opportunities presented to students through institutionally based comprehensive aid programs. Currently, few institutions (e.g., Harvard University, Stanford University, University of North Carolina, University of Virginia) offer a need-blind admissions process with a full tuition support model. For talented, low-income students like those in this study, the breadth of opportunities MAU's comprehensive model provides both during and post-college is staggering. Study findings demonstrate how comprehensive aid removes family obligation and burden, opens academic opportunities, provides for improved mental health and stability, and simply allows students to enjoy college. However, as best described by Samesh, students understand the magnitude of this opportunity yet struggle that these aid packages are so limited in existence,

Sometimes it's just overwhelming that I have this [financial program] opportunity. Like, there are plenty of other kids out there who are smart like me and work hard - harder than me - but they didn't get to come to MAU. Now they are going to another school that is not as good as MAU and probably have way more debt now, too. Sometimes I feel bad about it. Like, it's not fair. But I know I'm really lucky, too.

Concerning, however, is the future of these aid models and the ability to expand similar models to institutions of varying selectivities. In recent years, the University of Virginia and the University of North Carolina have faced legislative backlash for how finances are appropriated for aid programs (Bellows, 2017; Carolina Alumni Review, 2014). Moreover, policy shifts within institutional board governance have limited how tuition dollars may be applied toward aid. These changes threaten the very existence of successful aid programs at highly competitive institutions and continuation of these policy demands limits opportunities for aid programs to be expanded across less selective institutions. Moreover, these changes make already difficult allocations for need-based aid at smaller colleges increasingly difficult, which, in turn, lessens opportunities for low-income student attendance. While this study's findings identify the 
important role comprehensive aid plays in college attendance for low-income students at MAU, these findings offer new perspective on the importance of, and policy issues surrounding, comprehensive aid models in academic decision-making, persistence, completion, and postgraduation outcomes.

This study's findings also support the value low-income students place on the humanities as an integral part of the college experience. Students identified the humanities as providing critical thinking, creativity, communication skills, and an appreciation for diversity that were deemed important outcomes of college attendance. Moreover, students identified the humanities as providing the necessary transferable skills to make them highly competitive in the labor market, which align with the desires of employers (Hart 2009, 2010, 2013). Moreover, the findings suggest that humanities coursework fills gaps in knowledge not often found in strictly vocational or pre-professional education curriculum and, through interdisciplinary approaches, can allow students to feel more competitive. Through these findings, reconsideration of federal, state, and institutional funding cuts to humanities programs is urged as well as a shift from program removal at universities to improved interdisciplinary options toward strengthened labor market outcomes as a means of furthering the humanities while appeasing skeptics.

The implications for practice stem from study findings regarding specific external and college influences on the low-income student academic decision-making experience over time. To begin, findings from this study identify deficits in understanding in the academic major choice process both prior to matriculating and once enrolled. As families and high school teachers are a primary pre-college influence, offering parents, students, and high school counselors additional support information, including accurate labor market statistics, regarding major choice prior to college is recommended. This is particularly important for academically 
gifted students, such as those at MAU, who may be actively considering rigorous majors, or double majors, in a competitive environment. Similarly, a common tendency across universities is to front load substantial information during the orientation and matriculation process of the first year of college. However, findings from this study suggest the need for continued education on academic major choice beyond the first few weeks of the first year and, specific to MAU, improved advising relationships.

Findings from this study provide a useful basis for academic advisors to better understand the barriers experienced and supports desired by low-income students and a baseline for creating policy, procedures, and programming to avoid the currently seen decline in self-efficacy. Hurst (2010) identified the critical need for academic advisors to be cognizant of how social class hierarchies create divisions across higher education and the barriers and concerns specific to this population. While the original intent of academic advising was to simply assist students with selecting classes, modern day advising includes expanded responsibilities. In addition to course selection, major declaration, and career planning, students look to advisors as resources for navigating transition issues, mental and emotional well-being, and a variety of issues as they arise. For low-income students, who already struggle to seek resources, losing confidence in academic advisors simply becomes another barrier in the decision-making process. By understanding the breadth of knowledge advisors need to be successful resources for low-income students, institutions have an opportunity to build trusting relationships and bridge deficits upon entry. Moreover, institutions may be well-served to better identify and track low-income students, as is common practice with other marginalized populations, to create appropriate supports and resources for these students in a timely and inclusive manner. As posited by Kezar, Walpole, and Perna (2014), institutions often lack appropriate resources and outreach to low- 
income students that help inform their academic decisions and improve outcomes and efficacy.

Improvements in outreach are also suggested. Study findings indicate that little information regarding the major choice process was provided outside the initial time of entry or once a deadline was rapidly approaching or missed. Given these students have a history of needing additional support, identifying timely methods for delivery when students are most likely to best receive information may remove barriers in the process. Moreover, it should not be assumed that if a student is not seeking assistance, he or she is successfully navigating a situation. Through better tracking of marginalized populations and offering repetitive, proactive attempts to share information in ways that create a culture of belonging and mattering, these deficits in information and understanding can be bridged.

A compelling study finding concerns the prevalence of low-income students turning to upper class peers for support and guidance rather than seeking faculty or university assistance. The finding is understandable given what is known about low-income student inability to connect with faculty resources (Lareau, 2003) and the presence of upper class students as less threatening sources of information. However, some risk remains in this relationship as the information provided by upper class students regarding academic decision-making may be inaccurate or misleading. Institutions would be well-served to further investigate how lowincome students are obtaining academic information, particularly from peers, and to identify ways to support these relationships. For instance, rather than relying on somewhat chance interactions and haphazardly formed peer-to-peer mentoring relationships, institutions might consider using one upper-class student as a mentor to a cohort of students may be an effective way to bridge gaps. However, mentoring is only effective when mentors received the appropriate training and guidance to be successful, as we cannot simply rely upon goodwill of 
students and sharing of personal stories to close deficits for low-income students. Through intentional training and university support, mentors provide a bridge for new students to establish academic and social involvement across campus while remaining a knowledgeable resource for students when needed. Living-learning communities are also high impact practices where mentoring related to academic decision-making may be effective. As findings from this study demonstrate, having students from different academic class years, and from a mix of background characteristics and major interests, residing together at the same time, living-learning communities create prime opportunities for older students to mentor younger peers, but under the guided supervision of the community. While most upper class peer mentoring relationships reported in this study were happenstance, institutions have an opportunity to create initiatives with greater purpose and consistency without being intrusive.

Finally, findings from this study reinforce the importance of humanities disciplines to low-income students, yet, it is uncertain whether administrators and faculty within these disciplines understand this impact. By sharing these findings, faculty and administrators have an opportunity to better understand the influence his or her classroom environment, feedback, support, and teaching has on a particular population of students. Moreover, these findings prompt reconsideration of how the humanities are promoting offerings within the campus community and encouraging major enrollment. Rather than low-income students circling back to the humanities after facing barriers and deficits in college, receiving greater information earlier in the academic tenure may allow students to see the humanities as viable options prior to facing challenges. Perhaps, this may result in increased enrollment, funding, and opportunities specific to the needs of low-income students. While controversial across faculties, the growth of interdisciplinary collaboration also serves as an important way to overcome the stigma of 
humanities study and to meet the pre-professional and vocational desires students believe lead to labor market outcomes. In the same vein, humanities administrators, along with admissions officers and career planners, could to be more forthcoming with the positive labor market outcomes associated with humanities study. Given low-income students are often concerned about future earnings, providing a more accurate picture to dispel negative rhetoric may provide early comfort for students in decision-making. Finally, the perceptions offered by students identifying the ability of humanities faculty to foster inclusive, supportive learning environments should be heeded by non-humanities faculty. By understanding not only the negative experiences low-income students report having in non-humanities classrooms and with faculty but that humanities faculty are identified as best practices for what low-income student actually desire in an academic setting could be quite beneficial in fostering a culture of change across campuses.

\section{Implications for Theory}

While this study was not intended to develop new theory, the findings did offer insight into the use of Social Cognitive Career Theory and Bronfenbrenner's Ecological Systems Theory as frameworks in higher education research. Originally intended to understand career decisionmaking in various contexts, this study lends support to the expanded use of SCCT to explore and explain other pivotal decisions in the college experience. In particular, SCCT allows for consideration of pre-existing conditions (e.g., low-income status, race, gender) as well as learning experiences prior to and during college which may shape academic decision-making, as demonstrated in this study. Moreover, SCCT provides opportunities for identifying specific barriers that contribute to rises and declines in self-efficacy specific to academics as well as how expectations are shaped. As major choice is closely affiliated with career decision-making for college students, employing SCCT over time to understand the numerous decisions a student 
makes across the college experience is suggested. An additional approach may be to adapt the existing SCCT framework for the higher education setting where specific components (e.g., learning experiences, efficacy and expectations, resulting actions and goal setting) can be repeated to determine specific influences on major choice and resulting experiences related to subsequent career choice. An extension to examining decision-making through SCCT may be to include the college choice process as a starting point as it is a precursor to major and career choice.

Bronfenbrenner's Ecological Systems Theory provided a useful partner framework to SCCT as it allowed for consideration of shifting environmental influences across varying points of time and contexts that influenced self-efficacy and outcome expectations. However, a concern exists with the Bronfenbrenner model as the parameters for considering influences are so broad that they are easily applied to any setting and in any discipline. Across the higher education literature, Bronfenbrenner is widely used in adaptation to meet the specific needs of the college experience. Moreover, extant higher education literature and theory, particularly Astin's (1991) Input-Environment-Output (IEO) model and Holland's (1985) Person-environment fit theory, strongly supports examining environmental influences, typically within the college context, for understanding academic and social outcomes. While future research will always have a unique set of theoretical needs, having a formally adapted version of Bronfenbrenner's model to represent both relevant college environments in addition to influential externalities may provide continuity and greater depth in understanding findings and identifying supports and barriers specific to this population.

\section{Implications for Future Research}

As this study was designed to contribute to a fledgling research base on the academic 
decision-making of low-income students and, in particular, those with humanities interests, the opportunities for potential research expansion are vast. Findings from this study provide a baseline in understanding the general external and college influences shaping both self-efficacy and decision-making of low-income students' choice of major. Three broad and four specific research expansions are offered as preliminary starting points.

First, this study was set in a unique context that undoubtedly shaped findings. In order to better understand this study's findings and to improve generalizability, additional research should include institutions of differing selectivities, Pell-grant eligibility, financial aid models, and varying academic major choice processes. For students lacking the academic prowess of those at MAU and who may not have the luxury of full financial aid support, the barriers encountered and supports desired may look quite different. Next, future research using comparison samples is necessary. While this study solely considered low-income students to better understand this specific experience, the findings offer an opportunity to consider the academic decision-making of well-resourced students, both in humanities and non-humanities fields, as a comparison. Moreover, student demographics and experiences, such as race, gender, birth order, first-generation college student status, and cultural upbringing, are worthwhile considerations in finding nuances in decision-making. An important consideration would also be to map findings of this study on to non-humanities majors to determine if low-income students in those disciplines are finding the same barriers and desiring the same supports in their major pursuits. Some of the qualitative findings concerning students who are currently in nonhumanities majors appear to suggest that there are similarities in experiences. Finally, this research needs to be conducted over time. As resources prevented longitudinal study, following a cohort of students throughout the academic decision-making process would allow for 
confirmation of these findings and additional insight unable to be produced with this research design.

A concern throughout the study findings surrounded students' inability to connect academic majors with career desires or personal goals and outcomes. This inability may also contribute to the late timing in declaring a major and the lack of confidence students expressed in their ability to declare a major with satisfaction. Additional research specific to the barriers faced in connecting academic decisions with future plans and goals is warranted. Second, an exploration of the informal upper class peer relationships that evolve into academic mentoring should be examined. If upper class students are seemingly filling the role of faculty, advisors, and university resources for low-income students, it is important to strengthen an understanding of how these relationships are developed and the ways in which these students are effectively providing support to this marginalized population. This study offers a fledgling insight into one area of the peer relationship that may be ripe for expansion. As found in this study, students are often finding peer support through campus involvement. However, many of these relationships were reportedly developed through situations where an upper class student was informally designated as the "big sibling" to the student upon joining a campus organization and served as a small group leader, pledge class guide, or project captain. This informal structure of an older student mentoring a younger peer is representative of a formal, traditional institutional mentoring relationship where upper class students are paired with younger students for guidance through a particular part of the college experience. If students are effectively creating these relationship in social circles and without university guidance, considering the establishment, functionality, and information sharing abilities of these relationships in a formal context and as a benefit to lowincome students is important. Next, the study's findings offer loose insight into the experiences 
students found in humanities classrooms and, specifically, with humanities faculty. Students repeatedly identified humanities faculty as possessing different personalities than faculty in other disciplines and creating a sense of warmth and community that was welcoming. Additional insight into these perceptions is warranted to determine if conditions exist that may be of benefit to marginalized populations or if these experiences are simply reflective of poor experiences found with non-humanities faculty and the positive interaction was simply relief. Finally, the shift in support systems as demonstrated when a student leaves high school and enters college deserves further consideration. Specifically, researchers should consider the ways in which parents may remain actively engaged in the academic decision-making process as a system of support for students rather than being removed from a place of influence. While low-income students, particularly those who are first generation, may believe that parents do not possess the information needed to be helpful, the emotional and moral support provided when facing unforeseen barriers may still have a positive impact in decision-making as it does in other facets of the college experience. 


\section{References}

ACT. (2014). Poor fit between interests and intended college majors does not improve for many students as they progress to college. College Choice Process Part II: Enrollment Patterns. Retrieved from http://www.act.org/newsroom/poor-fit-between-interests-andintended-college-majors-does-not-improve-for-many-students-as-they-progress-tocollege/.

Allen, T. D. 2003. Mentoring others: A dispositional and motivational approach. Journal of Vocational Behavior, 62: 134- 154.

American Academy of Arts \& Sciences. (2015). Humanities indicators. The state of the humanities: higher education 2015. Retrieved from http://www.humanitiesindicators.org/binaries/pdf/HI_HigherEd2015.pdf Association of American Colleges and Universities. (1995). Liberal Learning and Arts of Connection for the New Academy. Washington, DC: Author.

Association of American Colleges and Universities. (2005). Liberal Education Outcomes: A Preliminary Report on Student Achievement in College. Washington, DC: Association of American Colleges and Universities.

Association of American Colleges and Universities. (2011). The LEAP Vision for Learning: Outcomes, Practices, Impact, and Employers'Views. Washington, DC: Author Association of American Colleges and Universities. (2015). Bridging cultures to form a nation: Difference, community, and democratic thinking. Washington, DC: Author.

Astin, A. W. (1991). The changing American college student: implications for educational policy and practice. Higher Education, 22(2), 129-143.

Astin, A. W. (1993). What matters in college?: Four critical years revisited (Vol. 1). San 
Francisco: Jossey-Bass.

Astin, A. W. (1997). Liberal education \& democracy: The case for pragmatism. Liberal Education, 83(4), 4-15.

Astin, A. W., Astin, H. S., Lindholm, J. A., Bryant, A. N., Szelényi, K., \& Calderone, S. (2005). The spiritual life of college students: A national study of college students' search for meaning and purpose. Los Angeles, CA: UCLA Higher Education Research Institute.

Bagnoli, A. (2009). Beyond the standard interview: the use of graphic elicitation and arts-based methods. Qualitative Research 9(5): 547-570.

Bailey, M. J., \& Dynarski, S. M. (2011). Gains and gaps: Changing inequality in US college entry and completion (No. w17633). National Bureau of Economic Research.

Bailyn, B. (1986). Glimpses of the Harvard past. Harvard University Press.

Bandura, A. (1977). Self-efficacy: Toward a unifying theory of behavioral change. Psychological Review, 84, 191-215.

Bandura, A. \& Schunk, D.H. (1981). Cultivating competence, self-efficacy, and intrinsic interest through proximal self-motivation. Journal of Personality and Social Psychology, 41, 586598.

Barge, M. A. (2015, September 7). Complete list of extracurricular activities. Prep Scholar [blog post]. Prep Scholar. Retrieved from http://blog.prepscholar.com/list-of-extracurricularactivities-examples

Baum, S., \& Chingos, M. M. (2015). Evaluating campaign proposals. Washington, DC: The Urban Institute.

Baum, S., Ma, J., \& Payea, K. (2013). Education pays 2013. The College Board. 
Bellows, K. (2017, January 26). Out-of-state admissions, financial aid under debate at General Assembly. The Cavalier Daily. Retrieved from:

http://www.cavalierdaily.com/article/2017/01/out-of-state-admissions-financial-aidunder-debate-at-general-assembly

Berends, L. (2011). Embracing the visual: Using timelines with in-depth interviews on substance use and treatment. The Qualitative Report, 16(1), 1.

Bergerson, A. A. (2007). Exploring the impact of social class on adjustment to college: Anna's story. International Journal of Qualitative Studies in Education, 20(1), 99-119.

Bettinger, E. P., Long, B. T., Oreopoulos, P., \& Sanbonmatsu, L. (2012). The role of application assistance and information in college decisions: Results from the H\&R Block FAFSA experiment. The Quarterly Journal of Economics, 127(3), 1205-1242.

Blom, E., Cadena, B. C., Keys, Benjamin J. (2015). Investment over the business cycle: Insights from college major choice, IZA Discussion Papers, No. 9167

Bloom, J. (2008). Moving on from college. In V. Gordon, W. Habley, T. Grites, \& \&. Associates (Eds.), Academic advising: A comprehensive handbook (pp. 179, 181). San Francisco, CA: Jossey-Bass.

Bong, M. \& Skaalvik, E.M. (2003). Academic self-concept and self-efficacy: How different are they really? Educational Psychology Review, 15, 1-40.

Breen, R., \& Goldthorpe, J. H. (1997). Explaining educational differentials towards a formal rational action theory. Rationality and society, 9(3), 275-305.

Bronfenbrenner, U. (1979). The ecology of human development: Experiments by nature and design. Cambridge, MA: Harvard University Press. 
Bronfenbrenner, U. (1993). The ecology of cognitive development: Research models and fugitive findings. In R.H. Wozniak \& K.W. Fisher (Eds.), Development in context: Acting and thinking in specific environments (pp. 3-44). Hillsdale, NJ: Erlbaum.

Bronfenbrenner, U. (1995). Developmental ecology through space and time: A future perspective. In P. Moen \& G. H. Elder, Jr. (Eds.), Examining lives in context: Perspectives on the ecology of human development (pp. 619-647). Washington, DC: American Psychological Association.

Bures, K. (2011, September). Why choosing a major is not choosing a career (...and not the end of the world). Academic Advising Today, 34(3).

Cabrera, A. F., \& La Nasa, S. M. (2000). Understanding the college-choice process. New directions for institutional research, 2000(107), 5-22.

Carbery, J., \& Buhrmester, D. (1998). Friendship and need fulfillment during three phases of young adulthood. Journal of Social and Personal Relationships, 15(3), 393-409.

Carnevale, A.P., Cheah, B., Hanson, A. R. (2015). The economic value of college majors. Washington, D.C.: Georgetown University Center on Education and the Workforce.

Carnevale, A. P., Cheah, B., \& Strohl, J. (2014). Hard times, college majors, unemployment and earnings: Not all college degrees are created equal. Washington, DC: Georgetown University Center on Education and the Workforce.

Carnevale, A. P., Smith, N., \& Strohl, J. (2013). Recovery: Job growth and education requirements through 2020. Washington, D.C.: Georgetown University Center on Education and the Workforce. 
Carnevale, A. P., Strohl, J., \& Melton, M. (2011). What's it Worth? The economic value of college majors. Washington, D.C.: Georgetown University Center on Education and the Workforce.

Carnevale, A. and Rose, S. J. (2015). The Economy Goes to College: The Hidden Promise of Higher Education in the Post- Industrial Service Economy. Washington, D.C.: Georgetown University Center on Education and the Workforce.

Carolina Alumni Review. (2011, July). Carolina's cut is 18 percent - Biggest in the UNC system. Retrieved from https://alumni.unc.edu/news/carolinas-cut-is-18-percent-biggest-in-theunc-system/

Chambliss, D.F. \& Takacs, C. G. (2014). How college works. Cambridge, MA: Harvard University Press.

Chemers, M.M., Hu, L. \& Garcia, B.F. (2001). Academic self-efficacy and first-year college student performance and adjustment. Journal of Educational Psychology, 93, 55-64.

Chen, P. D., \& Simpson, P. A. (2015). Does Personality Matter?: Applying Holland's Typology to Analyze Students' Self-Selection into Science, Technology Engineering, and Mathematics Majors. The Journal of Higher Education, 86(5), 725-750.

Chetty, R., Hendren, N., Kline, P., \& Saez, E. (2014). Where is the land of opportunity? The geography of intergenerational mobility in the United States. Cambridge, MA: National Bureau of Economic Research.

Chickering, A. W. (1969). Education and identity. San Francisco: Jossey-Bass.

Chickering, A. W., \& Reisser, L. (1993). Education and identity. San Francisco: Jossey-Bass

Choy, S. P. (2001). Findings from the condition of education 2001: Students whose parents did not go to college: Postsecondary access, persistence, and attainment (NCES 2001-126). 
US Department of Education. National Center for Education Statistics. Washington, DC: US Government Printing Office.

Clawson, D. \& Leiblum, M. (2008). Class struggle in higher education. Equity \& Excellence in Education, 41(1), 12-30.

Commission on the Humanities and Social Sciences. (2013). The Heart of the Matter: The humanities and social sciences for a vibrant, competitive, and secure nation. Cambridge, MA: American Academy of Arts and Sciences.

Creswell, J. W. (2002). Educational research: Planning, conducting, and evaluating quantitative and qualitative research. Upper Saddle River, NJ: Pearson.

Creswell, J. W. (2003). Research design: Qualitative, quantitative, and mixed methods approaches (2nd ed.). Thousand Oaks, CA: Sage.

Creswell, J. W. (2007). Qualitative inquiry \& research design: Choosing among five approaches (2nd ed.). Thousand Oaks, CA: Sage.

Creswell, J. W., Plano Clark, V. L., Gutmann, M., \& Hanson, W. (2003). Advanced mixed methods research designs. In A. Tashakkori \& C. Teddlie (Eds.), Handbook of mixed methods in social and behavioral research (pp. 209-240). Thousand Oaks, CA: Sage.

Crisp, G., Nora, A., \& Taggart, A. (2009). Student characteristics, pre-college, college, and environmental factors as predictors of majoring in and earning a stem degree: An analysis of students attending a Hispanic serving institution. American Educational Research Journal, 46, 924-942.

Crow, M. M., \& Dabars, W. B. (2015). Designing the new American university. JHU Press.

Daly, M. C., \& Bengali, L. (2014). Is it still worth going to college?. FRBSF Economic Letter, 13. 
Davis-Kean, P. E. (2005). The influence of parent education and family income on child achievement: the indirect role of parental expectations and the home environment. Journal of family psychology, 19(2), 294.

DeRosa, E., \& Dolby, N. (2014). “I don’t think the university knows me”: Institutional culture and lower-income, first-generation college students. InterActions: UCLA Journal of Education and Information Studies, 10(2).

Desrochers, D. \& Hurlburg, S. (2016). Trends in college spending 2003-2013: Where does the money come from? Where does it go? What does it buy? Washington, DC: American Institutes of Research.

Dey, E. R., Barnhardt, C. I., \& Antonaros, M. (2009). Civic responsibility: What is the campus climate for learning? Washington, DC: Association of American Colleges and Universities.

Dubow, E. F., \& Ullman, D. G. (1989). Assessing social support in elementary school children: The survey of children's social support. Journal of Clinical Child Psychology, 18, 52-64.

Dynarski, S. M., \& Scott-Clayton, J. E. (2006). The cost of complexity in federal student aid: Lessons from optimal tax theory and behavioral economics (No. w12227). National Bureau of Economic Research.

Eccles, J. S. (1987). Gender roles and women's achievement-related decisions. Psychology of Women Quarterly 2: 62-72.

Eccles, J., \& Harold, R. (1993). Parent-school involvement during the early adolescent years. The Teachers College Record, 94(3), 568-587. 
Engle, J., \& O'Brien, C. (2007). Demography is not destiny: Increasing the graduation rates of low-income college students at large public universities. Washington, DC: The Pell Institute for the Study of Opportunity in Higher Education.

Engle, J. \& Tinto, J. (2008). Moving beyond access: College success for low-income, firstgeneration students. Washington, DC: The Pell Institute for the Study of Opportunity in Higher Education.

Erickson, F. (1986). Qualitative methods in research on teaching. Handbook of research on teaching. New York: Macmillan.

Erickson, L. D., McDonald, S., \& Elder, G. H. (2009). Informal mentors and education: Complementary or compensatory resources? Sociology of Education, 82, 344-367.

Evans, N. J., Forney, D. S., Guido, F. M., Patton, L. D., \& Renn, K. A. (2010). Student development in college: Theory, research, and practice. John Wiley \& Sons.

Federal Student Aid. (2015). Federal Pell Grant Information. Retrieved from https://studentaid.ed.gov/sa/types/grants-scholarships/pell.

Fincher, S., \& Tenenberg, J. (2005). Making sense of card sorting data. Expert Systems, 22(3), 89-93.

Fogg, N., Harrington, P. E., \& Harrington, T. F. (2004). College Majors Handbook with Real Career Paths and Payoffs: The Actual Jobs, Earnings, and Trends for Graduates of 60 College Majors. Jist Works.

Franzwa, A. (2013, November 13). Science versus humanities: God help us all. The Seattle Spectator. Retrieved from http://www.seattlespectator.com/2013/11/13/science-versushumanities-god-help-us-all/ 
Furman, W., \& Buhrmester, D. (1985). Children's perceptions of the personal relationships in their social networks. Developmental Psychology, 21, 1016-1024.

Gair, M. \& Mullins, G. (2001). Hiding in plain sight. In E. Margolis (Ed.). The hidden curriculum in higher education (p. 21-42). New York, NY: Routledge.

Gardner, J. N. (2009). Introduction. In G. L. Kramer (Ed.). Fostering student success in the campus community (Vol. 138) Hoboken, NJ: John Wiley \& Sons.

Geer, R. E. \& Halisky, L. H. (2011). College grads need skills, not liberal arts. Bloomberg Business Report: The Debate Room. Retrieved from http://www.businessweek.com/debateroom/archives/2011/07/college_grads_need_skills_ not_liberal_arts.html.

George-Jackson, C. E. (2012). Generation Me: Influences on Students' Choice of Major. Project STEP-UP. University of Illinois at Urbana-Champaign.

Giancola, J., \& Kahlenberg, R. D. (2016). True merit: Ensuring our brightest students have access to our best colleges and universities. Leesburg, VA: Jack Kent Cooke Foundation.

Gibbons, M. M., \& Shoffner, M. F. (2004). Prospective first-generation college students: Meeting their needs through social cognitive career theory. Professional School Counseling, 91-97.

Gilbert, C., \& Heller, D. (2010). The Truman commission and its impact on higher education policy, 1947-2010. University Park, PA: Center for the Study of Higher Education.

Gill, A. M., \& Leigh, D. E. (2000). Community college enrollment, college major, and the gender wage gap. Industrial \& Labor Relations Review, 54(1), 163-181. 
Goyette, K. A., \& Mullen, A. L. (2006). Who studies the arts and sciences? Social background and the choice and consequences of undergraduate field of study. Journal of Higher Education, 497-538.

Grafton, A. (2012). Our universities: Why are they failing?. Educational Studies, (2), 273-284.

Granfield, R. (1991). Making it by faking it: Working-class students in an elite academic environment. Journal of Contemporary Ethnography, 20(3), 331-351.

Greene, J. C., Caracelli, V. J., \& Graham, W. F. (1989). Toward a conceptual framework for mixed-method evaluation designs. Educational Evaluation and Policy Analysis, 11(3), $255-274$.

Gunn, D. (2016, May). Making College Accessible to Low-Income Students Is About More Than Just Tuition. Pacific Standard Magazine https://psmag.com/making-collegeaccessible-to-low-income-students-is-about-more-than-just-tuitiond343fb190572\#.cfg3301jy

Hackett, G., Betz, N. E., O'Halloran, M. S., \& Romac, D. S. (1990). Effects of verbal and mathematics task performance on task and career self-efficacy and interest. Journal of Counseling Psychology, 37(2), 169.

Hackett, G., \& Lent, R. W. (1992). Theoretical advances and current inquiry in career psychology. In S. D. Brown \& G. Hackett (eds.), Handbook of counseling psychology (2nd ed.) (pp. 419-451). New York, NY: Wiley.

Harpham, G. G. (2011). The humanities and the dream of America. University of Chicago Press. Hart Research Associates, Inc. (2007). How Should Colleges Prepare Students to Succeed in Today's Global Economy? Accessed August 17, 2015 at http://www.aacu.org/leap/documents/Re8097abcombined.pdf. 
Hart Research Associates, Inc. (2010). Raising the Bar: Employers'Views on College Learning in the Wake of the Economic Downturn. Accessed August 17, 2015 at http://www.aacu.org/leap/documents/2009_EmployerSurvey.pdf.

Hart Research Associates, Inc. (2008). How Should Colleges Assess and Improve Student Learning? Employers' Views on the Accountability Challenge. Accessed August 17, 2015 at http://www.aacu.org/leap/documents/2008_Business_Leader_Poll.pdf.

Hart Research Associates, Inc. (2013). It takes more than a major: employer priorities for college learning and student success. Washington, DC: The Association of American Colleges and Universities.

Harvard University, Arts and Humanities Division. (2013). The teaching of the arts and humanities at Harvard College: Mapping the future. Cambridge, MA: Harvard University.

Harvard University, Committee on the Objectives of General Education in a Free Society. (1945). General education in a free society. Cambridge, MA: Harvard University Press. Hearn, J. C., \& Belasco, A. S. (2015). Commitment to the Core: A Longitudinal Analysis of Humanities Degree Production in Four-Year Colleges. The Journal of Higher Education, $86(3), 387-416$.

Hill, N. E., Castellino, D. R., Lansford, J. E., Nowlin, P., Dodge, K. A., Bates, J. E., \& Pettit, G. S. (2004). Parent academic involvement as related to school behavior, achievement, and aspirations: Demographic variations across adolescence. Child development, 75(5), 1491 1509.

Holland, J. L. (1985). The Self-Directed Search Professional manual. Odessa, FL: Psychological Assessment Resources, Inc. 
Holland, J. L., \& Nichols, R. C. (1964). Explorations of a theory of vocational choice: iii. A longitudinal study of change in major field of study. Personnel and Guidance Journal, $43,235-242$.

Holm, P., Jarrick, A., \& Scott, D. (2015). Humanities world report. Washington, D.C.

Hoover-Dempsey, K. V., \& Sandler, H. M. (1997). Why do parents become involved in their children's education?. Review of educational research, 67(1), 3-42.

Hoxby, C. M., \& Avery, C. (2009, January). The missing “one-offs”: The hidden supply of high merit students for highly selective colleges. Paper presented at the American Economic Association annual meeting, San Francisco, CA.

Hurd, N. M., Sanchez, B., Zimmerman, M.A., \& Caldwell, C. H. (2012). Natural mentors, racial identity, and educational attainment among African American adolescents: Exploring pathways to success. Child Development, 83, 1196-1212.

Hurd, N. M., \& Sellers, R. M. (2013). Black adolescents' relation- ships with natural mentors: Associations with academic engagement via social and emotional development. Cultural Diversity and Ethnic Minority Psychology, 19, 76-85.

Hurd, N. M., Tan, J. S., \& Loeb, E. L. (2016). Natural mentoring relationships and the adjustment to college among underrepresented students. American Journal of Community Psychology, 57(3-4), 330-341.

Hurd, N. M., Varner, F. A., \& Rowley, S. J. (2013). Involved vigilant parenting and socioemotional well-being among Black youth: The moderating influence of natural mentoring relation- ships. Journal of Youth and Adolescence, 42, 1583-1595.

Hurst, A. L. (2010). The burden of academic success: Loyalists, renegades, and double agents. New York, NY: Rowman \& Little. 
Idrobo, M. (2015, September 26). Humanities enrollment declines in Wellesley and nation. The Wellesley News. Retrieved from http://thewellesleynews.com/2015/09/26/humanitiesenrollment-declines-in-wellesley-and-nation/f

Inkelas, K. K., Vogt, K. E., Longerbeam, S. D., Owen, J., \& Johnson, D. (2006). Measuring outcomes of living-learning programs: Examining college environments and student learning and development. The Journal of General Education, 40-76.

Isaacs, J., Sawhill, I., \& Haskins, R. (2008). Getting Ahead or Losing Ground: Economic Mobility in America. Washington, DC: The Brookings Institution.

Jefferson, T. (1780) Thomas Jefferson's Monticello. Thomas Jefferson Encyclopedia. Retrieved from http://www.monticello.org/jefferson/bill-more-general-diffusion-knowledge

Jenkins, N. (2015, September 16). Alarm Over Huge Cuts to Humanities and Social Sciences at Japanese Universities. Time Magazine. Retrieved from http://time.com/4035819/japanuniversity-liberal-arts-humanities-social-sciences-cuts/.

Johnson, J. and DiStasi, C. (2014) Divided we fail: Why it's time for a broader, more inclusive conversation on the future of higher education. Dayton, $\mathrm{OH}$ : The Kettering Foundation.

Jones S. \& Fox S. (2009) Generations online in 2009. Washington, DC: Pew Internet and American Life Project.

Kelly, G.A. (1955). The Psychology of Personal Constructs. New York: W.W. Norton.

Kezar, A. J., Walpole, M., \& Perna, L. W. (2014). Engaging Low-Income Students. Student Engagement in Higher Education: Theoretical Perspectives and Practical Approaches for Diverse Populations, 237.

Kuh, G. D. (2008). High-Impact Educational Practices: What They Are, Who Has Access to Them, and Why They Matter. Washington, DC: Association of American Colleges and 
Universities.

Kuh, G. D., Kinzie, J., Buckley, J. A., Bridges, B. K., \& Hayek, J. C. (2007). Piecing together the student success puzzle. Research, propositions, and recommendations. ASHE Higher Education Report 32. San Francisco: Jossey-Bass.

Kraus, J. W. (1961) The development of a curriculum in early American colleges. History of Education Quarterly, 1(2), 64-76. Retrieved from http:/www.jstor.org/stable/36764/.

Lackland, A. C., \& De Lisi, R. (2001). Students' choices of college majors that are gender traditional and nontraditional. Journal of College Student Development.

Lareau, A. (2003). Unequal childhoods: Race, class, and family life. Berkeley: University of California Press.

Lent, R.W., Brown, S.D. \& Hackett, G. (1994). Toward a unifying social cognitive theory of career and academic interest, choice, and performance. Journal of Vocational Behavior, $45,79-122$.

Lent, R.W., Brown, S.D. \& Hackett, G. (1996). Career development from a social cognitive perspective. In D. Brown, L. Brooks \& Associates (Eds.), Career Choice and Development (3rd ed.) (pp. 373-421). San Francisco: Jossey-Bass Publishers.

Lent, R. W., Lopez, F. G., \& Bieschke, K. J. (1991). Mathematics self-efficacy: Sources and relation to science-based career choice. Journal of counseling psychology, 38(4), 424.

Lewin, T. (2013). As interest fades in the humanities, colleges worry. The New York Times. Retrieved from http://www.nytimes.com/2013/10/31/education/as-interest-fades-in-thehumanities-colleges-worry.html?_r=0 
Louie, V. (2004). Being practical or doing what I want: The role of parents in the academic choices of Chinese Americans. Becoming New Yorkers: The Second Generation in a Global City. New York: Russell Sage Foundation, 79-109.

Lovelace, D. L. (2012). Third grade matters: The significance of social and cultural capital on early college predisposition. (Doctoral dissertation). University of Virginia, Charlottesville, VA.

Lucas, S. R. (2001). Effectively Maintained Inequality: Education Transitions, Track Mobility, and Social Background Effects. American Journal of Sociology, 106(6), 1642-1690.

Luzer, D. (2013). We don't have enough liberal arts majors. Washington Monthly Magazine. Retrieved from http://www.washingtonmonthly.com/college_guide/blog/we_dont_have_enough_liberal_ ar.php\#

Ma, Y. (2009). Family socioeconomic status, parental involvement, and college major choicesGender, race/ethnic, and nativity patterns. Sociological Perspectives, 52(2), 211-234.

Magolda, M. B. (2001). Making their own way: Narratives for transforming higher education to promote self-authorship. Sterling, VA: Stylus.

Magolda, M. B. (2008). Three elements of self-authorship. Journal of College Student Development, 49(4), 269-284.

Malecki, C. K., \& Demaray, M. K. (2003). What type of support do they need? Investigating student adjustment as related to emotional, informational, appraisal, and instrumental support. School Psychology Quarterly, 18(3), 231.

Malgwi, C. A., Howe, M. A., \& Burnaby, P. A. (2005). Influences on students' choice of college major. Journal of Education for Business, 80(5), 275-282. 
Marshall, C., \& Rossman, G. (1989). B. (1999). Designing qualitative research. Newbury Park/London/New Delhi.

Matney M. \& Borland K. (2009) Facebook, blogs, tweets: How staff and units can use social networking to enhance student learning. Presentation at the annual meeting of the National Association for Student Personnel Administrators, Seattle, WA.

Maxwell, J. A. (2005). Qualitative research design: An interactive approach (2nd ed.). Thousand Oaks, CA: SAGE publication.

Menand, L. (2010) The Marketplace of Ideas: Reform and Resistance in the America University. New York: Norton \& Co.

Miles, M. B., \& Huberman, A. M. (1994). Qualitative data analysis: A sourcebook. Beverly Hills: Sage Publications.

Morgan, S. L., Gelbgiser, D., \& Weeden, K. A. (2013). Feeding the pipeline: Gender, occupational plans, and college major selection. Social Science Research, 42(4), 9891005.

Mortenson, T. (2014). Unequal family income and unequal higher education opportunity, 1970 to 2013. Postsecondary Educational Opportunity, no. 267, Washington, D. C.: Pell Institute for the Study of Opportunity in Higher Education.

Musil, C. M. (2015). A step away from complacent knowing: Reinvigorating democracy through the humanities. Arts and Humanities in Higher Education, 14(3), 239-259.

National Academy of Science. (2007). Rising above the gathering storm: Energizing and employing America for a brighter economic future. Washington, DC: The National Academies Press. 
National Center for Education Statistics (NCES). (2015a). Institutional Retention and Graduation Rates for Undergraduate Students. Retrieved from http://nces.ed.gov/programs/coe/indicator_cva.asp.

National Center for Education Statistics (NCES). (2015b). The condition of education: postsecondary education: Undergraduate degree fields. Retrieved from http://nces.ed.gov/programs/coe/indicator_cta.asp.

National Foundation on the Arts and the Humanities Act of 1965, 20 U.S.C $\S \S 89-209$. (1965, 1985). Retrieved from http://www.gpo.gov/fdsys/pkg/STATUTE-79/pdf/STATUTE-79Pg845.pdf.

National Research Council. (2012). Research Universities and the Future of America: Ten Breakthrough Actions Vital to Our Nation's Prosperity and Security. Washington, DC: The National Academies Press.

National Task Force on Civic Learning and Democratic Engagement (2012). A crucible moment: college learning and democracy's future. Washington, DC: Association of American Colleges \& Universities.

Nauta, M. M. (2007). Assessing college students' satisfaction with their academic majors. Journal of Career Assessment, 15(4), 446-462.

Nussbaum, M. (2010). Not for profit. Why democracy needs the humanities. Princeton: Princeton University Press.

Obama, B. (24, February 2009). Remarks of President Barack Obama. Address to the Joint Session of Congress.

OECD. (2013). Education at a glance. Retrieved from http://www.oecd.org/edu/eag.htm. 
O’Neill, N. (2010). Internships as a high-impact practice: Some reflections on quality. Peer Review, 12(4), 4-8.

Ostrove, J. M., \& Long, S. M. (2007). Social class and belonging: Implications for college adjustment. The Review of Higher Education, 30(4), 363-389.

Pascarella, E. T., \& Terenzini, P. T. (2005). How college affects students (Vol. 2). K. A. Feldman (Ed.). San Francisco, CA: Jossey-Bass.

Pinsker, J. (2015). Rich kids study English. The Atlantic. Retrieved from http://www.theatlantic.com/business/archive/2015/07/college-major-rich-families-liberal$\operatorname{arts} / 397439 /$

Pike, G. R. (2006). Students' personality types, intended majors, and college expectations: Further evidence concerning psychological and sociological interpretations of Holland's theory. Research in Higher Education, 47, 801-822.

Pittaoulis, M. (2012). Getting through school: A study of how students select their college majors and plan for the future. (Doctoral dissertation). Temple University, Philadelphia, PA.

Porter, S. R., \& Umbach, P. D. (2006). College major choice: An analysis of personenvironment fit. Research in Higher Education, 47, 429-449.

President's Commission on Higher Education. (1947). Higher Education for American Democracy Volume I. New York: Harper and Brothers.

Redden, E. (2016, April 13). President of Ireland Affirms Value of the Humanities. Inside Higher Education. Retrieved from https://www.insidehighered.com/quicktakes/2016/04/13/president-ireland-affirms-valuehumanities 
Ridgeway, C. L., \& Fisk, S. R. (2012). Class rules, status dynamics, and "gateway" interactions. In S. T. Fiske \& H. R. Markus (Eds.), Facing social class: How societal rank influences interaction (pp. 131-151). New York, NY: Russell Sage Foundation.

Riegle-Crumb, C., \& King, B. (2010). Questioning a white male advantage in STEM examining disparities in college major by gender and race/ethnicity. Educational Researcher, 39(9), 656-664.

Renn, K.A. \& Arnold, K.D. (2003). Reconceptualizing research on college student peer culture. The Journal of Higher Education, 74, 261-291.

Rugg, G., \& McGeorge, P. (2005). The sorting techniques: a tutorial paper on card sorts, picture sorts and item sorts. Expert Systems, 22(3), 94-107.

Sanchez, R. J., Bauer, T. N., \& Paronto, M. E. (2006). Peer-mentoring freshmen: Implications for satisfaction, commitment, and retention to graduation. Academy of Management Learning \& Education, 5(1), 25-37.

Saks, R. E., \& Shore, S. H. (2005). Risk and career choice. The BE Journal of Economic Analysis \& Policy, 5(1).

Salant, P., \& Dillman, D. A. (1994). How to conduct your own survey. New York: Wiley. Sanford, N. (1967). Where colleges fail: A study of the student as a person. San Francisco: Jossey-Bass.

Schlossberg, N. K. (1989). Marginality and mattering: Key issues in building community. New directions for student services, 1989(48), 5-15.

Schulten, K. (2013). Is It an Unaffordable Luxury to Major in the Humanities in College? The New York Times. Retrieved from http://learning.blogs.nytimes.com/2013/11/06/is-it-awaste-of-time-to-study-the-humanities-in-college/ 
Schunk, D.H. (1991). Self-efficacy and academic motivation. Educational Psychologist, 26, 207231.

Scrivener, S., Weiss, M. J., Ratledge, A., Rudd, T., Sommo, C., \& Fresques, H. (2015). Doubling graduation rates: Three-year effects of CUNY's accelerated study in associate programs (ASAP) for developmental education students. New York: MDRC.

Seidman, I. (2013). Interviewing as qualitative research: A guide for researchers in education and the social sciences. Teachers college press.

Selingo, J. (2016). There is life after college: What parents and students should know about navigating school to prepare for the jobs of tomorrow. New York, NY: Harper Collins.

Sheridan, J., Chamberlain, K., \& Dupuis, A. (2011). Timelining: visualizing experience. Qualitative Research, 11(5), 552-569.

Shernoff, D. J., \& Hoogstra, L. (2001). Continuing motivation beyond the high school classroom. New Directions for Child and Adolescent Development, 93, 73-87.

Simpson, J. C. (2001). Segregated differences by subject: Racial differences in the factors influencing academic major between European Americans, Asian Americans, and African, Hispanic, and Native Americans. Journal of Higher Education 72(1): 63-100.

Smart, J. C., Feldman, K. A., \& Ethington, C. A. (2000). Academic disciplines: Holland's theory and the study of college students and faculty. Nashville, TN: Vanderbilt University Press.

Sparks, E., \& Waits, M. J. (2011). Degrees for What Jobs? Raising Expectations for Universities and Colleges in a Global Economy. NGA Center for Best Practices.

St. John, E. (2000). Majors. Black Issues In Higher Education, 21-27.

Stake, R. E. (2005). Qualitative case studies. The Sage handbook of qualitative research, 443466. 
Staniec, J. F. O. (2004). The effects of race, sex, and expected returns on the choice of college major. Eastern Economic Journal, 549-562.

Stanton-Salazar, R. (1997). A social capital framework for understanding the socialization of racial minority children and youths. Harvard educational review, 67(1), 1-41.

Stebleton, M. J. (2011). Understanding immigrant college students: Applying a developmental ecology framework to the practice of academic advising. NACADA Journal, 31(1), 42-54.

Strategic National Arts Alumni Project (SNAAP). (2013). Snaapshot 2013, debt \& earnings. Retrieved from http://snaap.indiana.edu/snaapshot/\#debt

Swan, A. K. (2011). Exploring the experiences of female students in introductory project-based engineering courses at two- and four-year institutions. (Doctoral dissertation). University of Virginia, Charlottesville, VA.

Swanson, J. L., \& Woitke, M. B. (1997). Theory into practice in career assessment for women: Assessment and interventions regarding perceived career barriers. Journal of Career Assessment, 5, 431-450.

Tashakkori, A., \& Teddlie, C. (1998). Mixed methodology: Combining qualitative and quantitative approaches. Thousand Oaks, CA: Sage.

Terras, M., Priego, E., Liu, A., Rockwell, G., Sinclair, S., Hensler, C., and Thomas, L. (2013). The humanities matter! Retrieved from http://www.4humanities.org/infographic.

Thelin, J. R. (2011). A history of American higher education. 2nd ed. Baltimore, MD: The Johns Hopkins University Press.

Thompson, R. J. (2014). Beyond reason and tolerance: The purpose and practice of higher education. New York: Oxford University Press. 
Tierney, W. G. (2000). Power, identity, and the dilemma of college student departure. Reworking the student departure puzzle, 213-234.

Tinto, V. (1993). Building community. Liberal Education, 79(4), 16-21.

Trusty, J. (1998). Family influences on educational expectations of late adolescents. The Journal of educational research, 91(5), 260-271.

U.S. Department of Education (2016). Fulfilling the promise, serving the need: Advancing college opportunity for low-income students. Washington, DC: U.S. Department of Education.

U.S. Department of Health and Human Services (2016). United States Federal Poverty Guidelines. Retrieved from https://aspe.hhs.gov/poverty-guidelines.

Van Dyke, R. (2013, November 13). Losing faith in the humanities. The State Times. Retrieved from http://thestatetimes.com/2013/11/13/losing-faith-in-the-humanities/

Vedder, R., Denhart, C., \& Robe, J. (2013). Why Are Recent College Graduates Underemployed? University Enrollments and Labor-Market Realities. Center for College Affordability and Productivity (NJ1).

Vogel, R. M., \& Feldman, D. C. (2009). Integrating the levels of person-environment fit: The roles of vocational fit and group fit. Journal of Vocational Behavior, 75(1), 68-81.

Walpole, M. (2003) Socioeconomic status and college: How SES affects college experiences and outcomes. Review of Higher Education, 27(1), 45-73.

Walpole, M. (2011). Academics, campus administration, and social interaction: Examining campus structures using post-structural theory. In A. Kezar (Ed.). Recognizing and serving low-income students in higher education: An examination of institutional policies, practices and culture (p. 99-120). New York, NY: Routledge. 
Wang, X. (2013). Why students choose stem majors: motivation, high school learning, and postsecondary context of support. American Educational Research Journal, 50(5), 10811121. doi:10.3102/0002831213488622

White House. (2014). Increasing college opportunity for low-income students promising models and a call to action. The Executive Office of the President: Issue Brief.

White House. (2015). A new college scorecard. Statement from the Press Secretary. Retrieved from https:/www.whitehouse.gov/the-press-office/2015/09/12/weekly-address-newcollege-scorecard

Xie, Y. \& Shauman, K. (2003). Women in science: Career processes and outcomes. Cambridge, MA: Harvard University Press.

Yin, R. K. (1994). Discovering the future of the case study method in evaluation research. Evaluation practice, 15(3), 283-290.

Yin, R. K. (1994). Case study research: Design and methods (4th ed.). Thousand Oaks, CA: Sage.

Zhang, W. (2007). Why IS: Understanding undergraduate students' intentions to choose an Information Systems major. Journal of Information Systems Education, 18(4), 447.

Zimmerman, M. A., Bingenheimer, J. B., \& Behrendt, D. E. (2005). Natural mentoring relationships. In D. L. DuBois \& M. J. Karcher (Eds.), Handbook of Youth Mentoring (pp. 143-157). Thousand Oaks, CA: Sage.

Zook, G. F. (1947). Higher education for American democracy: A Report (Vol. 1). U.S. Government Printing Office. 
Zumbrunn, S., McKim, C., Buhs, E., \& Hawley, L. R. (2014). Support, belonging, motivation, and engagement in the college classroom: A mixed method study. Instructional Science, 42(5), 661-684. 


\section{Appendix A}

Mid-Atlantic University (MAU) academic degree programs identified within the National Foundation of the Arts and the Humanities Act (1965) definition for humanities study and, given the contemporary nature of emerging degree programs, the American Academy of Arts \& Sciences Humanities Indicators measures. Degree programs identified with an asterisk (*) below are considered interdisciplinary by MAU but possess at least 50 percent of degree requirements in humanities courses, therefore, were included for this study.

- African-American Studies \& African Studies

- American Studies (all concentrations)*

- Area Studies - Latin American Studies

- Archaeology*

- Art (History and Studio)

- Chinese Language and Literature*

- Classics (Latin and Greek)

- Comparative Literature

- Drama

- East Asian Studies*

- English (Medieval \& Renaissance, Modern Studies, Poetry Writing)

- French

- German

- German Studies*

- History

- Italian

- Japanese Language \& Literature*

- Jewish Studies*

- Linguistics*

- Media Studies - Policy \& Ethics*

- Medieval Studies*

- Middle Eastern Languages and Literatures*

- Middle Eastern Studies*

- Music

- Philosophy

- Political \& Social Thought*

- Political Philosophy, Policy \& Law*

- Religious Studies (African Religions, Buddhism, Christianity, Hinduism, Islam, Judaism)

- Slavic Languages \& Literatures (Russian \& East European Studies, Language, Literature)

- South Asian Languages \& Literatures*

- South Asian Studies*

- Spanish (General, Linguistics \& Philosophy, Literature \& Culture)

- Women, Gender, and Sexuality* 


\section{Appendix B}

\section{Survey Consent and Instrument}

\section{Introduction and Informed Consent Agreement}

Thank you for your interest in participating in the project entitled "Academic Decision-Making and Major Choice." Please read this consent agreement carefully before you decide to participate in the study.

This study aims to understand the influences shaping the choice of academic major for low-income students across various points in the college career. More specifically, we are interested in understanding the individuals, experiences, influences, and resources contributing to efficacious decision-making. To help us understand these influences, you will be asked to (a) complete an online survey and (b) may be contacted regarding participation in paid, follow up interviews.

You may skip any question that makes you uncomfortable and may stop the survey at any time by simply closing the browser. The study will require approximately 15 minutes of your time.

There are no anticipated risks associated with this study. There are also no direct benefits to you for participating in this research study. The study may help us understand the academic and social experiences of students who are the first in their families to attend college or have overcome financial or other challenges to enroll in college and thus improve future programs and services.

\section{Those who complete the entire survey will receive a $\$ 10$ Amazon gift card delivered via email within 72 hours of completion.}

The information that you give in the study will be handled confidentially. Your information will be assigned a 5-digit number. The list connecting your name to this numeric code will be kept in a locked file. When the study is completed and the data have been analyzed, this list will be destroyed. If the results of this study are published, there will be no information that would identify you as a participant.

Your participation in the study is completely voluntary. You have the right to withdraw from the study at any time without penalty. To withdraw, simply exit the survey by closing your browser window.

If you have questions about the study, contact:

Sarah E. Whitley

Doctoral Candidate, Higher Education

Curry School of Education

University of Virginia, Charlottesville, VA22903.

Telephone: (804) 691-2838

Email: sew4dq@virginia.edu

If you have questions about your rights in the study, contact:

Tonya R. Moon, Ph.D.

Chair, Institutional Review Board for the Social and Behavioral Sciences

One Morton Dr Suite 500

University of Virginia, P.O. Box 800392

Charlottesville, VA 22908-0392

Telephone: (434) 924-5999

If you chose to not participate in this survey, simply close this browser window.

By selecting the arrow at the bottom right and proceeding to the survey, you are agreeing to participate in the study as described above. 
Think back to when you were applying to college. From only the list of academic majors below, please identify only those you were considering at the time of your admission. Drag those majors from the column on the left into the boxes on the right based upon your level of interest.

\section{If you do not move a major, it is understood that you had NO interest in this major.}

Items

African-American and African Studies

American Studies (all concentrations)

Area Studies - Latin American Studies

Archeology

Art (Studio/Art History

Chinese Language and Literature

Classics (Greek, Latin)

Comparative Literature

Drama

East Asian Studies

English (all concentrations)

French

German

German Studies

History

Italian

Japanese Language \& Literature

Jewish Studies

Linguistics

Media Studies - Policy \& Ethics

Medieval Studies

Middle Eastern Languages \&

Literatures

Middle Eastern Studies

Music

Philosophy

Political \& Social Thought

Political Philosophy, Policy \& Law

Religious Studies (all

concentrations)

Slavic Languages \& Literatures (all concentrations)

South Asian Languages \&

Literatures

South Asian Studies

Spanish (all concentrations)

Women, Gender \& Sexuality

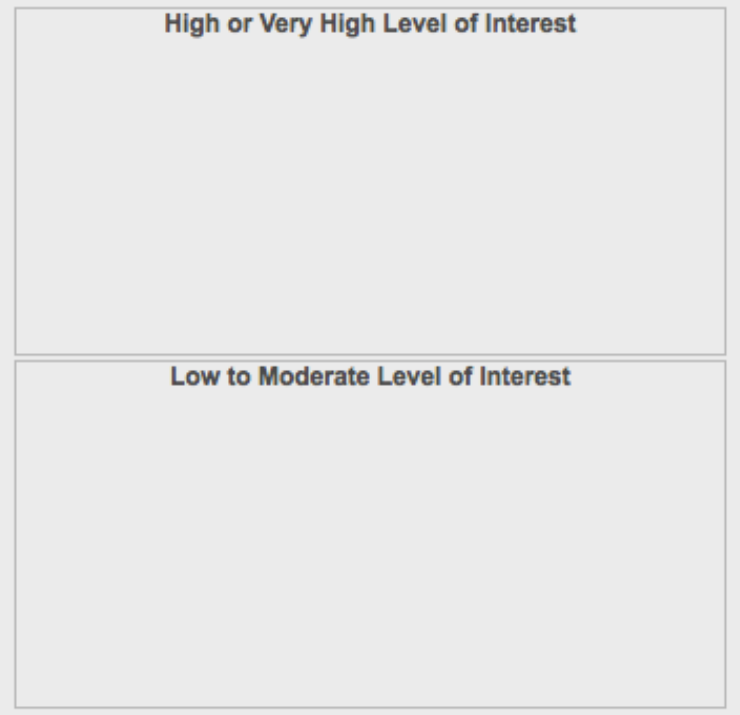


The next section includes questions related to your choice of academic major since arriving at

Have you officially declared an academic major or majors at the University of Virginia?

Yes, I've officially declared my major(s)

No, I've not yet officially declared my major(s)

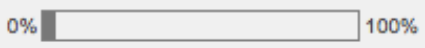

If student selected "Yes, I've officially declared my major, questions branched to the following:

From the list below, please select the primary academic major you've declared:

Have you declared a secondary academic major?

Yes, I've declared a second academic major.

No, I have only declared one major and do not plan to declare another.

No, I have only declared one major but am considering adding a second. 
From the list below, please select the secondary academic major you've declared or plan to declare.

To select multiple options, please use the "command" key when selecting.

\begin{tabular}{l} 
African-American and African Studies \\
American Studies (all concentrations) \\
Anthropology \\
Archaeology \\
Architecture/Arch History (all concentrations) \\
Area Studies - Latin American Studies \\
Art - Studio/Art History (all concentrations) \\
Astronomy/Astronomy-Physics \\
Biology Public Policy and Leadership \\
\hline
\end{tabular}

Which of the following best describes the timing of your major declaration?

I applied for admission to my major as soon as I was eligible.

I declared my major (no application required) as soon as I was eligible.

It was sometime between when I was eligible and the deadline; I wasn't in a big hurry.

I waited until close to the required deadline for declaring my major.

The university had to contact me and ask that I declare my major. I missed the deadline.

Please indicate the degree to which you agree or disagree with the following statements regarding your declared academic major.

Strongly Disagree
I often wish I had not gotten into
this major.
I wish I was happier with my
choice of an academic major.
I am strongly considering
changing to another major.
Overall, I am happy with the
major I've chosen.
I feel good about the major I've
selected.
I would like to talk to someone
about changing my major.


If a student previously responded as "No, I have not yet officially declared my major," questions branched to the following:

Please select ALL the academic major(s) you are considering at this time.

To select multiple options, please use the "command" key when selecting.

\begin{tabular}{l} 
African-American and African Studies \\
American Studies (all concentrations) \\
Anthropology \\
Archaeology \\
Architecture/Arch History (all concentrations) \\
Area Studies - Latin American Studies \\
Art - Studio/Art History (all concentrations) \\
Astronomy/Astronomy-Physics \\
\hline \\
Biology Public Policy and Leadership
\end{tabular}

How confident are you in declaring a major at this point in your academic career?

Very Confident

Confident

Lacking Some Confidence

Not Confident 
At this point, all students resumed the following sequence of questions.

The following section concerns the challenges, resources, and influences involved in selecting an academic major.

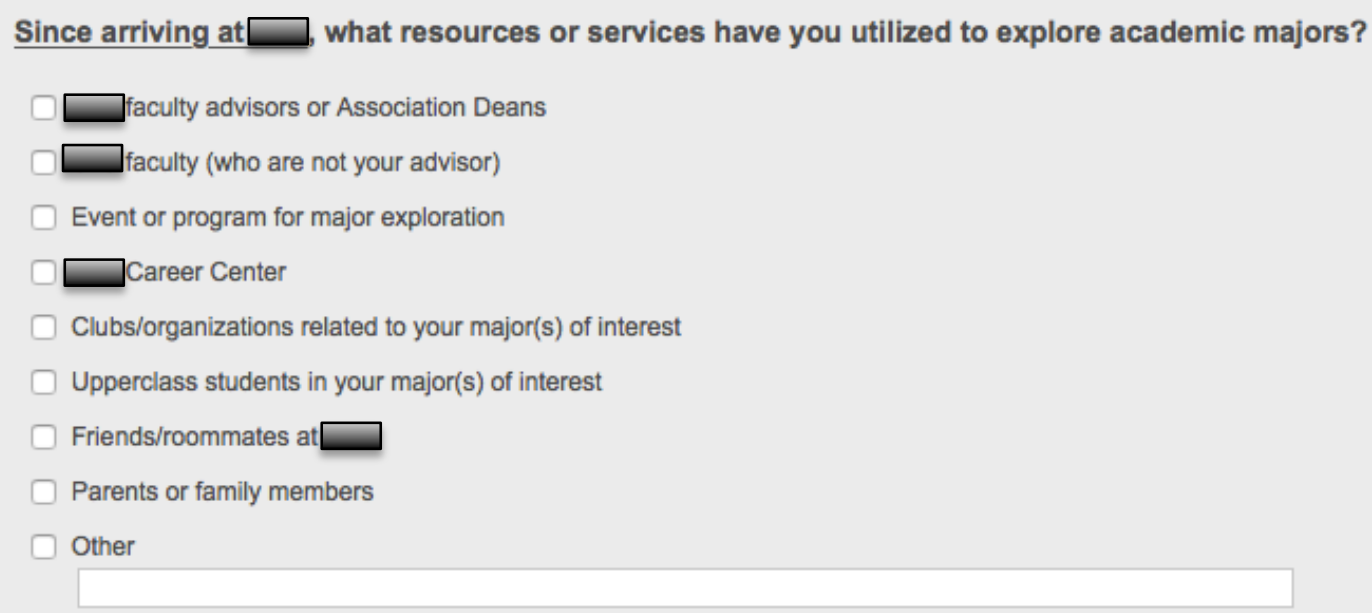

Since arriving at $\square$ who have been the most influential individuals involved in your academic major decision-process?

Parents
Grandparents
Siblings
Other family members
Significant Other
Friends/Classmates at

Parents

Frends/Classmates

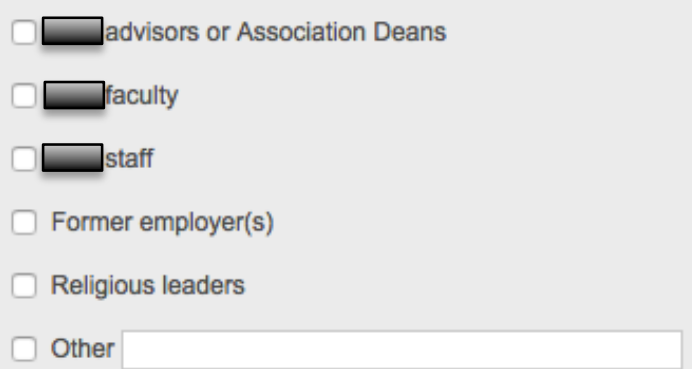




\section{What would you consider to be your greatest challenges in declaring an academic major?}

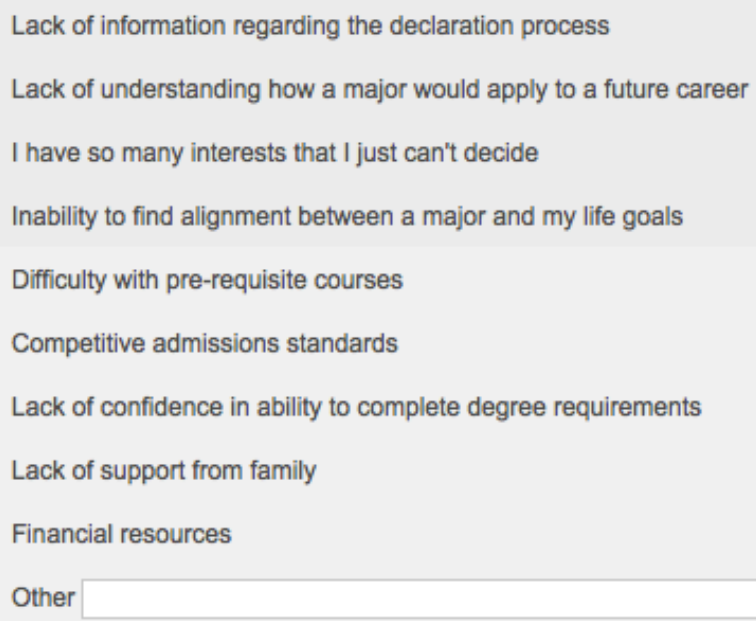

Through what media outlets (i.e., TV, internet, newspapers, blogs, social media etc.) do you typically gather news and information? If you use specific outlets to learn about higher education or your academic interests, please be sure to include those.

From the broad categories below, please select those that best describe your extracurricular involvement at

Check all that apply.

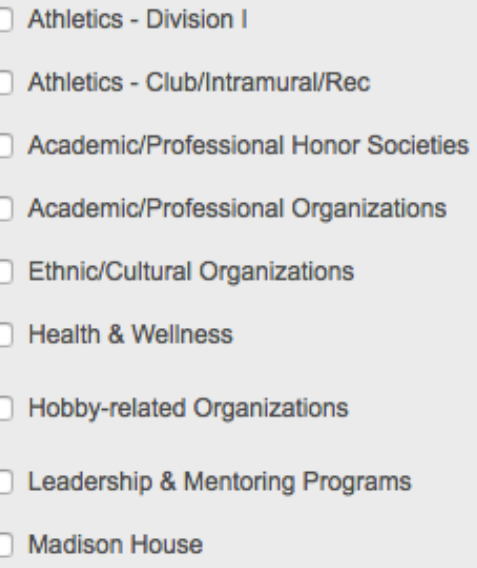


From the broad categories below, please select those that best describe how your spend your free time.

Check all that apply.

Attending church services/religious events

Practicing a personal hobby or interest

Attending parties/social events

Visiting family and friends at home

$\square$ Attending $\square$ sponsored programs or events

Visiting friends at other colleges

Hanging out with friends

Watching movies/TV (i.e., Netflix, Hulu)

$\square$ Informal sports

Working out/Going to the gym

Playing video games

Working a part-time job

Reading for pleasure

Other

Please indicate how strongly you agree or disagree with the following statements regarding influences on your choice of academic major:

My choice of academic major is influenced by:

\begin{tabular}{|c|c|c|c|c|c|}
\hline & Strongly Agree & Agree & Neutral & Disagree & Strongly Disagree \\
\hline My parents or immediate family & 0 & 0 & 0 & 0 & 0 \\
\hline My friends at $\square$ & 0 & 0 & 0 & 0 & 0 \\
\hline My friends from home & 0 & 0 & 0 & 0 & 0 \\
\hline Experiences with faculty at $\square$ & 0 & 0 & 0 & 0 & O \\
\hline $\begin{array}{l}\text { Experiences with high school } \\
\text { teachers }\end{array}$ & 0 & 0 & 0 & 0 & 0 \\
\hline $\begin{array}{l}\text { Classroom experiences I've had } \\
\text { at } \square\end{array}$ & 0 & 0 & 0 & 0 & D \\
\hline $\begin{array}{l}\text { Classroom experiences I had in } \\
\text { high school }\end{array}$ & 0 & 0 & 0 & 0 & 0 \\
\hline Personal interests or hobbies & 0 & 0 & 0 & 0 & 0 \\
\hline Academic skills or aptitude & 0 & 0 & 0 & 0 & 0 \\
\hline
\end{tabular}


My choice of academic major is influenced by:

\begin{tabular}{|c|c|c|c|c|c|}
\hline & Strongly Agree & Agree & Neutral & Disagree & Strongly Disagree \\
\hline $\begin{array}{l}\text { My perceived ability to get a job } \\
\text { after college. }\end{array}$ & 0 & $\mathrm{O}$ & 0 & O & 0 \\
\hline $\begin{array}{l}\text { My perceived ability to make a } \\
\text { lucrative income after college. }\end{array}$ & 0 & 0 & 0 & 0 & 0 \\
\hline $\begin{array}{l}\text { My ability to help others or make } \\
\text { a difference through pursuing } \\
\text { this major. }\end{array}$ & O & 0 & 0 & 0 & O \\
\hline $\begin{array}{l}\text { Messages I hear from } \\
\text { policymakers regarding the } \\
\text { importance of my major. }\end{array}$ & $\mathrm{O}$ & $\mathrm{O}$ & $\mathrm{O}$ & $\mathrm{O}$ & \\
\hline $\begin{array}{l}\text { Messages I hear from family \& } \\
\text { friends regarding the importance } \\
\text { of my major. }\end{array}$ & O & $\mathrm{O}$ & O & 0 & 0 \\
\hline $\begin{array}{l}\text { Messages I hear from media } \\
\text { regarding the importance of my } \\
\text { major. }\end{array}$ & O & $\mathrm{O}$ & $\mathrm{O}$ & 0 & 0 \\
\hline
\end{tabular}

My choice of academic major is influenced by:

\begin{tabular}{|c|c|c|c|c|c|}
\hline & Strongly Agree & Agree & Neutral & Disagree & Strongly Disagree \\
\hline $\begin{array}{l}\text { Involvement (i.e., clubs, } \\
\text { organizations, athletics) I } \\
\text { enjoyed in high school. }\end{array}$ & 0 & 0 & 0 & 0 & O \\
\hline $\begin{array}{l}\text { Clubs and organizations (i.e., } \\
\text { clubs, organizations, athletics) I } \\
\text { enjoy in college. }\end{array}$ & O & 0 & 0 & O & O \\
\hline $\begin{array}{l}\text { General education courses I've } \\
\text { taken at UVa }\end{array}$ & 0 & 0 & 0 & 0 & 0 \\
\hline $\begin{array}{l}\text { Pre-requisite courses for the } \\
\text { major I've taken at UVa }\end{array}$ & 0 & 0 & 0 & O & 0 \\
\hline $\begin{array}{l}\text { AP, IB, Dual Enrollment or } \\
\text { simular courses taken during } \\
\text { high school }\end{array}$ & O & 0 & 0 & 0 & $\mathrm{C}$ \\
\hline $\begin{array}{l}\text { Internships, shadowing or other } \\
\text { related practical experiences }\end{array}$ & 0 & 0 & 0 & 0 & 0 \\
\hline $\begin{array}{l}\text { Future interest in attending } \\
\text { graduate school }\end{array}$ & 0 & 0 & 0 & O & O \\
\hline
\end{tabular}

\section{My choice of academic major is influenced by:}

Strongly Agree
Opportunities to participate in
undergraduate research
Opportunities to enhance critical
thinking and analytic reasoning
skills
Opportunities to enhance oral
and written communication skills
Opportunities to explore diverse
populations and cultures
Opportunities to develop
personally and intellectually


My choice of academic major is influenced by:

\begin{tabular}{|c|c|c|c|c|c|}
\hline & Strongly Agree & Agree & Neutral & Disagree & Strongly Disagree \\
\hline my race or ethnicity & $\bigcirc$ & $\bigcirc$ & 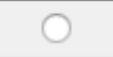 & O & $\bigcirc$ \\
\hline my gender identification & $\mathrm{O}$ & 0 & $\mathrm{O}$ & O & $\mathrm{O}$ \\
\hline my socioeconomic status & $\mathrm{O}$ & 0 & 0 & 0 & 0 \\
\hline my religion & O & O & O & $\mathrm{O}$ & O \\
\hline my sexual orientation & 0 & $\mathrm{O}$ & 0 & O & $\mathrm{O}$ \\
\hline my political affiliation & 0 & 0 & 0 & 0 & $\mathrm{O}$ \\
\hline
\end{tabular}

After completing your degree, how important are the following outcomes to you?

\begin{tabular}{|c|c|c|c|c|}
\hline & Not Important & Somewhat Important & Very Important & Essential \\
\hline $\begin{array}{l}\text { Becoming accomplished in one } \\
\text { of the performing arts (e.g., } \\
\text { acting, dancing, singing, etc.) }\end{array}$ & O & O & O & 0 \\
\hline $\begin{array}{l}\text { Creating artistic work (e.g., } \\
\text { painting, sculpture, film, etc.) }\end{array}$ & 0 & 0 & O & O \\
\hline $\begin{array}{l}\text { Writing original works (e.g., } \\
\text { poems, novels, short stories, } \\
\text { etc.) }\end{array}$ & 0 & 0 & & \\
\hline $\begin{array}{l}\text { Making a theoretical contribution } \\
\text { to science }\end{array}$ & 0 & O & & \\
\hline $\begin{array}{l}\text { Working to find a cure for a } \\
\text { disease or illness }\end{array}$ & 0 & 0 & O & O \\
\hline \multirow[t]{2}{*}{ Becoming a community leader } & 0 & 0 & 0 & 0 \\
\hline & Not Important & Somewhat Important & Very Important & Essential \\
\hline $\begin{array}{l}\text { Becoming involved in activities } \\
\text { that preserve and enrich the } \\
\text { environment }\end{array}$ & O & 0 & O & \\
\hline $\begin{array}{l}\text { Helping others who are in } \\
\text { difficulty }\end{array}$ & 0 & 0 & $\mathrm{O}$ & O \\
\hline $\begin{array}{l}\text { Improving my understanding of } \\
\text { other countries and cultures }\end{array}$ & 0 & 0 & 0 & 0 \\
\hline $\begin{array}{l}\text { Keeping up to date with political } \\
\text { affairs }\end{array}$ & 0 & $\mathrm{O}$ & 0 & O \\
\hline $\begin{array}{l}\text { Developing a meaningful } \\
\text { philosophy of life }\end{array}$ & 0 & O & 0 & 0 \\
\hline $\begin{array}{l}\text { Helping to promote racial } \\
\text { understanding }\end{array}$ & 0 & 0 & O & 0 \\
\hline
\end{tabular}




\begin{tabular}{|c|c|c|c|c|}
\hline & Not Important & Somewhat Important & Very Important & Essential \\
\hline \multicolumn{5}{|l|}{ Influencing social values } \\
\hline \multicolumn{5}{|c|}{ Influencing the political structure } \\
\hline \multicolumn{5}{|l|}{ Integrating spirituality into my life } \\
\hline \multicolumn{5}{|l|}{ Volunteering in my community } \\
\hline \multicolumn{5}{|l|}{$\begin{array}{l}\text { Obtaining recognition from my } \\
\text { colleagues for contributions to } \\
\text { my field of expertise }\end{array}$} \\
\hline \multicolumn{5}{|l|}{$\begin{array}{l}\text { Having administrative } \\
\text { responsibility for the work of } \\
\text { others }\end{array}$} \\
\hline & Not Important & Somewhat Important & Very Important & Essential \\
\hline \multicolumn{5}{|l|}{$\begin{array}{l}\text { Working in a prestigious } \\
\text { occupation }\end{array}$} \\
\hline \multicolumn{5}{|l|}{ Making a lot of money } \\
\hline $\begin{array}{l}\text { Becoming successful in a } \\
\text { business of my own }\end{array}$ & & & & \\
\hline
\end{tabular}

It is important that my future career...

allows me to live in a particular geographic
location
provides flexibility for having/raising children
includes business travel
allows me to remain near my parents/family
offers a competitive benefits package
supports graduate or continuing education

\section{Since arriving at $\square$ how often have you done the following:}

Talked about career plans with a faculty member
Worked with a faculty member on activities other
than coursework (committees, student groups, etc.)
Worked with a faculty member on a research project
Discussed course topics, ideas, or concepts with a
faculty member outside of class
Discussed your academic performance with a
faculty member




\section{The next two questions will ask questions regarding your opinions of college attendance and majors.}

People choose to attend college for different reasons. From the list below, select the FIVE (5) most important reasons why YOU chose to attend college.

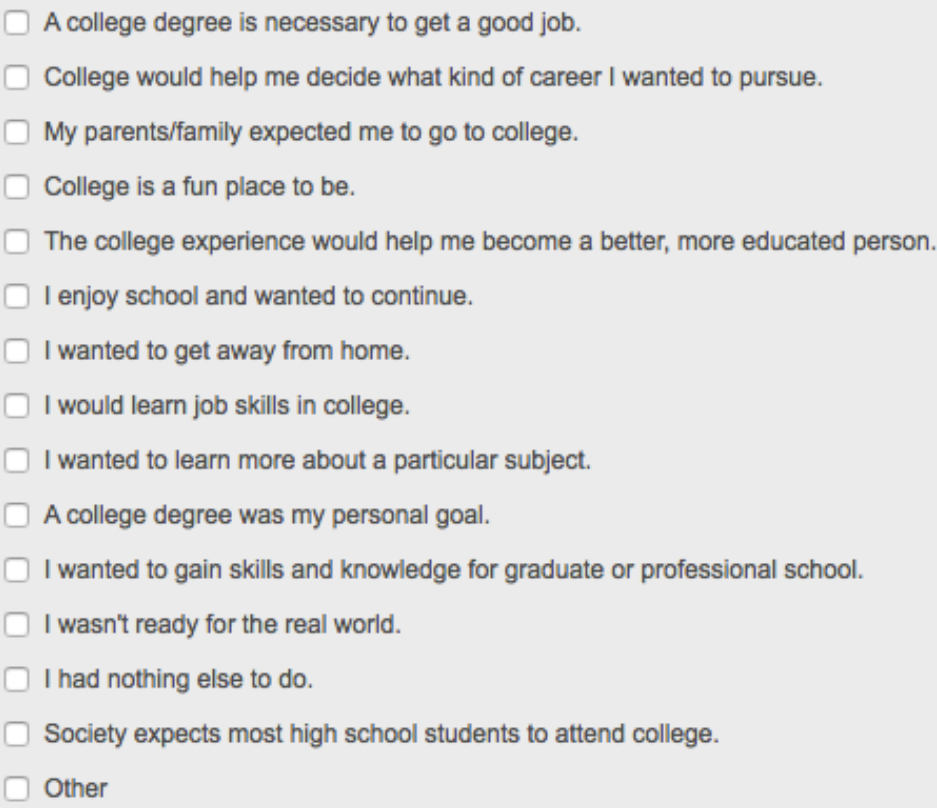

Let's continue with a few questions related to your academic and extracurricular experiences PRIOR to attending

Which of the following best describes your high school?

Note: If you attended multiple high schools, please select the one where you spent the most time.

Public

Private, Catholic

Private, Other Religions

Private, Non-Religious

Boarding School

Specialty School (i.e., Math \& Science, Performing Arts)

lational Baccalaureate (IB) or Dual Enrollment (DE) courses 
Please select the Advanced Placement (AP), International Baccalaureate (IB) or Dual Enroliment (DE) courses you completed while in high school.

Note: you may select a course even if you did not take the exam associated with the course.

\begin{tabular}{|c|c|}
\hline Research & $\square$ Computer Science \\
\hline Art History & $\square$ Statistics \\
\hline Music Theory & $\square$ Biology \\
\hline Studio Art: Design & $\square$ Chemistry \\
\hline Studio Art: Drawing & $\square$ Environmental Science \\
\hline English Language and Composition & $\square$ Physics: Electricity and Magnetism \\
\hline English Literature and Composition & Physics: Mechanics \\
\hline Comparative Government and Politics & $\square$ Chinese Language and Culture \\
\hline European History & $\square$ French Language and Culture \\
\hline Human Geography & $\square$ German Language and Culture \\
\hline Macroeconomics & $\square$ Italian Language and Culture \\
\hline Microeconomics & $\square$ Japanese Language and Culture \\
\hline Psychology & $\square$ Latin \\
\hline United States Government and Politics & $\square$ Spanish Language and Culture \\
\hline United States History & $\square$ Spanish Literature and Culture \\
\hline World History & Other (please specify) \\
\hline
\end{tabular}

Using the groups below, please select those which best describe your extracurricular involvement PRIOR to attending $\square$

Check all that apply.

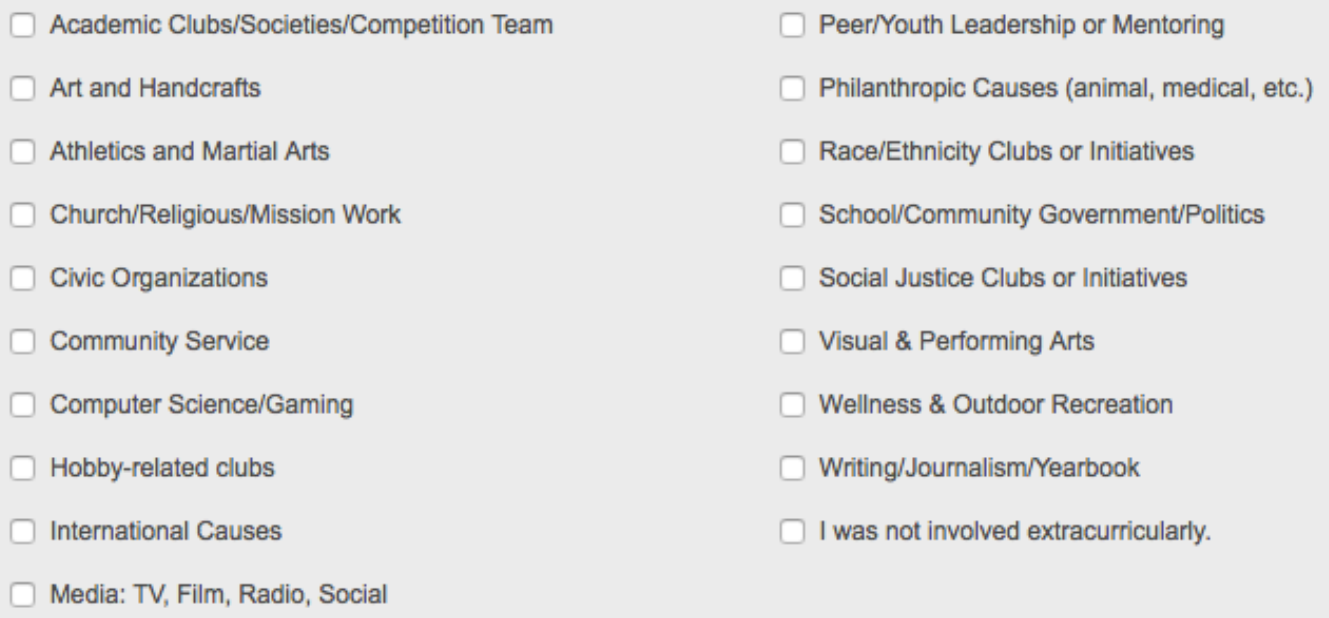


Across your life, how often have you done the following:

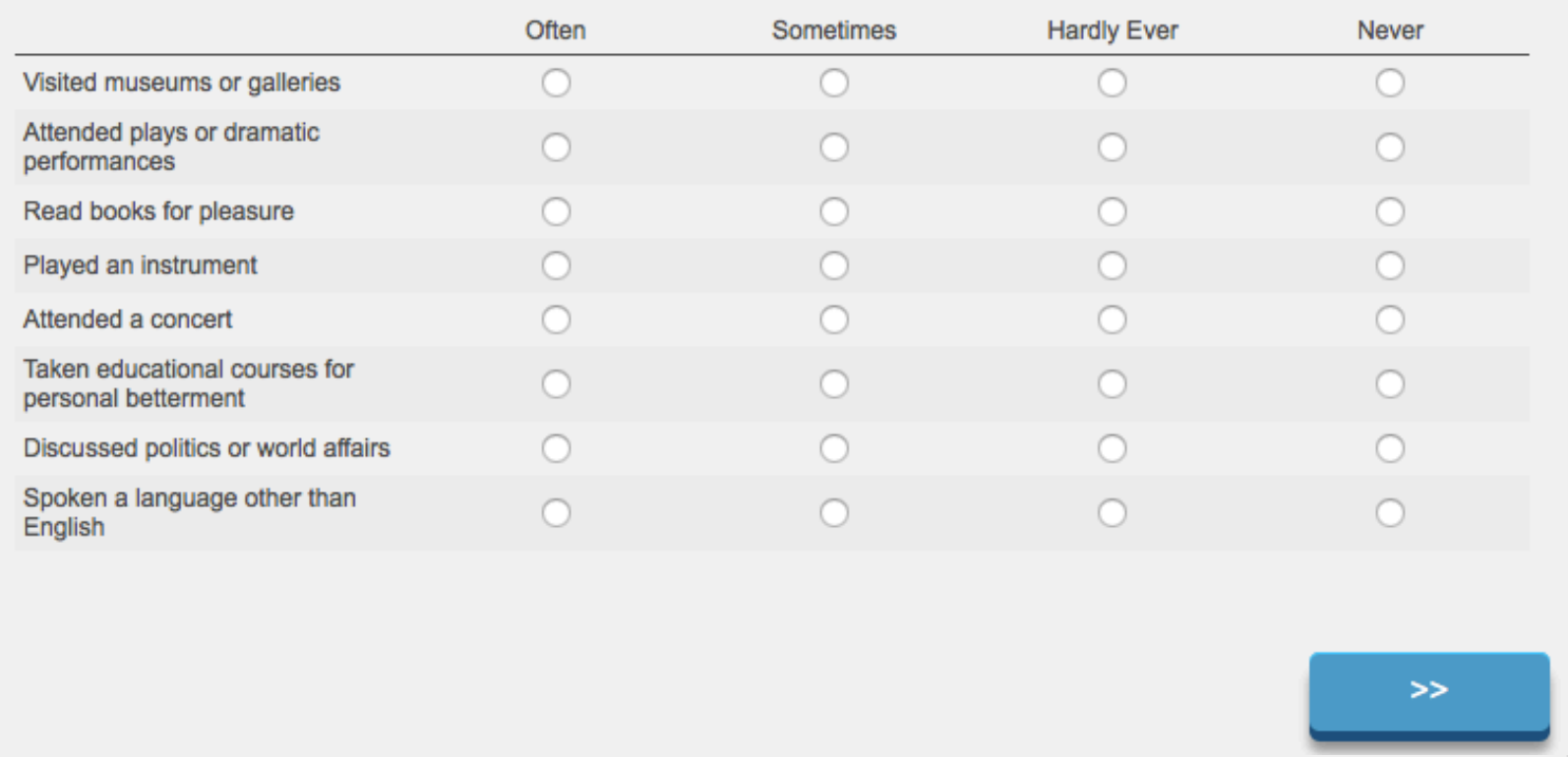

Prior to attending $\square$ what resources or services did you utilize to explore academic majors you were considering for college?

Check all that apply.

High school guidance counselor(s)

College preparation or information fairs

$\square$ Tests or quizzes about potential majors

$\square$ Shadowing or internship opportunities

$\square$ Internet research on majors

$\square$ Parents or family members

$\square$ Clubs or activities related to majors of interest

$\square$ I didn't think about academic majors before coming to UVa.

$\square$ Other 
Prior to attending $\square$ who were the most influential individuals involved in your academic major decision process?

Check all that apply.

Parents

Grandparents

Siblings

Other family members

Friends/Classmates from high school

High school teachers
High school guidance counselors

High school coaches or mentors

College preparation program staff

Former employer(s)

Religious leaders

Other

This final section includes questions related to your family and background.

From the list below, please select the TWO (2) INDIVIDUALS who you would consider to be your caregiver(s) at the time you entered college. (the order in which you select the individuals bears no weight)

\begin{tabular}{l|cc} 
& $\begin{array}{c}\text { Choose One In Each } \\
\text { Column } \\
\text { Caregiver } \\
1\end{array}$ & $\begin{array}{c}\text { Caregiver } \\
\text { 2 }\end{array}$ \\
\hline Biological Mother & 0 & 0 \\
Biological Father & 0 & 0 \\
Adoptive/Legal Mother & 0 & 0 \\
Adoptive/Legal Father & 0 & 0 \\
Step-Mother & 0 & 0 \\
Step-Father & 0 & 0 \\
Partner of Mother & 0 & 0 \\
Partner of Father & 0 & 0 \\
Female Sibling & 0 & 0 \\
Male Sibling & 0 & 0 \\
Female Grandparent & 0 & 0 \\
Male Grandparent & 0 & 0 \\
Aunt & 0 & 0 \\
Uncle & 0 & 0 \\
Other & 0 & 0 \\
No Caregiver & 0 & 0
\end{tabular}


What is the highest level of education completed by CAREGIVER 1?

No schooling completed

Pre-K through 4th grade

5 th grade -8 th grade

9th grade - 12th grade: NO DIPLOMA

High School Graduate (high school diploma, GED, or equivalent)

Vocational, trade or business school

Some college or university; no degree

Associate's Degree

Bachelor's Degree

Some graduate school; no degree

Graduate Degree (Master's, Doctorate or Professional Degree)

I'm not sure.

To the best of your ability, please list the present, or most recent, occupation of this first person (Caregiver 1) you selected.

What is the highest level of education completed by CAREGIVER 2?

No schooling completed

Pre-K through 4th grade

5 th grade -8 th grade

9th grade - 12th grade: NO DIPLOMA

High School Graduate (high school diploma, GED, or equivalent)

Vocational, trade or business school

Some college or university; no degree

Associate's Degree

Bachelor's Degree

Some graduate school; no degree

Graduate Degree (Master's, Doctorate or Professional Degree)

I'm not sure. 
To the best of your ability, please list the present, or most recent, occupation of the second person (Caregiver 2) you selected.

To the best of your knowledge, how often have your primary caregiver(s) done the following:

\begin{tabular}{|c|c|c|c|c|}
\hline & Often & Sometimes & Hardly Ever & Never \\
\hline Visited museums or galleries & 0 & 0 & 0 & 0 \\
\hline $\begin{array}{l}\text { Attended plays or dramatic } \\
\text { performances }\end{array}$ & 0 & 0 & O & 0 \\
\hline Read books for pleasure & 0 & O & O & 0 \\
\hline Played an instrument & 0 & O & O & 0 \\
\hline Attended a concert & 0 & O & O & O \\
\hline $\begin{array}{l}\text { Taken educational courses for } \\
\text { personal betterment }\end{array}$ & 0 & 0 & 0 & 0 \\
\hline Discussed politics or world affairs & O & 0 & 0 & O \\
\hline $\begin{array}{l}\text { Spoken a language other than } \\
\text { English }\end{array}$ & 0 & 0 & 0 & 0 \\
\hline
\end{tabular}




\author{
Appendix C \\ Interview Protocol: Meeting One
}

\title{
Background/Building Relationships
}

- $\quad$ To begin, share with me a little bit about yourself pre-MAU....

$\circ$ where are you from

o what were you involved with in high school

$\circ$ family make up

- Now...what about since arriving at MAU...

○ academic year and major

$\circ$ involvement

- general ideas on your experience so far

- Talk with me about your college decision process.

- Where were you considering?

- What were you looking for in a college?

- Who was involved in your decision?

$\circ$ Why did you ultimately choose MAU?

- At this point, how do you feel about your decision to attend MAU?

\section{General Decision Making}

- Prior to coming to MAU, who did you consider to be your support system?

○ Who would you normally turn to when trying to make important personal decisions?

- What about important academic decisions?

- How has your support system changed now that you are in college?

$\circ$ Who is your sounding board for personal decisions?

- What about academic decisions?

- What process do you normally take when a decision is needed?

○ Follow Up: Are you a talk to multiple people kind of person? Do you work it out on your own and then seek guidance? Consult nobody? Do a lot of research to support your thoughts?

\section{Personal Academic Decision Making Process}

- A lot of our time together will be focused on academic decision-making - or - how your chose your major. So, to get started, tell me where you are in the major decision process.

- If early in process, learn more about potential options.

o If in a major, learn more about his or her level of comfort.

- Please talk with me about the earliest memory you have of considering any academic major? What did you want to be when you "grew up"?

o What experiences do you feel encouraged this interest?

- Were there particular individuals who encouraged or discouraged your interest?

- When did you start seriously thinking about college majors? 
- Did it factor in to where you were planning to attend?

- In what ways was it on your mind in high school? Did your parents, teachers, others discuss options with you?

- What about the major you've declared now...OR....the majors you are currently considering?

- If declared, do you feel confident in your decision and at what point did you feel this way?

- In not declared, what needs to happen to make you feel confident in your decision?

- What experiences do you feel encouraged this interest?

- Were there particular individuals who encouraged or discouraged your interest?

- What factors contributed to your decision-making?

- As you've been considering majors, have you felt any particular pressures or stressors to make a certain decision?

\section{Future Plans}

- What are you planning to do after college?

- What are the long-term goals you currently have for your life? What would you be doing personally and professionally in an ideal world?

Let's say you are on an elevator with the CEO of a company you'd really like to work for. They turn to you and say, "What's the number one reason you chose to be a major." How would you respond?

\section{<MOVE TO ANALYTIC VIGNETTES>}

\section{Analytic Vignettes}

(Note: The vignettes below were developed for use with female students. Male participants received the same scenarios but with "Jack" replaced as the student's name.)

Logistics: Participants received a printed copy of each vignette to reach independently during the interview. Debrief began immediately after completion. The subsequent vignette was distributed and the process continued until all vignettes were read and debrief completed.

\section{Vignette Prompt One:}

Olivia is beginning her junior year of high school and has received college brochures in the mail all summer. Her family has always been a little nervous about the cost of college but, given her strong academic standing in high school, Olivia would like to attend. She thinks it might be a good idea to decide what her major will be in order to pick the right college. Olivia has always excelled in math and science courses and, during middle school, attended a summer enrichment program for girls in STEM. However, the highlight of Olivia's time in high school has been serving as a writer for the student newspaper and she is slated to become editor her senior year. 


\section{Vignette One Debrief Questions:}

- What steps might Olivia take to begin considering a potential major?

- Who might she involve in her decision?

- What challenges might she face in her decisions?

- Who might Olivia look to for support in her decisions?

- How might her decision factor into where she attends college?

- What would you do if you were Olivia?

\section{Vignette Prompt Two:}

It is now her senior year and Olivia decides to look for colleges with a strong English department where she can focus on journalism and creative writing. Because she enjoys her role with the student newspaper, Olivia believes it is an ideal choice of college major. She talks with her family about this decision and they express concern about Olivia's ability to find a job and make a lucrative salary after college. Although Olivia will be primarily funded through financial aid and loans, her family indicates they only support her college attendance if she pursues a science or math field. Olivia's father tells her, "there's always jobs and money in science. Hospitals, engineers, lots of options. Plus, you are good at the science classes anyway. Just do that." Olivia leaves the conversation confused and concerned.

\section{Vignette Two Debrief Questions:}

- What would you identify as Olivia's largest barrier to making her decision now?

- What advice might you give Olivia to help navigate this situation?

- Are there particular resources that might benefit Olivia at this point?

- What would you do in this situation?

- How would your respond to her father's statements?

- How would this conversation look if it were with your family?

\section{Vignette Prompt Three:}

After being accepted to a selective state university, Olivia decided to enter her first year as an undeclared student. She learned during orientation that she doesn't have to declare a major until her second year. In addition to taking the required freshman composition course, Olivia signs up to take two pre-requisite science and math courses for biology and engineering majors. During the student involvement fair, Olivia also signs up to join a poetry club and has submitted a writing sample for a position with the student newspaper. Olivia's roommate plans to major in chemistry while her suitemates are considering psychology and business. While she is enjoying college, Olivia is still struggling to determine her major. She also knows college is expensive and, given she has multiple loans, doesn't want her degree to extend beyond four years.

\section{Vignette Three Debrief Questions:}

- Now that Olivia is in college, what might she do to assist in determining her major?

- What are the most important things Olivia should consider to be more confident in her decision-making?

- Who might Olivia look to for support in this situation?

- What might be Olivia's greatest barriers to overcome?

- If you were in Olivia's position, what might you do? 


\section{Appendix D}

\section{Interview Two Protocol}

\section{- Greetings \& Catch Up (\$40 payment)}

- Begin with Timeline Activity (see more information at end of protocol)

- Please talk with me about what process you used to develop your timeline.

- Please walk me through the elements of your timeline.

- What points or milestones on your timeline came to you quickly as being important when developing?

- What points or milestones took a bit more time to remember?

- Were you surprised by any of the points or milestones that you included? Was this a new realization of the impacts of these events on your decision-making?

- Identify the points on your timeline in which you felt the most supported in your decision-making.

- Identify the points on your timeline in which you felt challenges or barriers existed in your decision-making.

- Identify the points on your timeline in which you felt quite confident in your decision/were able to execute your decision with confidence.

- Identify the points on your timeline in which you felt unsure or conflicted in your decisions/felt unable to execute your decision.

- Who have been the most influential people on your timeline?

- What are the most influential experiences on your timeline?

- What's missing from your timeline? Are there things you might have done differently now that you are reflecting upon the experience?

- What do you wish you had known throughout the experience that you know now?

- Talk with me about the next steps you see in your timeline. How might your decisionmaking impact what you choose to do next in terms of school, career, goals, etc.

\section{Confidence}

- Think about your closest friends at UVa. What do you know about their major choice process? How does their experience compare or differ from yours?

- What do you think would have make your decision-making experience earlier?

○ Particular resources? Certain supports? Ability to overcome particular barriers? Involvement of certain people?

\section{Relationships with Faculty/Staff}

- Talk with me about the relationships you've built with faculty/staff since you've been at MAU.

- Have these relationships impacted your decision-making?

- How have these relationships influenced your decision-making in comparison with your high school teachers?

- What about upper class students? How did you engage with them as your were choosing your major? 


\section{Relationships with University Resources}

- In what ways have you engaged with university resources since you arrived at MAU? (business offices, career center, advising, student activities, etc.)

\section{Academic Preparation}

- How academically prepared did/do you feel when you declared your major? Did you think you could succeed? How did you compare your self to classmates?

- Did you feel that you needed to have specific academic skills or aptitude to choose your major?

\section{Survey Themes}

- A common concern on the survey was student's feeling they lack an ability in understanding how to apply major to future career/personal goals. In what ways is this a concern for you? How do you overcome it?

- In what ways do you feel your socioeconomic status has shaped your choice of academic major?

- Do you believe there are benefits to being required to choose an academic major?

\section{Student Specific Questions}

\section{Extra Questions (if time allows)}

- What's the most enjoyable part of your academic major?

- What's the least enjoyable part of your academic major?

- What do you feel is the most beneficial educational component of your major? How might you use that in the future?

\section{Graphic Elicitation through Timeline Mapping}

Logistics: Given the time constraints of an interview meeting, participants were offered the prompt below and materials at the conclusion of the first interview. The students were asked to complete the task at home and bring the completed timeline to the next meeting. This provided opportunity to reflect upon interview conversations and life experiences while allowing ample time for details to be included. Moreover, it offered a temporal dimension to the discussion. During the interview, the opportunity to talk through the timeline was provide as an additional opportunity for verbalization of experiences that may provide new detail. As interviews were held approximately 2 weeks apart, this allowed for planning without creating a gap so wide that the assignment was forgotten.

Materials: Students were provided an envelope with white and colored paper, pencils, and colored pencils/markers to use for the assignment as to not implore any financial burden. 
Students were welcome to utilize other materials, photographs, objects, or texts should it be helpful. Because the use of physical drawing is meant to elucidate memories and experiences, a request to use technology was only be accommodated should it be for medical or disability purposes. This proved to be unnecessary.

Activity Prompt: Using the materials provided in this packet, create a timeline of your academic major choice process. Please begin as early in life as you can recognize influences on your choice and continue through today. If your major will shape future plans and goals, feel free to include. Please think about the people, experiences, opportunities, and ideas that have shaped your major choice and be as detailed as possible. You are welcome to make lists, draw a physical timeline, mind map, etc. If you'd like to include or bring in pictures, objects, or documents that have assisted your decision-making or the creative process, it is encouraged. Please be creative and utilize whatever means will assist your reflective process. I'd encourage you to begin soon and allow the next two weeks to guide additions as you have time to reflect. If you have questions or need additional materials, please contact me.

\section{During Second Interview - Initial Timeline Debrief:}

- Please talk with me about what process you used to develop your timeline.

- Please walk me through the elements of your timeline.

- What points or milestones on your timeline came to you quickly as being important when developing?

- What points or milestones took a bit more time to remember?

- Were you surprised by any of the points or milestones that you included? Was this a new realization of the impacts of these events on your decision-making?

- Identify the points on your timeline in which you felt the most supported in your decision-making.

- Identify the points on your timeline in which you felt challenges or barriers existed in your decision-making.

- Identify the points on your timeline in which you felt quite confident in your decision/were able to execute your decision with confidence.

- Identify the points on your timeline in which you felt unsure or conflicted in your decisions/felt unable to execute your decision.

- Who have been the most influential people on your timeline?

- What's missing from your timeline? Are there things you might have done differently now that you are reflecting upon the experience?

- What do you wish you had known throughout the experience that you know now?

- Talk with me about the next steps you see in your timeline. How might your decisionmaking impact what you choose to do next in terms of school, career, goals, etc. 


\section{Appendix E}

Interview Three Protocol

\section{Greetings \& Payment (\$60)}

\section{Interview begins with card sorting activity}

Prompt: Recently, I've been collecting media headlines concerning a debate in higher education regarding the value of college students majoring in humanities fields. I've been collecting the headlines in a social media style format - Twitter - to get a snapshot of what's going on across the country. I'd like to share with you what I've found and get your thoughts. I've added a headline to each of these cards and I'm going to ask you to review the cards and then sort them based upon some categories and questions. You'll have plenty of time to read each and make your decisions but please go with your gut instincts. Please ask me questions at any time.

\section{Sorting Questions One:}

- Take a read through the cards and sort into two piles, the headlines you've heard before and those you haven't. It doesn't matter if you heard the headline from the same media outlet listed, just the general information.

- Using the stack of headlines you've heard, sort into piles based upon where you heard the information. So, for example, you may have a pile for what you've heard directly for the media, what you heard from your parents, friends, or counselors.

- Now, sort into piles based upon information you heard prior to college and information you've heard since arriving at MAU.

\section{Debrief Questions:}

- What was your reaction to hearing this information originally?

- How did the source of the information (media, family, etc.) shape your thoughts?

- How do you feel this information shaped your thoughts about college?

- From the stack of headlines that were new to you, what are your thoughts on that information? Are you surprised?

Sorting Question Two:

- Next, I'd like you to sort the cards into two piles. Statements you agree with and statements you disagree with.

\section{Debrief Questions:}

- Talk with me a bit about the statements you agree with. Why do you find those agreeable? Is it about the content or the source of the information?

- Now, let's follow up on the statements you disagree with? What do you find disagreeable? Do you disagree because you are opposed to the information or because it is a counterpoint to your personal interest or plans?

\section{Sorting Question Three:}

- Finally, sort into two piles based upon headlines you feel influence(d) or could influence your choice of academic major and those that do not. 


\section{Debrief Questions:}

- In what ways did this specific information shape your thoughts about academic majors?

- How do you feel information of this sort could shape the thoughts of high school or college students as they are debating their best options for an academic major?

\section{Post-Activity Debrief Questions:}

- Across all the cards you read, what did you find most surprising?

- Were you aware of this ongoing debate within higher education? How do you feel about it?

- The cards represented media headlines. Have you heard these sentiments from others? Your family? Friends? Former teachers?

- Since arriving at MAU, have you heard a similar debate or stereotypes?

- In what ways might these headlines inform the general public about the college major choice or attending college in general?

- What role do you believe the media plays in shaping how a college student thinks about their major?

- What role do you believe policy makers play in shaping how a college student thinks about their major?

\section{General Protocol Questions}

- In what ways has society influenced your choice of academic major?

- Every student is required to take humanities courses during their time at MAU. What do you think of this requirement?

- What do you believe the humanities contribute to a student's college education? Are humanities courses ever a detriment?

- What are your basic thoughts and assumptions about students who choose to major in humanities fields? What about those who choose other fields - like engineering or business?

- We've talked a lot about what seems to have driven your choice in academic major. Do you think what influenced you is common for other students?

- Think about your friends and classmates. What do you think are the greatest influences on their choice of academic major?

- What role should future financial stability play in the choice of academic major?

- When you make a big decision - like choosing a university or major - you want to feel confident in your decision. What has made you feel most confident in your major decision?

○ What do you think helps most students feel confident in their choice of major?

- Do you have concerns about your academic major leading you toward your intended life goals?

- What do you believe are the fundamental skills a student should possess when they graduate from college?

- One of the reasons you were chosen for this study is because you receive a substantial amount of financial support from the university to finance your education. In what ways do you feel your socioeconomic status has shaped your choice of academic major? 
- In what ways do you feel the amount of financial aid a student possesses shapes how they make choices about an academic major? What if the aid is grants (AffordU) or loans (needing repayment).

- In a perfect world, all academic majors would result in a job at graduation and everyone would make a comparable salary. If that was the case, what academic major would you choose?

- If you could speak at new student orientation and explain to first years the best way to go about choosing an academic major, what would you tell them?

\section{Qualitative Elicitation through Card Sorting Overview}

To better understand the influences of the public rhetoric and debate surrounding the humanities and higher education, card sorting using headlines displayed through a social media framework were used. Because only providing a student with one or two articles would limit the scope of the debate and possibly insert bias, a collection of headlines from newspaper, television, government websites, and blogs were compiled using a Twitter-style social media design. In accordance with traditional card sort methods, each headline was placed on a card of equal size, shape, and color. Participants were asked to sort the cards based upon categories or questions. This design was chosen given college students often receive information in short snippets. Examples of the headlines and format are available on subsequent pages. All headlines included are accurate, from the original media outlet, and occurred while the student was matriculating to or attending college. Each media outlet was represented twice, with a pro-humanities and provocation headline, so any preexisting beliefs by the participant regarding the media outlet would not cause bias.

Note: The card below was used as an example and instructional tool to allow the student to become comfortable with the activity, confirm understanding, and ask questions before beginning. The cards shown on subsequent pages are those used for the activity but in a reduced size to preserve space.

\section{M \\ NBBC ${ }^{\circledR M S N B C}$}

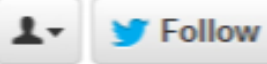

Only 8 percent of students now major in the humanities - down from a peak of more than 17 percent in 1967.

Reply $\nmid \mathbf{7}$ Retweet $\mathbf{t}$ Favorite $\bullet \bullet$ More

7:17 PM - 17 Jul 16 - Embed this Tweet 
INSIDE Inside Higher Ed @InsideHE

2. 5 Follow

N.C. Gov McRory Proposes Humanities Majors Attend Private Colleges; Leave STEM for Publics.

$\leftarrow$ Reply $\uparrow 7$ Retweet $\downarrow$ Favorite $\cdots$ More

6:04 PM - 15 Apr 15 - Embed this Tweet

INSIDE Inside Higher Ed

@InsideHE

2. Yollow

Burns to NEH: Humanities - while under attack - help us understand a broad range of different topics and perspectives and promote unity through understanding.

$\uparrow$ Reply 47 Retweet $\downarrow$ Favorite $\cdots$ More

10:57 PM - 9 May 16 - Embed this Tweet

Chronicle of Higher
Education
@TheChronicle

\section{C \\ Chronicle of Higher \\ Education \\ 2. Follow \\ @The Chronicle}

To save Law \& Engineering, expand humanities rather than cut; infuse throughout curriculum.

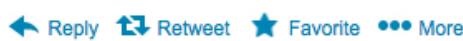

9:12 AM - 1 May 16 - Embed this Tweet

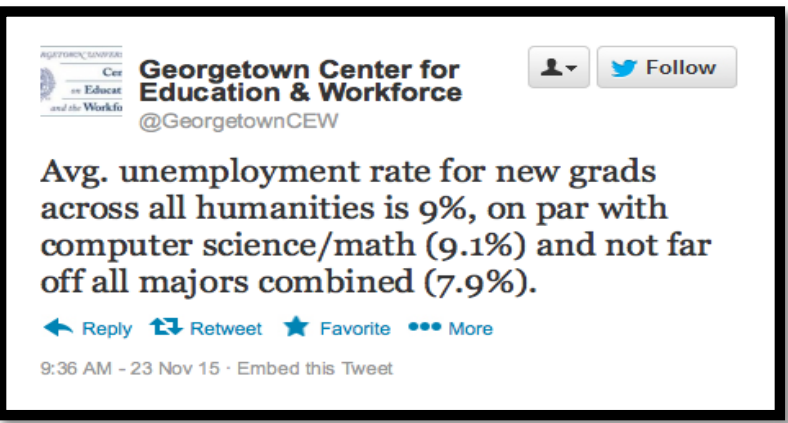

Georgetown Center for
Top Earners in Liberal Arts End Up
Matching Only the Bottom Earners in
STEM; Some Earn Less than High School
Grads in Vocational Jobs.
\& Reply 27 Retweet $\star$ Favorite $\cdots$ More
6:33 AM - 17 Feb 16 . Embed this Tweet

\section{त्:}

New York Times

@NYTimes

2. Follow

Educators incensed not over workforce development but lawmaker disdain for the humanities.

$\leftarrow$ Reply $\uparrow 7$ Retweet $\downarrow$ Favorite $\bullet \bullet$ More

8:47 AM - 02 Feb 16 - Embed this Tweet

\section{๔) \\ New York Times \\ @NY Times \\ 2. $y$ Follow}

In Higher Education, A Rising Call to Promote STEM Education and Cut Liberal Arts Funding, Reward Earners.

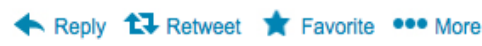

3:17 PM - 21 Feb 16 - Embed this Tweet 


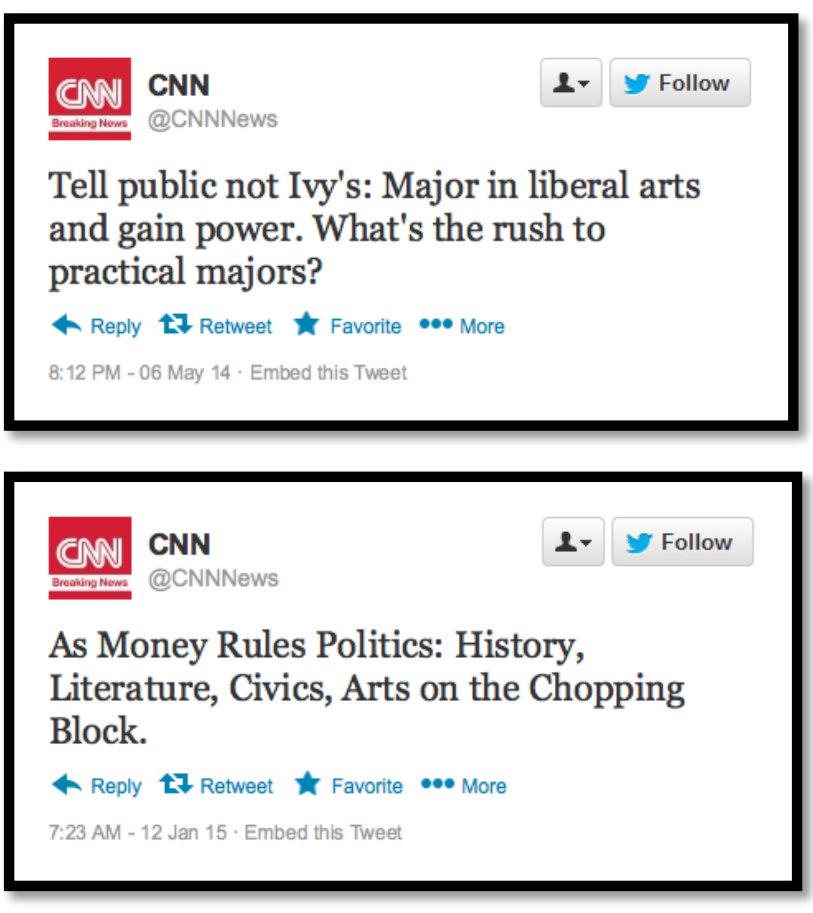

INSIDE Inside Higher Education 2- y Follow
HIGHERED @InsideHigherEd

Fed to HE: Employ differential tuition make students majoring in humanities pay more than STEM, vocational majors.

४ Reply $\mathbf{\imath}$ Retweet $\downarrow$ Favorite $\bullet \bullet$ More

2:27 PM - 13 Aug 16 - Embed this Tweet

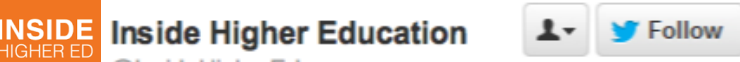
@InsideHigherEd

Right "tech" credentials no job guarantee; employers wants problem solvers, communicators, creativity, team players

廿 Reply $\$ 7$ Retweet Favorite $\cdots$ More

2:27 PM - 3 Apr 16 - Embed this Tweet

\section{Times Higher Education

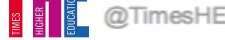

2. Y Follow

Will U.S. institutions follow Japan as govn't requires "purging of unnecessary liberal arts and humanities" courses across all universities?

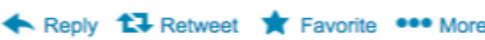

1:12 PM - 15 Aug 16 - Embed this Tweet
Whi] Washington Post

2. Follow

WASHINGTO

Parents refuse to allow college students to study literature, take humanities fearing low ROI. Students are listening.

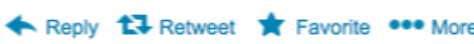

5:39 AM - 3 Mar 16 - Embed this Tweet

\section{Mil] Washington Post wastuncton@WaPo}

U.S. military is great on STEM; should also be great on liberal arts. Officers should read Shakespeare, know history, understand psychology.

4 Reply $\{7$ Retweet \ Favorite $\bullet \bullet$ More

8:47 PM - 7 Oct 16 - Embed this Tweet

\section{T1 Huffington Post}

1. y Follow

Forget Pre-Conceived Notions; Drop

Stereotypes: Don't Leave College Without

Arts \& Humanities

$\leftarrow$ Reply $\lfloor 7$ Retweet $\downarrow$ Favorite $\cdots$ More

10:37 AM - 13 Jan 16 - Embed this Tweet

\section{工1 $\begin{aligned} & \text { Huffington Post } \\ & \text { @HuffPost }\end{aligned}$ \\ 2. y Follow}

Double majors up 40\% in college - one vocational major to satisfy parental pressure, another in liberal arts to satisfy own interests.

$\leftarrow$ Reply $\lfloor 7$ Retweet $\downarrow$ Favorite $\cdots$ More

9:23 AM - 17 Feb 16 - Embed this Tweet

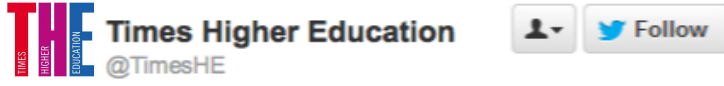

Ireland's President Higgins says prioritizing vocational training over humanities is "moment of intellectual crisis" \& "betrays purpose of education."

४ Reply $\$ 7$ Retweet \ Favorite $\cdots$ More

4:17 PM - 18 Jun 16 - Embed this Tweet 